\title{
CONDORCET
}

Marquis de Jean-Antoine-Nicolas de Caritat

(1793-1794)

\section{ESQUISSE \\ D'UN TABLEAU HISTORIQUE DES PROGRÈS DE L'ESPRIT HUMAIN}

\author{
Un document produit en version numérique par Jean-Marie Tremblay, bénévole, \\ professeur de sociologie au Cégep de Chicoutimi \\ Courriel: jean-marie tremblay@uqac.ca \\ Site web pédagogique : http://www.uqac.ca/jmt-sociologue/ \\ Dans le cadre de la collection: "Les classiques des sciences sociales" \\ Site web: http://www.uqac.ca/Classiques_des_sciences_sociales/ \\ Une collection développée en collaboration avec la Bibliothèque \\ Paul-Émile-Boulet de l'Université du Québec à Chicoutimi \\ Site web: http://bibliotheque.uqac.ca/
}


Cette édition électronique a été réalisée par Jean-Marie Tremblay, bénévole, professeur de sociologie au Cégep de Chicoutimi à partir de l'article de :

Condorcet, Esquisse d'un tableau historique des progrès de l'esprit humain (1793-1794). Texte revu et présenté par O.H. Prior (professeur à l'Université de Cambridge). Nouvelle édition présentée par Yvon Belaval (professeur à la Sorbonne). Paris : Librairie philosophique J. Vrin, 1970, 247 pp. Collection : Bibliothèques des textes philosophiques.

Polices de caractères utilisée :

Pour le texte: Times New Roman, 14 points.

Pour les citations : Times New Roman 12 points.

Pour les notes de bas de page : Times New Roman, 12 points.

Édition électronique réalisée avec le traitement de textes Microsoft Word 2004 pour Macintosh.

Mise en page sur papier format :

LETTRE (US letter), 8.5'” x 11’’)

Édition numérique réalisée le 17 janvier 2005 à Chicoutimi, Ville de Saguenay, province de Québec, Canada.

\section{Fait avec}

Macintosh 


\section{CONDORCET}

Marquis de Jean-Antoine-Nicolas de Caritat

\section{Condorcet, Esquisse d'un tableau historique des progrès de l'esprit humain (1793-1794).}

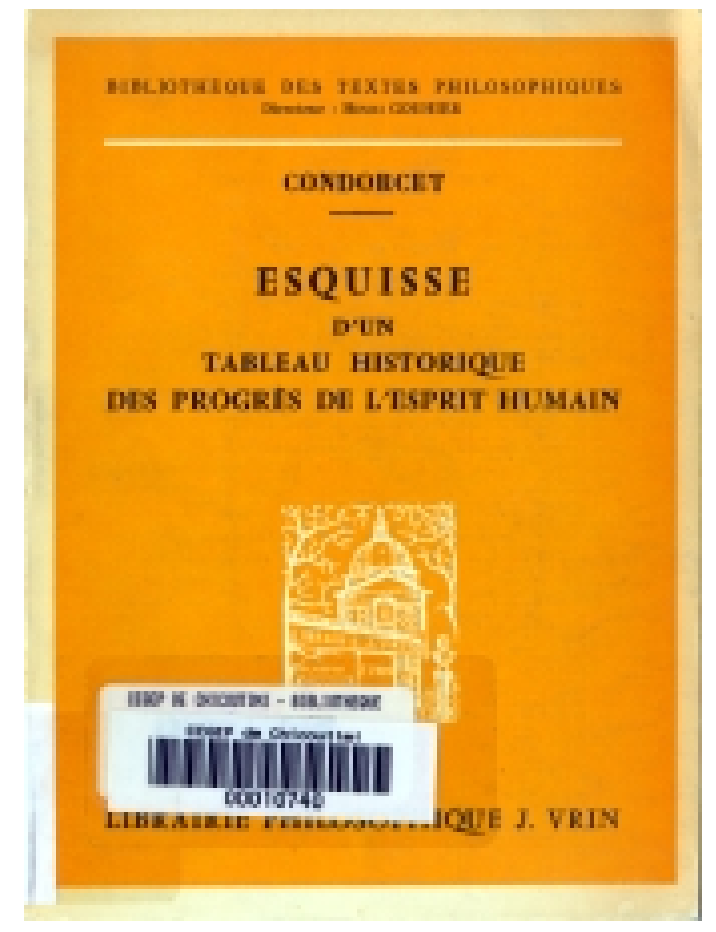

Texte revu et présenté par O.H. Prior (professeur à l’Université de Cambridge). Nouvelle édition présentée par Yvon Belaval (professeur à la Sorbonne). Paris: Librairie philosophique J. Vrin, 1970, 247 pp. Collection : Bibliothèques des textes philosophiques. 


\section{Table des matières}

$\underline{\text { Index des noms }}$

Présentation

Introduction

Avertissement

Avant-propos

Première époque. Les hommes sont réunis en peuplades

Deuxième époque. Les peuples pasteurs. - Passage de cet état à celui des peuples agriculteurs

Troisième époque. Progrès des peuples agriculteurs, jusqu'à l'invention de l'écriture alphabétique

Quatrième époque. Progrès de l'esprit humain dans la Grèce, jusqu'au temps de la division des sciences, vers le siècle d'Alexandre

Cinquième époque. Progrès des sciences depuis leur division jusqu'à leur décadence

Sixième époque. Décadence des lumières, jusqu'à leur restauration, vers le temps des croisades

Septième époque. Depuis les premiers progrès des sciences, lors de leur restauration dans l'Occident, jusqu'à l'invention de l'imprimerie

Huitième époque. Depuis l'invention de l'imprimerie jusqu'au temps où les sciences et la philosophie secouèrent le joug de l'autorité

Neuvième époque. Depuis Descartes jusqu'à la formation de la République française

Dixième époque. Les progrès futurs de l'esprit humain

Bibliographie 


\section{Index des noms cités dans l'esquisse}

$\underline{\text { Retour à la table des matières }}$

Agricola

Alexandre le Grand, Althusius

Anaxagore

Anthemius

Apelles

Archimède

Aristophane

Aristote

Augustin (rhéteur)

Bacon

Bayle

Beccaria

Boccace

Bolingbroke

Carraches

César

Charles-Quint

Cicéron

Colomb

Collins

Constantin

Copernic

Corneille

Cyrus

D'Alembert

Dante

Democrite

Démosthène

Descartes

Diophante

\begin{tabular}{ll} 
& Kepler \\
Écossais (philosophes) & \\
Édouard (roi d'Angle- & Languet \\
\multicolumn{1}{c}{ terre) } & Leibniz \\
Élisabeth & Locke \\
Épicure & Lucien \\
Euclide & Lucrèce \\
Euripide & Luther \\
& \\
Fontenelle & Marc-Aurèle \\
François 1er & Machiavel \\
Franklin & Mahomet \\
Frédéric II (Barbe- & Moïse \\
$\quad$ rousse) & Molière \\
& Montesquieu \\
Galilée & Morus \\
Gama & \\
Gesner & Needham \\
(Gutenberg) & Nerva \\
& Newton \\
Haller & Numa \\
Harrington & \\
Henri VIII & Palissy (Bernard de) \\
Hipparque & Périclès \\
Hippocrate & Pétrarque \\
Hobbes & Phidias \\
Homère & Photius \\
Howard & Pindare \\
Huyghens & Platon \\
Jésus & Pline \\
Julien & Plutarque \\
Justinien & Pope \\
& Pricestley \\
& \\
&
\end{tabular}




$\begin{array}{lll}\begin{array}{l}\text { Proclus } \\ \text { Ptolémée } \\ \text { Pythagore }\end{array} & \begin{array}{l}\text { Socrate } \\ \text { Sophocle } \\ \text { Smith } \\ \text { Stewart }\end{array} & \text { Vignes (Pierre des) } \\ \text { Racine } & \text { Virgile } \\ \text { Raphaël } & \text { Thalès } & \text { Voltaire } \\ \text { Rei (Jean) } & \text { Thucydide } & \text { Wicleff } \\ \text { Rousseau } & \text { Tibère } & \text { Witt (Jean de) } \\ \text { Sénèque } & \text { Turgot } & \text { Xénophon } \\ & & \text { Zénon (de Cittium) }\end{array}$




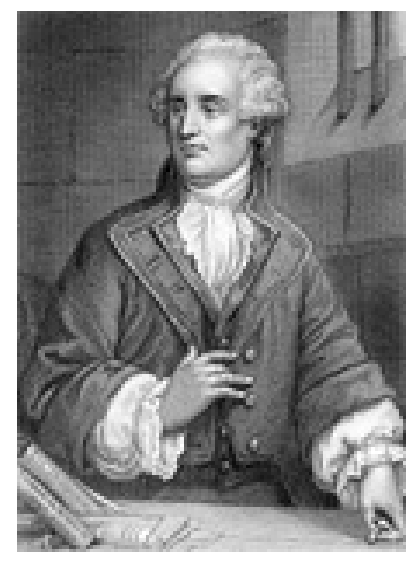

\section{CONDORCET}

Marquis de Jean-Antoine-Nicolas de Caritat 
CONDORCET,

Esquisse d'un tableau historique des progrès de l'esprit humain

(1793-1794).

Présentation

\author{
Par Yvon Belaval
}

$\underline{\text { Retour à la table des matières }}$

En reproduisant cette édition, il a paru préférable, par déférence et par commodité, de conserver l'Introduction et l'Avertissement d'O.H. Prior, où l'on trouve sur la vie et l'œuvre du marquis révolutionnaire, comme sur les manuscrits de notre texte, les premiers renseignements indispensables. L'on ajoute un Index Nominum limité à la seule Esquisse dont il circonscrit l'horizon intellectuel, et l'on complète, à partir de celle établie par Alberto Cento (1956) ${ }^{1}$, la bibliographie par trop insuffisante de Prior. Cela dit, aucun auteur ne mériterait d'être relu s'il ne progressait et ne permettait de progresser avec lui ; en d'autres termes, si, avec le recul incessant du passé, il ne se prêtait sans cesse à une lecture nouvelle. Peut-être n'est-il pas mauvais, en quelques pages, de revenir sur le progrès décrit, analysé, prophétisé par Condorcet ${ }^{2}$.

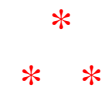

1 Alberto Cento : Condorcet e l'idea di progresso. Firenze, 1956.

2 Les chiffres entre parenthèses renverront à la pagination de l'Esquisse, dans la présente édition. 
Voici un livre écrit à l'ombre de la mort. Oppressé par le temps, l'auteur se borne à une esquisse, il faut prendre le mot à la lettre : programme, plan, survol, vue anticipée, prospectus -selon un autre intitulé du titre. Ainsi s'explique l'usage, de plus en plus fréquent, des futurs - nous montrerons..., nous chercherons..., nous examinerons.... nous exposerons... - qui sont comme autant de repères, de blancs, dans un travail à terminer. Ainsi encore comprend-on que l'historique ne soit qu'esquissé lui aussi, sans fiches, à vue de mémoire. À coup sûr, Condorcet, s'il avait vécu et qu'il en ait eu les loisirs, aurait complété son ouvrage - peut-être l'eût-il alourdi -, mais il n'en serait pas tombé pour autant dans l'histoire d'érudition qui risque d'obscurcir le sens sous l'amas des faits et des références, il aurait gardé à l'ensemble l'aspect d'un tableau synoptique. Car c'est bien de cela qu'il s'agit : découvrir le Sens de l'histoire pour pouvoir lui donner un sens à l'avenir. Sens et progrès sont synonymes pour notre philosophe.

Ce progrès, comment le caractériser du dehors ?

À le suivre dans sa démarche, il part, on ne sait d'où, de la Nature dont il se libère (3) en se rendant de plus en plus son maître et possesseur, et il se dirige vers la cité universelle. Qui pourrait en fixer le terme ? Il est indéfini (237) ; expansif, il n'occupait d'abord qu'une faible partie du globe (199) et se répand avec les moyens de circulation qu'on doit principalement au commerce $(209,110)$; plus ou moins rapide, selon la résistance des intérêts religieux et politiques qui le freinent (141), le hasard des génies qui le favorisent (176), l'impulsion de la liberté qui l'accélère $(151,149)$; avec des hauts et des bas selon, ici encore, le hasard des événements (27) ; mais continu, par la continuité même des générations et, au total, jamais rétrograde (3, 198). Il franchit certaines étapes, ou, pour parler comme Buffon de la Nature, certaines époques : Condorcet en énumère dix dont les premières - chasse et pêche, domestication de quelques animaux, agriculture (avec l'institution de la propriété) -, parce qu'elles sont beaucoup moins définies par des documents qu'imaginées par déduction, sont communes à tous les penseurs du XVIIIe siècle jusqu'à Hegel. De ces étapes constatées (ou soi-disant constatées) se dégage-t-il une loi ? Vers 1751, donc bien avant Auguste Comte, Turgot avait énoncé la loi 
des trois états ${ }^{3}$. Condorcet aurait pu s'inspirer de son ami. Il ne le fait pas. Il est sans doute trop hanté par l'idée de « combinaison », on verra pourquoi. Tout au plus, de l'arithmétique à Y « art social », démêlerait-on dans l'Esquisse un ordre d'apparition des sciences, qui ne s'accorderait pas trop mal avec la classification comtienne des sciences.

On sait déjà, par le titre de l'ouvrage, ce qui anime le progrès : l'esprit humain. Il concerne l'espèce entière dont la perfectibilité n'a d'autre terme "que la durée du globe », tant que la Terre " occupera la même place dans le système de l'univers, et que les lois générales de ce système ne produiront sur ce globe, ni un bouleversement général, ni des changements qui ne permettraient Plus à l'espèce humaine d'y conserver, d'y déployer les mêmes facultés, et d'y trouver les mêmes ressources » (3). Non pas que, prise en général, cette perfectibilité soit, comme chez Rousseau qui, dans le second Discours, imprime encore en italique ce néologisme, le propre métaphysique de l'homme : elle appartient, ainsi que son contraire, la dégénération, à tous les organismes, végétaux et animaux (236). Aussi bien les progrès de la médecine et des instruments « qui augmentent l'intensité et dirigent l'emploi [des facultés intellectuelles], ou même celui de l'organisation naturelle de l'homme » (205) entrent-ils dans les progrès de l'esprit humain. Mais, en définitive, c'est toujours pour l'esprit humain que travaillent la médecine et l'industrie des instruments qui accroissent la portée de nos sens ou, comme l'imprimerie, de notre mémoire. Or, l'esprit ne meurt pas : ce sont les individus qui croissent et qui dépérissent. Condorcet aurait pu reprendre la formule de l'Encyclopédie (à laquelle, curieusement, il ne fait pas allusion) : c'est « à l'être qui ne meurt point » qu'il dédie son ouvrage. Ne mourant point, cet être échappe à la dégénération, car son propre est d'être une espèce parlante, capable de communiquer ses connaissances, de les fixer, de les transmettre, de les cumuler, de s'en servir pour perfectionner le langage qui, en retour, les perfectionne, et ainsi de suite. Somme de vérités (141) qui ne peut que s'accroître, ne retombe jamais à une somme antérieure, ne recommence pas, ce progrès ne peut être, du même

3 ..Plan de deux Discours sur l'histoire universelle, dans Oeuvres, Paris, 1844, t. II, p. 656. - Condorcet se contente d'observer dans l'Esquisse « que d'après les lois générales du développement de nos facultés, certains préjugés ont dû naître à chaque époque de nos progrès... » (10). 
coup, qu'un progrès historique, et l'histoire devient celle de la raison. Il a pour premier mobile ce besoin d'idées ou de sensations nouvelles qui, certes, recourt, même chez les peuplades, à des moyens physiques pour se satisfaire - liqueurs fermentées, boissons chaudes, opium, tabac, bétel - et qui développe le goût des super-fluidités du luxe, mais qui, intellectuellement, est l'aiguillon de l'industrie et de la science (36). Ce premier signe de la perfectibilité serait inconcevable sans la faculté du langage. Communication entre les hommes, le langage implique une communauté et se développe avec elle dans l'accroissement des échanges, la multiplication des besoins, qui, réciproquement, suscitent des idées et des sensations nouvelles. La langue est œuvre collective. Condorcet la distingue des facteurs individuels où le premier mobile, au hasard des génies, pousse vers l'invention des techniques et des sciences : "L'invention de l'arc avait été l'ouvrage d'un homme de génie : la formation d'une langue fut celui de la société entière » (16). Le collectif et l'individuel s'associent dans la fonction qui détermine la courbe du progrès. L'inventeur part des inventions emmagasinées dans la mémoire collective, transmises par l'enseignement - on sait toute l'importance que, rapporteur d'un projet scolaire (1791), Condorcet attachait, comme son ami Helvetius, à la réforme de l'instruction ${ }^{4}$ - et il bénéficie des loisirs cultivés sans lesquels la recherche serait impossible et que seule une société assez avancée peut permettre ${ }^{5}$. En retour, une invention élève la vie collective - si l'invention de l'arc, dans le premier état de l'humanité, change l'art de la chasse et de la pêche, l'invention de la charrue ne peut, dans le troisième état, qu'améliorer l'agriculture - ; de proche en proche, en transformant l'économie, l'inventeur transforme la société elle-même où il introduit, sans même avoir à y songer, la division du travail (28), la division par classes propriétaires, domestiques, esclaves, ouvriers, marchands, nobles, etc. $(28,34)$ - la plus-value $(21,152-153)$, avec, chaque fois, des changements de la constitution politique. Là-dessus, qu'on n'aille pas faim de notre marquis un marxiste : c'est un bourgeois, un Girondin et, surtout, un mathématicien qui, comme tous les mathématiciens est d'abord attentif au fonctionnement de l'esprit. Il juxtapose ses remarques sur le travail, les classes sociales, la plus-value ; il ne les lie pas l'une à l'autre par un rapport dialectique, et s'il devait donner un fon-

4 Rapport sur l'instruction publique, éd. Compayré, Paris, 1883.

5 Idem. 
dement à ces rapports, ce fondement ne serait pas économique, mais intellectualiste. Parce qu'il est mathématicien au siècle des Lumières, l'obstacle majeur au progrès est, à ses yeux, la superstition sous toutes ses formes -principalement le catholicisme (84) - ; il ne voit dans les préjugés que l'inertie de l'habitude et, dans les religions ou les mauvais systèmes politiques, que des inventions passionnelles guidées par des intérêts égoïstes, en contraste avec les inventions rationnelles réglées sur l'utilité sociale. Le progrès coïncide donc avec le progrès des Lumières. Il ne touche d'abord que quelques hommes, puis ne cesse de se répandre, de l'homme ou du groupe isolé et, par suite, borné $(8,37)$ en son pauvre langage, jusqu'à « la masse entière d'un grand peuple, dont la langue serait universellement répandue, dont les relations commerciales embrasseraient toute l'étendue du globe » (9). Le hasard des génies lui-même s'organise grâce à « ce concert des savants, cette réunion de leurs forces, si utile, si nécessaire » (85). Individus et collectivités coopèrent de plus en plus pour rationaliser le monde humain. Comme s'ils avaient pris « pour cri de guerre, raison, tolérance, humanité » (161), il semble que tous se proposent le bonheur et la vérité, l'égalité et, enfin, vocation essentielle de l'esprit (144), la liberté. Tout se tient, et les occupations intellectuelles, "quelque différentes qu'elles soient par leur objet, leur méthode, ou par les qualités d'esprit qu'elles exigent, ont concouru aux progrès de la raison humaine », et élaborent un système dont les parties ne doivent former qu'un seul tout et tendre à un but unique (197-198). La possession des objets de consommation les plus communs s'attache, par l'histoire, au gain de la bataille de Salamine ; "Le matelot, qu'une exacte observation de la longitude préserve du naufrage, doit la vie à une théorie qui, par une chaîne de vérités, remonte à des découvertes faites dans l'école de Platon, et ensevelies pendant vingt siècles dans une entière inutilité »(202).

Nous n'avons encore considéré le progrès que du dehors, et ce n'est pas rendre justice à l'originalité de Condorcet. Il faut en pénétrer le mécanisme interne : l'originalité de Condorcet se caractériserait alors par le titre : Esquisse d'une théorie combinatoire du progrès.

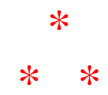


Dès la première page on assiste à une algébrisation d'un problème psychologique, que la loi des grands nombres, l'homogénéité du calcul transforment régulièrement en problème sociologique ou, pour-mieux dire avec notre auteur, en "art social ». Sans doute importe-t-il de souligner cette transformation, pour ne pas imputer à Condorcet un individualisme qui n'est pas le sien. Il part de la psychologie de Locke, revue par Condillac, approuvée par Helvetius, et suppose une analogie entre le développement individuel et le progrès de l'esprit humain, résultat de ce développement "relativement aux individus qui existent dans le même temps sur un espace donné, et si on le suit de générations en générations ». Passage illégitime du psychologique au social ? Non. Condorcet ne s'intéresse nullement à l'individu psychologique, il n'en retient que les lois générales qui le classent parmi les hommes. En d'autres termes, il ne s'y intéresse qu'en calculateur : l'individu n'est plus que l'élément (défini en compréhension) d'un ensemble et que l'on peut soumettre (du moins en théorie) au calcul statistique ou combinatoire. L'ensemble n'est pas hétérogène à l'élément.

Revenons à l'algébrisation analytique du problème. Les principes en seraient les suivants :

1. Nos pensées sont des combinaisons d'idées complexes.

2. Les idées complexes sont des combinaisons d'idées simples qui ont leur origine dans des sensations élémentaires (71).

3. Le nombre de nos idées (complexes) est proportionnel à celui de nos besoins (thèse banale au XVIIIe siècle).

4. L'idée peut être caractérisée par un signe stable, et ce signe, substitué à l'idée. Ici réside le secret de l'analyse. La faiblesse de l'algèbre alexandrine se dénonce dans l'emploi du langage commun (66). La supériorité de la science est d'instituer " une langue exacte et précise, où chaque signe représente une idée bien déterminée, bien circonscrite » par une analyse rigoureuse (50). Attacher de bons signes à des objets permet de mieux les reconnaître et de faciliter des combinaisons nouvelles (1). 
5. L'invention (et donc, le progrès) est une combinaison nouvelle d'idées disponibles. Ici est la clef du progrès. L'arithmétique en offre le modèle : sa fécondité consiste dans le "moyen heureux de représenter tous les nombres avec un petit nombre de signes, et d'exécuter par des opérations techniques très simples, des calculs auxquels notre intelligence, livrée à elle-même, ne pourrait atteindre. C'est là le premier exemple de ces méthodes qui doublent les forces de l'esprit humain, et à l'aide desquelles il peut reculer indéfiniment ses limites, sans qu'on puisse fixer un terme où il lui soit interdit d'atteindre » (39). L'honneur d'Aristote est d'avoir appliqué l'art des combinaisons aux formes du raisonnement, et cette application est riche d'avenir (71, 111). Il est alors facile de comprendre l'indéfinité du progrès. Le nombre de combinaisons croît avec le nombre d'éléments; et plus le nombre des éléments s'élève, plus l'adjonction d'une seule unité élève le taux de croissance des combinaisons. Or, le nombre d'éléments dont dispose l'esprit humain est pratiquement sans limite : il n'épuisera jamais les faits de la nature, la précision de leurs mesures, leur analyse, leurs rapports (217). En revanche, des formules de plus en plus simples rendent bientôt faciles les combinaisons de plus en plus compliquées, et ainsi, «la vigueur, l'étendue réelle des têtes humaines sera restée la même ; mais les instruments qu'elles peuvent employer se seront multipliés et perfectionnés... » (218). Les acquisitions du progrès s'intègrent dans le progrès même, participent à la conquête de nouvelles acquisitions. Et de tout cela " il résulte que la masse réelle des vérités que forme le système des sciences d'observation, d'expérience ou de calcul, peut augmenter sans cesse... » (219).

6. On voit comment le calcul des probabilités devient chez Condorcet à la fois une philosophie et une technique du progrès. À coup sûr, "le hasard des événements viendra troubler sans cesse la marche lente, mais régulière de la nature... » (27). Mais le calcul des probabilités peut nous élever par degrés du fait de hasard à la loi des " observations calculées » $(68,189,238)$, et c'est précisément dans l'art social que ses applications doivent maintenant se risquer. Que ne peut-on attendre de lui ? Disposer les observations de manière à en saisir avec plus de facilité les rapports, les résultats, l'ensemble ; déterminer la vraisemblance des faits extraordinaires; calculer le retour constant de phénomènes dont on ne connaît pas encore la loi (par exemple, en médecine) ; supputer si une convergence est fortuite ou 
intentionnelle ; mesurer les degrés de certitude (en ce qui touche l'opinion ou les décisions judiciaires) ; critiquer les témoignages ; prédire statistiquement la durée de la vie en fonction de la différence des sexes, des climats, des professions, des gouvernements ; régler l'économie politique (rentes, tontines, caisses de secours, assurances), etc. Bref, « l'application du calcul des combinaisons et des probabilités « à l'art social » promet des progrès d'autant plus importants, qu'elle est à la fois le seul moyen de donner à leurs résultats une précision presque mathématique, et d'en apprécier le degré de certitude ou de vraisemblance » (224).

L'originalité de Condorcet est donc bien, d'abord, d'avoir pressenti l'importance du calcul des probabilités pour les sciences humaines : en ce qui concerne les sciences de la nature, il n'y voit guère qu'un instrument de simplification des formules et de classification, il ne devine pas le rôle que jouera cette branche des mathématiques quelques années après sa mort, dès le début du XIXe siècle, avec la fondation de la Thermodynamique. Cette différence de clairvoyance s'explique vraisemblablement par une vue encore trop sommaire de ce calcul. Voilà pour la méthode. Passons à l'originalité de sa philosophie. Cette algébrisation de la psychologie lockienne dépasse le sensualisme dont elle légitime, par l'emploi qu'elle en fait, le caractère abstrait, et l'intellectualisme dont, en principe, elle concrétise les notions trop générales, par exemple celles de vie, de peuple, d'économie, de justice, et même d'homme. Car nous ne croyons pas, avec M. A. Cento ${ }^{6}$, que la définition par Condorcet de " la nature de l'homme »soit simplement naturaliste : " ce qui doit être le résultat des facultés communes aux hommes toutes les fois que des circonstances extraordinaires ne s'y opposent point ; ce que l'homme fera presque toujours dans une circonstance donnée » ; cette définition est, davantage, statistique. Encore une originalité de Condorcet : il ose prévoir et consacrer au futur la dernière « époque » de son Esquisse, où il prophétise la destruction

6 Op. cit., p. 9, note 47. La citation est tirée du Manuscrit de la Bibliothèque Nationale, Fol. 36-37. 
de l'inégalité entre les nations, entre les citoyens d'une même nation, entre les sexes, le perfectionnement réel de l'homme (204, 228, 236).

Que cette philosophie ait ses ambiguïtés, ses faiblesses, ses erreurs, rien de plus certain ! Le progrès de l'esprit humain s'y confond avec le progrès des sciences : on ne saurait accorder moins de place aux disciplines littéraires. En effet, si les lumières se caractérisent par les idées claires et si le modèle des idées claires se présente dans les mathématiques et dans les sciences dans la mesure où elles sont mathématisables, elles occupent nécessairement le premier plan dans le tableau historique de l'esprit humain (et l'on n'oubliera pas qu'à l'Académie des sciences Condorcet avait rédigé, comme l'avait fait avant lui Fontenelle, les admirables Éloges des savants que, sans les citer, devaient piller ensuite tant de dictionnaires). Mais il y a de la naïveté à croire qu'il suffit d'éclairer les hommes pour les rendre meilleurs. Subordonnant alors le meilleur aux lumières, on n'est plus attentif qu'au progrès des lumières et, tandis que l'on en déroule l'histoire, celle de la morale, en arrière-plan, paraît moins nette, plus lente, et, à la limite, le bien moral est posé comme un but immuable. Ainsi, -et la remarque, souvent faite, vaudrait pour la plupart des philosophes du XVIIIe - le moralisme semble éternitaire et la science est historique.

Le progrès de l'homme est-il qualitatif ? quantitatif ? La question ne va pas sans difficulté, car elle n'a été formulée qu'avec les théories que nous devons à l'évolutionnisme et à ses suites : personne ne songeait au XVIIIe siècle que la conscience enfantine pût être qualitativement différente de celle de l'adulte. Soulever la question expose à l'illusion rétrospective. Nécessairement, la réponse en garde quelque ambiguïté. Tantôt, par le principe même de la théorie, le progrès, seulement quantitatif, est une accumulation de connaissances qui se multiplient par leurs combinaisons, de même que l'enfant paraissait n'être qu'un petit adulte ignorant qui n'accédait à la maturité qu'en acquérant des idées - et la fameuse comparaison de Pascal - d'ailleurs traditionnelle et sans cesse reprise - de " toute la suite des hommes » à un seul homme qui apprend continuellement ${ }^{7}$, ne signifie pas autre chose. Et Condorcet, lorsqu'il parle d'une « compassion naturelle » (22) - la pitié

7 Voir notre étude : Pascal savant, Revue de Théologie et de Philosophie, Lausanne, 1963. 
chez Rousseau - ou précise que la vigueur et l'étendue des têtes humaines restent les mêmes (218), ne se donne-t-il pas au départ une nature humaine, de qualité immuable, à laquelle l'habitude ne peut qu'ajouter ? Cependant, il dit aussi que la bonté de l'homme est le " résultat nécessaire de son organisation » et, à ce titre, susceptible de perfectionnement (228). Dès lors, ne passe-t-on pas à quelque changement qualitatif ? Considérons le physique : «... les facultés physiques, la force, l'adresse, la finesse des sens, ne sont-elles pas au nombre de ces qualités dont le perfectionnement individuel peut se transmettre ? » L'observation des diverses races d'animaux domestiques suggère que oui (238). Mais si les qualités morales « résultent » de la constitution physique, ces observations ne doivent-elles pas s'étendre « jusque sur les facultés intellectuelles et morales » ? (Ibid.). Condorcet - de notre point de vue, pas du sien - oscille entre le perfectionnement quantitatif par l'habitude et l'accumulation des idées, et la transformation qualitative que les changements physiologiques dont les progrès de la science nous rendront maîtres peuvent produire sur nos facultés. Il n'a su, ni choisir clairement entre l'une et l'autre hypothèse, ni les concilier en une synthèse dialectique.

Et, par conséquent, on devine pourquoi, dans ce tableau, les lois qualitatives du progrès historique n'apparaissent, ou, plutôt, ne transparaissent que pour mémoire et non par la logique interne du système. Pour mémoire, parce que Condorcet n'a pas pu ne pas garder en souvenir les pensées de son ami, non mathématicien, Turgot qui a énoncé - fût-ce dans un autre contexte que celui d'Auguste Comte - la loi qualitative des trois états ${ }^{8}$. Mais, lui, il est mathématicien, même modeste. L'homogénéité du calcul efface - ou, en tout cas, estompe - la différenciation qualitative. Elle privilégie la loi de progression quantitative. Et encore faut-il le dire avec prudence, car l'idée de loi n'est encore que faiblement associée, chez Condorcet, à celle du calcul des probabilités.

On hésiterait même à parier d'une philosophie de l'histoire. C'est que l'Esquisse nous présente un décor historique, bien plus que comme il adviendra chez Cournot - une étude historique. On s'y trom-

8 Que l'on n'objecte pas : Auguste Comte était mathématicien, au moins autant que Condorcet. Oui. Mais il se défiait du calcul des probabilités. 
perait parce que, soucieux des bouleversements de son siècle, Condorcet a le sens du sociologique. Et sur ce décor historique on voit se dérouler le rêve d'un d'Alembert qui se serait converti au calcul des probabilités. C'est une philosophie du progrès. Ce n'est peut-être pas une philosophie du progrès historique.

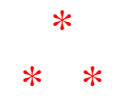

\section{Comment fixer la situation de Condorcet ?}

Il a sa place dans une lignée de penseurs qui, en France, naît, avec Perrault, de la querelle des Anciens et des Modernes et trouve en Fontenelle son fondateur philosophique. Elle fluctue d'abord entre les Lettres et les Sciences, mais cherche de plus en plus en ces dernières et, particulièrement, dans les mathématiques, l'excellence de l'esprit humain. Jusqu'à Condorcet, on inscrirait dans cette lignée des penseurs, parfois bien différents par ailleurs, comme Montesquieu, Voltaire, Turgot auquel notre philosophe associe Price et Priestley (166) Bailly, Volney. Et, après Condorcet, les idéologues, même si, comme Cabanis et Destutt de Tracy, ils s'en défendent, Comte, Cournot - qui, dès la première page de la Préface à ses Considérations sur la marche des idées dans les temps modernes, ne manque pas de faire allusion à l'Esquisse 9 - et disons, pour finir, Léon Brunschvicg.

Tous rejettent la métaphysique classique et désacralisent l'Histoire.

\section{Et qu'en est-il des prophéties de Condorcet?}

La science ne l'a point démenti. Elle est allée très au-delà de tout ce qu'il pouvait prévoir et peut-être est-elle à la veille de prolonger la

9 Dans les livres d'histoire, constate Cournot dès la première phrase de son ouvrage, « il est d'usage de joindre, par forme de complément ou d'appendice, une esquisse des progrès de l'esprit humain dans les sciences, les arts, l'industrie, durant la même période de temps. Pourquoi ne pas suivre quelquefois une marche inverse, en prenant pour le fond de son sujet le travail de l'esprit humain, et pour accessoire ou appendice... ce qui n'est en quelque sorte que de la biographie sur une grande échelle, la biographie d'un peuple ou celle du genre humain ? ». Considérations, éd. F. Mentré, Paris (1934). 
vie et de changer notre constitution ; elle devient de plus en plus l'ingénieur de l'homme, et cela, grâce, surtout, au calcul des probabilités. Quant au progrès moral, Alexandre Koyré était encore en droit de soutenir au lendemain de la dernière Guerre - et à propos de Condorcet que la philosophie des Lumières venait de nous sauver de la barbarie. Mais, depuis, le temps a coulé. Les machines à calcul travaillent plutôt pour l'esclavage, volontaire ou involontaire, que pour la liberté. Depuis, chaque jour nous apprend qu'avec l'accélération de l'Histoire, nous ne vivons plus à l'échelle du XVIIIe siècle, et que - cela non plus Condorcet ne pouvait le prévoir - le rationnel se sépare de plus en plus du raisonnable.

\section{Yvon BELAVAL.}


CONDORCET,

Esquisse d'un tableau historique des progrès de l'esprit humain

(1793-1794).

\section{Introduction}

Par O. H. Prior

$\underline{\text { Retour à la table des matières }}$

Condorcet occupe une place à part dans l'histoire de la pensée française. Il est le dernier des "philosophes », le seul qui ait pris une part active à la Révolution. Il n'a pas conçu de système absolument original, mais il rassemble toutes les théories de ses prédécesseurs. Nous retrouvons chez lui les idées de Voltaire, de Rousseau, de Turgot, d'Helvétius, de Condillac, peu à peu façonnées en un tout harmonieux dont la dernière expression est l'Esquisse, sorte de résumé philosophique du XVIIIe siècle.

Il représente en outre à merveille, sous les principaux aspects, la sensibilité de son temps ; et rien ne saurait mieux expliquer pourquoi, loin de guider les événements, il a été entraîné par eux. Comme tant d'autres, Condorcet a été le jouet et enfin la victime de la Révolution.

Voilà ce qui ressort des études accumulées autour de son œuvre et de sa personne. 
Marie-Jean-Antoine-Nicolas Caritat, marquis de Condorcet, naquit le 17 septembre 1743, à Ribemont en Picardie. Son père, officier de cavalerie, avait épousé Mme de Saint-Félix, jeune veuve d'origine bourgeoise, de santé délicate, fort dévote, mais riche.

L'année même de sa naissance, le père de Condorcet fut tué à Neuf-Brisach. L'enfant, de constitution chétive, fut entouré par sa mère de soins extraordinaires ; jusqu'à huit ans il fut voué au blanc et porta le costume d'une fille. " La tutelle d'une mère aussi tendre, mais aussi timorée, dit $\mathrm{M}$. Cahen ${ }^{10}$, imprima au caractère de l'enfant comme an cachet de féminité. À une délicatesse extrême, à un besoin impérieux d'intimité et d'affection, s'ajoutèrent de l'indécision, une certaine frayeur pour soi-même, une impressionnabilité dangereuse... Il se ressentit toute sa vie, le fait n'est pas douteux, de cette enfance anormale. »

C'était, évidemment, une mauvaise préparation pour la vie de collège. L'oncle de Condorcet, évêque d'Auxerre, confia d'abord l'éducation de son neveu à un précepteur jésuite. Puis l'enfant étudia chez les Jésuites de Reims. En 1758, il entra au collège de Navarre. De ces années d'études, nous ne savons presque rien. Condorcet n'y fait que de rares allusions ; mais il en rapporta la haine des Jésuites, de leurs méthodes; et Une se fit pas un seul ami. Cela n'est pas surprenant, si l'on songe à sa première éducation. Ces années de collège recouvrent sans doute une période de souffrances intimes.

Condorcet était destiné à la carrière des armes. Contre le désir de sa famille, il préféra les sciences et s'établit à Paris. A l'âge de vingtdeux ans, il présente à l'Académie son Essai sur le calcul intégral, « rempli, nous dit Lagrange, d'idées sublimes et fécondes ». C'est ainsi qu'il devint le protégé et l'ami de d'Alembert, d'Helvétius, de Turgot surtout. Dès 1769, il travaille à l'Académie des Sciences, et compose les Éloges des académiciens d'avant 1699. En 1773, il est nommé secrétaire-adjoint de cette Académie, et, en 1785, secrétaire perpétuel. En 1774, Turgot, devenu ministre des finances, nomme Condorcet inspecteur général des monnaies. Enfin, en 1782, il entre à l'Académie française.

10 Cahen, Condorcet et la Révolution française, p. 5. 
On ne peut dire avec précision à quel moment Condorcet, renonçant aux mathématiques, s'est consacré aux sciences politiques. Déjà ses Éloges avaient montré l'intérêt qu'il prenait à des questions en dehors de son sujet habituel. En 1774, dans ses Lettres d'un théologien à l'auteur du dictionnaire des trois siècles, il se révèle polémiste ardent et apôtre de la tolérance. En 1777 il prend part à un concours de l'Académie française et aborde pour la première fois un sujet de morale et de politique dans son Éloge de Michel de l'Hôpital, dont la vie, disait-il, " peut être offerte en exemple à ceux qui, se trouvant placés dans des circonstances difficiles, auraient à choisir entre le repos et le bien public ». La liste chronologique des oeuvres de Condorcet montre clairement que, d'assez bonne heure, les sciences mathématiques n'ont pas été son unique préoccupation.

Ses amis, les Encyclopédistes, les Physiocrates, Turgot, Voltaire, ont beaucoup contribué à l'orienter vers les choses sociales. D'autres influences devaient s'exercer dans le même sens : les salons qu'il fréquentait, ceux de Mlle de Lespinasse et de Mme Helvétius, celui de Mme de Condorcet elle-même, que Michelet appelle « le centre naturel de l'Europe pensante ». Dans un tel milieu ses idées politiques se sont affermies et l'ont incité à travailler activement pour le bien public.

Dès 1789, il est membre de la Commune de Paris, et dès lors son œuvre est celle plutôt d'un journaliste que d'un homme de science. Il contribue surtout à la littérature de combat. Il est rédacteur à la Chronique de Paris, collabore à la Bibliothèque de l'Homme public, à la Bouche de Fer, à d'autres feuilles éphémères où se multiplient les articles d'occasion et se renouvelle la discussion des événements journaliers. C'est la fin des traités techniques et des ouvrages de longue haleine. Le philosophe fait trop souvent place au polémiste. Mais il étudie les questions politiques au point de vue pratique avec un entier désintéressement. Nous avons ainsi une série d'articles de grande valeur ; toutefois ils n'ont guère aidé à la formation de la constitution républicaine.

L'activité politique de Condorcet fut remarquable pendant toute la durée de la Constituante, bien qu'il n'ait pas été membre de cette As- 
semblée. Avec Siéyès, il fonda la Société de 1789, centre des nobles d'esprit libéral. Par l'intermédiaire du journal de la Société, il fait tous ses efforts pour diriger l'opinion, cherchant toujours à faciliter la transition du régime despotique au régime de la liberté.

En 1791, il est élu à Paris membre de l'Assemblée législative : c'est le point culminant de sa carrière politique. Son rôle est vraiment important dans une assemblée en majorité monarchique, où ses mérites de grand seigneur, d'académicien et de démocrate ont toute leur valeur aux yeux des bourgeois libéraux. Il n'appartient à aucun parti : « Je m'étais lié, écrit-il, dans l'Assemblée nationale, avec un petit nombre d'hommes justes et éclairés, incorruptibles, zélés défenseurs des droits du peuple ${ }^{11}$. » Telle sera constamment son attitude politique. Il ne penche ni à droite, ni à gauche, ce qui explique comment il a pu, sous la Convention, partager les opinions des Girondins et cependant donner tout son appui à Danton.

Il fut élu secrétaire, vice-président, puis président de la Législative. Il n'était nullement orateur. Malgré tout, l'Assemblée lui était favorable, écoutait patiemment ses discours, discutait avec respect ses déclarations, ses proclamations. Suivant les conséquences de sa philosophie, il réclame l'abolition de la religion d'État, répudie l'esprit de conquête et montre que la France entend respecter l'indépendance des peuples, il rédige le fameux rapport sur l'instruction publique ; enfin, l'un des premiers, il prononce le mot de République.

Son rôle lut plus effacé sous la Convention où il fut élu en 1792 par cinq départements et siégea comme député de l'Aisne, son pays natal. Il fut, de prime abord, en opposition avec la majorité de ses collègues lors du procès du roi. Il vota contre l'exécution de Louis XVI. Comme membre du comité de la Constitution, il présenta un rapport que les Jacobins attaquèrent violemment et auquel ils substituèrent un autre projet qui fut voté peu après. Alors Condorcet écrivit un pamphlet pour en appeler au peuple contre l'Assemblée.

Le 8 juillet 1793, il est dénoncé par Chabot et décrété d'arrestation, « comme prévenu de conspiration contre l'unité et l'indivisibilité de la

11 Cité par Cahen, op. cit., p. 437. 
République ». C'est le commencement du drame. Condorcet se réfugie chez Mme Vernet, rue des Fossoyeurs (aujourd'hui, 16, rue Servandoni). Il y reste neuf mois. Là, mis hors la loi, sous la menace de la guillotine, il achève son ouvrage le plus célèbre, l'Esquisse d'un tableau des progrès de l'esprit humain. Mais, redoutant une perquisition et craignant de compromettre son hôtesse, il décide de s'enfuir. Il écrit son testament, ainsi que l'Avis d'un proscrit à sa fille, et, dès le 25 mars 1794, trompant la surveillance de Mme Vernet, il s'élance dans la rue. Il se rend à Fontenag-aux-Roses, pensant y demander asile à ses vieux amis, les Suard, qu'il avait obligés autrefois. Sans doute les Suard se croyaient-ils eux-mêmes menacés, car, après une longue conversation, Condorcet fut éconduit. Réfugié dans les carrières de Montrouge, il y passe la nuit, la journée, la nuit encore ; mais, le 27 mars, mourant de faim, il entre dans un cabaret de Clamart où ses réponses embarrassées et sa miné étrange le font arrêter. Blessé à la jambe, trop faible pour marcher, il est conduit, monté sur un cheval, à Bourg-la-Reine et enfermé dans un cachot.

Le lendemain matin, 28 mars 1794, son geôlier le trouva mort. Selon le rapport de l'officier de santé, Condorcet aurait succombé à une congestion sanguine. D'après une légende, vulgarisée dès 1795, il se serait empoisonné ; mais, comme l'a très suffisamment démontré $\mathrm{M}$. Cahen ${ }^{12}$, ce fait est des plus douteux.

Condorcet a donné lieu à des appréciations aussi diverses que le panégyrique de Diannyère et la critique sévère, voire amère de SainteBeuve. D'Alembert dépeint son jeune ami comme « un volcan couvert de neige »; Turgot l'appelle "un mouton enragé »; la plupart des biographes font ressortir «la bonté » du philosophe. Tous ces traits n'ont rien d'incompatible. Sous son extérieur " de neige », Condorcet cache une âme ardente qui lui fait parfois perdre toute mesure lorsqu'il attaque une injustice, comme dans ces Lettres d'un théologien contre l'intolérance, qui justifient l'épithète de Turgot et cette remarque de Voltaire : «Fallait-il donc se permettre de publier un ouvrage aussi audacieux, quand on ne commandait pas à deux cent mille soldats? »

12 Cahen, op. cit., p. 540. 
Mlle de Lespinasse nous a laissé le portrait physique et moral de son ami ${ }^{13}$ : " Il a tous les genres de bonté, celle qui fait compatir, secourir, celle qui rend facile et indulgent, celle qui prévient les besoins d'une âme délicate et sensible... Avec cette bonté, il pourrait se passer de sensibilité ; eh bien, il est d'une sensibilité profonde, et ce n'est point une manière de parler. Il est malheureux du malheur de ses amis, Il souffre de leurs maux, et cela est si vrai que son repos et sa santé en sont souvent altérés... Il a le tact le plus sûr et le plus délié pour saisir les ridicules et pour démêler toutes les nuances de la vanité ; il a même une sorte de malignité pour les peindre, qui contraste d'une manière frappante avec cet air de bonté qui ne l'abandonne jamais... Cette âme calme et modérée dans le cours ordinaire de la vie devient ardente et pleine de feu s'il s'agit de défendre les opprimés, ou de défendre ce qui lui est plus cher encore, la liberté des hommes et la vertu des malheureux ; alors son zèle va jusqu'à la passion... » Il serait facile d'illustrer tous ces traits de caractère au moyen d'exemples tirés des ouvrages de notre philosophe : cette sensibilité nous explique sa carrière politique, et surtout son œuvre de journaliste.

Le portrait tracé par Mlle de Lespinasse a certainement deux faces. On peut d'ailleurs le compléter par la correspondance de Condorcet avec Mme Suard, si bien analysée par M. Doumic. Elle nous fait entrevoir un Condorcet, sensible il est vrai, mais aussi, entier, irritable. «Le « bon » Condorcet, dit Doumic, fut un des hommes les plus haineux qu'il y ait eu dans ces temps de violence et de haine... : tel est l'envers de la sensibilité ». Toutefois, ce côté agressif ne se montre guère que dans les relations de notre philosophe avec Necker, et dans son anticléricalisme. Son attitude envers le célèbre directeur des finances est un exemple frappant de ce que peuvent les haines politiques. Necker, protectionniste convaincu, était l'adversaire naturel de Turgot et des Physiocrates. De là vient la haine de Condorcet qui voyait dans le libre échange une des conditions nécessaires au progrès de l'humanité. Tant il est vrai que les conflits de doctrines mènent à des violences aussi déchaînées que les conflits de sentiments.

13 Portrait de M. le marquis de Condorcet par Mlle de Lespinasse. Oeuvres de Condorcet, éd. Arago, t. I, pp. 626-635). 
L' « anticléricalisme » de Condorcet, si l'on peut user de ce terme, paraît, de même, avoir une origine plutôt politique que religieuse. L'ami de Voltaire et des Encyclopédistes n'a jamais révélé le fond de sa pensée sur les questions de dogme. Il y touche assez légèrement dans sa Vie de Voltaire. Il n'était certainement pas athée. On peut même croire que, dans le fond de son cœur, il est resté chrétien. Notons aussi qu'il a soutenu le droit de l'Église à l'indemnité lors de la confiscation des biens. Tout comme le Chancelier de l'Hôpital, dont la vie a été un de ses premiers sujets d'étude, il était apôtre de la tolérance, et, sans demander expressément la séparation de l'Église et de l'État, il ne voit dans leur alliance qu'un danger. Il estimait que les intérêts de l'Église ne concordaient pas nécessairement avec ceux du peuple et de la liberté. D'autre part, les abus du haut clergé, les procès contre les Jansénistes et les Jésuites, les cas de fanatisme assez fréquents, justifient jusqu'à un certain point la violence de ses attaques, conformes à l'esprit du temps, mais qui nous paraissent aujourd'hui un peu excessives.

La sensibilité de notre philosophe se montre sous un meilleur jour quand il prend la défense des opprimés. Une grande part lui revient dans la réhabilitation de La Barre, généralement attribuée à Voltaire seul. Il combattit l'esclavage et en montra l'infamie ${ }^{14}$. Ce fat lui qui rédigea les statuts de la Société des Amis des Noirs ${ }^{15}$.

Son cœur n'est d'ailleurs pas à l'abri de sentiments plus tendres. MI" de Lespinasse dut employer toute son influence et tout son tact pour le sauver d'une Célimène, Mlle d'Ussé. À l'âge de quarante-deux ans, il tomba une fois encore amoureux, et sans remède, d'une jeune fille de vingt-trois ans, Mlle de Grouchy, qu'il épousa en 1786 et qui fut pour lui, en dépit de la médisance, une fidèle compagne ${ }^{16}$.

Une des pages les plus intéressantes de sa vie est celle de ses relations avec Voltaire et Turgot. Il doit sans doute au premier ses idées

14 Réflexions sur l'esclavage des nègres. Oeuvres, éd. Arago, t. VII.

15 Cahen, La Société des amis des Noirs et Condorcet, dans la Révolution française, janvier-juin 1906, t. L, pp. 481-511.

16 A. Guillois, La marquise de Condorcet, sa famille, son salon, ses amis, Paris, 1897. 
sur la tolérance, sur la religion ; au second, en grande partie, ses théories sur l'économie politique. Toutefois il garde son indépendance et maintiendra, par exemple, contre Voltaire, le droit du peuple à l'éducation. Ses vies de Voltaire (1787) et de Turgot (1789) sont deux monuments élevés à l'amitié. Son admiration pour ces deux grands hommes est profonde, quelquefois un peu partiale. C'est ainsi qu'il écrit, à propos de Voltaire cette phrase qui n'est pas exempte de quelque naïveté : "Sans faste dans ses vertus, et sans dissimulation dans ses erreurs, dont l'aveu lui échappait avec franchise, mais qu'il ne publiait pas avec orgueil, il a existé peu d'hommes qui aient honoré leur vie par plus de bonnes actions et qui Paient souillée par moins d'hypocrisie. " La Vie de Turgot est surtout précieuse comme résumé des opinions de Condorcet lui-même sur la politique.

L'influence de la sensibilité sur l'œuvre de Condorcet est évidente. Mais la sensibilité n'explique pas tout. Il faut tenir compte du génie de l'homme, qui lui permet de saisir tous les côtés d'une question, de suggérer des remèdes aux abus, de voir, dans l'avenir même, les progrès possibles et les méthodes qu'il faut suivre pour les réaliser.

Sa philosophie forme un système parfaitement net. Elle relève, comme presque toute la pensée française de l'époque révolutionnaire, à la fois du sensualisme de Condillac et du rationalisme cartésien ${ }^{17}$. Les traits essentiels lui paraissent si évidents qu'il se contente de les indiquer en quelques lignes dans son introduction à l'Esquisse; nous y renvoyons le lecteur. Le sujet n'est même pas approfondi, aussi est-il nécessaire de compléter la théorie pour la rattacher au reste du système.

Les sensations forment le contenu de l'intelligence humaine. Toute la pensée peut se ramener, en dernière analyse, à des sensations. La faculté de les recevoir se développe " par l'action des choses extérieures, c'est-à-dire par la présence de certaines sensations composées

17 Bouillier (Histoire de la Philosophie cartésienne, Il, p. 641) fait observer les éléments cartésiens qui se trouvent chez notre philosophe : la raison universelle, la doctrine de perfectibilité, l'appel aux lois immuables du juste et de l'injuste ; la justice et les droits absolus dans la morale sociale et dans la politique. 
dont la constance... est indépendante de l'homme ». Ainsi l'esprit humain n'est pas créateur : il reçoit seulement, et retient, des signes extérieurs. Chaque sensation est accompagnée de plaisir ou de douleur. « L'homme a la faculté, de transformer ces impressions momentanées en sentiments durables, doux ou pénibles. »Ainsi se développe toute la vie affective de l'homme. Enfin, grâce à cette sensibilité combinée avec la faculté de penser, l'homme établit « entre lui et ses semblables des relations d'intérêt et de devoir ».

La raison, et c'est là un des traits essentiels du système, est universelle. Elle est la même partout. Tous les hommes sont identiques en tant qu'êtres capables de former des raisonnements et d'acquérir des idées morales. Il y a des vérités morales, applicables à l'humanité entière, dont la loi est justement fournie par la raison sur laquelle doit être fondée la société.

La raison enseigne à l'homme qu'il a des droits naturels, dérivant de sa nature d'être sensible et raisonnable. Ces droits, antérieurs aux institutions sociales, comprennent la LIBERTÉ et l'ÉGALITÉ, dont le maintien est le seul but de la réunion des hommes en sociétés politiques. Condorcet n'admet donc pas l'idée d'un contrat entre le peuple et les magistrats, ni celle d'une division sociale entre ceux qui gouvernent et ceux qui obéissent. Tous les hommes sont égaux sous le rapport des droits.

De l'effort pour maintenir les droits naturels résultent les droits civils et politiques, et l'art politique lui-même qui définit les différentes formes de liberté : liberté politique, liberté individuelle, liberté de conscience, liberté de la presse ${ }^{18}$. Condorcet, dans cette énumération, est surtout disciple de Voltaire. Mais, comme le fait remarquer $\mathbf{M}$. Sée ${ }^{19}$, cette théorie a été complétée plus tard sous l'influence de la Révolution américaine, et surtout de son ami Thomas Paine. C'est alors qu'il définit les droits naturels de l'homme «dans toute leur étendue, ceux de la sûreté, ceux de la propriété, ceux de la liberté, en-

18 Cf. Sée, Condorcet, ses idées et soit rôle politique. Revue de synthèse historique, janvier à juin 1905.

19 Sée, Évolution de la pensée politique en France, p. 280 et s. 
core si méconnus, ceux de toutes les nations qui osent se vanter d'être libres $\gg 20$.

Le premier principe de l'art social est donc le maintien de l'égalité naturelle qui résulte nécessairement du fait de l'égalité de la raison chez les hommes. C'est le devoir de l'État d'assurer à chaque citoyen la jouissance de ses droits ; l'État doit supprimer toutes les inégalités artificielles qui proviennent de l'organisation sociale actuelle : inégalités de richesse, d'état, d'instruction ${ }^{21}$. L'inégalité de richesse sera supprimée par l'abolition des lois qui favorisent les fortunes privées ; les inégalités d'état, par exemple les inégalités entre patrons et ouvriers, seront au moins adoucies par les assurances pour les vieillards et les veuves. Enfin l'inégalité d'instruction sera détruite par un système d'enseignement public exposé par Condorcet en 1791, dans cinq Mémoires sur l'instruction publique, qui sont peut-être son plus grand titre de gloire ${ }^{22}$.

Il y préconise des réformes si audacieuses qu'elles ne sont point encore toutes réalisées. C'est un traité d'organisation où la psychologie de l'enfant n'est pas en cause ; et, de fait, le point faible du système de Condorcet est le manque d'expérience pratique de son auteur. Mais, comme théoricien, il est supérieur à tous les écrivains du XVIIIe siècle qui se sont occupés du sujet.

Il attribue à l'éducation un pouvoir immense, sans pourtant aller aussi loin qu'Helvétius pour qui l'esprit, la vertu, sont des produits d'une science qui pourrait multiplier à volonté les hommes de génie.

Le système d'éducation de Condorcet est partie intégrante de son économie politique. C'est l'éducation démocratique qui doit supprimer toutes les inégalités sociales et rendre à l'homme sa liberté native. « Nous ferons voir que, par un choix heureux, et des connaissances elles-mêmes et des méthodes de les enseigner, on peut instruire la

20 Essai sur les Assemblées provinciales, cité par H. Sée. Évolution, p. 280.

21 Condorcet doit certainement à Rousseau la théorie d'égalité, mais il traite surtout du côté civil plutôt que social de la question.

22 Parus dans la Bibliothèque de l'homme publie. Oeuvres, éd. Arago, t. VII, pp. 167-437. 
masse entière d'un peuple de tout ce que chaque homme a besoin de savoir pour l'économie domestique, pour l'administration de ses affaires, pour le libre développement de son industrie et de ses facultés, pour connaître ses droits, les défendre et les exercer ; pour être instruit de ses devoirs ; pour pouvoir les bien remplir ; pour juger ses actions et celles des autres d'après ses propres lumières, et n'être étranger à aucun des sentiments élevés ou délicats qui honorent la nature humaine; pour ne pas dépendre aveuglément de ceux auxquels il est obligé de confier le soin de ses affaires ou l'exercice de ses droits; pour être en état de les choisir et de les surveiller ; pour n'être pas la dupe de ces erreurs populaires qui tourmentent la vie de craintes superstitieuses et d'espérances chimériques ; pour se défendre contre les préjugés avec les seules forces de sa raison ; enfin, pour échapper aux prestiges du charlatanisme qui tendrait des pièges à sa fortune, à sa santé, à la liberté de ses opinions et de sa conscience sous prétexte de l'enrichir, de le guérir et de le sauver. » Pour arriver à ces fins, Condorcet veut donner à tous les enfants les mêmes chances de s'instruire. Il admet, contre Helvétius, que « les esprits sont naturellement inégaux »; il propose donc d'établir un système d'éducation gratuite composée de plusieurs degrés, depuis l'enseignement élémentaire, commun à tous, jusqu'au plus haut, réservé aux étudiants les mieux doués.

La liberté de l'enseignement supérieur doit être complète, et Condorcet cherche à protéger le corps enseignant contre toute ingérence du gouvernement qui doit restreindre son rôle, même dans l'éducation élémentaire, à "répandre les lumières ". Il réclame une absolue liberté de conscience; il veut qu'on respecte toutes les croyances et toutes les opinions. Aucune religion ne doit être enseignée dans les écoles, pas même «ce qu'on appelle religion naturelle »; par conséquent, le clergé de toute confession sera exclu. Seule une morale générale sera inscrite au programme. Mais chaque religion pourra être enseignée dans les temples, par ses propres ministres, pendant des heures réservées à cet effet. Les opinions politiques devront être également respectées : un exposé de la constitution aura sa place dans le tableau des leçons, mais exempt de tout esprit de propagande. " Il ne s'agit pas de soumettre chaque génération aux opinions comme à la volonté de celle qui la précède, mais de les éclairer de plus en 
plus, afin que chacun devienne de plus en plus digne de se gouverner par sa propre raison. »

Une des conséquences naturelles du principe d'égalité est le féminisme. Condorcet a reconnu à la femme tous les droits politiques des hommes, et, en matière d'éducation, il a même préconisé l'école mixte.

Une autre conséquence est la souveraineté du peuple. Condorcet devait donc considérer la république comme le gouvernement idéal ${ }^{23}$. Il semble pourtant s'en être tenu longtemps à la théorie de Montesquieu pour qui la république était le gouvernement propre à un petit État. La révolution américaine lui ouvrit les yeux à cet égard. Cependant il resta monarchiste, ou, tout au moins, fidèle au roi, jusqu'à la fuite de Varennes. Il opte pour un gouvernement représentatif, où les pouvoirs du peuple seront garantis. Il admet donc la représentation par députés, comme Montesquieu; mais, de plus, il recommande l'appel direct aux électeurs, dans certains cas, sorte de référendum qui s'accorde avec la théorie de Rousseau sur le pouvoir souverain du peuple. C'est une habile combinaison des deux systèmes. Condorcet a toujours combattu la théorie de la séparation des pouvoirs de l'Esprit des Lois, où il voit une violation directe de l'égalité primitive. Il ne comprend pas l'engouement du temps pour la constitution anglaise. « C'est l'ouvrage du hasard devenu, aux yeux du vulgaire, celui d'une raison profonde » ${ }^{24}$. Comme dit M. Sée, oit attribue à la constitution de l'Angleterre la liberté dont on jouit en ce pays, alors que tout l'honneur en revient à la liberté de la presse et à l'habeas corpus.

L'égalité doit régler non seulement les rapports des individus, mais ceux des peuples. Un des plus grands espoirs de Condorcet est la destruction de l'inégalité entre les nations. Il condamne sévèrement toute oppression d'une nation par une autre, toute violence envers les populations dites sauvages. Il prévoit l'affranchissement des colonies et « ce moment où le soleil n'éclairera plus sur la terre que des hommes libres, ne reconnaissant d'autres maîtres que leur raison>. La destruction de l'inégalité entre les nations aura pour conséquences Ici dispari-

23 Cahen, op. cit., p. 266.

24 Cité par Sée, Évolution, p. 286. 
tion de l'esprit de conquête et celle de la guerre, l'organisation des tribunaux d'arbitrage et d'une société des nations.

Enfin Condorcet est un précurseur des études les plus modernes, de l'application des mathématiques aux choses sociales, de l'emploi scientifique des courbes et des statistiques. Frappé par l'exemple des progrès de ta physique grâce aux mathématiques, il décide de faire un usage semblable des sciences dans le cas de la morale sociale. C'est une nouvelle science qu'il appelle lui-même " La mathématique sociale>. Il ne doute pas des avantages qui en résulteront pour l'humanité. «La mathématique sociale, écrit-il ${ }^{25}$, peut avoir pour objet les hommes, les choses, ou à la fois les choses et les hommes.

« Elle a les hommes pour objet, lorsqu'elle enseigne à déterminer, à connaître l'ordre de la mortalité dans telle ou telle contrée ; lorsqu'elle calcule les avantages ou les inconvénients d'an mode d'élection. Elle a les choses pour objet, lorsqu'elle évalue les avantages d'une loterie, et qu'elle cherche d'après quels principes doit être déterminé le taux des assurances maritimes. Enfin elle a en même temps l'homme et les choses pour objet, quand elle traite des rentes viagères, des assurances sur la vie... Ainsi la science dont nous traitons ici doit naturellement être précédée par cinq théories mathématiques qui peuvent être développées indépendamment de toute application : $1^{\circ}$ La théorie des grandeurs susceptibles d'accroissements proportionnels au temps, qui renferme celle des intérêts de l'argent ; $2^{\circ}$ La théorie des combinaisons ; $3^{\circ}$ Celle de la méthode de déduire, des faits observés, soit les faits généraux, soit les lois Plus générales encore ; $4^{\circ}$ La théorie du calcul des probabilités ; $5^{\circ}$ Enfin, celle des valeurs moyennes. »

L'idée qui couronne l'œuvre de Condorcet, qu'il a développée dans l'Esquisse, qui est restée attachée à son nom, est celle du Progrès. Toutes les théories précédentes la préparent : le sensualisme, la raison universelle, l'égalité surtout, qui, grâce à l'éducation, permet à l'humanité de s'élever sans cesse au point de vue intellectuel et moral. Condorcet est, avant tout, un optimiste.

Tableau général de la science qui a pour objet l'application du calcul aux sciences politiques et morales. Oeuvres, éd. Arago, t. I, pp. 539-573. 
Dans la pensée de l'auteur, l'Esquisse était une simple introduction à un ouvrage de dimensions encyclopédiques. Il l'appelle lui-même, dans son manuscrit, "Prospectus » d'un tableau historique. Selon M. Cahen, Condorcet a dû avoir un certain nombre de livres à sa disposition dans sa retraite ${ }^{26}$. La composition de cet essai n'en représente pas moins un prodigieux effort de synthèse.

Le plan rappelle celui des ÉPOQUES DE LA NATURE. Condorcet, il est vrai, ne se laisse pas emporter par son sujet : il évite les métaphores et les hyperboles, et son style n'a rien de celui de Buffon. Mais il sait convaincre par sa simplicité même, par le sentiment de profonde conviction, d'honnêteté scientifique et politique que respire chaque ligne de l'Esquisse.

Il n'y a pas lieu de discuter ici les sources de notre philosophe : il cite lui-même de nombreux écrivains français et étrangers, tels que Priestley et Harington, dont les idées s'apparentent plus ou moins aux siennes.

La théorie de l'Idée de Progrès 27 a été développée surtout en France, où Bodin, Descartes, Pascal, Fontenelle, l'abbé de Saint-Pierre l'ont soutenue. Le XVIIe siècle avait conçu l'idée d'un développement historique où l'humanité est en progrès et non en décadence. Le XVIIIe siècle a cru en l'évolution de l'humanité à partir d'un passé barbare vers un avenir de perfection scientifique. Cette thèse est, avant Condorcet, celle de Castellux, de Sébastien Mercier, de Volney même dans ses Ruines ; surtout, celle de Turgot ${ }^{28}$.

Les principes de Condorcet sont les mêmes que ceux de son ami. Il complète l'ébauche de Turgot, en atténue un peu l'esprit chrétien, y ajoute des déductions. Pour la première fois, l'histoire est divisée, non pas en fonction des événements politiques, mais du progrès des connaissances. Comparé à ses prédécesseurs, Condorcet est original,

26 Cahen, op. cit., p. 528.

27 J.-B. Bury, The Idea of Progress, 1921. - J. Delvaille, Histoire de l'idée de Progrès, 1910.

28 Turgot, Tableau phiIosophique des progrès successifs de l'esprit humain, 1750. Oeuvres, éd. Schelle, Paris 1913-1923, 5 vol., t. I, pp. 298-323. 
en ce qu'il insiste sur l'avenir et qu'il en prévoit même la direction. Beaucoup de ses prévisions ont été des prophéties. Il a des défauts, dus souvent à l'état des connaissances de son temps : le moyen âge lui est inconnu ; il promet plus qu'il ne peut tenir au point de vue des origines historiques; sa vision de l'avenir ne se formule pas en lois de développement comme chez Auguste Comte 29. Mais il a bien vu l'importance de l'histoire ; il a cru surtout que la connaissance de ses lois devait nous donner la clef du progrès de l'humanité : principe de grand avenir qui devait guider tous ceux qui, après lui, ont eu la vision du progrès : Cabanis, les Idéologues, Mme Staël, Guizot, Saint-Simon, Auguste Comte. Il a trouvé son poète en Victor Hugo.

L'œuvre de Condorcet a vieilli sous bien des rapports ; mais l'auteur de l'Esquisse, plus que tout autre, s'en serait félicité : c'est le plus bel argument en faveur de l'idée de Progrès.

\section{O.H. PRIOR.}

29 De récents travaux ont démenti plutôt que confirmé la croyance de Condorcet en une perfectibilité indéfinie de l'homme, de son organisation physique et de ses facultés. Voir à ce sujet les ouvrages de L. Cuénot sur l'Adaptation (Doin) et La Genèse des espèces animales (Alcan), ainsi que les travaux de J. Chevalier: L'habitude (Roivin), Trois conférences d'Oxford (Ed. Spes), En quoi consiste le progrès de l'humanité, Acad. des Sciences morales et politiques, 26 oct. 1929. 


\section{Avertissement}

$\underline{\text { Retour à la table des matières }}$

La Bibliothèque de l'Institut possède trois liasses de papiers divers de Condorcet, catalogués sous la cote No 885.

La troisième liasse, dans un carton séparé, contient le manuscrit autographe de l'Esquisse, intitulé par le philosophe lui-même : Prospectus d'un tableau historique des progrès de l'esprit humain.

Nous sommes ici en présence de l'ouvrage écrit à la rue Servandoni sous l'ombre de l'échafaud, et terminé, comme l'auteur même nous le dit : « Ce vendredi 4 octobre 1793 ancien style, 13, du le, mois de l'an deux de la republique francaise $"{ }^{30}$, c'est-à-dire presque six mois avant la fuite tragique du 25 mars 1794.

Le texte original n'est peut-être qu'un brouillon. Il se compose presque entièrement de feuilles de deux pages, écrites sur deux colonnes : celle de droite contient le texte, celle de gauche les corrections et les additions.

30 Condorcet écrit « republique » sans accent, et « francaise » sans cédille. 
Le manuscrit est évidemment écrit à la hâte, parfois sur le dos de proclamations et parfois sur d'autres feuilles volantes prises au hasard. Les fautes d'orthographe, de grammaire et de syntaxe y abondent. Condorcet oublie souvent, à la fin d'un paragraphe, le sujet auquel se rapporte l'adjectif ou le participe, et néglige ainsi les règles d'accord les plus élémentaires. Les corrections, les renvois sont très nombreux et compliqués.

Dans les deux autres liasses du manuscrit de l'Institut et dans un manuscrit relié de la Bibliothèque Nationale ${ }^{31}$ se trouvent en outre de nombreuses notes. C'est la genèse de l'Esquisse. Comme le suggère M. Cahen ${ }^{32}$, Condorcet avait sans doute posé les premiers jalons de son ouvrage avant même de s'être réfugié chez Mme Vernet. L'auteur développe des idées dont certains éléments seront reproduits littéralement dans l'Esquisse. Mais en général, il résume ses notes en quelques lignes, quelques mots même. Il a sa conserver l'essentiel et sacrifier le superflu.

Avant d'écrire l'Esquisse, Condorcet s'était tracé un plan très détaillé qui nous est conservé dans le manuscrit de la Bibliothèque nationale. Les grandes divisions, les titres des chapitres sont tous indiqués d'avance. L'ordre des matières est resté le même dans la version finale. D'Alembert n'a sans doute pas fait autrement pour sa Préface à l'Encylopédie. Comme on le voit, la description de notre philosophe écrivant son Tableau d'un seul jet, sans préparation, sans plan déterminé, est une légende.

Condorcet a-t-il recopié son manuscrit après l'avoir terminé le 4 octobre 1793, ou l'a-t-il envoyé à son secrétaire pour le faire corriger et mettre au net, comme tant d'autres de ses ouvrages ? Nous n'avons rien pu découvrir à cet égard. La première édition, imprimée en l'An III, diffère beaucoup du manuscrit $\mathrm{N}^{\circ} 885$ soit par des additions, soit par de nombreuses corrections indispensables. Les différences dans l'édition Arago sont encore plus frappantes. Arago nous dit qu'il a revu l'Esquisse «sur le manuscrit ». Mais de quel manuscrit s'agit-il ? et

31 Fonds français, nouvelles acquisitions. $N^{\circ} 4586$.

32 Cahen, Condorcet et la Révolution française, p. 528. 
peut-on vraiment se fier à Arago ? M. Cahen ${ }^{33}$ nous met en garde contre les inexactitudes de cette édition de 1847 . On serait donc tenté de l'écarter d'emblée en faveur de la première édition imprimée de l'An III. Celle-ci, répandue par toute la France aux frais de la République, a certainement l'avantage d'avoir reçu le sceau officiel ; mais ce n'est pas, nous l'admettons, une preuve irréfutable d'authenticité. Nous sommes donc encore en présence d'une véritable énigme littéraire dont seul le manuscrit consulté par Arago pourrait nous donner la clef. Dans le doute, nous réimprimons l'édition Arago, mais avec toutes les réserves que comporte le cas.

Toutes les additions ou interpolations de passages de quelque étendue qui ne se trouvent pas dans le manuscrit de la Bibliothèque de l'Institut sont mises entre crochets : le lecteur pourra ainsi se former une idée de la différence qui existe entre le texte du manuscrit et celui des deux éditions, celle de l'An III et celle d'Arago.

33 Cahen, o. c., p. 17. 


\title{
CONDORCET, \\ Esquisse d'un tableau historique des progrès de l'esprit humain
}

\author{
Avant-propos
}

L'homme naît avec la faculté de recevoir des sensations ; d'apercevoir et de distinguer les sensations simples dont elles sont composées, de les retenir, de les reconnaître, de les combiner ; de comparer entre elles ces combinaisons ; de saisir ce qu'elles ont de commun et ce qui les distingue ; d'attacher des signes à tous ces objets, pour les reconnaître mieux, et faciliter des combinaisons nouvelles.

Cette faculté se développe en lui par l'action des choses extérieures, c'est-à-dire, par la présence de certaines sensations composées, dont la constance, soit dans leur identité, soit dans les lois de leurs changements, est indépendante de lui. Elle se développe également par la communication avec des individus semblables à lui ; enfin, par des moyens artificiels, que ces premiers développements ont conduit les hommes à inventer. 
Les sensations sont accompagnées de plaisir et de douleur; et l'homme a de même la faculté de transformer ces impressions momentanées en sentiments durables, doux ou pénibles ; d'éprouver ces sentiments à la vue ou au souvenir des plaisirs ou des douleurs des autres êtres sensibles. Enfin, de cette faculté unie à celle de former et de combiner des idées, naissent, entre lui et ses semblables, des relations d'intérêt et de devoir, auxquelles la nature même a voulu attacher la portion la plus précieuse de notre bonheur et les plus douloureux de nos maux.

Si l'on se borne à observer, à connaître les faits généraux et les lois constantes que présente le développement de ces facultés, dans ce qu'il a de commun aux divers individus de l'espèce humaine, cette science porte le nom de métaphysique.

Mais si l'on considère ce même développement dans ses résultats, relativement aux individus qui existent dans le même temps sur un espace donné, et si on le suit de générations en générations, il présente alors le tableau des progrès de l'esprit humain. Ce progrès est soumis aux mêmes lois générales qui, s'observent dans le développement des facultés chez les individus, puisqu'il est le résultat de ce développement, considéré en même temps dans un grand nombre d'individus réunis en société. Mais le résultat que chaque instant présente dépend de celui qu'offraient les instants précédents; il influe sur celui des temps qui doivent suivre.

Ce tableau est donc historique, puisque, assujetti à de perpétuelles variations, il se forme par l'observation successive des sociétés humaines aux différentes époques qu'elles ont parcourues. Il doit présenter l'ordre des changements, exposer l'influence qu'exerce chaque instant sur l'instant qui lui succède, et montrer ainsi, dans les modifications qu'a reçues l'espère humaine, en se renouvelant sans cesse au milieu de l'immensité des siècles, la marche qu'elle a suivie, les pas qu'elle a faits vers la vérité ou le bonheur. Ces observations, sur ce que l'homme a été, sur ce qu'il est aujourd'hui, conduiront ensuite aux moyens d'assurer et d'accélérer les nouveaux progrès que sa nature lui permet d'espérer encore. 
Tel est le but de l'ouvrage que j'ai entrepris, et dont le résultat sera de montrer, par le raisonnement et par les faits, que la nature n'a marqué aucun terme au perfectionnement des facultés humaines; que la perfectibilité de l'homme est réellement indéfinie ; que les progrès de cette perfectibilité, désormais indépendants de toute puissance qui voudrait les arrêter, n'ont d'autre terme que la durée du globe où la nature nous a jetés. Sans doute, ces progrès pourront suivre une marche plus ou moins rapide ; mais jamais elle ne sera rétrograde, tant que la terre, (lu moins, occupera la même place dans le système de l'univers, et que les lois générales de ce système ne produiront sur ce globe, ni un bouleversement général, ni des changements qui ne permettraient plus à l'espèce humaine d'y conserver, d'y déployer les mêmes facultés, et d'y trouver les mêmes ressources.

Le premier état de civilisation où l'on ait observé l'espèce humaine, est celui d'une société peu nombreuse d'hommes subsistant de la chasse et de la pêche ; ne connaissant que l'art grossier de fabriquer leurs armes et quelques ustensiles de ménage, de construire ou de se creuser des logements ; mais ayant déjà une langue pour se communiquer leurs besoins, et un petit nombre d'idées morales, où ils trouvaient des règles communes de conduite; vivant en familles; se conformant à des usages généraux qui leur tiennent lieu de lois ; ayant même une forme grossière de gouvernement.

On sent que l'incertitude et la difficulté de pourvoir à sa subsistance, l'alternative nécessaire d'une fatigue extrême et d'un repos absolu, ne laissent point a l'homme ce loisir, où, s'abandonnant à ses idées, il peut enrichir *son intelligence de combinaisons nouvelles. Les moyens de satisfaire à ses besoins sont même trop dépendants du hasard et des saisons, pour exciter utilement une industrie dont les progrès puissent se transmettre ; et chacun se borne à perfectionner son habileté ou son adresse personnelle.

Ainsi, les progrès de l'espèce humaine durent alors être très lents ; elle ne pouvait en faire que de loin en loin, et lorsqu'elle était favorisée par des circonstances extraordinaires. Cependant, à la subsistance tirée de la chasse, de la pêche, ou des fruits offerts spontanément par la terre, nous voyons succéder la nourriture fournie par des animaux que l'homme a réduits à l'état de domesticité, qu'il sait conserver et 
multiplier. À ces moyens se joint ensuite une agriculture grossière ; l'homme ne se contente plus des fruits ou des plantes qu'il rencontre ; il apprend à en former des provisions, à les rassembler autour de lui, à les semer ou à les planter, à favoriser leur reproduction par le travail de la culture.

La propriété, qui, dans le premier état, se bornait à celle des animaux tués par lui, de ses armes, de ses filets, des ustensiles de son ménage, devint d'abord celle de son troupeau, et ensuite celle de la terre qu'il avait défrichée et cultivée. À la mort du chef, cette propriété se transmet naturellement à la famille. Quelques-uns possèdent un superflu susceptible d'être conservé. S'il est absolu, il fait naître de nouveaux besoins ; s'il n'a lieu que pour une seule chose, tandis qu'on éprouve la disette d'une autre, cette nécessité donne l'idée des échanges : dès lors, les relations morales se compliquent et se multiplient. Une sécurité plus grande, un loisir plus assuré et plus constant, permettent de se livrer à la méditation, ou du moins, à une observation suivie. L'usage s'introduit, pour quelques individus, de donner une partie de leur superflu en échange d'un travail dont ils seront dispensés eux-mêmes. Il existe donc une classe d'hommes dont le temps n'est pas absorbé par un labeur corporel, et dont les désirs s'étendent au delà de leurs simples besoins. L'industrie s'éveille ; les arts déjà connus s'étendent et se perfectionnent ; les faits que le hasard présente à l'observation de l'homme plus attentif et plus exercé, font éclore des arts nouveaux ; la population s'accroît à mesure que les moyens de vivre deviennent moins périlleux et moins précaires ; l'agriculture, qui peut nourrir un plus grand nombre d'individus sur le même terrain, remplace les autres sources de subsistance : elle favorise cette multiplication, qui, réciproquement, en accélère les progrès ; les idées acquises se communiquent plus promptement et se perpétuent plus sûrement dans une société devenue plus sédentaire, plus rapprochée, plus intime. Déjà l'aurore des sciences commence à paraître ; l'homme se montre séparé des autres espèces d'animaux, et ne semble plus borné comme eux à un perfectionnement purement individuel.

Les relations plus étendues, plus multipliées, plus compliquées, que les hommes forment alors entre eux, leur font éprouver la nécessité d'avoir un moyen de communiquer leurs idées aux personnes absentes, de perpétuer la mémoire d'un fait avec plus de précision que par la 
tradition orale, de fixer les conditions d'une convention plus sûrement que par le souvenir des témoins, de constater, d'une manière moins sujette à des changements, ces coutumes respectées, auxquelles les membres d'une même société sont convenus de soumettre leur conduite.

On sentit donc le besoin de l'écriture, et elle fut inventée. Il paraît qu'elle était d'abord une véritable peinture, à laquelle succéda une peinture de convention, qui ne conserva que les traits caractéristiques des objets, Ensuite, par une espèce de métaphore analogue à celle qui déjà s'était introduite dans le langage, l'image d'un objet physique exprima des idées morales. L'origine de ces signes, comme celle des mots, dut s'oublier à la longue, et l'écriture devint l'art d'attacher un signe conventionnel à chaque idée, à chaque mot, et par la suite, à chaque modification des idées et des mots.

Alors, on eut une langue écrite et une langue parlée, qu'il fallait également apprendre, entre lesquelles il fallait établir une correspondance réciproque.

Des hommes de génie, des bienfaiteurs éternels de l'humanité, dont le nom, dont la patrie même sont pour jamais ensevelis dans l'oubli, observèrent que tous les mots d'une langue n'étaient que les combinaisons d'une quantité très limitée d'articulations premières ; que le nombre de celles-ci, quoique très borné, suffisait pour former un nombre presque infini de combinaisons diverses. Ils imaginèrent de désigner, par des signes visibles, non les idées ou les mots qui y répondent, mais ces éléments simples dont les mots sont composés.

Dès lors, l'écriture alphabétique fut inventée ; un petit nombre de signes suffit pour tout écrire, comme un petit nombre de sons suffisait pour tout dire. La langue écrite fut la même que la langue parlée ; on n'eut besoin que de savoir reconnaître et former ces signes peu nombreux, et ce dernier pas assura pour jamais les progrès de l'espèce humaine.

[Peut-être serait-il utile aujourd'hui d'instituer une langue écrite qui, réservée uniquement pour les sciences, n'exprimant que les combinaisons de ces idées simples qui sont exactement les mêmes dans 
tous les esprits, n'étant employée que pour des raisonnements d'une rigueur logique, pour des opérations dé l'entendement précises et calculées, fût entendue par les hommes de tous les pays, et se traduisît dans tous leurs idiomes, sans pouvoir s'altérer comme eux, en passant dans l'usage commun.]

[Alors, par une révolution singulière, ce même genre d'écriture, dont la conservation n'eût servi qu'à prolonger l'ignorance, deviendrait, entre les mains de la philosophie, un instrument utile à la prompte propagation des lumières, au perfectionnement de la méthode des sciences.]

C'est entre ce degré de civilisation, et celui où nous voyons encore les peuplades sauvages, que se sont trouvés tous les peuples dont l'histoire s'est conservée ; en embrassant d'un coup l'histoire universelle des peuples, on les voit tour à tour, tantôt faisant de nouveaux progrès, tantôt se replongeant dans l'ignorance, tantôt se perpétuant au milieu de ces alternatives, ou s'arrêtant à un certain terme, tantôt disparaissant de la terre sous le fer des conquérants, se confondant avec les vainqueurs, ou subsistant dans l'esclavage, tantôt enfin, recevant des lumières d'un peuple plus éclairé, pour les transmettre à d'autres nations, formant une chaîne non interrompue entre le commencement des temps historiques et le siècle où nous vivons, entre les premières nations qui nous soient connues, et les peuples actuels de l'Europe.

On peut donc apercevoir déjà trois parties bien distinctes dans le tableau que je me suis proposé de tracer.

Dans la première, où les récits des voyageurs nous montrent l'état de l'espèce humaine chez les peuples les moins civilisés, nous sommes réduits à deviner par quels degrés l'homme isolé, ou plutôt borné à l'association nécessaire pour se reproduire, a pu acquérir ces premiers perfectionnements dont le dernier terme est l'usage d'un langage articulé ; nuance la plus marquée, et même la seule qui, avec quelques idées morales plus étendues, et un faible commencement d'ordre social, le fait alors différer des animaux vivant comme lui en société régulière et durable. Ainsi nous ne pouvons avoir ici d'autre guide que des observations théoriques sur le développement de nos facultés intellectuelles et morales. 
Ensuite, pour conduire l'homme au point où il exerce des arts, où déjà la lumière des sciences commence à l'éclairer, où le commerce unit les nations, où enfin l'écriture alphabétique est inventée, nous pouvons joindre à ce premier guide l'histoire des diverses sociétés qui ont été observées dans presque tous les degrés intermédiaires ; quoiqu'on ne puisse en suivre aucune dans tout l'espace qui sépare ces deux grandes époques de l'espèce humaine.

Ici le tableau commence à s'appuyer en grande partie sur la suite des faits que l'histoire nous a transmis : mais il est nécessaire de les choisir dans celle de différents peuples, de les rapprocher, de les combiner, pour en tirer l'histoire hypothétique d'un peuple unique, et former le tableau de ses progrès.

Depuis l'époque où l'écriture alphabétique a été connue dans la Grèce, l'histoire se lie à notre siècle, à l'état actuel de l'espèce humaine dans les pays les plus éclairés de l'Europe, par une suite non interrompue de faits et d'observations ; et le tableau de la marche et des progrès de l'esprit humain est devenu véritablement historique. La philosophie n'a plus rien à deviner, n'a plus de combinaisons hypothétiques à former ; il suffit de rassembler, d'ordonner les faits, et de montrer les vérités utiles qui naissent de leur enchaînement et de leur ensemble.

Il ne resterait enfin qu'un dernier tableau à tracer, celui de nos espérances, des progrès qui sont réservés aux générations futures, et que la constance des lois de la nature semble leur assurer. Il faudrait y montrer par quels degrés ce qui nous paraîtrait aujourd'hui un espoir chimérique doit successivement devenir possible, et même facile ; pourquoi, malgré les succès passagers des préjugés, et l'appui qu'ils reçoivent de la corruption des gouvernements ou des peuples, la vérité seule doit obtenir un triomphe durable ; par quels liens la nature a indissolublement uni les progrès des lumières et ceux de la liberté, de la vertu, du respect pour les droits naturels de l'homme ; comment ces seuls biens réels, si souvent séparés qu'on les a crus même incompatibles, doivent au contraire devenir inséparables, dès l'instant où les lumières auront atteint un certain terme dans un plus grand nombre de nations à la fois, et qu'elles auront pénétré la masse entière d'un grand peuple, dont la langue serait universellement répandue, dont les rela- 
tions commerciales embrasseraient toute l'étendue du globe. Cette réunion s'étant déjà opérée dans la classe entière des hommes éclairés, on ne compterait plus dès lors parmi eux que des amis de l'humanité, occupés de concert à accélérer son perfectionnement et son bonheur.

Nous exposerons l'origine, nous tracerons l'histoire des erreurs générales, qui ont plus ou moins retarde ou suspendu la marche de la raison, qui souvent même, autant que les événements politiques, ont fait rétrograder l'homme vers l'ignorance.

Les opérations de l'entendement qui nous conduisent à l'erreur ou qui nous y retiennent, depuis le paralogisme subtil, qui peut surprendre l'homme le plus éclairé, jusqu'aux rêves de la démence, n'appartiennent pas moins que la méthode de raisonner juste ou celle de découvrir la vérité, à la théorie du développement de nos facultés individuelles : et, par la même raison, la manière dont les erreurs générales s'introduisent parmi les peuples, s'y propagent, s'y transmettent, s'y perpétuent, fait partie du tableau historique des progrès de l'esprit humain. Comme les vérités qui le perfectionnent et qui l'éclairent, elles, sont la suite nécessaire de son activité, de cette disproportion toujours existante entre ce qu'il connaît, ce qu'il a le désir et ce qu'il croit avoir le besoin de connaître.

On peut même observer que, d'après les lois générales du développement de nos facultés, certains préjugés ont dû naître à chaque époque de nos progrès, mais pour étendre bien au delà leur séduction ou leur empire ; parce que les hommes conservent encore les préjugés de leur enfance, ceux de leur pays et de leur siècle, longtemps après avoir reconnu toutes les vérités nécessaires pour les détruire.

Enfin, dans tous les pays, dans tous les temps, il est des préjugés différents, suivant le degré d'instruction des diverses classes d'hommes, comme suivant leurs professions. Ceux des philosophes nuisent aux nouveaux progrès de la vérité ; ceux des classes moins éclairées retardent la propagation des vérités déjà connues ; ceux de certaines professions accréditées ou puissantes y opposent des obstacles : ce sont trois genres d'ennemis que la raison est obligée de combattre sans cesse, et dont elle ne triomphe souvent qu'après une lutte longue et pénible. L'histoire de ces combats, celle de la naissance, du triomphe 
et de la chute des préjugés, occupera donc une grande place dans cet ouvrage, et n'en sera la partie ni la moins importante, ni la moins utile.

[S'il existe une science de prévoir les progrès de J'espèce humaine, de les diriger, de les accélérer, l'histoire des progrès qu'elle a déjà faits en doit être la base première.]

[La philosophie a dû prescrire sans doute cette superstition, qui croyait ne pouvoir trouver des règles de conduite que dans l'histoire des siècles passés, et des vérités que dans l'étude des opinions anciennes. Mais ne doit-elle pas proscrire également le préjugé qui rejetterait avec orgueil les leçons de l'expérience ? Sans doute, la méditation seule peut, par d'heureuses combinaisons, nous conduire aux vérités générales de la science de l'homme. Mais si l'observation des individus de l'espèce humaine est utile au métaphysicien, au moraliste, pourquoi celle des sociétés le serait-elle moins et à eux et au philosophe politique ? S'il est utile d'observer les diverses sociétés qui existent en même temps, d'en étudier les rapports, pourquoi ne le serait-il pas de les observer aussi dans la succession des temps ? En supposant même que ces observations puissent être négligées dans la recherche des vérités spéculatives, doivent-elles l'être, lorsqu'il s'agit d'appliquer ces vérités à la pratique, et de déduire de la science l'art qui en doit être le résultat utile ? Nos préjugés, les maux qui en sont la suite, n'ont-ils pas leur source dans les préjugés de nos ancêtres? Un des moyens les plus sûrs de nous détromper des uns, de prévenir les autres, n'est-il pas de nous en développer l'origine et les effets ?]

[Sommes-nous au point où nous n'ayons plus à craindre, ni de nouvelles erreurs, ni le retour des anciennes; où aucune institution corruptrice ne puisse plus être présentée par l'hypocrisie, adoptée par l'ignorance ou par l'enthousiasme ; où aucune combinaison vicieuse ne puisse plus faire le malheur d'une grande nation ? Serait-il donc inutile de savoir comment les peuples ont été trompés, corrompus, ou plongés dans la misère ?]

[Tout nous dit que nous touchons à l'époque d'une des grandes révolutions de l'espèce humaine. Qu'y a-t-il de plus propre à nous éclairer sur ce que nous devons en attendre, à nous offrir un guide sûr pour nous conduire au milieu de ses mouvements, que le tableau des révo- 
lutions qui l'ont précédée et préparée ? L'état actuel des lumières nous garantit qu'elle sera heureuse ; mais n'est-ce pas aussi à condition que nous saurons nous servir de toutes nos forces ? Et pour que le bonheur qu'elle promet soit moins chèrement acheté, pour qu'elle s'étende avec plus de rapidité dans un plus grand espace, pour qu'elle soit plus complète dans ses effets, n'avons-nous pas besoin d'étudier dans l'histoire de l'esprit humain quels obstacles nous restent à craindre, quels moyens nous avons de surmonter ces obstacles ?]

Je diviserai en neuf grandes époques l'espace que je me propose de parcourir ; [et j'oserai, dans une dixième, hasarder quelques aperçus sur les destinées futures de l'espèce humaine].

[Je me bornerai à présenter ici les principaux traits qui caractérisent chacune de ces époques; je ne donnerai que les masses, sans m'arrêter ni aux exceptions, ni aux détails.]

[J'indiquerai les objets et les résultats ; l'ouvrage même offrira les développements et les preuves.] 


\section{Les hommes sont réunis en peuplades.}

Aucune observation directe ne nous instruit sur ce qui a précédé cet état ; et c'est seulement en examinant les facultés intellectuelles ou morales, et la constitution physique de l'homme, qu'on peut conjecturer comment il s'est élevé à ce premier degré de civilisation.

Des observations sur les qualités physiques de l'homme qui peuvent favoriser la première formation de la société, et une analyse sommaire du développement de nos facultés intellectuelles et morales, doivent donc servir d'introduction au tableau de cette époque.

Une société de famille paraît naturelle à l'homme. Formée d'abord par le besoin que les enfants ont de leurs parents, par la tendresse des mères, par celle des pères, quoique moins générale et moins vive ; la longue durée de ce besoin des enfants a dû donner le temps de naître et de se développer à un sentiment propre à inspirer le désir de perpé- 
tuer cette réunion. Cette même durée a suffi pour en faire sentir les avantages. Une famille placée sur un sol qui offrait une subsistance facile, a pu ensuite se multiplier et devenir une peuplade.

Les peuplades qui auraient pour origine la réunion de plusieurs familles séparées, ont dû se former plus tard et plus rarement, puisque la réunion dépend alors et de motifs moins pressants et de la combinaison d'un plus grand nombre de circonstances.

L'art de fabriquer des armes, de donner une préparation aux aliments, de se procurer les ustensiles nécessaires pour cette préparation, celui de conserver ces mêmes aliments pendant quelque temps, d'en faire des provisions pour les saisons où il était impossible de s'en procurer de nouveaux ; ces arts, consacrés aux plus simples besoins, furent le premier fruit d'une réunion prolongée, et le premier caractère qui distingua la société humaine de celle que forment plusieurs espèces d'animaux.

Dans quelques-unes de ces peuplades, les femmes cultivent autour des cabanes quelques plantes qui servent à la nourriture, et qui suppléent au produit de la chasse ou de la pêche. Dans d'autres, formées aux lieux où la terre offre spontanément une nourriture végétale, le soin de la chercher et de la recueillir occupe une partie du temps des sauvages. Dans ces dernières, où l'utilité de rester unis se fait moins sentir, on a pu observer la civilisation réduite presque à une simple société de famille. Cependant, on a trouvé partout l'usage d'une langue articulée.

Des relations plus fréquentes, plus durables avec les mêmes individus ; l'identité de leurs intérêts ; les secours mutuels qu'ils se donnaient, soit dans des chasses communes, soit pour résister à un ennemi, ont dû produire également et le sentiment de la justice et une affection mutuelle entre les membres de la société. Bientôt cette affection s'est transformée en attachement pour la société elle-même.

Une haine violente, un inextinguible désir de vengeance contre les ennemis de la peuplade, en devenaient la conséquence nécessaire. 
Le besoin d'un chef, afin de pouvoir agir en commun, soit pour se défendre, soit pour se procurer avec moins de peine une subsistance plus assurée et plus abondante, introduisit dans ces sociétés les premières idées d'une autorité politique. Dans les circonstances où la peuplade entière était intéressée, où elle devait prendre une résolution commune, tous ceux qui devaient concourir à l'exécution devaient être consultés. La faiblesse des femmes, qui les excluait des chasses éloignées et de la guerre, objets ordinaires de ces délibérations, les en fit exclure également. Comme ces résolutions exigeaient de l'expérience, on n'y admettait que ceux à qui l'on pouvait en supposer. Les querelles qui s'élevaient dans le sein d'une même société en troublaient l'harmonie ; elles auraient pu la détruire ; il était naturel de convenir que la décision en serait remise à ceux qui, par leur âge, par leurs qualités personnelles, inspiraient le plus de confiance.

Telle fut l'origine des premières institutions politiques.

La formation d'une langue a dû précéder ces institutions. L'idée d'exprimer les objets par des signes conventionnels paraît au-dessus de ce qu'était l'intelligence humaine dans cet état de civilisation ; mais il est vraisemblable que ces signes n'ont été introduits dans l'usage qu'à force de temps, par degrés, et d'une manière en quelque sorte imperceptible.

L'invention de l'arc avait été l'ouvrage d'un homme de génie : la formation d'une langue fut celui de la société entière. Ces deux genres de progrès appartiennent également à l'espèce humaine. L'un, plus rapide, est le fruit des combinaisons nouvelles que les hommes favorisés de la nature ont le pouvoir de former ; il est le prix de leurs méditations et de leurs efforts : l'autre, plus lent, naît des réflexions, des observations qui s'offrent aux hommes réunis, et même des habitudes qu'ils contractent dans le cours de leur vie commune.

[Les mouvements mesurés et réguliers s'exécutent avec moins de fatigue. Ceux qui les voient ou les entendent en saisissent l'ordre ou les rapports avec plus de facilité. Ils sont donc, par cette double raison, une source de plaisir. Aussi l'origine de la danse, de la musique, de la poésie, remonte-t-elle à la première enfance de la société. La danse y est employée pour l'amusement de la jeunesse, et dans les fê- 
tes publiques. On y trouve des chansons d'amour et des chants de guerre : on y sait même fabriquer quelques instruments de musique. L'art de l'éloquence n'est pas absolument inconnu dans ces peuplades : du moins on y sait prendre dans les discours d'appareil un ton plus grave et plus solennel ; et même alors l'exagération oratoire ne leur est point étrangère.]

La vengeance et la cruauté envers les ennemis érigées en vertu ; l'opinion qui condamne les femmes à une sorte d'esclavage; le droit de commander à la guerre regardé comme la prérogative d'une famille ; enfin, les premières idées des diverses espèces de superstitions, telles sont les erreurs qui distinguent cette époque, et dont il faudra rechercher l'origine et développer les motifs. Car l'homme n'adopte pas sans motif l'erreur que sa première éducation ne lui a pas rendue en quelque sorte naturelle : s'il en reçoit une nouvelle, c'est qu'elle est liée à des erreurs de l'enfance ; c'est que ses intérêts, ses passions, ses opinions, ou les événements l'ont disposé à la recevoir.

Quelques connaissances grossières d'astronomie, celles de quelques plantes médicinales employées pour guérir les maladies ou les blessures, sont les seules sciences des sauvages ; et déjà elles sont corrompues par un mélange de superstition.

Mais cette même époque nous présente encore un fait important dans l'histoire de l'esprit humain.

On peut y observer les premières traces d'une institution qui a eu sur sa marche des influences opposées, accélérant le progrès des lumières, en même temps qu'elle répandait l'erreur; enrichissant les sciences de vérités nouvelles, mais précipitant le peuple dans l'ignorance et dans la servitude religieuse ; faisant acheter quelques bienfaits passagers par une longue et honteuse tyrannie.

J'entends ici la formation d'une classe d'hommes dépositaires des principes des sciences ou des procédés des arts, des mystères ou des cérémonies de la religion, des pratiques de la superstition, souvent même des secrets de la législation et de la politique. J'entends cette séparation de l'espèce humaine en deux portions : l'une destinée à enseigner, l'autre faite pour croire ; l'une cachant orgueilleusement ce 
qu'elle se vante de savoir, l'autre recevant avec respect ce qu'on daigne lui révéler ; l'une voulant s'élever au-dessus de la raison ; l'autre renonçant humblement à la sienne, et se rabaissant au-dessous de l'humanité, en reconnaissant dans d'autres hommes des prérogatives supérieures à leur commune nature.

Cette distinction, dont, à la fin du XVIIIe siècle, nos prêtres nous offrent encore les restes, se trouve chez les sauvages les moins civilisés ; ils ont déjà leurs charlatans et leurs sorciers. Elle est trop générale, on la rencontre trop constamment à toutes les époques de la civilisation, pour qu'elle n'ait pas un fondement dans la nature même: aussi trouverons-nous dans ce qu'étaient les facultés de l'homme à ces premiers temps des sociétés, la cause de la crédulité des premières dupes, comme celle de la grossière habileté des premiers imposteurs. 


\section{Deuxième époque}

\section{Les peuples pasteurs.}

\section{Passage de cet état à celui des peuples agriculteurs.}

L'idée de conserver les animaux pris à la chasse dut se présenter aisément, lorsque la douceur de ces animaux en rendait la garde facile, que le terrain autour des habitations leur fournissait une nourriture abondante, que la famille avait du superflu, et qu'elle pouvait craindre d'être réduite à la disette par le mauvais succès d'une autre chasse, ou par l'intempérie des saisons.

Après avoir gardé ces animaux comme une simple provision, l'on observa qu'ils pouvaient se multiplier, et offrir par là une ressource plus durable. Leur lait en présentait une nouvelle ; et ces produits d'un troupeau qui, d'abord, n'étaient qu'un supplément à celui de la chasse, devinrent un moyen de subsistance plus assuré, plus abondant, moins pénible. La chasse cessa donc d'être le premier, et ensuite, d'être même comptée au nombre de ces moyens ; elle ne fut plus conservée que comme un plaisir, comme une précaution nécessaire pour défendre contre les bêtes féroces les troupeaux qui, étant devenus plus nombreux, ne pouvaient plus trouver une nourriture suffisante autour des habitations. 
Une vie plus sédentaire, moins fatigante, offrait un loisir favorable au développement de l'esprit humain. Assurés de leur subsistance, n'étant plus inquiets pour leurs premiers besoins, les hommes cherchèrent des sensations nouvelles dans les moyens d'y pourvoir.

Les arts firent quelques progrès ; on acquit quelques lumières sur celui de nourrir les animaux domestiques, d'en favoriser la reproduction, et même d'en perfectionner les espèces.

On apprit à employer la laine pour les vêtements, à substituer l'usage des tissus à celui des peaux.

La société dans les familles devint plus douce, sans devenir moins intime. Comme les troupeaux de chacune de ces familles ne pouvaient se multiplier avec égalité, il s'établit une différence de richesse. Alors, on imagina de partager le produit de ses troupeaux avec un homme qui n'en avait pas, et qui devait consacrer son temps et ses forces aux soins qu'ils exigent. Alors, on vit que le travail d'un individu jeune, bien constitué, valait plus que ne coûtait sa subsistance rigoureusement nécessaire ; et l'on prit l'habitude de garder les prisonniers de guerre pour esclaves, au lieu de les égorger.

L'hospitalité, qui se pratique aussi chez les sauvages, prend chez les peuples pasteurs un caractère plus prononcé, plus solennel, même parmi ceux qui errent dans des chariots ou sous des tentes. Il s'offre de plus fréquentes occasions de l'exercer réciproquement d'individu à individu, de famille à famille, de peuple à peuple. Cet acte d'humanité devient un devoir social, et on l'assujettit à des règles.

Enfin, comme certaines familles avaient non seulement une subsistance assurée, mais un superflu constant, et que d'autres hommes manquaient du nécessaire, la compassion naturelle pour leurs souffrances fit naître le sentiment et l'habitude de la bienfaisance,

Les mœurs durent s'adoucir ; l'esclavage des femmes eut moins de dureté ; les femmes des riches cessèrent d'être condamnées àdes travaux pénibles. 
Plus de variété dans les choses employées à satisfaire les divers besoins, dans les instruments qui servaient à les préparer, plus d'inégalité dans leur distribution, durent multiplier les échanges, et produire un véritable commerce ; il ne put s'étendre sans faire sentir la nécessité d'une mesure commune, d'une espèce de monnaie.

Les peuplades devinrent plus nombreuses : leurs habitations, quand elles restèrent fixes, se séparèrent davantage, afin de nourrir plus facilement les troupeaux: ou bien, elles se changèrent en campements mobiles, quand les hommes eurent appris à se servir, pour porter ou traîner les fardeaux, de quelques-unes des espèces d'animaux qu'ils avaient subjuguées.

Chaque nation eut un chef pour la guerre ; mais s'étant divisée en plusieurs tribus, par la nécessité de s'assurer des pâturages, chaque tribu eut aussi son chef. Presque partout, cette supériorité fut attachée à certaines familles. Les chefs de famille qui avaient de nombreux troupeaux, beaucoup d'esclaves, qui employaient à leur service un grand nombre de citoyens plus pauvres, partagèrent l'autorité des chefs de leur tribu, comme ceux-ci partageaient celle des chefs de nation ; du moins, lorsque le respect dû à l'âge, à l'expérience, aux exploits, leur en donnait le crédit : et c'est à cette époque de la société qu'il faut placer l'origine de l'esclavage et de l'inégalité de droits politiques entre les hommes parvenus à l'âge de la maturité.

Ce furent les conseils formés *des chefs de famille ou des chefs de tribu qui, d'après la justice naturelle, ou d'après les usages reconnus, décidèrent les contestations, déjà plus nombreuses et plus compliquées. La tradition de ces jugements, en attestant les usages, en les perpétuant, forma bientôt une espèce de jurisprudence plus régulière, plus constante, que les progrès de la société avaient rendue nécessaire. L'idée de la propriété et de ses droits avait acquis plus d'étendue et de précision. Le partage des successions, devenu plus important, avait besoin d'être assujetti à des règles fixes. Les conventions plus fréquentes ne se bornaient plus à des objets aussi simples; elles durent être soumises à des formes ; la manière d'en constater l'existence, pour en assurer l'exécution, eut aussi ses lois. 
L'utilité de l'observation des étoiles, l'occupation qu'elles offraient pendant de longues veilles, le loisir dont jouissaient les bergers, durent amener quelques faibles progrès dans l'astronomie.

Mais en même temps on vit se perfectionner l'art de tromper les hommes pour les dépouiller, et d'usurper sur leurs opinions une autorité fondée sur des craintes et des espérances chimériques. Il s'établit des cultes plus réguliers, des systèmes de croyance moins grossièrement combinés. Les idées des puissances surnaturelles se raffinèrent en quelque sorte : et avec ces opinions, on vit s'établir ici des princes pontifes, là des familles ou des tribus sacerdotales, ailleurs des collèges de prêtres ; mais toujours une classe d'individus affectant d'insolentes prérogatives ; se séparant des hommes pour les mieux asservir ; cherchant à s'emparer exclusivement de la médecine, de l'astronomie, pour réunir tous les moyens de subjuguer les esprits, et ne leur en laisser aucun de démasquer son hypocrisie, de détruire sa tyrannie.

[Les langues s'enrichirent sans devenir moins figurées ou moins hardies. Les images qu'elles employaient furent plus variées et plus douces : on les prit dans la vie pastorale, comme dans celle des forêts, dans les phénomènes réguliers de la nature, comme dans ses bouleversements. Le chant, les instruments, la poésie se perfectionnèrent dans un loisir qui rendait les auditeurs plus paisibles, et dès lors plus difficiles, qui permettait d'observer ses propres sentiments, de juger ses premières idées, et de choisir entre elles.]

L'observation a dû faire remarquer que certaines plantes offraient aux troupeaux une subsistance meilleure ou plus abondante : on a senti l'utilité de favoriser leur reproduction, de les séparer des autres plantes qui ne donnaient qu'une nourriture faible, malsaine, même dangereuse ; et l'on est parvenu à en trouver les moyens.

De même, dans les pays où des plantes, des graines, des fruits spontanément offerts par le sol, contribuaient, avec les produits des troupeaux, à la nourriture de l'homme, on a dû observer aussi comment ces végétaux se multipliaient ; et, dès lors, chercher à les rassembler dans les terrains les plus voisins des habitations ; à les séparer des végétaux inutiles, pour que ce terrain leur appartînt tout entier ; à 
les mettre à l'abri des animaux sauvages, des troupeaux, et même de la rapacité des autres hommes.

Ces idées ont dû naître encore, et même plus tôt, dans les pays plus féconds, où ces productions spontanées de la terre suffisaient presque à la subsistance des hommes. Ils commencèrent donc à se livrer à l'agriculture.

Dans un pays fertile, dans un climat heureux, le même. espace de terrain produit en grains, en fruits, en racines, de quoi nourrir beaucoup plus d'hommes que s'il était employé en pâturages. Ainsi, lorsque la nature du sol ne rendait pas cette culture trop pénible ; lorsqu'on eut découvert le moyen d'y employer les mêmes animaux qui servaient aux peuples pasteurs pour les voyages ou pour les transports ; lorsque les instruments aratoires eurent acquis quelque perfection ; l'agriculture, au milieu de ces progrès, devint la source d'une subsistance plus abondante, l'occupation première des peuples; et le genre humain atteignit sa troisième époque.

Quelques peuples sont restés, depuis un temps immémorial, dans un des deux états que nous venons de parcourir. Non seulement, ils ne se sont pas élevés d'eux-mêmes à de nouveaux progrès, mais les relations qu'ils ont eues avec les peuples parvenus à un très haut degré de civilisation, le commerce qu'ils ont ouvert avec eux, n'y ont pu produire cette révolution. Ces relations, ce commerce leur ont donné quelques connaissances, quelque industrie, et surtout beaucoup de vices, mais n'ont pu les tirer de cette espèce d'immobilité.

Le climat, les habitudes, les douceurs attachées à cette indépendance presque entière, qui ne peut se retrouver que dans une société plus perfectionnée même que les nôtres; l'attachement naturel des hommes aux opinions reçues dès l'enfance, et aux usages de leur pays ; l'aversion naturelle de l'ignorance pour toute espèce de nouveauté ; la paresse de corps, et surtout celle d'esprit, qui l'emportaient sur la curiosité si faible encore ; l'empire que la superstition exerçait déjà sur ces premières sociétés ; telles ont été les principales causes de ce phénomène ; mais il faut y joindre l'avidité, la cruauté, la corruption, les préjugés des peuples policés. Les peuples policés se montraient à ces nations, plus puissants, plus riches, plus instruits, plus 
actifs, mais plus vicieux, et surtout moins heureux qu'elles. Elles ont dû souvent être moins frappées de la supériorité de ces peuples, qu'effrayées de la multiplicité et de l'étendue de leurs besoins, des tourments de leur avarice, des éternelles agitations de leurs passions toujours actives, toujours insatiables. Quelques philosophes ont plaint ces nations ; d'autres les ont louées : ils ont appelé sagesse et vertu, ce que les premiers appelaient stupidité et paresse.

La question élevée entre eux se trouvera résolue dans le cours de cet ouvrage. On y verra pourquoi les progrès de l'esprit n'ont pas toujours été suivis du progrès des sociétés vers le bonheur et la vertu ; comment le mélange des préjugés et des erreurs a pu altérer le bien qui doit naître des lumières, mais qui dépend plus encore de leur pureté que de leur étendue. [Alors, on verra que ce passage orageux et pénible d'une société grossière à l'état de civilisation des peuples éclairés et libres, n'est point une dégénération de l'espèce humaine, mais une crise nécessaire dans sa marche graduelle vers son perfectionnement absolu. On verra que ce n'est pas l'accroissement des lumières, mais leur décadence, qui a produit les vices des peuples policés ; et qu'enfin, loin de jamais corrompre les hommes, les lumières les ont adoucis, lorsqu'elles n'ont pu les corriger ou les changer.] 


\section{Troisième époque}

\section{Progrès des peuples agriculteurs, jusqu'à l'invention de l'écriture alphabétique.}

L'uniformité du tableau que nous avons tracé jusqu'ici va bientôt disparaître. Ce ne sont plus de faibles nuances qui sépareront les mœurs, les caractères, les opinions, les superstitions des peuples attachés à leur sol, et perpétuant presque sans mélange une première famille.

Les invasions, les conquêtes, la formation des empires, leurs bouleversements, vont bientôt mêler et confondre les nations, tantôt les disperser sur un nouveau territoire, tantôt couvrir à la fois un même sol de peuples différents.

Le hasard des événements viendra troubler sans cesse la marche lente, mais régulière de la nature, la retarder souvent, l'accélérer quelquefois.

Le phénomène qu'on observe chez une nation, dans un tel siècle, a souvent pour cause une révolution opérée à mille lieues et à dix siècles de distance; et la nuit du temps a couvert une grande partie, de 
ces événements, dont nous voyons les influences s'exercer sur les hommes qui nous ont précédés, et quelquefois s'étendre sur nousmêmes.

Mais il faut considérer d'abord les effets de ce changement dans une seule nation, et indépendamment de l'influence que les conquêtes et le mélange des peuples ont pu exercer.

L'agriculture attache l'homme au sol qu'il cultive. Ce n'est plus sa personne, sa famille, ses instruments de chasse, qu'il lui suffirait de transporter ; ce ne sont plus même ses troupeaux qu'il aurait pu chasser devant lui. Des terrains qui n'appartiennent à personne ne lui offriraient plus de subsistances dans sa fuite, ou pour lui-même, ou pour les animaux qui lui fournissent sa nourriture.

Chaque terrain a un maître à qui seul les fruits en appartiennent. La récolte s'élevant au-dessus des dépenses nécessaires pour l'obtenir, de la subsistance et de l'entretien des hommes et des animaux qui l'ont préparée, offre à ce propriétaire une richesse annuelle, qu'il n'est obligé d'acheter par aucun travail.

Dans les deux premiers états de la société, tous les individus, toutes les familles du moins, exerçaient à peu près tous les arts nécessaires.

Mais, lorsqu'il y eut des hommes qui, sans travail, vécurent du produit de leur terre, et d'autres hommes qui vécurent des salaires que leur payaient les premiers; quand les travaux se furent multipliés ; quand les procédés des arts furent devenus plus étendus et plus compliqués, l'intérêt commun força bientôt à les diviser. On s'aperçut que l'industrie d'un individu se perfectionnait davantage, lorsqu'elle s'exerçait sur moins d'objets ; que la main exécutait avec plus de promptitude et de précision un plus petit nombre de mouvements, quand une longue habitude les lui avait rendus plus familiers ; qu'il fallait moins d'intelligence pour bien faire un ouvrage, quand on l'avait plus souvent fait et refait.

Ainsi, tandis qu'une partie des hommes se livrait aux travaux de la culture, d'autres en préparaient les instruments. La garde des bestiaux, 
l'économie intérieure, la fabrication des étoffes, devinrent également des occupations séparées. Comme, dans les familles qui n'avaient qu'une propriété peu étendue, un seul de ces emplois ne suffisait pas pour occuper tout le temps d'un individu, plusieurs d'entre elles se partagèrent le travail et le salaire d'un seul homme. Bientôt les substances employées dans les arts se multipliant, et leur nature exigeant des procédés différents, celles qui en demandaient d'analogues formèrent des genres séparés, à chacun desquels s'attacha une classe particulière d'ouvriers. Le commerce s'étendit, embrassa un plus grand nombre d'objets, et les tira d'un plus grand territoire ; et alors se forma une autre classe d'hommes uniquement occupée à acheter des denrées, à les conserver, à les transporter, à les revendre avec profit.

Ainsi aux trois classes qu'on pouvait distinguer déjà dans la vie pastorale, celle des propriétaires, celle des domestiques attachés à la famille des premiers, et celle des esclaves, il faut maintenant ajouter celle des ouvriers de toute espèce et celle des marchands.

C'est alors que, dans une société plus fixe, plus rapprochée et plus compliquée, on a senti la nécessité d'une législation plus régulière et plus étendue ; qu'il a fallu déterminer avec une précision plus rigoureuse, soit des peines pour les crimes, soit des formes pour les conventions ; soumettre à des règles plus sévères les moyens de vérifier les faits auxquels on devait appliquer la loi.

[Ces progrès furent l'ouvrage lent et graduel du besoin et des circonstances : ce sont quelques pas de plus dans la route que déjà l'on avait suivie chez les peuples pasteurs.]

[Dans les premières époques, l'éducation fut purement domestique. Les enfants s'instruisaient auprès de leur père, soit dans les travaux communs, soit dans les arts qu'il savait exercer ; ils recevaient de lui et le petit nombre de traditions qui formaient l'histoire de la peuplade et celle de la famille, et les fables qui s'y étaient perpétuées, et la connaissance des usages nationaux, des principes ou des préjugés qui devaient composer leur morale grossière. On se formait dans la société de ses amis au chant, à la danse, aux exercices militaires.] 
[À l'époque où nous sommes parvenus, les enfants des familles plus riches reçurent une sorte d'éducation commune, soit dans les villes par la conversation des vieillards, soit dans la maison d'un chef auquel ils s'attachaient. C'est là qu'ils s'instruisaient des lois du pays, de ses usages, de ses préjugés, et qu'ils apprenaient à chanter les poèmes dans lesquels on en avait renfermé l'histoire.]

[L'habitude d'une vie plus sédentaire avait établi entre les deux sexes une plus grande égalité. Les femmes ne furent plus considérées comme un simple objet d'utilité, comme des esclaves seulement plus rapprochées du maître. L'homme y vit des compagnes, et apprit enfin ce qu'elles pouvaient pour son bonheur. Cependant, même dans les pays où elles furent le plus respectées, où la polygamie fut proscrite, ni la raison, ni la justice n'allèrent jusqu'à une entière réciprocité dans les devoirs ou dans le droit de se séparer, jusqu'à l'égalité dans les peines portées contre l'infidélité.]

[L'histoire de cette classe de préjugés et de leur influence sur le sort de l'espèce humaine, doit entrer dans le tableau que je me suis proposé de tracer; et rien ne servira mieux à montrer jusqu'à quel point son bonheur est attaché aux progrès de la raison.]

Quelques nations restèrent dispersées dans les campagnes. D'autres se réunirent dans des villes, qui devinrent la résidence du chef de la nation, des chefs de tribu qui partagèrent son pouvoir, et des anciens de chaque famille. C'est là qu'on rassemblait ses richesses les plus précieuses, pour les soustraire aux brigands qui durent se multiplier en même temps que ces richesses sédentaires. Lorsque les nations restèrent dispersées sur leur territoire, l'usage détermina un lieu et une époque pour les réunions des chefs, pour les délibérations sur les intérêts communs, pour les tribunaux qui prononçaient les jugements.

Les nations qui se reconnaissaient une origine commune, qui parlaient la même langue, sans renoncer à se faire la guerre entre elles, formèrent presque toujours une fédération plus ou moins intime ; elles convinrent de se réunir, soit contre des ennemis étrangers, soit pour venger mutuellement leurs injures, soit pour remplir en commun quelque devoir religieux. 
L'hospitalité et le commerce produisirent même quelques relations constantes entre des nations différentes par leur origine, leurs coutumes et leur langage : relations que le brigandage et la guerre interrompaient souvent, mais que renouait ensuite la nécessité, plus forte que l'amour du pillage et la soif de la vengeance.

Égorger les vaincus, les dépouiller et les réduire à l'esclavage, ne formèrent plus le seul droit reconnu entre les nations ennemies. Des cessions de territoire, des rançons, des tributs, prirent en partie la place de ces violences barbares.

À cette époque, tout homme qui possédait des armes était soldat ; celui qui en avait de meilleures, qui avait pu s'exercer davantage à les manier, qui pouvait en fournir à d'autres, qui, par les provisions qu'il avait rassemblées, se trouvait en état de subvenir à leurs besoins, devenait nécessairement un chef : mais cette obéissance presque volontaire n'entraînait pas une dépendance servile.

Comme rarement on avait besoin de faire des lois nouvelles; comme il n'était pas de dépenses publiques auxquelles les citoyens fussent forcés de contribuer, et que, si elles devenaient nécessaires, le bien des chefs ou les terres conservées en commun devaient les acquitter ; comme l'idée de gêner par des règlements l'industrie et le commerce n'avait pu naître encore ; comme la guerre offensive était décidée par le consentement général, ou faite uniquement par ceux que l'amour de la gloire et le goût du pillage y entraînaient volontairement ; l'homme se croyait libre dans ces gouvernements grossiers, malgré l'hérédité presque générale des premiers chefs ; malgré la prérogative, usurpée par d'autres chefs inférieurs, de partager seuls l'autorité politique, et d'exercer les fonctions du gouvernement, comme celles de la magistrature.

Mais souvent un chef se livrait à des vengeances personnelles, à des actes arbitraires de violence ; souvent, dans ces familles privilégiées, l'orgueil, la haine héréditaire, les fureurs de l'amour et la soif de l'or, multipliaient les crimes, tandis que les chefs réunis dans les villes, instruments des passions des rois, y excitaient les factions et les guerres civiles, opprimaient le peuple par des jugements iniques, le tourmentaient par les crimes de leur ambition et par leurs brigandages. 
Chez un grand nombre de nations, les excès de ces familles lassèrent la patience des peuples : elles furent anéanties, chassées, ou soumises à la loi commune; rarement elles conservèrent leur titre avec une autorité limitée par la loi commune ; et l'on vit s'établir ce qu'on a depuis appelé des républiques.

Ailleurs, ces rois entourés de satellites, parce qu'ils avaient des armes et des trésors à leur distribuer, exercèrent une autorité absolue : telle fut l'origine de la tyrannie.

Dans d'autres contrées, surtout dans celles où les petites nations ne se réunirent point dans des villes, les premières formes de ces constitutions grossières furent conservées, jusqu'au moment où l'on vit ces peuples, ou tomber sous le joug d'un conquérant, ou, entraînés euxmêmes par l'esprit de brigandage, se répandre sur un territoire étranger.

Cette tyrannie, resserrée nécessairement dans un petit espace, ne pouvait avoir qu'une courte durée. Les peuples secouèrent bientôt ce joug imposé par la force seule, et que l'opinion même n'eût pu maintenir. Le monstre était vu de trop près, pour ne pas inspirer plus d'horreur que d'effroi : et la force comme l'opinion ne peuvent forger des chaînes durables, si les tyrans n'étendent pas leur empire à une distance assez grande pour pouvoir cacher à la nation qu'ils oppriment, en la divisant, le secret de sa puissance et de leur faiblesse.

L'histoire des républiques appartient à l'époque suivante; mais celle qui nous occupe va nous présenter un spectacle nouveau.

Un peuple agriculteur, soumis à une nation étrangère, n'abandonne point ses foyers : la nécessité le contraint à travailler pour ses maîtres.

Tantôt la nation dominatrice se contente de laisser, sur le territoire conquis, des chefs pour le gouverner, des soldats pour le défendre, et surtout pour en contenir les habitants, et d'exiger du peuple soumis et désarmé un tribut en monnaie ou en denrées. Tantôt elle s'empare du territoire même, en distribue la propriété à ses soldats, à ses capitaines ; mais alors elle attache à chaque terre l'ancien colon qui la culti- 
vait, et le soumet à ce nouveau genre de servitude, réglé par des lois plus ou moins rigoureuses. Un service militaire, un tribut, sont, pour les individus du peuple conquérant, la condition attachée à la jouissance de ces terres.

D'autres fois, elle se réserve la propriété même du territoire, et n'en distribue que l'usufruit, en imposant les mêmes conditions. Presque toujours les circonstances font employer à la fois ces trois manières de récompenser les instruments de la conquête, et de dépouiller les vaincus.

De là nous voyons naître de nouvelles classes d'hommes : les descendants du peuple dominateur, et ceux du peuple opprimé ; une noblesse héréditaire, qu'il ne faut pas confondre avec le patriciat des républiques ; un peuple condamné aux travaux, à la dépendance, à l'humiliation, sans l'être à l'esclavage ; enfin, des esclaves de la glèbe, distingués des esclaves domestiques, et dont la servitude moins arbitraire peut opposer la loi aux caprices de leurs maîtres.

C'est encore ici que l'on peut observer l'origine de la féodalité, qui n'a pas été un fléau particulier à nos climats, mais qu'on a retrouvé presque sur tout le globe aux mêmes époques de la civilisation, et toutes les fois qu'un même territoire a été occupé par deux peuples, entre lesquels la victoire avait établi une inégalité héréditaire.

Le despotisme, enfin, fut encore le fruit de la conquête. J'entends ici par despotisme, pour le distinguer des tyrannies passagères, l'oppression d'un peuple sous un seul homme, qui le domine par l'opinion, par l'habitude, surtout par une force militaire plus soumise encore à son autorité -arbitraire, mais respectée dans ses préjugés, flattée dans ses caprices, caressée dans son avidité et dans son orgueil.

Immédiatement entouré d'une portion nombreuse et choisie de cette force armée formée de la nation conquérante, environné des chefs les plus puissants de la milice, retenant les provinces par des généraux dont les ordres s'étendent sur plusieurs portions de cette même armée, le despotisme règne par la terreur, et personne dans ce peuple -abattu, ou parmi ces chefs dispersés, et rivaux l'un de l'autre, 
ne conçoit la possibilité de lui opposer des forces, que celles dont il dispose ne puissent écraser à l'instant.

Un soulèvement de la garde, une sédition de la capitale peuvent être funestes au despote, mais sans affaiblir le despotisme. Le général d'une armée victorieuse peut, en détruisant une famille consacrée par le préjugé, fonder une dynastie nouvelle ; mais c'est pour exercer la même tyrannie.

Dans cette troisième époque, les peuples qui n'ont encore éprouvé le malheur ni d'être conquérants, ni d'être conquis, nous offrent ces vertus simples et fortes des nations agricoles, ces mœurs des temps héroïques, dont un mélange de grandeur et de férocité, de générosité et de barbarie, rend le tableau si attachant, et nous séduit encore au point de les admirer, même de les regretter.

Le tableau des mœurs qu'on observe dans les empires fondés par les conquérants, nous présente au contraire toutes les nuances de l'avilissement et de la corruption, où le despotisme et la superstition peuvent amener l'espèce humaine. C'est là que l'on voit naître les tributs sur l'industrie et le commerce, les exactions qui font acheter le droit d'employer ses facultés à son gré, les lois qui gênent l'homme dans le choix de son travail et dans l'usage de sa propriété, celles qui attachent les enfants à la profession de leurs pères, les confiscations, les supplices atroces ; en un mot, tout ce que le mépris pour l'espèce humaine a pu inventer d'actes arbitraires, de tyrannies légales et d'atrocités superstitieuses.

[On peut remarquer que dans les peuplades qui n'ont point éprouvé de grandes révolutions, les progrès de la civilisation se sont arrêtés à un terme très peu avancé. Les hommes y connaissaient cependant déjà ce besoin d'idées ou de sensations nouvelles, premier mobile des progrès de l'esprit humain ; ce goût des superfluités du luxe, aiguillon de l'industrie ; cette curiosité perçant d'un oeil avide le voile dont la nature a caché ses secrets. Mais il est arrivé presque partout que, pour échapper à ces besoins, les hommes ont cherché, ont adopté avec une sorte de fureur des-moyens physiques de se procurer des sensations qui pussent se renouveler sans cesse : telle est l'habitude des liqueurs fermentées, des boissons chaudes, de l'opium, du tabac, du bétel. Il est 
peu de peuples chez qui l'on n'observe une de ces habitudes, d'où naît un plaisir qui remplit les journées entières, ou se répète à toutes les heures ; qui empêche de sentir le poids du temps, satisfait au besoin d'être occupé ou réveillé, -finit par l'émousser, et prolonge pour l'esprit humain la durée de son enfance et de son inactivité ; et ces mêmes habitudes, qui ont été un obstacle aux progrès des nations ignorantes ou asservies, s'opposent encore, dans les pays éclairés, à ce que la vérité répande dans toutes les classes une lumière égale et pure.]

En exposant ce que furent les arts dans les deux premières époques de la société, on fera voir comment aux arts qui travaillent le bois, la pierre, ou les os d'animaux, qui préparent les peaux, et qui forment des tissus, ces peuples primitifs purent joindre les arts plus difficiles de la teinture, de la poterie, et même les commencements des travaux sur les métaux.

Les progrès de ces arts auraient été lents dans les nations isolées ; mais les communications, même faibles, qui s'établirent entre elles, en accélérèrent la marche. Un procédé nouveau, découvert chez un peuple, devint commun à ses voisins. Les conquêtes, qui tant de fois ont détruit les arts, commencèrent par les répandre, et servirent à leur perfectionnement, avant de l'arrêter ou de contribuer à leur chute.

[On voit plusieurs de ces arts portés au plus haut degré de perfection chez des peuples où la longue influence de la superstition et du despotisme a consommé la dégradation de toutes les facultés humaines. Mais si l'on observe les prodiges de cette industrie servile, on n'y verra rien qui annonce la présence du génie ; tous les perfectionnements y paraissent l'ouvrage lent et pénible d'une longue routine ; partout, à côté de cette industrie qui nous étonne, on aperçoit des traces d'ignorance et de stupidité qui nous en décèlent l'origine.] Dans des sociétés sédentaires et paisibles, l'astronomie, la médecine, les notions les plus simples de l'anatomie, la connaissance des minéraux et des plantes, les premiers éléments de l'étude des phénomènes de la nature, se perfectionnèrent, ou plutôt s'étendirent par le seul effet du temps, qui, multipliant les observations, conduisait d'une manière lente, mais sûre, à saisir facilement, et presque au premier coup d'œil, quelquesunes des conséquences générales auxquelles ces observations devaient conduire. 
Cependant ces progrès furent très faibles ; et les sciences seraient restées plus longtemps dans leur première enfance, si certaines familles, si surtout des castes particulières n'en avaient fait le premier fondement de leur gloire ou de leur puissance.

On avait déjà pu joindre l'observation de l'homme et des sociétés à celle de la nature. Déjà un petit nombre de maximes de morale pratique et de politique se transmettaient de générations en générations ; ces castes s'en emparèrent ; les idées religieuses, les préjugés, les superstitions accrurent encore leur domaine. Elles succédèrent aux premières associations, aux premières familles des charlatans et des sorciers ; mais elles employèrent plus d'art pour séduire des esprits moins grossiers. Leurs connaissances réelles, l'austérité apparente de leur vie, un mépris hypocrite pour ce qui est l'objet des désirs des hommes vulgaires, donnèrent de l'autorité à leurs prestiges, tandis que ces mêmes prestiges consacraient, aux yeux du peuple, et ces faibles connaissances et ces hypocrites vertus. Les membres de ces sociétés suivirent d'abord avec une ardeur presque égale deux objets bien différents : l'un, d'acquérir pour eux-mêmes de nouvelles connaissances ; l'autre, d'employer celles qu'ils avaient à tromper le peuple, à dominer les esprits.

Leurs sages s'occupèrent surtout de l'astronomie ; et, autant qu'on en peut juger par les restes épars des monuments de leurs travaux, il paraît qu'ils atteignirent le point le plus haut où l'on puisse s'élever, sans le secours des lunettes, sans l'appui des théories mathématiques supérieures aux premiers éléments.

En effet, à l'aide d'une longue suite d'observations, on peut parvenir à une connaissance des mouvements des astres assez précise, pour mettre en état de calculer et de prédire les phénomènes célestes. Ces lois empiriques, d'autant plus faciles à trouver, que les observations s'étendent sur un plus long espace de temps, n'ont point conduit ces premiers astronomes jusqu'à la découverte des lois générales du système du monde ; mais elles y suppléaient suffisamment pour tout ce qui pouvait intéresser les besoins de l'homme, ou sa curiosité, et servir à augmenter le crédit de ces usurpateurs du droit exclusif de l'instruire. 
Il paraît qu'on leur doit l'idée ingénieuse des échelles arithmétiques, de ce moyen heureux de représenter tous les nombres avec un petit nombre de signes, et d'exécuter par des opérations techniques très simples, des calculs auxquels notre intelligence, livrée à ellemême, ne pourrait atteindre. C'est là le premier exemple de ces méthodes qui doublent les forces de l'esprit humain, et à l'aide desquelles il peut reculer indéfiniment ses limites, sans qu'on puisse fixer un terme où il lui soit interdit d'atteindre.

Mais on ne voit pas qu'ils aient étendu la science de l'arithmétique au delà de ses premières opérations.

Leur géométrie, renfermant ce qui était nécessaire à l'arpentage, à la pratique de l'astronomie, s'est arrêtée à cette proposition célèbre que Pythagore transporta en Grèce, ou qu'il découvrit de nouveau.

Ils abandonnèrent la mécanique des machines à ceux qui devaient les employer. Cependant quelques récits mêlés de fables semblent annoncer que cette partie des sciences a été cultivée par eux-mêmes, comme un des moyens de frapper les esprits par des prodiges.

Les lois du mouvement, la mécanique rationnelle, ne fixèrent point leurs regards.

S'ils étudièrent la médecine et la chirurgie, surtout celle qui a pour objet le traitement des blessures, ils négligèrent l'anatomie.

Leurs connaissances en botanique, en histoire naturelle, se bornèrent aux substances employées comme remèdes, à quelques plantes, à quelques minéraux, dont les propriétés singulières pouvaient servir leurs projets.

Leur chimie, réduite à de simples procédés sans théorie, sans méthode, sans analyse, n'était que l'art de faire certaines préparations, la connaissance de quelques secrets, soit pour la médecine, soit pour les arts, ou de quelques prestiges propres à éblouir les yeux d'une multitude ignorante, soumise à des chefs non moins ignorants qu'elle. 
Les progrès des sciences n'étaient pour eux qu'un but secondaire, qu'un moyen de perpétuer ou d'étendre leur pouvoir. Ils ne cherchaient la vérité que pour répandre des erreurs; et il ne faut pas s'étonner qu'ils l'aient si rarement trouvée.

Cependant, ces progrès, quelque lents, quelque faibles qu'ils soient, auraient été impossibles, si ces mêmes hommes n'avaient connu l'art de l'écriture, seul moyen d'assurer les traditions, de les fixer, de communiquer et de transmettre les connaissances, dès qu'elles commencent à se multiplier.

Ainsi l'écriture hiéroglyphique, ou fut une de leurs premières inventions, ou avait été inventée avant la formation des castes enseignantes.

Comme leur but n'était pas d'éclairer, mais de dominer, non seulement ils ne communiquaient pas au peuple toutes leurs connaissances, mais ils corrompaient par des erreurs celles qu'ils voulaient bien lui révéler ; ils lui enseignaient, non ce qu'ils croyaient vrai, mais ce qui leur était utile.

Ils ne lui montraient rien, sans y mêler je ne sais quoi de surnaturel, de sacré, de céleste, qui tendît à les faire regarder comme supérieurs à l'humanité, comme revêtus d'un caractère divin, comme ayant reçu du ciel même des connaissances interdites au reste des hommes.

Ils eurent donc deux doctrines, l'une pour eux seuls, l'autre pour le peuple : souvent même, comme ils se partageaient en plusieurs ordres, chacun d'eux se réserva quelques mystères. Tous les ordres inférieurs étaient à la fois fripons et dupes ; et le système d'hypocrisie ne se développait en entier qu'aux yeux de quelques adeptes.

Rien ne favorisa plus l'établissement de cette double doctrine, que les -changements dans les langues, qui furent l'ouvrage du temps, de la communication et du mélange des peuples. Les hommes à double doctrine, en conservant pour eux l'ancienne langue, ou celle d'un autre peuple, s'assurèrent aussi l'avantage de posséder un langage entendu par eux seuls. 
La première écriture qui désignait les choses par une peinture plus ou moins exacte, soit de la chose même, soit d'un objet analogue, faisant place à une écriture plus simple, où la ressemblance de ces objets était presque effacée, où l'on n'employait que des signes déjà en quelque sorte de pure convention, la doctrine secrète eut son écriture comme elle avait déjà son langage.

Dans l'origine des langues, presque chaque mot est une métaphore, et chaque phrase une allégorie. L'esprit saisit à la fois le sens figuré et le sens propre ; le mot offre, en même temps que l'idée, l'image analogue, par laquelle on l'avait exprimée. Mais par l'habitude d'employer un mot dans un sens figuré, l'esprit finit par s'y arrêter uniquement, par faire abstraction du premier sens ; et ce sens, d'abord figuré, devient peu à peu le sens ordinaire et propre du même mot.

Les prêtres, qui conservèrent le premier langage allégorique, l'employèrent avec le peuple qui ne pouvait plus en saisir le véritable sens, et qui, accoutumé à prendre les mots dans une seule acception, devenue leur acception propre, entendait je ne sais quelles fables absurdes, lorsque les mêmes expressions ne présentaient à l'esprit des prêtres qu'une vérité très simple. Ils firent le même usage de leur écriture sacrée. Le peuple voyait des hommes, des animaux, des monstres, où les prêtres avaient voulu représenter un phénomène astronomique, un des faits de l'histoire de l'année.

Ainsi, par exemple, les prêtres, dans leurs méditations, s'étaient presque partout créé le système métaphysique d'un grand tout, immense, éternel, dont tous les êtres n'étaient que les parties, dont tous les changements observés dans l'univers n'étaient que les modifications diverses. Le ciel ne leur offrait que des groupes d'étoiles semés dans ces déserts immenses, que des planètes qui y décrivaient des mouvements plus ou moins compliqués, et des phénomènes purement physiques, résultant des positions de ces astres divers. Ils imposaient des noms à ces groupes d'étoiles et à ces planètes, aux cercles mobiles ou fixes imaginés pour en représenter les positions et la marche apparente, pour en expliquer les phénomènes.

Mais leur langage, leurs monuments, en exprimant pour eux ces opinions métaphysiques, ces vérités naturelles, offraient aux yeux du 
peuple le système de la plus extravagante mythologie, devenaient pour lui le fondement des croyances les plus absurdes, des cultes les plus insensés, des pratiques les plus honteuses ou les plus barbares.

Telle est l'origine de presque toutes les religions connues, qu'ensuite l'hypocrisie ou l'extravagance de leurs inventeurs et de leurs prosélytes ont chargées de fables nouvelles.

[Ces castes s'emparèrent de l'éducation, pour façonner l'homme à supporter plus patiemment des chaînes identifiées pour ainsi dire avec son existence, pour écarter de lui jusqu'à la possibilité du désir de les briser. Mais, si l'on veut connaître jusqu'à quel point, même sans le secours des terreurs superstitieuses, ces institutions peuvent porter leur pouvoir destructeur des facultés humaines, c'est sur la Chine qu'il faut un moment arrêter ses regards ; sur ce peuple, qui semble n'avoir précédé les autres dans les sciences et les arts, que pour se voir successivement effacé par eux tous ; ce peuple, que la connaissance de l'artillerie n'a point empêché d'être conquis par des nations barbares ; où les sciences, dont les nombreuses écoles sont ouvertes à tous les citoyens, conduisent seules à toutes les dignités, et où cependant, soumises à d'absurdes préjugés, les sciences sont condamnées à une éternelle médiocrité ; où enfin l'invention même de l'imprimerie est demeurée entièrement inutile aux progrès de l'esprit humain.]

Des hommes dont l'intérêt était de tromper durent se dégoûter bientôt de la recherche de la vérité. Contents de la docilité des peuples, ils crurent n'avoir pas besoin de nouveaux moyens pour s'en garantir la durée. Peu à peu ils oublièrent eux-mêmes une partie des vérités cachées sous leurs allégories ; ils ne gardèrent, de leur ancienne science, que ce qui était rigoureusement nécessaire pour conserver la confiance de leurs disciples; et ils finirent par être eux-mêmes la dupe. de leurs propres fables.

Dès lors, tout progrès dans les sciences s'arrêta ; une partie même de ceux dont les siècles antérieurs avaient été témoins se perdit pour les générations suivantes ; et l'esprit humain, livré à l'ignorance et aux préjugés, fut condamné à une honteuse immobilité dans ces vastes empires, dont l'existence non interrompue a déshonoré depuis si longtemps l'Asie. 
Les peuples qui les habitent sont les seuls où l'on ait pu observer à la fois ce degré de civilisation et cette décadence. Ceux qui occupaient le reste du globe, ou ont été arrêtés dans leurs progrès, et nous retracent encore les temps de l'enfance du genre humain, ou ont été entraînés par les événements, à travers les dernières époques, dont il nous reste à tracer l'histoire.

À l'époque où nous sommes parvenus, ces mêmes peuples de l'Asie avaient inventé l'écriture alphabétique, qu'ils avaient substituée aux hiéroglyphes, après avoir vraisemblablement employé celle où des signes conventionnels sont attachés à chaque idée, seule écriture que les Chinois connaissent encore aujourd'hui.

L'histoire et le raisonnement peuvent nous éclairer sur la manière dont a dû s'opérer le passage graduel des hiéroglyphes à cet art, en quelque sorte, intermédiaire : mais rien ne peut nous instruire avec quelque précision, ni sur le pays, ni sur le temps, où l'écriture alphabétique fut d'abord mise en usage.

Cette découverte fut ensuite portée chez les Grecs ; chez ce peuple qui a exercé sur les progrès de l'espèce humaine une influence si puissante et si heureuse, à qui le génie a ouvert toutes les routes de la vérité ; que la nature avait préparé, que le sort avait destiné pour être le bienfaiteur et le guide de toutes les nations, de tous les âges : honneur que jusqu'ici aucun autre peuple n'a partagé. Un seul a pu depuis concevoir l'espérance de présider à une révolution nouvelle dans les destinées du genre humain. La nature, la combinaison des événements, semblent s'être accordées pour lui en réserver la gloire. Mais ne cherchons point à pénétrer ce qu'un avenir incertain nous cache encore. 


\section{Quatrième époque}

\section{Progrès de l'esprit humain dans la Grèce, jusqu'au temps de la division des sciences, vers le siècle d'Alexandre.}

Les Grecs, dégoûtés de ces rois qui, se disant les enfants des dieux, déshonoraient l'humanité par leurs fureurs et par leurs crimes, s'étaient partagés en républiques, parmi lesquelles Lacédémone seule reconnaissait des chefs héréditaires, mais contenus par l'autorité des autres magistratures, mais soumis aux lois, comme les citoyens, et affaiblis par le partage de la royauté entre les aînés des deux branches de la famille des Héraclides.

Les habitants de la Macédoine, de la Thessalie, de l'Epire, liés aux Grecs par une origine commune, par l'usage d'une même langue, et gouvernés par des princes faibles et divisés entre eux, ne pouvaient opprimer la Grèce ; ils suffisaient pour la préserver au nord des incursions des nations scythiques.

À l'occident, l'Italie, partagée en États isolés et peu étendus, ne pouvait inspirer à la Grèce aucune crainte. Déjà même la Sicile presque entière, les plus beaux ports de la partie méridionale de l'Italie 
étaient occupés par des colonies grecques, qui, en conservant avec leurs métropoles des liens de fraternité, formaient néanmoins des républiques indépendantes. D'autres colonies s'étaient établies dans les îles de la mer Egée, et sur une partie des côtes de l'Asie Mineure.

Ainsi la réunion de cette partie du continent asiatique au vaste empire de Cyrus, fut, dans la suite, le seul danger réel qui pût menacer l'indépendance de la Grèce et la liberté de ses habitants.

La tyrannie, quoique plus durable dans quelques colonies, et surtout dans celles dont l'établissement avait précédé la destruction des familles royales, ne pouvait être considérée que comme un fléau passager et partiel qui faisait le malheur des habitants de quelques villes, sans influer sur l'esprit général de la nation.

La Grèce avait reçu des peuples de l'Orient leurs arts, une partie de leurs connaissances, l'usage de l'écriture alphabétique, et leur système religieux ; mais des communications établies entre elle et ces peuples, par des Orientaux exilés, qui avaient cherché un asile dans la Grèce, par des Grecs qui voyageaient en Orient, transportèrent seules dans la Grèce les lumières et les erreurs de l'Asie et de l'Égypte.

Les sciences ne pouvaient donc être devenues dans la Grèce l'occupation et le patrimoine d'une caste particulière. Les fonctions de leurs prêtres se bornèrent au culte des dieux. Le génie pouvait y déployer toutes ses forces, sans être assujetti à des observances pédantesques, au système d'hypocrisie d'un collège sacerdotal. Tous les hommes conservaient un droit égal à la connaissance de la vérité. Tous pouvaient chercher à la découvrir pour la communiquer à tous, et la leur communiquer tout entière.

Cette heureuse circonstance, plus encore que la liberté politique, laissait à l'esprit humain, chez les Grecs, une indépendance, garant assuré de la rapidité et de l'étendue de ses progrès.

Cependant, leurs sages, leurs savants, qui prirent bientôt après le nom plus modeste de philosophes ou d'amis de la science, de la sagesse, s'égarèrent dans l'immensité du plan trop vaste qu'ils avaient embrassé. Ils voulurent pénétrer la nature de l'homme et celle des 
dieux, l'origine du monde et celle du genre humain. Ils essayèrent de réduire la nature entière à un seul principe, et les phénomènes de l'univers à une loi unique. Ils cherchèrent à renfermer dans une seule règle de conduite, et tous les devoirs de la morale, et le secret du véritable bonheur.

Ainsi, au lieu de découvrir des vérités, ils forgèrent des systèmes ; ils négligèrent l'observation des faits, pour s'abandonner à leur imagination ; et ne pouvant appuyer leurs opinions sur des preuves, ils essayèrent de les défendre par des subtilités.

Cependant, ces mêmes hommes cultivaient avec succès la géométrie et l'astronomie. La Grèce leur dut les premiers éléments de ces sciences, et même quelques vérités nouvelles, ou du moins la connaissance de celles qu'ils avaient rapportées de l'Orient, non comme des croyances établies, mais comme des théories, dont ils connaissaient les principes et les preuves.

Au milieu de la nuit de ces systèmes nous voyons même briller deux idées heureuses, qui reparaîtront encore dans des siècles plus éclairés.

Démocrite regardait tous les phénomènes de l'univers comme le résultat des combinaisons et du mouvement de corps simples, d'une figure déterminée et immuable, ayant reçu une impulsion première, d'où résulte une quantité d'action qui se modifie dans chaque atome, mais qui, dans la masse entière, se conserve toujours la même.

Pythagore annonçait que l'univers était gouverné par une harmonie dont les propriétés des nombres devaient dévoiler les principes ; c'està-dire, que tous les phénomènes étaient soumis à des lois générales et calculées.

On reconnaît aisément, dans ces deux idées, et les systèmes hardis de Descartes, et la philosophie de Newton.

Pythagore découvrit par ses méditations, ou reçut des prêtres, soit de l'Égypte, soit de l'Inde, la véritable disposition des corps célestes et le vrai système du monde : il le fit connaître aux Grecs. Mais ce sys- 
tème était trop contraire au témoignage des sens, trop opposé aux idées vulgaires, pour que les faibles preuves sur lesquelles on pouvait en établir la vérité, fussent capables d'entraîner les esprits. Il resta caché dans le sein de l'école pythagoricienne, et fut oublié avec elle, pour reparaître vers la fin du XVIe siècle, appuyé de preuves certaines, qui ont alors triomphé et de la répugnance des sens, et des préjugés de la superstition, plus puissants encore et plus dangereux.

Cette école pythagoricienne s'était répandue principalement dans la grande Grèce ; elle y formait des législateurs et d'intrépides défenseurs des droits de l'humanité : elle succomba sous les efforts des tyrans. Un d'eux brûla les Pythagoriciens dans leur école ; et ce fut une raison suffisante sans doute, non pour abjurer la philosophie, non pour abandonner la cause des peuples, mais pour cesser de porter un nom devenu trop dangereux, et pour quitter des formes qui n'auraient plus servi qu'à réveiller les fureurs des ennemis de la liberté et de la raison.

Une des premières bases de toute bonne philosophie est de former pour chaque science une langue exacte et précise, où chaque signe représente une idée bien déterminée, bien circonscrite, et de parvenir à bien déterminer, à bien circonscrire les idées par une analyse rigoureuse.

Les Grecs, au contraire, abusèrent des vices de la langue commune, pour jouer sur le sens des mots, pour embarrasser l'esprit dans de misérables équivoques, pour l'égarer, en exprimant successivement par un même signe des idées différentes. Cette subtilité donnait cependant de la finesse aux esprits, en même temps qu'elle épuisait leur force contre de chimériques difficultés. Ainsi, cette philosophie de mots, en remplissant des espaces où la raison humaine semble s'arrêter devant quelque obstacle supérieur à ses forces, ne sert point immédiatement à ses progrès, mais elle les prépare ; et nous aurons encore occasion de répéter cette même observation.

C'était en s'attachant à des questions peut-être à jamais insolubles, en se laissant séduire par l'importance ou la grandeur des objets, sans songer si l'on aurait les moyens d'y atteindre ; c'était en voulant établir les théories avant d'avoir rassemblé les faits, et construire l'univers quand on ne savait pas même encore l'observer ; c'était cette erreur, 
alors bien excusable, qui, dès les premiers pas, avait arrêté la marche de la philosophie. Aussi Socrate, en combattant les sophistes, en couvrant de ridicule leurs vaines subtilités, criait-il aux Grecs de rappeler enfin sur la terre cette philosophie qui se perdait dans le ciel ; non qu'il dédaignât ni l'astronomie, ni la géométrie, ni l'observation des phénomènes de la nature ; non qu'il eût l'idée puérile et fausse de réduire l'esprit humain à la seule étude de la morale : c'est au contraire précisément à son école et à ses disciples que les sciences mathématiques et physiques durent leurs progrès ; parmi les ridicules qu'on cherche à lui donner dans les comédies, le reproche qui amène le plus de plaisanteries est celui de cultiver la géométrie, d'étudier les météores, de tracer des cartes de géographie, de faire des observations sur les verres brûlants, dont, par une singularité remarquable, l'époque la plus reculée ne nous a été transmise que par une bouffonnerie d'Aristophane.

Socrate voulait seulement avertir les hommes de se borner aux objets que la nature a mis à leur portée ; d'assurer chacun de leurs pas avant d'en essayer de nouveaux; d'étudier l'espace qui les entoure, avant de s'élancer au hasard dans un espace inconnu.

La mort de Socrate est un événement important dans l'histoire humaine ; elle fut le premier crime qui ait signalé cette guerre de la philosophie et de la superstition; guerre qui dure encore parmi nous, comme celle de la même philosophie contre les oppresseurs de l'humanité, dont l'incendie d'une école pythagoricienne avait marqué l'époque. L'histoire de ces guerres va devenir une des parties les plus importantes du tableau qui nous reste à tracer.

Les prêtres voyaient avec douleur des hommes qui, cherchant à perfectionner leur raison, à remonter aux causes premières, connaissaient toute l'absurdité de leurs dogmes, toute l'extravagance de leurs cérémonies, toute la fourberie de leurs oracles et de leurs prodiges. Ils craignaient que ces philosophes ne confiassent ce secret aux disciples qui fréquentaient leurs écoles : que d'eux il ne passât à tous ceux qui, pour obtenir de l'autorité ou du crédit, étaient obligés de donner quelque culture à leur esprit ; et qu'ainsi l'empire sacerdotal ne fût bientôt réduit à la classe la plus grossière du peuple, qui finirait elle-même par être désabusée. 
L'hypocrisie effrayée se hâta d'accuser les philosophes d'impiété envers les dieux, afin qu'ils n'eussent pas le temps d'apprendre aux peuples que ces dieux étaient l'ouvrage de leurs prêtres. Les philosophes crurent échapper à la persécution, en adoptant, à l'exemple des prêtres eux-mêmes, l'usage d'une double doctrine, en ne confiant qu'à des disciples éprouvés les opinions qui blessaient trop ouvertement les préjugés vulgaires.

Mais les prêtres présentaient au peuple comme des blasphèmes les vérités physiques même les plus simples. Ils poursuivirent Anaxagore, pour avoir osé dire que le soleil était plus grand que le Péloponèse.

Socrate ne put échapper à leurs coups. Il n'y avait plus dans Athènes de Périclès qui veillât à la défense du génie et de la vertu. D'ailleurs, Socrate était bien plus coupable. Sa haine pour les sophistes, son zèle pour ramener vers des objets plus utiles la philosophie égarée, annonçait aux prêtres que la vérité seule était l'objet de ses recherches ; qu'il voulait, non faire adopter par les hommes un nouveau système, et soumettre leur imagination à la sienne, mais leur apprendre à faire usage de leur raison ; et de tous les crimes, c'est celui que l'orgueil sacerdotal sait le moins pardonner.

Ce fut au pied du tombeau même de Socrate que Platon dicta les leçons qu'il avait reçues de son maître.

Son style enchanteur, sa brillante imagination, les tableaux riants ou majestueux, les traits ingénieux et piquants, qui, dans ses Dialogues, font disparaître la sécheresse des discussions philosophiques; ces maximes d'une morale douce et pure, qu'il a su y répandre ; cet art avec lequel il met ses personnages en action et conserve à chacun son caractère ; toutes ces beautés, que le temps et les révolutions des opinions n'ont pu flétrir, ont dû sans doute obtenir grâce pour les rêves philosophiques qui trop souvent forment le fond de ses ouvrages, pour cet abus des mots que son maître avait tant reproché aux sophistes, et dont il n'a pu préserver le plus grand de ses disciples.

On est étonné, en lisant ses Dialogues, qu'ils soient l'ouvrage d'un philosophe qui, par une inscription placée sur la porte de son école, en défendait l'entrée à quiconque n'aurait pas étudié la géométrie ; et que 
celui qui débite avec tant d'audace des hypothèses si creuses et si frivoles, ait été le fondateur de la secte, où l'on a soumis pour la première fois, à un examen rigoureux, les fondements de la certitude des connaissances humaines, et même ébranlé ceux qu'une raison plus éclairée aurait fait respecter.

Mais la contradiction disparaît, si l'on songe que jamais Platon ne parle en son nom ; que Socrate, son maître, s'y exprime toujours avec la modestie du doute; que les systèmes y sont présentés au nom de ceux qui en étaient, ou que Platon supposait en être les auteurs: qu'ainsi ces mêmes Dialogues sont encore une école de pyrrhonisme, et que Platon y a su montrer à la fois l'imagination hardie d'un savant qui se plaît à combiner, à développer de brillantes hypothèses, et la réserve d'un philosophe qui se livre à son imagination, sans se laisser entraîner par elle ; parce que sa raison, armée d'un doute salutaire, sait se défendre des illusions même les plus séduisantes.

Ces écoles où se perpétuaient la doctrine, et surtout les principes et la méthode d'un premier chef, pour qui ses successeurs étaient cependant bien éloignés d'une docilité servile ; ces écoles avaient l'avantage de réunir entre eux, par les liens d'une libre fraternité, les hommes occupés de pénétrer les secrets de la nature. Si l'opinion du maître y partageait trop souvent l'autorité, qui ne doit appartenir qu'à la raison ; si par là cette institution suspendait les progrès des lumières, elle servait à les propager avec plus de promptitude et d'étendue, dans un temps où l'imprimerie étant inconnue, et les manuscrits même très rares, ces grandes écoles, dont la célébrité appelait les élèves de toutes les parties de la Grèce, étaient le moyen le plus puissant d'y faire germer le goût de la philosophie, et d'y répandre les vérités nouvelles.

Ces écoles rivales se combattaient avec cette animosité que produit l'esprit de secte, et souvent l'on y sacrifiait l'intérêt de la vérité au succès d'une doctrine à laquelle chaque membre de la secte attachait une partie de son orgueil. La passion personnelle du prosélytisme corrompait la passion plus noble d'éclairer les hommes. Mais en même temps, cette rivalité entretenait dans les esprits une activité utile ; le spectacle de ces disputes, l'intérêt de ces guerres d'opinion réveillait, attachait à l'étude de la philosophie, une foule d'hommes, que le seul 
amour de la vérité n'aurait pu arracher ni aux affaires, ni aux plaisirs, ni même à la paresse.

Enfin, comme ces écoles, ces sectes que les Grecs eurent la sagesse de ne jamais faire entrer dans les institutions publiques, restèrent parfaitement libres ; comme chacun pouvait à son gré ouvrir une autre école, ou former une secte nouvelle, on n'avait point à craindre cet asservissement de la raison, qui, chez la plupart des autres peuples, opposait un obstacle invincible au progrès de l'esprit humain.

Nous montrerons quelle fut, sur la raison des Grecs, sur leurs mœurs, sur leurs lois, sur leurs gouvernements, l'influence des philosophes, influence qui doit être attribuée en grande partie à ce qu'ils n'eurent, ou même ne voulurent jamais avoir aucune existence politique, à ce que l'éloignement volontaire des affaires publiques était une maxime de conduite commune à presque toutes leurs sectes, enfin, à ce qu'ils affectaient de se distinguer des autres hommes, par leur vie, comme par leurs opinions.

En traçant le tableau de ces sectes différentes, nous nous occuperons moins de leurs systèmes que des principes de leur philosophie ; moins de chercher, comme on l'a fait trop souvent, quelles sont précisément les doctrines absurdes que nous dérobe un langage devenu presque inintelligible ; mais de montrer quelles erreurs générales les ont conduits dans ces routes trompeuses, et d'en trouver l'origine dans la marche naturelle de l'esprit humain.

Nous nous attacherons surtout à exposer les progrès des sciences réelles, et le perfectionnement successif de leurs méthodes.

À cette époque, la philosophie les embrassait toutes, excepté la médecine, qui déjà s'en était séparée. Les écrits d'Hippocrate nous montreront quel était alors l'état de cette science, et de celles qui y sont naturellement liées, mais qui n'existaient encore que dans leurs rapports avec elle.

Les sciences mathématiques avaient été cultivées avec succès, dans les écoles de Thalès et de Pythagore. Cependant, elles ne s'y élevèrent pas beaucoup au delà du terme où elles s'étaient arrêtées dans les col- 
lèges sacerdotaux des peuples de l'Orient, Mais, dès la naissance de l'école de Platon, elles s'élancèrent au delà de cette barrière que l'idée de les borner à une utilité immédiate et pratique leur avait opposée.

Ce philosophe résolut le premier le problème de la duplication du cube, à la vérité par un mouvement continu, mais par un procédé ingénieux, et d'une manière vraiment rigoureuse. Ses premiers disciples découvrirent les sections coniques, en déterminèrent les principales propriétés ; et par là, ils ouvrirent au génie cet horizon immense, où, jusqu'à la fin des temps, il pourra sans cesse exercer ses forces, mais dont à chaque pas il verra reculer les bornes devant lui.

Ce n'est pas à la philosophie seule que les sciences politiques durent leurs progrès chez les Grecs. Dans ces petites républiques, jalouses de conserver et leur indépendance et leur liberté, on eut presque généralement l'idée de confier à un seul homme, non la puissance de faire des lois, mais la fonction de les rédiger et de les présenter au peuple, qui, après les avoir examinées, leur accordait une sanction immédiate.

[Ainsi, le peuple imposait un travail au philosophe, dont les vertus ou la sagesse avaient obtenu sa confiance ; mais il ne lui conférait aucune autorité : il exerçait seul et par lui-même ce que depuis nous avons appelé le pouvoir législatif. L'habitude si funeste d'appeler] la superstition au secours des institutions politiques, a souillé trop souvent l'exécution d'une idée si propre à donner aux lois d'un pays cette unité systématique, qui peut seule en rendre l'action sûre et facile, comme en maintenir la durée. La politique d'ailleurs n'avait pas encore de principes assez constants, pour que l'on n'eût pas à craindre de voir les législateurs porter dans ces combinaisons leurs préjugés et leurs passions.

Leur objet ne pouvait être encore de fonder sur la raison, sur les droits que tous les hommes ont également reçus de la nature, enfin, sur les maximes de la justice universelle, l'édifice d'une société d'hommes égaux et libres, mais seulement d'établir les lois suivant lesquelles les membres héréditaires d'une société déjà existante pourraient conserver leur liberté, y vivre à l'abri de l'injustice, et déployer au dehors une force qui garantît leur indépendance. 
Comme on supposait que ces lois, presque toujours liées à la religion, et consacrées par des serments, auraient une durée éternelle, on s'occupait moins d'assurer à un peuple les moyens de les réformer d'une manière paisible, que de prévenir l'altération de ces lois fondamentales, et d'empêcher que des réformes de détail n'en altérassent le système, n'en corrompissent l'esprit. On chercha des institutions propres à exalter, à nourrir l'amour de la patrie, qui renfermait celui de sa législation, ou même de ses usages ; on chercha une organisation de pouvoirs, qui garantît l'exécution des lois contre la négligence ou la corruption des magistrats, contre le crédit des citoyens puissants, et les mouvements inquiets de la multitude.

Les riches, qui seuls étaient alors à portée d'acquérir des lumières, pouvaient, en s'emparant de l'autorité, opprimer les pauvres, et les forcer à se jeter dans les bras d'un tyran. L'ignorance, la légèreté du peuple, sa jalousie contre les citoyens puissants, pouvaient donner à ceuxci le désir et les moyens d'établir le despotisme aristocratique, ou livrer l'État affaibli à l'ambition de ses voisins. Forcés de se préserver à la fois de ces deux écueils, les législateurs grecs eurent recours à des combinaisons plus ou moins heureuses, mais portant presque toujours l'empreinte de cette finesse, de cette sagacité, qui dès lors caractérisait l'esprit général de la nation.

On trouverait à peine dans les républiques modernes, et même dans les plans tracés par les philosophes, une institution dont les républiques grecques n'aient offert le modèle ou donné l'exemple. Car la ligue Amphictyonique, celle des Etoliens, des Arcadiens, des Achéens, nous présentent des constitutions fédératives, dont l'union était plus ou moins intime ; et il s'était établi un droit des gens moins barbare, et des règles de commerce plus libérales entre ces différents peuples rapprochés par une origine commune, par l'usage de la même langue, par la ressemblance des mœurs; des opinions et des croyances religieuses.

[Les rapports mutuels de l'agriculture, de l'industrie, du commerce, avec la constitution d'un État et sa législation, leur influence sur sa prospérité, sur sa puissance, sur sa liberté, ne purent échapper aux regards d'un peuple ingénieux, actif, occupé des intérêts publics ; et l'on 
y aperçoit les premières traces de cet art si vaste, si utile, connu aujourd'hui sous le nom d'économie politique.]

L'observation seule des gouvernements établis suffisait donc pour faire bientôt de la politique une science étendue. [Aussi, dans les écrits mêmes des philosophes, paraît-elle plutôt une science de faits, et pour ainsi dire empirique, qu'une véritable théorie, fondée sur des principes généraux, puisés dans la nature, et avoués par la raison.]

[Tel est le point de vue sous lequel on doit envisager les idées politiques d'Aristote et de Platon, si l'on veut en pénétrer le sens et les apprécier avec justice.]

Presque toutes les institutions des Grecs supposent l'existence de l'esclavage, et la possibilité de réunir, dans une place publique, l'universalité des citoyens ; et pour bien juger de leurs effets, surtout pour prévoir ceux qu'elles produiraient dans les grandes nations modernes, il ne faut pas perdre un instant de vue ces deux différences si importantes. Mais on ne peut réfléchir sur la première, sans songer avec douleur, qu'alors les combinaisons même les plus parfaites n'avaient pour objet que la liberté, ou le bonheur de la moitié tout au plus de l'espèce humaine.

[L'éducation était chez les Grecs une partie importante de la politique. Elle y formait les hommes pour la patrie, bien plus que pour euxmêmes ou pour leur famille. Ce principe ne peut être adopté que pour des peuples peu nombreux, à qui l'on est plus excusable de supposer un intérêt national, séparé de l'intérêt commun de l'humanité. Il n'est praticable que dans les pays où les travaux les plus pénibles de la culture et des arts sont exercés par des esclaves. Cette éducation se bornait presque aux exercices du corps, aux principes des mœurs, aux habitudes propres à exciter un patriotisme exclusif : le reste s'apprenait librement dans les écoles des philosophes ou des rhéteurs, dans les ateliers des artistes ; et cette liberté est encore une des causes de la supériorité des Grecs.]

Dans leur politique, comme dans leur philosophie, on découvre un principe général, auquel l'histoire présente à peine un très petit nombre d'exceptions ; c'est de chercher dans les lois, moins à faire dispa- 
raître les causes d'un mal qu'à en détruire les effets, en opposant ces causes l'une à l'autre ; c'est de vouloir, dans les institutions, tirer parti des préjugés, des vices, plutôt que les dissiper ou les réprimer ; c'est de s'occuper plus souvent des moyens de dénaturer l'homme, d'exalter, d'égarer sa sensibilité, que de perfectionner, d'épurer les inclinations et les penchants qui sont le produit nécessaire de sa constitution morale : erreurs produites par l'erreur plus générale de regarder comme l'homme de la nature, celui que leur offrait l'état actuel de la civilisation, c'est-à-dire, l'homme corrompu par les préjugés, par les intérêts des passions factices, et par les habitudes sociales.

Cette observation est d'autant plus importante, il sera d'autant plus nécessaire de développer l'origine de cette erreur, pour mieux la détruire, qu'elle s'est transmise jusqu'à notre siècle, et qu'elle corrompt encore trop souvent parmi nous et la morale et la politique.

[Si l'on compare la législation, et surtout la forme et les règles des jugements dans la Grèce, et chez les Orientaux, on verra que chez les uns, les lois sont un joug sous lequel la force a courbé des esclaves ; chez les autres, les conditions d'un pacte commun fait entre des hommes. Chez les uns, l'objet des formes légales est que la volonté du maître soit accomplie ; chez les autres, que la liberté des citoyens ne soit pas opprimée. Chez les-uns, la loi est faite pour celui qui l'impose ; chez les autres, pour celui qui doit s'y soumettre. Chez les uns, on force à la craindre ; chez les autres, on instruit à la chérir : différences que nous retrouverons encore, chez les modernes, entre les lois des peuples libres et celles des peuples esclaves. On verra enfin que dans la Grèce, l'homme avait du moins le sentiment de ses droits, s'il ne les connaissait pas encore, s'il ne savait pas en approfondir la nature, en embrasser et en circonscrire l'étendue.]

À cette époque des premières lueurs de la philosophie chez les Grecs, et de leurs premiers pas dans les sciences, les beaux-arts s'y élevèrent à un degré de perfection qu'aucun peuple n'avait encore connu, qu'à peine quelques-uns ont pu atteindre depuis. Homère vécut pendant le temps de ces dissensions qui accompagnèrent la chute des. tyrans et la formation des républiques. Sophocle, Euripide, Pindare, Thucydide, Démosthène, Phidias, Apelles, furent contemporains de Socrate ou de Platon. 
Nous tracerons le tableau du progrès de ces arts ; nous en discuterons les causes ; nous distinguerons ce qu'on peut regarder comme une perfection de l'art, et ce qui n'est dû qu'à l'heureux génie de l'artiste ; distinction qui suffit pour faire disparaître ces bornes étroites, dans lesquelles on a renfermé le perfectionnement des beaux-arts. Nous montrerons l'influence qu'exercèrent sur leurs progrès la forme des gouvernements, le système de la législation, l'esprit du culte religieux ; nous rechercherons ce qu'ils durent à ceux de la philosophie, et ce qu'elle-même a pu leur devoir.

Nous montrerons comment la liberté, les arts, les lumières, ont contribué à l'adoucissement, à l'amélioration des mœurs ; nous ferons voir que ces vices des Grecs, si souvent attribués aux progrès mêmes de leur civilisation, étaient ceux des siècles plus grossiers ; et que les lumières, la culture des arts, les ont tempérés, quand elles n'ont pu les détruire ; nous prouverons que ces éloquentes déclamations contre les sciences et les arts, sont fondées sur une fausse application de l'histoire ; et qu'au contraire les progrès de la vertu ont toujours accompagné ceux des lumières, comme ceux de la corruption en ont toujours suivi ou annoncé la décadence. 
CONDORCET,

Esquisse d'un tableau historique des progrès de l'esprit humain

(1793-1794).

\section{Cinquième époque}

\section{Progrès des sciences depuis leur division jusqu'à leur décadence.}

Platon vivait encore, lorsque Aristote, son disciple, ouvrit, dans Athènes même, une école rivale de la sienne.

Non seulement il embrassa toutes les sciences, mais il appliqua la méthode philosophique à l'éloquence et à la poésie. Il osa concevoir le premier que cette méthode doit s'étendre à tout ce que l'intelligence humaine peut atteindre ; puisque cette intelligence, exerçant partout les mêmes facultés, doit partout être assujettie aux mêmes lois.

Plus le plan qu'il s'était formé était vaste, plus il sentit le besoin d'en séparer les diverses parties, et de fixer avec plus de précision les limites de chacune. À compter de cette époque, la plupart des philosophes, et même des sectes entières, se bornèrent à quelques-unes de ces parties.

Les sciences mathématiques et physiques formèrent seules une grande division. Comme elles se fondent sur le calcul et l'observation, 
comme ce qu'elles peuvent enseigner est indépendant des opinions qui divisaient les sectes, elles se séparèrent de la philosophie, sur laquelle ces sectes régnaient encore. Elles devinrent donc l'occupation de savants, qui presque tous eurent même la sagesse de demeurer étrangers aux disputes des écoles, où l'on se livrait à une lutte de réputation plus utile à la renommée passagère des philosophes, qu'aux progrès de la philosophie. Ce mot commença même à ne plus exprimer que les principes généraux de l'ordre du monde, la métaphysique, la dialectique et la morale, dont la politique faisait partie.

Heureusement l'époque de cette division précéda le temps où la Grèce, après de longs orages, devait perdre sa liberté.

Les sciences trouvèrent dans la capitale de l'Égypte un asile, que les despotes qui la gouvernaient auraient peut-être refusé àla philosophie. Des princes, qui devaient une grande partie de leur richesse et de leur pouvoir au commerce réuni de la Méditerranée et de l'Océan asiatique, devaient encourager des sciences utiles à la navigation et au commerce.

Elles échappèrent donc à cette décadence plus prompte qui se fit bientôt sentir dans la philosophie, dont l'éclat disparut avec la liberté. Le despotisme des Romains, si indifférents aux progrès des lumières, n'atteignit l'Égypte que très tard, et dans un temps où la ville d'Alexandrie était devenue nécessaire à la subsistance de Rome ; déjà en possession d'être la métropole des sciences, comme le centre du commerce, elle se suffisait à elle-même pour en conserver le feu sacré par sa population, par sa richesse, par le grand concours des étrangers, par les établissements que les Ptolémées avaient formés, et que les vainqueurs ne songèrent pas à détruire.

La secte académique, où les mathématiques avaient été cultivées dès son origine, et dont l'enseignement philosophique se bornait presque à prouver l'utilité du doute, et indiquer les limites étroites de la certitude, devait être la secte des savants ; et. cette doctrine ne pouvait effrayer les despotes : aussi domina-t-elle dans l'école d'Alexandrie.

La théorie des sections coniques, la méthode de les employer, soit pour la construction des lieux géométriques, soit pour la résolution 
des problèmes, la découverte de quelques autres courbes, étendirent la carrière, jusqu'alors si resserrée, de la géométrie. Archimède découvrit la quadrature de la parabole, il mesura la surface de la sphère ; et ce furent les premiers pas dans cette théorie des limites, qui détermine la dernière valeur d'une quantité, celle dont cette quantité se rapproche sans cesse en ne l'atteignant jamais, dans cette science qui enseigne, tantôt à trouver les rapports des quantités évanouissantes, tantôt àremonter de la connaissance de ces rapports à la détermination de ceux des grandeurs finies; dans ce calcul, en un mot, auquel, avec plus d'orgueil que de justesse, les modernes ont donné le nom de calcul de l'infini. C'est Archimède qui, le premier, détermina le rapport approché du diamètre du cercle et de sa circonférence, enseigna comme on pouvait en obtenir des valeurs toujours de plus en plus approchées, et fit connaître les méthodes d'approximation, ce supplément heureux de l'insuffisance des méthodes connues, et souvent de la science ellemême.

On peut, en quelque sorte, le regarder comme le créateur de la mécanique rationnelle. On lui doit la théorie du levier, et la découverte de ce principe d'hydrostatique, qu'un corps, placé dans un corps fluide, perd une portion de son poids égale à celui de la masse qu'il a déplacée.

La vis qui porte son nom, ses miroirs ardents, les prodiges du siège de Syracuse, attestent ses talents dans la science des machines, que les savants avaient négligée, parce que les principes de théorie, connus jusqu'alors, ne pouvaient y atteindre encore. Ces grandes découvertes, ces sciences nouvelles placent Archimède parmi ces génies heureux dont la vie est une époque dans l'histoire de l'homme, et dont l'existence parait un des bienfaits de la nature.

C'est dans l'école d'Alexandrie que nous trouvons les premières traces de l'algèbre, c'est-à-dire, du calcul des quantités considérées uniquement comme telles. La nature des questions proposées et résolues dans le livre de Diophante, exigeait que les nombres y fussent envisagés comme ayant une valeur générale, indéterminée, et assujettie seulement à certaines conditions. 
Mais cette science n'avait point alors, comme aujourd'hui, ses signes, ses méthodes propres, ses opérations techniques. On désignait ces valeurs générales par des mots ; et c'était par une suite de raisonnements que l'on parvenait à trouver, à développer la solution des problèmes.

Des observations chaldéennes, envoyées à Aristote par Alexandre, accélérèrent les progrès de l'astronomie. Ce qu'ils offrent de plus brillant est dû au génie d'Hipparque. Mais si, après lui, dans l'astronomie, comme après Archimède dans la géométrie et dans la mécanique, on ne trouve plus de ces découvertes, de ces travaux, qui changent, en quelque sorte, la face entière d'une science, elles continuèrent longtemps encore de se perfectionner, de s'étendre, et de s'enrichir du moins par des vérités de détail.

Dans son histoire des animaux, Aristote avait donné les principes et le modèle précieux de la manière d'observer avec exactitude, et de décrire avec méthode les objets de la nature, de classer les observations et de saisir les résultats généraux qu'elles présentent.

L'histoire des plantes, celle des minéraux, furent traitées après lui, mais avec moins de précision, et avec des vues moins étendues, moins philosophiques.

Les progrès de l'anatomie furent très lents, non seulement parce que des préjugés religieux s'opposaient à la dissection des cadavres, mais parce que l'opinion vulgaire en regardait l'attouchement comme une sorte de souillure morale.

La médecine d'Hippocrate n'était qu'une science d'observation, qui n'avait pu conduire encore qu'à des méthodes empiriques. L'esprit de secte, le goût des hypothèses infecta bientôt les médecins; mais si le nombre des erreurs l'emporta sur celui des vérités nouvelles, si les préjugés ou les systèmes des médecins firent plus de mal que leurs observations ne purent faire de bien, on, ne peut nier cependant que la médecine n'ait fait, durant cette époque, des progrès faibles, mais réels.

Aristote ne porta dans la physique, ni cette exactitude, ni cette sage réserve, qui caractérisent son histoire des animaux. Il paya le tribut 
aux habitudes de son siècle, à l'esprit des écoles, en défigurant la physique par ces principes hypothétiques qui, dans leur généralité vague, expliquent tout avec une sorte de facilité, parce qu'ils ne peuvent rien expliquer avec précision.

D'ailleurs, l'observation seule ne suffit pas ; il faut des expériences : elles exigent des instruments ; et il parait qu'on n'avait pas alors assez recueilli de faits, qu'on ne les avait pas vus avec assez de détail, pour sentir le besoin, pour avoir l'idée de cette manière d'interroger la nature et de la forcer à nous répondre. Aussi, dans cette époque, l'histoire des progrès de la physique doit-elle se borner au tableau d'un petit nombre de connaissances, dues au hasard et aux observations où conduit la pratique des arts, bien plus qu'aux recherches des savants. L'hydraulique, et surtout l'optique, présentent une moisson un peu moins stérile ; mais ce sont plutôt encore des faits remarqués, parce qu'ils se sont offerts d'eux-mêmes, que des théories ou des lois physiques, découvertes par des expériences, ou devinées par la méditation.

[L'agriculture s'était bornée jusqu'alors à la simple routine, et à quelques règles que les prêtres, en les transmettant aux peuples, avaient corrompues par leurs superstitions. Elle devint chez les Grecs, et surtout chez les Romains, un art important et respecté, dont les hommes les plus savants s'empressèrent de recueillir les usages et les préceptes. Ces recueils d'observations, présentées avec précision, rassemblées avec discernement, pouvaient éclairer la pratique, répandre les méthodes utiles ; mais on était encore bien loin du siècle des expériences et des observations calculées.]

Les arts mécaniques commencèrent à se lier aux sciences ; les philosophes en examinèrent les travaux, en recherchèrent l'origine, en étudièrent l'histoire, s'occupèrent de décrire les procédés et les produits de ceux qui étaient cultivés dans les diverses contrées, de recueillir ces observations, et de les transmettre à la postérité.

Ainsi, l'on vit Pline embrasser l'homme, la nature et les arts, dans le plan immense de son Histoire naturelle ; inventaire précieux (le tout ce qui formait alors les véritables richesses de l'esprit humain ; et les droits de Pline à notre reconnaissance ne peuvent être détruits par le reproche mérité d'avoir accueilli, avec trop peu de choix et trop de 
crédulité, ce que l'ignorance ou la vanité mensongère des historiens et des voyageurs avait offert à son insatiable avidité de tout connaître.

Au milieu de la décadence de la Grèce, Athènes, qui, dans les jours de sa puissance, avait honoré la philosophie et les lettres, leur dut, à son tour, de conserver plus longtemps quelques restes de son ancienne splendeur. On n'y balançait plus, à la tribune, les destins de la Grèce et de l'Asie; mais c'est dans ses écoles que les Romains apprirent à connaître les secrets de l'éloquence ; et c'est aux pieds de la lampe de Démosthène que se forma le premier de leurs orateurs.

L'Académie, le Lycée, le Portique, les jardins d'Epicure, furent le berceau et la principale école des quatre sectes qui se disputèrent l'empire de la philosophie.

On enseignait dans l'Académie qu'il n'y a rien de certain ; que, sur aucun objet, l'homme ne peut atteindre, ni à une vraie certitude, ni même à une compréhension parfaite ; enfin (et il était difficile d'aller plus loin), qu'il ne pouvait être sûr de cette impossibilité de rien connaître, et qu'il fallait douter même de la nécessité de douter de tout.

On y exposait, on y défendait, on y combattait les opinions des autres philosophes, mais comme des hypothèses propres à exercer l'esprit, et pour faire sentir davantage, par l'incertitude qui accompagnait ces disputes, la vanité des connaissances humaines, et le ridicule de la confiance dogmatique des autres sectes.

Mais ce doute, qu'avoue la raison, quand il conduit à ne point raisonner sur les mots auxquels nous ne pouvons attacher des idées nettes et précises, à proportionner notre adhésion au degré de la probabilité de chaque proposition, à déterminer, pour chaque classe de connaissances, les limites de la certitude que nous pouvons obtenir ; ce même doute, s'il s'étend aux vérités démontrées, s'il attaque les principes de la morale, devient ou stupidité ou démence ; il favorise l'ignorance et la corruption. et tel est l'excès où sont tombés les sophistes qui remplacèrent dans l'Académie les premiers disciples de Platon. 
Nous exposerons la marche de ces sceptiques, la cause de leurs erreurs ; nous chercherons ce que, dans l'exagération de leur doctrine, on doit attribuer à la manie de se singulariser par des opinions bizarres ; nous ferons observer que, s'ils furent assez solidement réfutés par l'instinct des autres hommes, par celui qui les dirigeait eux-mêmes dans la conduite de leur vie, jamais ils ne furent, ni bien entendus, ni bien réfutés par les philosophes.

Cependant, ce scepticisme outré n'avait pas entraîné toute la secte académique ; et l'opinion d'une idée éternelle du juste, du beau, de l'honnête, indépendante de l'intérêt des hommes, de leurs conventions, de leur existence même, idée qui, imprimée dans notre âme devenait pour nous le principe de nos devoirs et la règle de nos actions; cette doctrine, puisée dans les Dialogues de Platon, continuait d'être exposée dans son école, et y servait de base à l'enseignement de la morale.

Aristote ne connut pas mieux que ses maîtres l'art d'analyser les idées, c'est-à-dire, de remonter par degrés jusqu'aux idées les plus simples qui sont entrées dans leur combinaison ; de pénétrer jusqu'à l'origine de la formation de ces idées simples ; de suivre dans ces opérations la marche de l'esprit et le développement de ses facultés.

Sa métaphysique ne fut donc, comme celle des autres philosophés, qu'une doctrine vague, fondée, tantôt sur l'abus des mots, et tantôt sur de simples hypothèses.

C'est à lui cependant que l'on doit cette vérité importante, ce premier pas dans la connaissance de l'esprit humain, que nos idées même les plus abstraites, les plus purement intellectuelles, pour ainsi dire, doivent leur origine à nos sensations : mais il ne l'appuya d'aucun développement. Ce fut plutôt l'aperçu d'un homme de génie, que le résultat d'une suite d'observations analysées avec précision, et combinées entre elles pour en faire sortir une vérité générale : aussi ce germe, jeté dans une terre ingrate, ne produisit de fruits utiles qu'après plus de vingt siècles.

Aristote, dans sa logique, réduit les démonstrations à une suite d'arguments assujettis à la forme syllogistique ; il divise ensuite toutes les propositions en quatre classes qui les renferment toutes ; il apprend 
à reconnaître, parmi toutes les combinaisons possibles de propositions de ces quatre classes prises trois à trois, celles qui répondent à des syllogismes concluants, et qui y répondent nécessairement: par ce moyen, l'on peut juger de la justesse ou du vice d'un argument, en sachant seulement à quelle combinaison il appartient ; et l'art de raisonner juste est soumis, en quelque sorte, à des règles techniques.

Cette idée ingénieuse est restée inutile jusqu'ici ; mais peut-être doit-elle un jour devenir le premier pas vers un perfectionnement que l'art de raisonner et de discuter semble encore attendre.

Chaque vertu, suivant Aristote, est placée entre deux vices, dont l'un en est le défaut, et l'autre l'excès ; elle n'est, en quelque sorte, qu'un de nos penchants naturels, auquel la raison nous défend et de trop résister, et de trop obéir.

Ce principe général a pu s'offrir à lui d'après une de ces idées vagues d'ordre et de convenance, si communes alors dans la philosophie ; mais il le vérifia, en l'appliquant à la nomenclature des mots qui, dans la langue grecque, exprimaient ce qu'on y appelait des vertus.

Vers le même temps, deux sectes nouvelles, appuyant la morale sur des principes opposés, du moins en apparence, partagèrent les esprits, étendirent leur influence bien au delà des bornes de leurs écoles, et hâtèrent la chute de la superstition grecque, que malheureusement une superstition plus sombre, plus dangereuse, plus ennemie des lumières, devait bientôt remplacer.

Les stoïciens firent consister la vertu et le bonheur dans la possession d'une âme également insensible à la volupté et à la douleur, affranchie de toutes les passions, supérieure à toutes les craintes, à toutes les faiblesses, ne connaissant de véritable bien que la vertu, de mal réel que les remords. Ils croyaient que l'homme a le pouvoir de s'élever à cette hauteur, s'il en a une volonté forte et constante ; et qu'alors, indépendant de la fortune, toujours maître de lui-même, il est également inaccessible au vice et au malheur. 
Un esprit unique anime le monde ; il est présent partout, si même il n'est pas tout, s'il existe autre chose que lui. Les âmes humaines en sont des émanations. Celle du sage, qui n'a point souillé la pureté de son origine, se réunit, au moment de la mort, à cet esprit universel. La mort serait donc un bien, si, pour le sage soumis à la nature, endurci contre tout ce que les hommes vulgaires appellent des maux, il n'y avait pas plus de grandeur à la regarder comme une chose indifférente.

Epicure place le bonheur dans la jouissance du plaisir et dans l'absence de la douleur. -La vertu consiste à suivre les penchants naturels, mais en sachant les épurer et les diriger. La tempérance, qui prévient la douleur, qui, en conservant nos facultés naturelles dans toute leur force, nous assure toutes les jouissances que la nature nous a préparées ; le soin de se préserver des passions haineuses ou violentes, qui tourmentent et déchirent le cœur livré à leur amertume et à leurs fureurs ; celui de cultiver au contraire les affections douces et tendres ; de se ménager les voluptés qui suivent la pratique de la bienfaisance ; de conserver la pureté de son âme pour éviter la honte et les remords qui punissent le crime, pour jouir du sentiment délicieux qui récompense les belles actions; telle est la route qui conduit à la fois et au bonheur et à la vertu.

Epicure ne voyait dans l'univers qu'une collection d'atomes, dont les combinaisons diverses étaient soumises à des lois nécessaires. L'âme humaine était elle-même une de ces combinaisons. Les atomes qui la composaient, réunis à l'instant où le corps commençait la vie, se dispersaient au moment de la mort, pour se réunir à la masse commune, et entrer dans de nouvelles combinaisons.

Ne voulant pas heurter trop directement les préjugés populaires, il avait admis des dieux; mais, indifférents aux actions des hommes, étrangers à l'ordre de l'univers, et soumis, comme les autres êtres, aux lois générales de son mécanisme, ils étaient en quelque sorte un horsd'œuvre de ce système.

Les hommes durs, orgueilleux, injustes, se cachèrent sous le masque du stoïcisme. Des hommes voluptueux et corrompus se glissèrent souvent dans les jardins d'Epicure. On calomnia les principes des épicuriens, qu'on accusa de placer le souverain bien dans les voluptés 
grossières. On tourna en ridicule les prétentions du sage de Zénon, qui, esclave, tournant la meule, ou tourmenté de la goutte, n'en est pas moins heureux, libre et souverain.

Cette philosophie, qui prétendait s'élever au-dessus de la nature, et celle qui ne voulait qu'y obéir ; cette morale qui ne reconnaissait d'autre bien que la vertu, et celle qui plaçait le bonheur dans la volupté, conduisaient aux mêmes conséquences pratiques, en partant de principes si contraires, en tenant un langage si opposé. Cette ressemblance dans les préceptes moraux de toutes les religions, de toutes les sectes de philosophie, suffirait pour prouver qu'ils ont une vérité indépendante des dogmes de ces religions, des principes de ces sectes; que c'est dans la constitution morale de l'homme qu'il faut chercher la base de ses devoirs, l'origine de ses idées de justice et de vertu ; vérité dont la secte épicurienne s'était moins éloignée qu'aucune autre : et rien peut-être ne contribua davantage à lui mériter la haine des hypocrites de toutes les classes, pour qui la morale n'est qu'un objet de commerce dont ils se disputent le monopole.

La chute des républiques grecques entraîna celle des sciences politiques. Après Platon, Aristote et Xénophon, l'on cessa presque de les comprendre dans le système de la philosophie.

Mais il est temps de parler d'un événement qui changea le sort d'une grande partie du monde, et exerça sur les progrès de l'esprit humain une influence qui s'est prolongée jusqu'à nous.

Si l'on en excepte l'Inde et la Chine, la ville de Rome avait étendu son empire sur toutes les nations où l'esprit humain s'était élevé audessus de la faiblesse de sa première enfance.

Elle donnait des lois à tous les pays où les Grecs avaient porté leur langue, leurs sciences et leur philosophie. Tous ces peuples, suspendus à une chaîne que la victoire avait attachée au pied du Capitole, n'existaient plus que par la volonté de Rome et pour les passions de ses chefs.

[Un tableau vrai de la constitution de cette ville dominatrice ne sera point étranger à l'objet de cet ouvrage : on y verra l'origine du patri- 
ciat héréditaire, et les adroites combinaisons employées pour lui donner plus de stabilité et plus de force, en le rendant moins odieux ; un peuple exercé aux armes, mais ne les employant presque jamais dans ses dissensions domestiques ; réunissant la force réelle à l'autorité légale, et se défendant à peine contre un sénat orgueilleux, qui, en l'enchaînant par la superstition, l'éblouissait par l'éclat de ses victoires : une grande nation, tour à tour le jouet de ses tyrans ou de ses défenseurs, et pendant quatre siècles la dupe patiente d'une manière de prendre ses suffrages absurde, mais consacrée.]

[On verra cette constitution, faite pour une seule ville, changer de nature sans changer de forme, quand il fallut l'étendre à un grand empire ; ne pouvant se maintenir que par des guerres continuelles, et bientôt détruite par ses propres armées ; enfin, le peuple-roi avili par l'habitude d'être nourri aux dépens du trésor publie, corrompu par les largesses des sénateurs, vendant à un homme les restes illusoires de son inutile liberté.]

L'ambition des Romains les portait à chercher en Grèce des maîtres dans cet art de l'éloquence qui était chez eux une des routes de la fortune. Ce goût pour les jouissances exclusives et raffinées, ce besoin de nouveaux plaisirs, qui naît de la richesse et de l'oisiveté, leur fit rechercher les arts des Grecs, et même la conversation de leurs philosophes. Mais les sciences, la philosophie, les arts du dessin, furent toujours des plantes étrangères au sol de Rome. L'avarice des vainqueurs couvrit l'Italie des chefs-d'œuvre de la Grèce, enlevés par la force aux temples, aux cités dont ils faisaient l'ornement, aux peuples dont ils consolaient l'esclavage : mais les ouvrages d'aucun Romain n'osèrent s'y mêler. Cicéron, Lucrèce et Sénèque écrivirent éloquemment dans leur langue sur la philosophie ; mais c'était sur celle des Grecs ; et pour réformer le calendrier barbare de Numa, César fut obligé d'employer un mathématicien d'Alexandrie.

Rome, longtemps déchirée par les factions de généraux ambitieux, occupée de nouvelles conquêtes, ou agitée par les discordes civiles, tomba enfin de son inquiète liberté dans un despotisme militaire plus orageux encore. Quelle place auraient donc pu trouver les tranquilles méditations de la philosophie ou des sciences, entre des chefs qui aspiraient à la tyrannie, et bientôt après sous des despotes qui crai- 
gnaient la vérité, et qui haïssaient également les talents et les vertus ? D'ailleurs, les sciences et la philosophie sont nécessairement négligées dans tout pays où une carrière honorable, qui conduit aux richesses et aux dignités, est ouverte à tous ceux que leur penchant naturel porte vers l'étude : et telle était à Rome celle de la jurisprudence.

Quand les lois, comme dans l'Orient, sont liées à la religion, le droit de les interpréter devient un des plus forts appuis de la tyrannie sacerdotale. Dans la Grèce, elles avaient fait partie de ce code donné à chaque ville par son législateur : elles avaient été liées à l'esprit de la constitution et du gouvernement établi. Elles éprouvèrent peu de changements. Souvent les magistrats en abusèrent : les injustices particulières furent fréquentes ; mais les vices des lois n'y conduisirent jamais à un système de brigandage régulier et froidement calculé. A Rome, où longtemps on ne connut d'autre autorité que la tradition des coutumes ; où les juges déclaraient, chaque année, d'après quels principes ils décideraient les contestations pendant la durée de leur magistrature ; où les premières lois écrites furent une compilation des lois grecques, rédigée par des décemvirs plus occupés de conserver leur pouvoir que de l'honorer en présentant une bonne législation ; à Rome, où, depuis cette époque, des lois dictées tour à tour par le parti du sénat et par celui du peuple, se succédaient avec rapidité, étaient sans cesse détruites ou confirmées, adoucies ou aggravées par des dispositions nouvelles ; bientôt leur multiplicité, leur complication, leur obscurité, suite nécessaire du changement de la langue, firent une science à part de l'étude et de l'intelligence de ces lois. Le sénat, profitant du respect du peuple pour les anciennes institutions, sentit bientôt que le privilège d'interpréter les lois devenait presque équivalent au droit d'en faire de nouvelles ; et il se remplit de jurisconsultes. Leur puissance survécut à celle du sénat même ; elle s'accrut sous les empereurs ; parce qu'elle est d'autant plus grande, que la législation est plus bizarre et plus incertaine.

La jurisprudence est donc la seule science nouvelle que nous devions aux Romains. Nous en tracerons l'histoire, qui se lie à celle des progrès que la science de la législation a faits chez les modernes, et surtout à celle des obstacles qu'elle y a rencontrés. 
Nous montrerons comment le respect pour le droit positif des Romains a contribué à conserver quelques idées du droit naturel des hommes, ou empêché ensuite ces idées de s'agrandir et de s'étendre ; comment nous avons dû au droit romain un petit nombre de vérités utiles, et beaucoup plus de préjugés tyranniques.

[La douceur des lois pénales, sous la république, mérite de fixer nos regards. Elles avaient, en quelque sorte, rendu sacré le sang d'un citoyen romain. La peine de mort ne pouvait être portée contre lui, sans cet appareil d'un pouvoir extraordinaire, qui annonçait les calamités publiques et les dangers de la patrie. Le peuple entier pouvait être réclamé pour juge, entre un seul homme et la république. On avait senti que cette douceur est, chez un peuple libre, le seul moyen d'empêcher les dissensions politiques de dégénérer en massacres sanguinaires ; on avait voulu corriger, par l'humanité des lois, la férocité des mœurs d'un peuple qui, même dans ses jeux, prodiguait le sang de ses esclaves : aussi, en s'arrêtant au temps des Gracques, jamais, dans aucun pays, des orages si violents et si répétés ne coûtèrent moins de sang, ne produisirent moins de crimes.]

[Il ne nous est resté aucun ouvrage des Romains sur la politique. Celui de Cicéron sur les lois n'était vraisemblablement qu'un extrait embelli des livres des Grecs.

Ce n'était pas au milieu des convulsions de la liberté expirante, que la science sociale aurait pu se naturaliser et se perfectionner. Sous le despotisme des Césars, l'étude n'en eût paru qu'une conspiration contre leur pouvoir. Rien enfin ne prouve mieux combien elle fut toujours inconnue chez les Romains, que d'y voir l'exemple, unique jusqu'ici dans l'histoire, d'une succession non interrompue, depuis Nerva jusqu'à Marc-Aurèle, de cinq empereurs qui réunissaient les vertus, les talents, les lumières, l'amour de la gloire, le zèle du bien publie, sans qu'il soit émané d'eux une seule institution qui ait marqué le désir de mettre des bornes au despotisme ou de prévenir les révolutions, et de resserrer par de nouveaux liens les parties de cette masse immense, dont tout présageait la dissolution prochaine.]

La réunion de tant de peuples sous une même domination ; l'étendue des deux langues qui se partageaient l'empire, et qui toutes deux 
étaient familières à presque tous les hommes instruits ; ces deux causes, agissant de concert, devaient contribuer sans doute à répandre les lumières sur un plus grand espace avec plus d'égalité. Leur effet naturel devait être encore d'affaiblir peu à peu les différences qui séparaient les sectes philosophiques, de les réunir en une seule, qui choisirait dans chacune, les opinions les plus conformes à la raison, celles qu'un examen réfléchi avait le plus confirmées. C'était même àce point que la raison devait amener. les philosophes, lorsque l'effet du temps sur l'enthousiasme sectaire permettrait de n'écouter qu'elle. Aussi trouve-t-on déjà, dans Sénèque, quelques traces de cette philosophie : elle ne fut même jamais étrangère à la secte académique, qui parut se confondre presque entièrement avec elle ; et les derniers disciples de Platon furent les fondateurs de l'éclectisme.

Presque toutes les religions de l'empire avaient été nationales. Mais toutes aussi avaient de grands traits de ressemblance, et, en quelque sorte, un air de famille. Point de dogmes métaphysiques, beaucoup de cérémonies bizarres qui avaient un sens ignoré du peuple, et souvent même des prêtres ; une mythologie absurde, où la multitude ne voyait que l'histoire merveilleuse de ses dieux; où les hommes plus instruits soupçonnaient l'exposition allégorique de dogmes plus relevés : des sacrifices sanglants, des idoles qui représentaient les dieux, et dont quelques-unes, consacrées par le temps, avaient une vertu céleste ; des pontifes dévoués au culte de chaque divinité, sans former un corps politique, sans même être réunis dans une communion religieuse ; des oracles attachés à certains temples, à certaines statues ; enfin des mystères, que leurs hiérophantes ne communiquaient qu'en imposant la loi d'un inviolable secret. Tels étaient ces traits de ressemblance.

Il faut y ajouter encore que les prêtres, arbitres de la conscience religieuse, n'avaient jamais osé prétendre à l'être de la conscience morale ; qu'ils dirigeaient la pratique du culte, et non les actions de la vie privée. Ils vendaient à la politique des oracles ou des augures; ils pouvaient précipiter les peuples dans des guerres, leur dicter des crimes ; mais ils n'exerçaient aucune influence, ni sur le gouvernement, ni sur les lois.

Quand les peuples, sujets d'un même empire, eurent des communications habituelles, et que les lumières eurent fait partout des progrès 
presque égaux, les hommes instruits s'aperçurent bientôt que tous ces cultes étaient celui d'un dieu unique, dont les divinités si multipliées, objets immédiats de l'adoration populaire, n'étaient que les modifications ou les ministres.

Cependant, chez les Gaulois, et dans quelques cantons de l'Orient, les Romains avaient trouvé des religions d'un autre genre. Là, les prêtres étaient les juges de la morale : la vertu consistait dans l'obéissance à la volonté d'un dieu, dont ils se disaient les seuls interprètes. Leur empire s'étendait sur l'homme tout entier, le temple se confondait avec la patrie ; on était adorateur de Jéhova et d'Oesus, avant d'être citoyen ou sujet de l'empire ; et les prêtres décidaient à quelles lois humaines leur dieu permettait d'obéir.

Ces religions devaient blesser l'orgueil des maîtres du monde. Celle des Gaulois était trop puissante, pour qu'ils ne se hâtassent point de la détruire. La nation juive fut même dispersée ; mais la vigilance du gouvernement, ou dédaigna, ou ne put atteindre les sectes obscures, qui se formèrent en secret du débris de ces cultes antiques.

Un des bienfaits de la propagation de la philosophie grecque avait été de détruire la croyance des divinités populaires dans toutes les classes où l'on recevait une instruction un peu étendue. Un théisme vague, ou le pur mécanisme d'Epicure, était, même dès le temps de Cicéron, la doctrine commune de quiconque avait cultivé son esprit, de tous ceux qui dirigeaient les affaires publiques. Cette classe d'hommes s'attacha nécessairement à l'ancienne religion, mais en cherchant à l'épurer, parce que la multiplicité de ces dieux de tout pays avait lassé même la crédulité du peuple. On vit alors les philosophes former des systèmes sur les génies intermédiaires, se soumettre à des préparations, à des pratiques, à un régime religieux, pour se rendre plus dignes d'approcher de ces intelligences supérieures à l'homme : et ce fut dans les Dialogues de Platon qu'ils cherchèrent les fondements de cette doctrine.

Le peuple des nations conquises, les infortunés, les hommes d'une imagination ardente et faible, durent s'attacher de préférence aux religions sacerdotales, parce que l'intérêt des prêtres dominateurs leur inspirait précisément cette doctrine d'égalité dans l'esclavage, de re- 
noncement aux biens temporels, de récompenses célestes réservées à l'aveugle soumission, aux souffrances, aux humiliations volontaires ou supportées avec patience ; doctrine si séduisante pour l'humanité opprimée! Mais ils avaient besoin de relever, par quelques subtilités philosophiques, leur mythologie grossière ; et c'est encore à Platon qu'ils eurent recours. Ses Dialogues furent l'arsenal où les deux partis allèrent forger leurs armes théologiques. Nous verrons, dans la suite, Aristote obtenir un semblable honneur, et se trouver à la fois le maître des théologiens et le chef des athées.

Vingt sectes égyptiennes, judaïques, s'accordant pour attaquer la religion de l'empire, mais se combattant entre elles avec une égale fureur, finirent par se perdre dans la religion de Jésus. On parvint à composer de leurs débris une histoire, une croyance, des cérémonies, et une morale, auxquelles se réunit peu à peu la masse de ces illuminés.

[Tous croyaient à un christ, à un messie envoyé de Dieu, pour réparer le genre humain. C'est le dogme fondamental de toute secte qui veut s'élever sur les débris des sectes anciennes. On se disputait sur le temps, sur le lieu de son apparition, sur son nom mortel : mais celui d'un prophète, qui avait, dit-on, paru en Palestine, sous Tibère, éclipsa tous les autres; et les nouveaux fanatiques se rallièrent sous l'étendard du fils de Marie.]

Plus l'empire s'affaiblissait, plus cette religion chrétienne faisait des progrès rapides. L'avilissement des anciens conquérants du monde s'étendait sur les dieux, qui, après avoir présidé à leurs victoires, n'étaient plus que les témoins impuissants de leurs défaites. L'esprit de la nouvelle secte convenait mieux à des temps de décadence et de malheur. Ses chefs, malgré leurs fourberies et leurs vices, étaient des enthousiastes prêts à périr pour leur doctrine. Le zèle religieux des philosophes et des grands n'était qu'une dévotion politique ; et toute religion qu'on se permet de défendre comme une croyance qu'il est utile de laisser au peuple, ne peut plus espérer qu'une agonie plus ou moins prolongée. Bientôt le christianisme devient un parti puissant ; il se mêle aux querelles des Césars ; il met Constantin sur le trône, et s'y place lui-même, à côté de ses faibles successeurs. 
En vain un de ces hommes extraordinaires, que le hasard élève quelquefois à la souveraine puissance, Julien voulut délivrer l'empire de ce fléau, qui devait en accélérer la chute : ses vertus, son indulgente humanité, la simplicité de ses mœurs, l'élévation de son âme et de son caractère, ses talents, son courage, son génie militaire, l'éclat de ses victoires, tout semblait lui promettre un succès certain. On ne pouvait lui reprocher que de montrer pour une religion, devenue ridicule, un attachement indigne de lui, s'il était sincère ; maladroit par son exagération, s'il n'était que politique ; mais il périt au milieu de sa gloire, après un règne de deux années. Le colosse de l'empire romain ne trouva plus de bras assez puissants pour le soutenir ; et la mort de Julien brisa la seule digue qui pût encore s'opposer au torrent des superstitions nouvelles, comme aux inondations des Barbares.

Le mépris des sciences humaines était un des premiers caractères du christianisme. Il avait à se venger des outrages de la philosophie ; il craignait cet esprit d'examen et de doute, cette confiance en sa propre raison, fléau de toutes les croyances religieuses. La lumière des sciences naturelles lui était même odieuse et suspecte ; car elles sont très dangereuses pour le succès des miracles ; et il n'y a point de religion qui ne force ses sectateurs à dévorer quelques absurdités physiques. Ainsi le triomphe du christianisme fut le signal de l'entière décadence et des sciences et de la philosophie.

Les sciences auraient pu se préserver de cette décadence, si l'art de l'imprimerie eût été connu; mais les manuscrits d'un même livre étaient en petit nombre : il fallait, pour se procurer les ouvrages qui formaient le corps entier d'une science, des soins, souvent des voyages et des dépenses, auxquelles les hommes riches pouvaient seuls atteindre. Il était facile au parti dominant de faire disparaître les livres qui choquaient ses préjugés ou démasquaient ses impostures. Une invasion des Barbares pouvait, en un seul jour, priver pour jamais un pays entier des moyens de s'instruire. La destruction d'un seul manuscrit était souvent, pour toute un contrée, une perte irréparable. On ne copiait d'ailleurs que les ouvrages recommandés par le nom de leurs auteurs. Toutes ces recherches, qui ne peuvent acquérir d'importance que par leur réunion ; ces observations isolées, ces perfectionnements de détail qui 
servent à maintenir les sciences au même niveau, qui en préparent les progrès ; tous ces matériaux que le temps amasse, et qui attendent le génie, restaient condamnés à une éternelle obscurité. Ce concert des savants, cette réunion de leurs forces, si utile, si nécessaire même à certaines époques, n'existaient pas : il fallait que le même individu pût commencer et achever une découverte ; et il était obligé de combattre seul toutes les résistances que la nature oppose à nos efforts. Les ouvrages qui facilitent l'étude des sciences, qui en éclaircissent les difficultés, qui en présentent les vérités sous des formes plus commodes et plus simples; ces détails des observations, ces développements qui souvent éclairent sur les erreurs des résultats, et où le lecteur saisit ce que l'auteur n'a point lui-même aperçu ; ces ouvrages n'auraient pu trouver ni copistes, ni lecteurs.

Il était donc impossible que, déjà parvenues à une étendue qui en rendait difficiles et les progrès, et même l'étude approfondie, les sciences pussent se soutenir d'elles-mêmes, et résister à la pente qui les entraînait rapidement vers leur décadence. Ainsi, l'on ne doit pas s'étonner que le christianisme, qui, après l'invention de l'imprimerie, n'a point été assez puissant pour les empêcher de reparaître avec éclat, l'ait été alors assez pour en consommer la ruine.

Si l'on en excepte l'art dramatique, qui ne fleurit que dans Athènes, et qui dut tomber avec elle, et l'éloquence, qui ne respire que dans un air libre, la langue et la littérature des Grecs conservèrent longtemps leur splendeur. Lucien et Plutarque n'auraient point déparé le siècle d'Alexandre. Rome, il est vrai, s'éleva au niveau de la Grèce, dans la poésie, dans l'éloquence, dans l'histoire, dans l'art de traiter avec dignité, avec élégance, avec agrément, les sujets arides de la philosophie et des sciences. La Grèce même n'a point de poète qui donne, autant que Virgile, l'idée de la perfection ; elle n'a aucun historien qui puisse s'égaler à Tacite. Mais ce moment d'éclat fut suivi d'une prompte décadence. Dès le temps de Lucien, Rome n'avait plus que des écrivains presque barbares. Chrysostome parle encore la langue de Démosthène. On ne reconnaît plus celle de Cicéron ou de Tite-Live, ni dans Augustin, ni même dans Jérôme, qui n'a point pour excuse l'influence de la barbarie africaine. 
C'est que jamais à Rome l'étude des lettres, l'amour des arts, ne fut un goût vraiment populaire ; c'est que la perfection passagère de la langue y fut l'ouvrage, non du génie national, mais de quelques hommes que la Grèce avait formés ; c'est que le territoire de Rome fut toujours pour les lettres un sol étranger, où une culture assidue avait pu les naturaliser, mais où elles devaient dégénérer dès qu'elles resteraient abandonnées à elles-mêmes.

L'importance dont fut longtemps, à Rome et dans la Grèce, le talent de la tribune et celui du barreau, y multiplia la classe des rhéteurs. Leurs travaux ont contribué au progrès de l'art, dont ils ont développé les principes et les finesses. Mais ils en enseignaient un autre trop négligé par les modernes, et qu'il faudrait transporter aujourd'hui des ouvrages prononcés aux ouvrages imprimés. C'est l'art de préparer avec facilité, et en peu de temps, des discours que la disposition de leurs parties, la méthode qui y règne, les ornements qu'on sait y répandre, rendent du moins supportables ; c'est celui de pouvoir parler presque sur-le-champ, sans fatiguer ses auditeurs du désordre de ses idées, de la diffusion de son style, sans les révolter par d'extravagantes déclamations, par des non-sens grossiers, par de bizarres disparates. Combien cet art ne serait-il pas utile dans tous les pays où les fonctions d'une place, un devoir publie, un intérêt particulier, peuvent obliger à parler, à écrire, sans avoir le temps de méditer ses discours ou ses ouvrages! Son histoire mérite d'autant plus de nous occuper, que les modernes, à qui cependant il serait souvent nécessaire, semblent n'en avoir connu que le côté ridicule.

Dès les commencements de l'époque dont j'achève ici le tableau, les livres s'étaient assez multipliés ; la distance des temps avait répandu d'assez grandes obscurités sur les ouvrages des premiers écrivains de la Grèce, pour que cette étude des livres et des opinions, connue sous le nom d'érudition, formât une partie importante des travaux de l'esprit ; et la bibliothèque d'Alexandrie se peupla de grammairiens et de critiques.

On observe, dans ce qui nous reste d'eux, un penchant à mesurer leur admiration ou leur confiance, sur l'ancienneté d'un livre, sur la difficulté de l'entendre ou de le trouver ; une disposition à juger les opinions, non en elles-mêmes, mais sur le nom de leurs auteurs ; à 
croire d'après l'autorité, plutôt que d'après la raison ; enfin, l'idée si fausse et si funeste de la décadence du genre humain, et de la supériorité des temps antiques. L'importance que les hommes attachent à ce qui fait l'objet de leurs occupations, à ce qui leur a coûté des efforts, est à la fois l'explication et l'excuse de ces erreurs, que les érudits de tous les pays et de tous les temps ont plus ou moins partagées.

On peut reprocher aux érudits grecs et romains, et même à leurs savants et à leurs philosophes, d'avoir manqué absolument de cet esprit de doute, qui soumet à l'examen sévère de la raison, et les faits et leurs preuves. En parcourant, dans leurs écrits, l'histoire des événements ou des mœurs, celle des productions et des phénomènes de la nature, celle des produits et des procédés des arts, on s'étonne de les voir raconter avec tranquillité les absurdités les plus palpables, les prodiges les plus révoltants. Un on dit, on rapporte, placé au commencement de la phrase, leur paraît suffire pour se mettre à l'abri du ridicule d'une crédulité puérile. C'est surtout au malheur d'ignorer encore l'art de l'imprimerie qu'on doit attribuer cette indifférence, qui a corrompu chez eux l'étude de l'histoire, et qui s'est opposée à leurs progrès dans la connaissance de la nature. La certitude d'avoir rassemblé sur chaque fait toutes les autorités qui peuvent le confirmer ou le détruire ; la facilité de comparer les divers témoignages, de s'éclairer par les discussions que fait naître leur différence ; tous ces moyens de s'assurer de la vérité ne peuvent exister que lorsqu'il est possible d'avoir un grand nombre de livres, d'en multiplier indéfiniment les copies, de ne pas craindre de leur donner trop d'étendue.

Comment les relations de voyageurs, des descriptions, dont souvent il n'existait qu'une copie, qui n'étaient point soumises à la censure publique, auraient-elles pu acquérir cette autorité, dont la base première est l'avantage de n'avoir pas été contredites, et d'avoir pu l'être ? Ainsi, l'on rapportait tout également, parce qu'il était difficile de choisir avec quelque certitude ce qui méritait d'être rapporté. D'ailleurs, nous ne sommes pas en droit de nous étonner de cette facilité à présenter avec une même confiance, d'après des autorités égales, et les faits les plus naturels et les faits les plus miraculeux. Cette erreur est encore enseignée dans nos écoles, comme un principe de philosophie, tandis qu'une incrédulité exagérée dans le sens contraire nous porte à rejeter sans examen tout ce qui nous paraît hors de la nature; et la 
science qui peut seule nous apprendre à trouver, entre ces deux extrêmes, le point où la raison nous prescrit de nous arrêter, n'a commencé à exister que de nos jours. 
CONDORCET,

Esquisse d'un tableau historique des progrès de l'esprit humain

(1793-1794).

\section{Sixième époque}

\section{Décadence des lumières, jusqu'à leur restauration, vers le temps des croisades.}

Dans cette époque désastreuse, nous verrons l'esprit humain descendre rapidement de la hauteur où il s'était élevé, et l'ignorance traîner après elle, ici la férocité, ailleurs une cruauté raffinée, partout la corruption et la perfidie. A peine quelques éclairs de talents, quelques traits de grandeur d'âme ou dé bonté, peuvent-ils percer à travers cette nuit profonde. Des rêveries théologiques, des impostures superstitieuses, sont le seul génie des hommes : l'intolérance religieuse est leur seule morale ; et l'Europe, comprimée entre la tyrannie sacerdotale et le despotisme militaire, attend dans le sang et dans les larmes le moment où de nouvelles lumières lui permettront de renaître à la liberté, à l'humanité et aux vertus.

Ici, nous sommes obligés de partager le tableau en deux parties distinctes : la première embrassera l'Occident, où la décadence fut plus rapide et plus absolue, mais où le jour de la raison devait reparaître pour ne s'éteindre jamais ; et la seconde, l'Orient, pour qui cette déca- 
dence fut plus lente, longtemps moins entière, mais qui ne voit pas encore le moment où la raison pourra l'éclairer et briser ses chaînes.

À peine la piété chrétienne eut-elle abattu l'autel de la Victoire. que l'Occident devint la proie des Barbares. Ils embrassèrent la religion nouvelle, mais ils ne prirent point la langue des vaincus : les prêtres seuls la conservèrent ; et grâce à leur ignorance, à leur mépris pour les lettres humaines, on vit disparaître ce qu'on aurait pu espérer de la lecture de livres latins, puisque ces livres ne pouvaient plus être lus que par eux.

On connaît assez l'ignorance et les mœurs barbares des vainqueurs : cependant, c'est du milieu de cette férocité stupide que sortit la destruction de l'esclavage domestique, qui avait déshonoré les beaux jours de la Grèce, savante et libre.

Les serfs de la glèbe cultivaient les terres des vainqueurs. Cette classe opprimée fournissait pour leurs maisons des domestiques, dont la dépendance suffisait à leur orgueil et à leurs caprices. Ils cherchaient donc dans la guerre, non des esclaves, mais des terres et des colons.

D'ailleurs, les esclaves qu'ils trouvaient dans les contrées envahies par eux étaient en grande partie, ou des prisonniers faits sur quelqu'une des tribus de la nation victorieuse, ou les enfants de ces prisonniers. Un grand nombre, au moment de la conquête, avaient fui, ou s'étaient joints à l'armée des conquérants.

Enfin, les principes de fraternité générale, qui faisaient partie de la morale chrétienne, condamnaient l'esclavage ; et les prêtres, n'ayant aucun intérêt politique à contredire sur ce point des maximes qui honoraient leur cause, aidèrent par leurs discours à une destruction que les événements et les mœurs devaient nécessairement amener.

[Ce changement a été le germe d'une révolution dans les destinées de l'espèce humaine ; elle lui doit d'avoir pu connaître la véritable liberté. Mais ce changement n'eut d'abord qu'une influence presque insensible sur le sort des individus. On se ferait une fausse idée de la servitude chez les anciens, si on la comparait à celle de nos noirs. Les 
Spartiates, les grands de Rome, les satrapes de l'Orient, furent à la vérité des maîtres barbares. L'avarice déployait toute sa cruauté dans les travaux des mines ; mais, presque partout, l'intérêt avait adouci l'esclavage dans les familles particulières. L'impunité des violences commises contre le serf de la glèbe était plus grande encore, puisque la loi elle-même en avait fixé le prix. La dépendance était presque égale, sans être compensée par autant de soins et de secours. L'humiliation était moins continue; mais l'orgueil avait plus d'arrogance. L'esclave était un homme condamné par le hasard à un état auquel le sort de la guerre pouvait un jour exposer son maître. Le serf était un individu d'une classe inférieure et dégradée.]

[C'est donc principalement dans ces conséquences éloignées, que nous devons considérer cette destruction de l'esclavage domestique.]

Toutes ces nations barbares avaient à peu près la même constitution ; un chef commun appelé roi, qui, avec un conseil, prononçait des jugements et donnait les décisions qu'il eût été dangereux de retarder ; une assemblée de chefs particuliers qui était consultée sur toutes les résolutions un peu importantes; enfin, une assemblée du peuple, où se prenaient les délibérations qui intéressaient le peuple entier. Les différences les plus essentielles étaient dans le plus où moins d'autorité de ces trois pouvoirs, qui n'étaient pas distingués par la nature de leurs fonctions, mais par celle des affaires, et surtout de l'intérêt que la masse des citoyens y avait attaché.

Chez ces peuples agriculteurs, et surtout chez ceux qui avaient déjà formé un premier établissement sur un territoire étranger, ces constitutions avaient pris une forme plus régulière, plus solide, que chez les peuples pasteurs. D'ailleurs, la nation y était dispersée et non réunie dans des camps plus ou moins nombreux. Ainsi, le roi n'eut point auprès de lui une armée toujours rassemblée ; et le despotisme ne put y suivre presque immédiatement la conquête, comme dans les révolutions de l'Asie.

La nation victorieuse ne fut donc point asservie. En même temps, ces conquérants conservèrent des villes, mais sans les habiter euxmêmes. N'étant point contenues par une force armée, puisqu'il n'en 
existait point de permanente, ces villes acquirent une sorte de puissance ; et ce fut un point d'appui pour la liberté de la nation vaincue.

L'Italie fut souvent envahie par les Barbares ; mais ils ne purent y former d'établissements durables, parce que ses richesses excitaient sans cesse l'avarice de nouveaux vainqueurs, et que les Grecs conservèrent longtemps l'espérance de la réunir à leur empire. Jamais elle ne fut asservie par aucun peuple, ni tout entière, ni d'une manière durable. La langue latine, qui était la langue unique du peuple, s'y corrompit plus lentement ; l'ignorance n'y fut pas aussi complète, ni la superstition aussi stupide que dans le reste de l'Occident.

Rome, qui ne reconnut de maîtres que pour en changer, conservait une sorte d'indépendance. Elle était la résidence du chef de la religion. Ainsi, tandis que, dans l'Orient, soumis à un seul prince, le clergé, tantôt gouvernant les empereurs, tantôt conspirant contre eux, soutenait le despotisme, même en combattant le despote, et aimait mieux se servir de tout le pouvoir d'un maître absolu que de lui en disputer une partie, on vit, au contraire, dans l'Occident, les prêtres, réunis sous un chef commun, élever une puissance rivale de celle des rois, et former dans ces États divisés une sorte de monarchie unique et indépendante.

[Nous montrerons cette ville dominatrice essayant sur l'univers les chaînes d'une nouvelle tyrannie; ses pontifes subjuguant l'ignorante crédulité par des actes grossièrement forgés ; mêlant la religion à toutes les transactions de la vie civile, pour s'en jouer au gré de leur avarice ou de leur orgueil ; punissant d'un anathème terrible, pour la foi des peuples, la moindre opposition à leurs lois, la moindre résistance à leurs prétentions insensées; ayant dans tous les États une armée de moines, toujours prêts à exalter par leurs impostures les terreurs superstitieuses, afin de soulever plus puissamment le fanatisme ; privant les nations de leur culte et des cérémonies sur lesquelles s'appuyaient leurs espérances religieuses, pour les exciter à la guerre civile ; troublant tout pour tout dominer ; ordonnant au nom de Dieu la trahison et le parjure, l'assassinat et le parricide ; faisant tour à tour, des rois et des guerriers, les instruments et les victimes de leurs vengeances; disposant de la force, mais ne la possédant jamais ; terribles à leurs ennemis, mais tremblants devant leurs propres défenseurs; toutpuissants aux extrémités de l'Europe, mais impunément outragés au 
pied même de leurs autels ; ayant bien trouvé dans le ciel le point d'appui du levier qui devait remuer le monde, mais n'ayant pas su trouver sur la terre de régulateur qui pût, à leur gré, en diriger et en conserver l'action ; élevant enfin, mais sur des pieds d'argile, un colosse qui, après avoir opprimé l'Europe, devait encore la fatiguer longtemps du poids de ses débris.]

La conquête avait soumis l'Occident à une anarchie tumultueuse, dans laquelle le peuple gémissait sous la triple tyrannie des rois, des chefs guerriers et des prêtres: mais cette anarchie portait dans son sein des germes de liberté.

On doit comprendre dans cette portion de l'Europe, les pays où les Romains n'avaient point pénétré. Entraînés dans le mouvement général, conquérants et conquis tour à tour, ayant la même origine, les mêmes mœurs que les conquérants de l'empire, ces peuples se confondirent avec eux dans une masse commune. Leur état politique dut éprouver les mêmes changements et suivre une marche semblable.

Nous tracerons le tableau des révolutions de cette anarchie féodale, nom qui sert à la caractériser.

La législation y fut incohérente et barbare. Si l'on y trouve souvent des lois douces, cette humanité apparente n'était qu'une dangereuse impunité. On y observe cependant quelques institutions précieuses ; elles ne consacrent, à la vérité, que les droits des classes opprimantes, elles étaient par là un outrage de plus à ceux des hommes; mais du moins elles conservaient quelque faible idée de nos droits, et devaient un jour servir de guide pour les reconnaître et les rétablir.

[Cette législation présentait deux usages singuliers qui caractérisent et l'enfance des nations et l'ignorance des siècles grossiers.]

[Un coupable pouvait se racheter de la peine pour une somme d'argent fixée par la loi, qui appréciait la vie des hommes suivant leur dignité ou leur naissance. Les crimes n'étaient pas regardés comme une atteinte à la sûreté, aux droits des citoyens, que la crainte du supplice devait prévenir, mais comme un outrage fait à un individu, que luimême ou sa famille avaient droit de venger, et dont la loi leur offrait 
une réparation plus utile. On avait si peu d'idée des preuves par lesquelles la réalité d'un fait peut être établie, qu'on trouva plus simple de demander au ciel un miracle toutes les fois qu'il s'agissait de distinguer le crime d'avec l'innocence ; et le succès d'une épreuve superstitieuse ou le sort d'un combat furent regardés comme les moyens les plus sûrs de découvrir et de reconnaître la vérité.]

[Chez des hommes qui confondaient l'indépendance et la liberté, les querelles entre ceux qui dominaient sur une portion même très petite du territoire, devaient dégénérer en guerres privées ; et ces guerres se faisant de canton à canton, de village à village, livraient habituellement la surface entière de chaque pays à toutes ces horreurs, qui du moins ne sont que passagères dans les grandes invasions, et qui, dans les guerres générales, ne désolent que les frontières.]

[Toutes les fois que la tyrannie s'efforce de soumettre la masse d'un peuple à la volonté d'une de ses portions, elle compte parmi ses moyens les préjugés et l'ignorance de ses victimes; elle cherche à compenser par la réunion, par l'activité d'une force moindre, cette supériorité de force réelle qui semble ne pouvoir cesser d'appartenir au plus grand nombre. Mais le dernier terme de ses espérances, celui auquel elle peut rarement atteindre, c'est d'établir entre les maîtres et les esclaves une différence réelle, qui en quelque sorte rende la nature elle-même complice de l'inégalité politique.]

[Tel fut, dans les temps reculés, l'art des prêtres orientaux, lorsqu'on les voyait, à la fois, rois, pontifes, juges, astronomes, arpenteurs, artistes et médecins. Mais ce qu'ils durent à la possession exclusive des facultés intellectuelles, les tyrans grossiers de nos faibles ancêtres l'obtinrent par leurs institutions et par leurs habitudes guerrières. Couverts d'armes impénétrables, ne combattant que sur des chevaux invulnérables, comme eux, ne pouvant acquérir la force et l'adresse nécessaires pour dresser et conduire leurs chevaux, pour supporter et manier leurs armes, que par un long et pénible apprentissage, ils pouvaient opprimer avec impunité, et tuer sans péril l'homme du peuple, qui n'était pas assez riche pour se procurer ces armures coûteuses, et dont la jeunesse, consumée par des travaux utiles, n'avait pu être consacrée aux exercices militaires.] 
[Ainsi la tyrannie du petit nombre avait acquis, par l'usage de cette manière de combattre, une supériorité réelle de force, qui devait prévenir toute idée de résistance, et rendre longtemps inutiles les efforts mêmes du désespoir : ainsi, l'égalité de la nature avait disparu devant cette inégalité factice des forces physiques.]

La morale, enseignée par les prêtres seuls, renfermait ces principes universels qu'aucune secte n'a méconnus ; mais elle créait une foule de devoirs purement religieux, de péchés imaginaires. Ces devoirs étaient plus fortement recommandés que ceux de la nature; et des actions indifférentes, légitimes, souvent même vertueuses, étaient plus sévèrement reprochées et punies que des crimes réels. Cependant, un moment de repentir, consacré par l'absolution d'un prêtre, ouvrait le ciel aux scélérats ; des dons qui flattaient l'avarice, et quelques pratiques qui flattaient l'orgueil de l'Église, suffisaient pour expier une vie chargée de crimes. On alla même jusqu'à former un tarif de ces absolutions. On comprenait avec soin parmi ces péchés, depuis les faiblesses les plus innocentes de l'amour, depuis les simples désirs, jusqu'aux raffinements et aux excès de la débauche la plus crapuleuse. On savait que presque personne ne pouvait échapper à cette censure ; et c'était une des branches les pins productives du commerce sacerdotal. On imagina jusqu'à nu enfer d'une durée limitée, que les prêtres avaient le pouvoir d'abréger, dont ils pouvaient même dispenser ; et ils faisaient acheter cette grâce, d'abord aux vivants, ensuite aux parents, aux amis des morts. Ils vendaient des arpents dans le ciel pour un nombre égal d'arpents terrestres ; et ils avaient la modestie de ne pas exiger de retour.

Les moeurs de ces temps malheureux furent dignes d'un système si profondément corrupteur.

Les progrès de ce même système ; des moines tantôt inventant d'anciens miracles, tantôt en fabriquant de nouveaux, et nourrissant de fables et de prodiges l'ignorante stupidité du peuple, qu'ils trompaient pour le dépouiller; des docteurs employant tout ce qu'ils avaient d'imagination, pour enrichir leur croyance de quelque absurdité nouvelle, et renchérir, en quelque sorte, sur celles qui leur avaient été transmises ; des prêtres forçant les princes à livrer aux flammes, et les hommes qui osaient, ou douter d'un seul de leurs dogmes, ou entrevoir 
leurs impostures, ou s'indigner de leurs crimes, et ceux qui s'écartaient un moment d'une aveugle obéissance ; enfin, jusqu'aux théologiens eux-mêmes, quand ils se permettaient de rêver autrement que des chefs plus accrédités dans l'Église... Tels sont, dans cette époque, les seuls traits que les moeurs de la partie occidentale de l'Europe puissent fournir au tableau de l'espèce humaine.

Dans l'Orient, réuni sous un seul despote, nous verrons une décadence plus lente suivre l'affaiblissement graduel de l'empire ; l'ignorance et la corruption de chaque siècle l'emporter de quelques degrés sur l'ignorance et la corruption du siècle précédent ; tandis que les richesses diminuaient, que les frontières se rapprochaient de la capitale, que les révolutions étaient plus fréquentes, que la tyrannie était plus lâche et plus cruelle.

En suivant l'histoire de cet empire, en lisant les livres que chaque âge a produits, cette correspondance frappera les yeux les moins exercés et les moins attentifs.

Dans l'Orient, le peuple se livrait davantage aux querelles théologiques : elles y occupent une place plus grande dans l'histoire, $\mathrm{y}$ influent davantage sur les événements politiques ; les rêveries s'y montrent avec une subtilité que l'Occident jaloux ne pouvait encore atteindre. L'intolérance religieuse y est aussi oppressive, mais moins féroce.

Cependant, les ouvrages de Photius annoncent que le goût des études raisonnables n'était point éteint. Quelques empereurs, des princes, des princesses même, ne se bornèrent point à l'honneur de briller dans les disputes théologiques, et daignèrent cultiver les lettres humaines.

La législation romaine n'y fut altérée que lentement, par ce mélange de mauvaises lois que l'avidité et la tyrannie dictaient aux empereurs, ou que la superstition arrachait à leur faiblesse. La langue grecque perdit de sa pureté, de son caractère ; mais elle conserva sa richesse, ses formes, sa grammaire ; et les habitants de Constantinople pouvaient encore lire Homère et Sophocle, Thucydide et Platon. Anthémius exposait la construction des miroirs d'Archimède, que Proclus employait avec succès à la défense de la capitale. À la chute de l'empire, Constantinople renfermait quelques hommes qui se réfugièrent 
en Italie, et dont les connaissances y furent utiles au progrès des lumières. Ainsi, à cette époque même, l'Orient n'avait pas atteint le dernier terme de la barbarie : mais aussi rien n'y présentait l'espoir d'une restauration. Il devint la proie des Barbares ; ces faibles restes disparurent : et l'ancien génie de la Grèce y attend encore un libérateur.

Aux extrémités de l'Asie, et sur les confins de l'Afrique, existait un peuple qui, par sa position et son courage, avait échappé aux conquêtes des Perses, d'Alexandre et des Romains. De ces nombreuses tribus, les unes devaient leur subsistance à l'agriculture ; les autres avaient conservé la vie pastorale : toutes se livraient au commerce, et quelques-unes au brigandage. Réunies par une même origine, par un même langage, par quelques habitudes religieuses, elles formaient une grande nation, dont cependant aucun lien politique n'unissait les portions diverses. Tout à coup s'éleva au milieu d'elles un homme doué d'un ardent enthousiasme et d'une politique profonde, né avec les talents d'un poète et ceux d'un guerrier. Il conçoit le hardi projet de réunir en un seul corps les tribus arabes, et il a le courage de l'exécuter. Pour donner un chef à une nation jusqu'alors indomptée, il commence par élever sur les débris de l'ancien culte une religion plus épurée. Législateur, prophète, pontife, juge, général d'armée, tous les moyens de subjuguer les hommes sont entre ses mains, et il sait les employer avec adresse, mais avec grandeur.

Il débite un ramas de fables qu'il dit avoir reçues du ciel ; mais il gagne des batailles. La prière et les plaisirs de l'amour partagent ses moments. Après avoir joui vingt ans d'un pouvoir sans bornes, dont il n'existe point d'autre exemple, il déclare que, s'il a commis une injustice, il est prêt à la réparer. Tout se tait : une seule femme ose réclamer une petite somme de monnaie. Il meurt, et l'enthousiasme qu'il a communiqué à son peuple va changer la face des trois parties du monde.

Les mœurs des Arabes avaient de l'élévation et de la douceur ; ils aimaient et cultivaient la poésie ; et lorsqu'ils régnèrent sur les plus belles contrées de l'Asie, lorsque le temps eut calmé la fièvre du fanatisme religieux, le goût des lettres et des sciences vint se mêler à leur zèle pour la propagation de la foi, et tempérer leur ardeur pour les conquêtes. 
Ils étudièrent Aristote, dont ils traduisirent les ouvrages. Ils cultivèrent l'astronomie, l'optique, toutes les parties de la médecine, et enrichirent ces sciences de quelques vérités nouvelles. On leur doit d'avoir généralisé l'usage de l'algèbre, borné chez les Grecs à une seule classe de questions. Si la recherche chimérique du secret de transformer les métaux, et d'un breuvage d'immortalité, souilla leurs travaux dans la chimie, ils furent les restaurateurs, ou plutôt les inventeurs de cette science, jusqu'alors confondue avec la pharmacie ou avec l'étude des procédés des arts. C'est chez eux que la chimie paraît, pour la première fois, comme analyse des corps dont elle fait connaître les éléments, comme théorie de leurs combinaisons, et des lois auxquelles ces combinaisons sont assujetties.

Les sciences y étaient libres, et les Arabes durent à cette liberté d'avoir pu ressusciter quelques étincelles du génie des Grecs ; mais ils étaient soumis à un despotisme consacré par la religion. Aussi, cette lumière ne brilla-t-elle quelques moments que pour faire place aux plus épaisses ténèbres ; et ces travaux des Arabes auraient été perdus pour le genre humain, s'ils n'avaient pas servi à préparer cette restauration plus durable, dont l'Occident va nous offrir le tableau.

[L'on vit donc, pour la seconde fois, le génie abandonner les peuples qu'il avait éclairés ; et c'est encore devant la tyrannie et la superstition qu'il est forcé de disparaître. Né dans la Grèce, à côté de la liberté, il n'a pu ni en arrêter la chute, ni défendre la raison contre les préjugés des peuples, déjà dégradés par l'esclavage. Né chez les Arabes, dans le sein du despotisme, et près du berceau d'une religion fanatique, il n'a été, comme le caractère généreux et brillant de ce peuple, qu'une exception passagère aux lois générales de la nature, qui condamnent à la bassesse et à l'ignorance les nations asservies et superstitieuses.]

[Ainsi, ce second exemple ne doit pas nous effrayer sur l'avenir ; mais seulement il avertit nos contemporains de ne rien négliger pour conserver, pour augmenter les lumières, s'ils veulent devenir ou demeurer libres ; et de maintenir leur liberté, s'ils ne veulent pas perdre les avantages que les lumières leur ont procurés.] 
Je joindrai à l'histoire des travaux des Arabes, celle de l'élévation rapide et de la chute précipitée de cette nation, qui, après avoir régné des bords de l'océan Atlantique aux rives de l'Indus, chassée par les Barbares de la plus grande partie de ses conquêtes, n'ayant conservé les autres que pour y présenter le spectacle hideux d'un peuple dégénéré jusqu'au dernier terme de la servitude, de la corruption, de la misère, occupe encore son ancienne patrie, y a conservé ses mœurs, son esprit, son caractère, et a su y reconquérir, y défendre son ancienne indépendance.

J'exposerai comment la religion de Mahomet, la plus simple dans ses dogmes, la moins absurde dans ses pratiques, la plus tolérante dans ses principes, semble condamner à un esclavage éternel, à une incurable stupidité, toute cette vaste portion de la terre où elle a étendu son empire ; tandis que nous allons voir briller le génie des sciences et de la liberté sous les superstitions les plus absurdes, au milieu de la plus barbare intolérance. La Chine nous offre le même phénomène, quoique les effets de ce poison abrutissant y aient été moins funestes. 
CONDORCET,

Esquisse d'un tableau historique des progrès de l'esprit humain

(1793-1794).

\section{Septième époque}

\section{Depuis les premiers progrès des sciences, lors de leur restauration dans l'Occident, jusqu'à l'invention de l'imprimerie.}

Plusieurs causes ont contribué à rendre, par degrés, à l'esprit humain cette énergie, que des chaînes si honteuses et si pesantes semblaient devoir comprimer pour toujours.

L'intolérance des prêtres, leurs efforts pour s'emparer des pouvoirs politiques, leur avidité scandaleuse, le désordre de leurs mœurs, rendu plus révoltant par leur hypocrisie, devaient soulever contre eux les âmes pures, les esprits sains, les caractères courageux. On était frappé de la contradiction de leurs dogmes, de leurs maximes, de leur conduite, avec ces mêmes évangiles, premier fondement de leur doctrine comme de leur morale, et dont ils n'avaient pu cacher entièrement la connaissance au peuple.

Il s'éleva donc contre eux des réclamations puissantes. Dans le midi de la France, des provinces entières se réunirent pour adopter une doctrine plus simple, un christianisme plus épuré, où l'homme, soumis 
à la divinité seule, jugerait d'après ses propres lumières, de ce qu'elle a daigné révéler dans les livres émanés d'elle.

Des armées fanatiques, dirigées par des chefs ambitieux, dévastèrent ces provinces. Les bourreaux, conduits par des légats et des prêtres, immolèrent ceux que les soldats avaient épargnés. On établit un tribunal (le moines, chargé d'envoyer au bûcher quiconque serait soupçonné d'écouter encore sa raison.

Cependant, ils ne purent empêcher cet esprit de liberté et d'examen de faire sourdement des progrès. Réprimé dans le pays où il osait se montrer, où plus d'une fois l'intolérante hypocrisie alluma des guerres sanglantes, il se reproduisait, il se répandait en secret dans une autre contrée. On le retrouve à toutes les époques, jusqu'au moment où, secondé par l'invention de l'imprimerie, il fut assez puissant pour délivrer une partie de l'Europe du joug de la cour de Rome.

[Déjà il existait même une classe d'hommes qui, supérieurs à toutes les superstitions, se contentaient de les .mépriser en secret, ou se permettaient tout au plus de répandre sur elles, en passant, quelques traits d'un ridicule rendu plus piquant par un voile de respect, dont ils avaient soin de le couvrir. La plaisanterie obtenait grâce pour ces hardiesses, qui, semées avec précaution dans les ouvrages destinés à l'amusement des grands ou des lettrés, mais ignorés du peuple, ne réveillaient pas la haine des persécuteurs.]

[Frédéric II fut soupçonné d'être ce que nos prêtres du XVIIIe siècle ont depuis appelé un philosophe. Le pape l'accusa, devant toutes les nations, d'avoir traité de fables politiques les religions de Moïse, de Jésus et de Mahomet. On attribuait à son chancelier, Pierre des Vignes, le livre imaginaire des Trois Imposteurs. Mais le titre seul annonçait l'existence d'une opinion, résultat bien naturel de l'examen de ces trois croyances, qui, nées de la même source, n'étaient que la corruption d'un culte plus pur, rendu, par des peuples plus anciens, à l'âme universelle du monde.]

[Les recueils de nos fabliaux, le Décaméron de Boccace, sont pleins de traits qui respirent cette liberté de penser, ce mépris des pré- 
jugés, cette disposition à en faire le sujet d'une dérision maligne et secrète.]

[Ainsi, cette époque nous présente de paisibles contempteurs de toutes les superstitions, à côte des réformateurs enthousiastes de leurs abus les plus grossiers ; et nous pourrons presque lier l'histoire de ces réclamations obscures, de ces protestations en faveur des droits de la raison, à celle des derniers philosophes de l'école d'Alexandrie.]

[Nous examinerons si, dans un temps où le prosélytisme philosophique eût été si dangereux, il ne se forma point des sociétés secrètes, destinées à perpétuer, à répandre sourdement et sans danger, parmi quelques adeptes, un petit nombre de vérités simples, comme de sûrs préservatifs contre les préjugés dominateurs.]

[Nous chercherons si l'on ne doit point placer au nombre de ces sociétés cet ordre célèbre contre lequel les papes et les rois conspirèrent avec tant de bassesse, et qu'ils détruisirent avec tant de barbarie.]

Les prêtres étaient obligés d'étudier, soit pour se défendre, soit pour couvrir de quelques prétextes leurs usurpations sur la puissance séculière, et se perfectionner dans l'art de fabriquer des pièces supposées. D'un autre côté, pour soutenir avec moins de désavantage cette guerre, où les prétentions s'appuyaient sur l'autorité et sur les exemples, les rois favorisèrent des écoles destinées à former les jurisconsultes, qu'ils avaient besoin d'opposer aux prêtres.

Dans ces disputes entre le clergé et les gouvernements, entre le clergé de chaque pays et le chef de l'Église, ceux qui avaient un esprit plus juste, un caractère plus franc, plus élevé, combattirent pour la cause des hommes contre celle des prêtres, pour la cause du clergé national contre le despotisme du chef étranger. Ils attaquèrent ces abus, ces usurpations dont ils cherchaient à dévoiler l'origine. Cette hardiesse ne nous paraît aujourd'hui qu'une timidité servile; nous rions de voir prodiguer tant de travaux pour prouver ce que le simple bon sens devait apprendre : mais ces vérités, alors nouvelles, décidaient souvent du sort d'un peuple : ces hommes les cherchaient avec une âme indépendante ; ils les défendaient avec courage ; et c'est par 
eux que la raison humaine a commencé à se ressouvenir de ses droits et de sa liberté.

Dans les querelles qui s'élevaient entre des rois et les seigneurs, les premiers s'assurèrent l'appui des grandes villes, ou par des privilèges, ou par la restauration de quelques-uns des droits naturels de l'homme ; ils cherchèrent, par des affranchissements, à multiplier celles qui jouiraient du droit de commune. Ces mêmes hommes qui renaissaient à la liberté sentirent combien il leur importait d'acquérir, par l'étude des lois, par celle de l'histoire, une habileté, une autorité d'opinion qui les aidât à contre-balancer la puissance militaire de la tyrannie féodale.

La rivalité des empereurs et des papes empêcha l'Italie de se réunir sous un maître, et y conserva un grand nombre de sociétés indépendantes. Dans les petits États, on a besoin d'ajouter le pouvoir de la persuasion à celui de la force, d'employer la négociation aussi souvent que les armes ; et, comme cette guerre politique y avait pour principe une guerre d'opinion, comme jamais l'Italie n'avait absolument perdu le goût de l'étude, elle devait être, pour l'Europe, un foyer de lumières, faible encore, mais qui promettait de croître avec rapidité.

Enfin, l'enthousiasme religieux entraîna les Occidentaux à la conquête des lieux consacrés, à ce qu'on disait, par la mort et par les miracles du Christ : et en même temps que cette fureur était favorable à la liberté, par l'affaiblissement et l'appauvrissement des seigneurs, elle étendait les relations des peuples européens avec les Arabes ; liaisons que déjà leur mélange avec les chrétiens d'Espagne avait formées, que le commerce de Pise, de Gênes, de Venise, avait cimentées. On apprit la langue des Arabes ; on lut leurs ouvrages ; on s'instruisit d'une partie de leurs découvertes ; et si l'on ne s'éleva point au-dessus du point où ils avaient laissé les sciences, on eut du moins l'ambition de les égaler.

[Ces guerres, entreprises pour la superstition, servirent à la détruire. Le spectacle de plusieurs religions finit par inspirer aux hommes de bon sens, une égale indifférence pour ces croyances également impuissantes contre les vie£\% ou les passions des hommes ; un mépris égal pour l'attachement également sincère, également opiniâtre de leurs sectateurs à des opinions contradictoires.] 
Il s'était formé en Italie des républiques dont quelques-unes avaient imité les formes des républiques grecques, tandis que les autres essayèrent de concilier avec la servitude, dans un peuple sujet, la liberté, l'égalité démocratique d'un peuple souverain. En Allemagne, dans le Nord, quelques villes, obtenant une indépendance presque entière, se gouvernèrent par leurs propres lois. Dans quelques portions de l'Helvétie, le peuple brisa les fers de la féodalité, comme ceux du pouvoir royal. Dans presque tous les grands États, on vit naître des constitutions imparfaites, où l'autorité de lever des subsides, de faire des lois nouvelles, fut partagée, tantôt entre le roi, les nobles, le clergé et le peuple, tantôt entre le roi, les barons et les communes; où le peuple, sans sortir encore de l'humiliation, était du moins à l'abri de l'oppression ; où ce qui compose vraiment les nations était appelé au droit de défendre ses intérêts, et d'être entendu de ceux qui réglaient ses destinées. En Angleterre, un acte célèbre, solennellement juré par le roi et par les grands, garantit les droits des barons, et quelques-uns de ceux des hommes.

D'autres peuples, des provinces, des villes même, obtinrent aussi des chartes semblables, moins célèbres et moins bien défendues. Elles sont l'origine de ces déclarations des droits, regardées aujourd'hui par tous les hommes éclairés comme la base de la liberté, et dont les anciens n'avaient pas conçu, ne pouvaient concevoir l'idée ; parce que l'esclavage domestique souillait leurs constitutions; parce que, chez eux, le droit de citoyen était héréditaire, ou conféré par une adoption volontaire ; parce qu'ils ne s'étaient pas élevés jusqu'à la connaissance de ces droits inhérents à l'espèce humaine, et appartenant à tous les hommes avec une entière égalité.

[En France, en Angleterre, chez quelques autres grandes nations, le peuple parut vouloir ressaisir ses véritables droits ; mais il était plus aveuglé par le sentiment de l'oppression qu'éclairé par la raison ; et des violences, expiées par des vengeances plus barbares, des pillages suivis d'une misère plus grande, furent le fruit unique de ses efforts.]

[Cependant, chez les Anglais, les principes du réformateur Wicleff avaient été le motif d'un de ces mouvements dirigés par quelques-uns de ses disciples, présage des tentatives plus suivies et mieux combi- 
nées que les peuples devaient faire sous d'autres réformateurs, dans un siècle plus éclairé.]

La découverte d'un manuscrit du code de Justinien fit renaître l'étude de la jurisprudence, comme celle de, la législation, et servit à rendre moins barbare la jurisprudence, même des peuples qui surent en profiter, sans vouloir s'y soumettre.

Le commerce de Pise, de Gênes, de Florence, de Venise, des cités de la Belgique, de quelques villes libres d'Allemagne, embrassait la Méditerranée, la Baltique et les côtes de l'Océan européen. Leurs négociants allèrent chercher les denrées précieuses du Levant, dans les ports de l'Égypte, et aux extrémités de la mer Noire.

La politique, la législation, l'économie publique, n'étaient pas encore des sciences ; on ne s'occupait point d'en chercher, d'en approfondir, d'en développer les principes ; mais en commençant à s'éclairer par l'expérience, on rassemblait les observations qui pouvaient $\mathrm{y}$ conduire ; on s'instruisait des intérêts qui devaient en faire sentir le besoin.

On ne connut d'abord Aristote que par une traduction faite d'après l'arabe ; et sa philosophie, persécutée dans les premiers instants, régna bientôt dans toutes les écoles. Elle n'y porta point la lumière ; mais elle y donna plus de régularité, plus de méthode à cet art de l'argumentation, que les disputes théologiques avaient enfanté. Cette scolastique ne conduisait pas à la découverte de la vérité ; elle ne servait même pas à discuter, à bien apprécier les preuves ; mais elle aiguisait les esprits : et ce goût des distinctions subtiles, cette nécessité de diviser sans cesse les idées, d'en saisir les nuances fugitives, de les représenter par des mots nouveaux ; tout cet appareil employé pour embarrasser un ennemi dans la dispute, Du pour échapper à ses pièges, fut la première origine de cette analyse philosophique, qui depuis a été la source féconde de nos progrès.

[Nous devons à ces scolastiques des notions plus précises sur les idées qu'on peut se former de l'Etre suprême et de ses attributs ; sur la distinction entre la cause première et l'univers qu'elle est supposée gouverner ; sur celle de l'esprit et de la matière ; sur les différents sens 
que l'on peut attacher au mot de liberté, sur ce qu'on entend par la création, sur la manière de distinguer entre elles les diverses opérations de l'esprit humain, et de classer les idées qu'il se forme des objets réels et de leurs propriétés.]

Mais cette même méthode ne pouvait que retarder dans les écoles le progrès des sciences naturelles. Quelques recherches anatomiques ; des travaux obscurs sur la chimie, uniquement employés à chercher le grand oeuvre ; des études sur la géométrie, l'algèbre, qui ne s'élevèrent ni jusqu'à savoir tout ce que les Arabes avaient découvert, ni jusqu'à entendre les ouvrages des anciens ; enfin, des observations, des calculs astronomiques qui se bornaient à former, à perfectionner des tables, et que souillait un ridicule mélange d'astrologie ; tel est le tableau que ces sciences présentent. Cependant, les arts mécaniques commencèrent à se rapprocher de la perfection qu'ils avaient conservée en Asie. La culture de la soie s'introduisait dans les pays méridionaux de l'Europe ; les moulins à vent, les papeteries, s'y étaient établis ; J'art de mesurer le temps y avait passé les limites où il s'était arrêté chez les anciens et chez les Arabes. Enfin, deux découvertes importantes marquent cette même époque. La propriété qu'a l'aimant de se diriger vers un même point du ciel, propriété connue des Chinois, et même employée par eux à guider les vaisseaux, fut aussi observée en Europe. On apprit à se servir de la boussole, dont l'usage augmenta l'activité du commerce, perfectionna l'art de la navigation, donna l'idée de ces voyages qui, depuis, ont fait connaître un monde nouveau, et permit à l'homme de porter ses regards sur toute l'étendue du globe où il est placé. Un chimiste, en mêlant le salpêtre à une matière inflammable, trouva le secret de cette poudre, qui a produit une révolution inattendue dans l'art de la guerre. Malgré les effets terribles des armes à feu, en éloignant les combattants, elles ont rendu la guerre moins meurtrière et les guerriers moins féroces. Les expéditions militaires sont plus dispendieuses ; la richesse peut balancer la force : les nations même les plus belliqueuses sentent le besoin de se préparer, de s'assurer les moyens de combattre, en s'enrichissant par le commerce et les arts. Les peuples policés n'ont plus à craindre le courage aveugle des nations barbares. Les grandes conquêtes, et les révolutions qui les suivent, sont devenues presque impossibles. 
Cette supériorité, qu'une armure de fer, que l'art de conduire un cheval presque invulnérable, de manier la lance, la massue ou l'épée, donnait à la noblesse sur le peuple, a fini par disparaître totalement ; et la destruction de ce dernier obstacle à la liberté des hommes, à leur égalité réelle, est due à une invention qui semblait, au premier coup d'œil, menacer d'anéantir la race humaine.

En Italie, la langue était parvenue presque à sa perfection vers le quatorzième siècle. Le Dante est souvent noble, précis, énergique ; Boccace a de la grâce, de la simplicité, de l'élégance. L'ingénieux et sensible Pétrarque n'a point vieilli. Dans cette contrée, dont l'heureux climat se rapproche de celui de la Grèce, on étudiait les modèles de l'antiquité ; on essayait de transporter dans la langue nouvelle quelques-unes de leurs beautés ; on tâchait de les imiter dans la leur. Déjà quelques essais faisaient espérer que, réveillé par la vue des monuments antiques, instruit par ces muettes mais éloquentes leçons, le génie des arts allait, pour la seconde fois, embellir l'existence de l'homme, et lui préparer ces plaisirs purs dont la jouissance est égale pour tous, et s'accroît à mesure qu'elle se partage.

Le reste de l'Europe suivait de loin ; mais le goût des lettres et de la poésie y commençait du moins à polir les langues encore barbares.

Les mêmes causes qui avaient forcé les esprits à sortir de leur longue léthargie devaient aussi diriger leurs efforts. La raison ne pouvait être appelée à décider les questions que les intérêts opposés forçaient d'agiter: la religion, loin de reconnaître son autorité, prétendait la soumettre et se vantait de l'humilier; la politique regardait comme juste ce qui était consacré par des conventions, par un usage constant, par des coutumes anciennes.

On ne se doutait pas que les droits des hommes fussent écrits dans le livre de la nature, et qu'en consulter d'autres c'était les méconnaître et les outrager. C'est dans les livres sacrés, dans les auteurs respectés, dans les bulles des papes, dans les rescrits des rois, dans les recueils des coutumes, dans les annales des églises, qu'on cherchait les maximes ou les exemples dont il pouvait être permis de tirer des conséquences. Il ne s'agissait pas d'examiner un principe en lui-même, mais d'interpréter, de discuter, de détruire ou de fortifier par d'autres textes 
ceux sur lesquels on l'appuyait. On n'adoptait pas une proposition parce qu'elle était vraie, mais parce qu'elle était écrite dans un tel livre, et qu'elle avait été admise dans tel pays et depuis tel siècle.

Ainsi, partout, l'autorité des hommes était substituée à celle de la raison. On étudiait les livres beaucoup plus que la nature, et les opinions des anciens plutôt que les phénomènes de l'univers. Cet esclavage de l'esprit, dans lequel même on n'avait pas encore la ressource d'une critique éclairée, fut alors plus nuisible aux progrès de l'espèce humaine en corrompant la méthode d'étudier, que par ses effets immédiats. On était si loin d'avoir atteint les anciens, qu'il n'était pas temps encore de chercher à les corriger ou à les surpasser.'

Les mœurs conservèrent, durant cette époque, leur corruption et leur férocité ; l'intolérance religieuse fut même plus active ; et les discordes civiles, les guerres perpétuelles d'une foule de petits princes remplacèrent les invasions des Barbares, et le fléau plus funeste des guerres privées. A la vérité, la galanterie des ménestrels et des troubadours, l'institution d'une chevalerie, professant la générosité et la franchise, se dévouant au maintien de la religion et à la défense des opprimés, comme au service des dames, semblaient devoir donner aux mœurs plus de douceur, de décence et d'élévation. Mais ce changement, borné aux cours et aux châteaux, n'atteignit pas la masse du peuple. Il en résultait un peu plus d'égalité entre les nobles, moins de perfidie et de cruauté dans leurs relations entre eux ; mais leur mépris pour le peuple, la violence de leur tyrannie, l'audace de leur brigandage, restèrent les mêmes ; et les nations, également opprimées, furent également ignorantes, barbares et corrompues.

Cette galanterie poétique et militaire, cette chevalerie, dues en grande partie aux Arabes, dont la générosité naturelle résista longtemps en Espagne à la superstition et au despotisme, furent sans doute utiles : elles répandirent des germes d'humanité qui ne devaient fructifier que dans des temps plus heureux ; et ce fut le caractère général de cette époque d'avoir disposé l'esprit humain pour la révolution que la découverte de l'imprimerie devait amener, et d'avoir préparé la terre que les âges suivants devaient couvrir d'une moisson si riche et si abondante. 
CONDORCET,

Esquisse d'un tableau historique des progrès de l'esprit humain

(1793-1794).

\section{Huitième époque}

\section{Depuis l'invention de l'imprimerie jusqu'au temps où les sciences et la philosophie secouèrent le joug de l'autorité.}

Ceux qui n'ont pas réfléchi sur la marche de l'esprit humain dans la découverte, soit des vérités des sciences, soit des procédés des arts, doivent s'étonner qu'un si-long espace de temps ait séparé la connaissance de l'art d'imprimer les dessins, et la découverte de celui d'imprimer des caractères.

Sans doute, quelques graveurs de planches avaient eu l'idée de cette application de leur art ; mais ils avaient été plus frappés de la difficulté de l'exécution que des avantages du succès; et il est même heureux qu'on n'ait pu en soupçonner toute l'étendue ; car les prêtres et les rois se seraient unis pour étouffer, dès sa naissance, l'ennemi qui devait les démasquer et les détrôner.

L'imprimerie multiplie indéfiniment, et à peu de frais, les exemplaires d'un même ouvrage. Dès lors, la faculté d'avoir des livres, d'en 
acquérir suivant son goût et ses besoins, a existé pour tous ceux qui savent lire ; et cette facilité de la lecture a augmenté et propagé le désir et les moyens de s'instruire.

Ces copies multipliées se répandant avec une rapidité plus grande, non seulement les faits, les découvertes, acquièrent une publicité plus étendue, mais ils l'acquièrent avec une plus grande promptitude. Les lumières sont devenues l'objet d'un commerce actif, universel.

On était obligé de chercher les manuscrits, comme aujourd'hui nous cherchons les ouvrages rares. Ce qui n'était lu que de quelques individus, a donc pu l'être d'un peuple entier, et frapper presque en même temps tous les hommes qui entendaient la même langue.

On a connu le moyen de parler aux nations dispersées. On a vu s'établir une nouvelle espèce de tribune, d'où se communiquent des impressions moins vives, mais plus profondes; d'où l'on exerce un empire moins tyrannique sur les passions, mais en obtenant sur la raison une puissance plus sûre et plus durable ; où tout l'avantage est pour la vérité, puisque l'art n'a perdu sur les moyens de séduire qu'en gagnant sur ceux d'éclairer. Il s'est formé une opinion publique, puissante par le nombre de ceux qui la partagent ; énergique, parce que les motifs qui la déterminent agissent à la fois sur tous les -esprits, même à des distances très éloignées. Ainsi, l'on a vu s'élever, en faveur de la raison et de la justice, un tribunal indépendant de toute puissance humaine, auquel il est difficile de rien cacher et impossible de se soustraire.

Les méthodes nouvelles, l'histoire des premiers pas dans la route qui doit conduire à une découverte, les travaux qui la préparent, les vues qui peuvent en donner l'idée ou seulement inspirer le désir de la chercher, se répandant avec promptitude, offrent à chaque individu l'ensemble des moyens que les efforts de tous ont pu créer ; et, par ces mutuels secours, le génie semble avoir plus que doublé ses forces.

Toute erreur nouvelle est combattue dès sa naissance souvent attaquée avant même d'avoir pu se propager, elle n'a point le temps de pouvoir s'enraciner dans les esprits. Celles qui, reçues dès l'enfance, se sont, en quelque sorte, identifiées avec la raison de chaque individu, 
que les terreurs ou l'espérance ont rendues chères aux âmes faibles, ont été ébranlées par cela seul qu'il est devenu impossible d'en empêcher la discussion, de cacher qu'elles pouvaient être rejetées et combattues, de s'opposer aux progrès des vérités qui, de conséquences en conséquences, doivent à la longue en faire reconnaître l'absurdité.

C'est à l'imprimerie que l'on doit la possibilité de répandre les ouvrages que sollicitent les circonstances du moment, ou les mouvements passagers de l'opinion, et par là d'intéresser à chaque question qui se discute dans un point unique, l'universalité des hommes qui parlent une même langue.

Sans le secours de cet art, aurait-on pu multiplier ces livres destinés à chaque classe d'hommes, à chaque degré d'instruction ? Les discussions prolongées, qui seules peuvent porter une lumière sûre dans les questions douteuses, et affermir sur une base inébranlable ces vérités trop abstraites, trop subtiles, trop éloignées des préjugés du peuple ou de l'opinion commune des savants, pour ne pas être bientôt oubliées et méconnues ; les livres purement élémentaires, les dictionnaires, les ouvrages où l'on rassemble, avec tous leurs détails, une multitude de faits, d'observations, d'expériences, où toutes les preuves sont développées, tous les doutes discutés ; ces collections précieuses qui renferment, tantôt tout ce qui a été observé, écrit, pensé, sur une branche particulière des sciences, tantôt le résultat des travaux annuels de tous les savants d'un même pays ; ces tables, ces tableaux de toute espèce, dont les uns offrent aux yeux des résultats que l'esprit n'aurait saisis qu'avec un travail pénible, les autres montrent à volonté le fait, l'observation, le nombre, la formule, l'objet qu'on a besoin de connaître, tandis que d'autres enfin présentent, sous une forme commode, dans un ordre méthodique, les matériaux dont le génie doit tirer des vérités nouvelles: tous ces moyens de rendre la marche de l'esprit humain plus rapide, plus sûre et plus facile, sont encore des bienfaits de l'imprimerie.

Nous en montrerons de nouveaux encore, lorsque nous analyserons les effets de la substitution des langues nationales à l'usage presque exclusif, pour les sciences, d'une langue commune aux savants de tous les pays. 
Enfin, l'imprimerie n'a-t-elle pas affranchi l'instruction des peuples de toutes les chaînes politiques et religieuses ? En vain l'un ou l'autre despotisme aurait-il envahi toutes les écoles ; en vain aurait-il, par des institutions sévères, invariablement fixé de quelles erreurs il prescrivait d'infecter les esprits, de quelles vérités il ordonnait de les préserver ; en vain les chaires, consacrées à l'instruction morale du peuple ou à celle de la jeunesse dans la philosophie et dans les sciences, seraient-elles condamnées à ne transmettre jamais qu'une doctrine favorable au maintien de cette double tyrannie : l'imprimerie peut encore répandre une lumière indépendante et pure. Cette instruction, que chaque homme peut recevoir par les livres dans le silence et la solitude, ne peut être universellement corrompue : il suffit qu'il existe un coin de terre libre, où la presse puisse en charger ses feuilles. Comment, dans cette multitude de livres divers, d'exemplaires d'un même livre, de réimpressions, qui, en quelques instants, le multiplient de nouveau, pourra-t-on fermer assez exactement toutes les portes par lesquelles la vérité cherche à s'introduire ? Ce qui était difficile, même lorsqu'il ne s'agissait que de détruire quelques exemplaires d'un manuscrit pour l'anéantir sans retour, lorsqu'il suffisait de proscrire une vérité, une opinion pendant quelques années, pour la dévouer à un éternel oubli, n'est-il pas devenu impossible, aujourd'hui qu'il faudrait employer une vigilance sans cesse renouvelée, une activité qui ne se reposerait jamais ? Comment, si même on parvenait à écarter ces vérités trop palpables qui blessent directement les intérêts des inquisiteurs, empêcherait-on de pénétrer, de se répandre, celles qui renferment ces vérités proscrites, sans trop les laisser apercevoir, qui les préparent, qui doivent un jour y conduire? Le pourrait-on, sans être forcé de quitter ce masque d'hypocrisie, dont la chute serait presque aussi funeste que la vérité à la puissance de l'erreur ? Aussi verrons-nous la raison triompher de ces vains efforts; nous la verrons, dans cette guerre, toujours renaissante et souvent cruelle, triompher de la violence comme de la ruse ; braver les bûchers et résister à la séduction, écrasant tour à tour sous sa main toute-puissante, et l'hypocrisie religieuse qui exige pour ses dogmes une adoration sincère, et l'hypocrisie politique qui conjure à genoux de souffrir qu'elle profite en paix des erreurs dans lesquelles il est, à l'en croire, aussi utile aux peuples qu'à elle-même de les laisser à jamais plongés. 
L'invention de l'imprimerie coïncide presque avec deux autres événements, dont l'un a exercé une action immédiate sur les progrès de l'esprit humain, tandis que l'influence de l'autre sur la destinée de l'humanité entière ne doit avoir de terme que sa durée.

Je parle de la prise de Constantinople par les Turcs, et de la découverte, soit du nouveau monde, soit de la route qui a ouvert à l'Europe une communication directe avec les parties orientales de l'Afrique et de l'Asie.

Les littérateurs grecs, fuyant la domination tartare, cherchèrent un asile en Italie. Ils enseignèrent à lire. dans leur langue originale, les poètes, les orateurs, les historiens, les philosophes, les savants de l'ancienne Grèce ; ils en multiplièrent d'abord les manuscrits, et bientôt après les éditions. On ne se borna plus à l'adoration de ce qu'on était convenu d'appeler la doctrine d'Aristote ; on chercha, dans ses propres écrits, ce qu'elle avait été réellement ; on osa la juger et la combattre ; on lui opposa Platon : et c'était avoir déjà commencé à secouer le joug, que de se croire le droit de choisir un maître.

La lecture d'Euclide, d'Archimède, de Diophante, d'Hippocrate, du livre des animaux, de la physique même d'Aristote, ranimèrent le génie de la géométrie et de la physique ; et les opinions antichrétiennes des philosophes réveillèrent les idées presque éteintes des anciens droits de la raison humaine.

Des hommes intrépides, guidés par l'amour de la gloire et la passion des découvertes, avaient reculé pour l'Europe les bornes de l'univers, lui avaient montré un nouveau ciel, et ouvert des terres inconnues. Gama avait pénétré dans l'Inde, après avoir suivi, avec une infatigable patience, l'immense étendue des côtes africaines; tandis que Colomb, s'abandonnant aux flots de l'Océan Atlantique, avait atteint ce monde jusqu'alors inconnu, qui s'étend entre l'occident de l'Europe et l'orient de l'Asie.

Si ce sentiment, dont l'inquiète activité embrassant dès lors tous les objets, présageait les grands progrès de l'espèce humaine ; si une noble curiosité avait animé les héros de la navigation, une basse et cruelle avidité, un fanatisme stupide et féroce dirigeaient les rois et les 
brigands qui devaient profiter de leurs travaux. Les êtres infortunés qui habitaient ces contrées nouvelles ne furent point traités comme des hommes, parce qu'ils n'étaient pas des chrétiens. Ce préjugé, plus avilissant pour les tyrans que pour les victimes, étouffait toute espèce de remords, abandonnait sans frein à leur soif inextinguible d'or et de sang, ces hommes avides et barbares que l'Europe vomissait de son sein. Les ossements de cinq millions d'hommes ont couvert ces terres infortunées, où les Portugais et les Espagnols portèrent leur avarice, leurs superstitions et leur fureur. Ils déposeront jusqu'à la fin des siècles contre cette doctrine de l'utilité politique des religions, qui trouve encore parmi nous des apologistes.

C'est à cette époque seulement que l'homme a pu connaître le globe qu'il habite ; étudier, dans tous les pays, l'espèce humaine modifiée par la longue influence des causes naturelles ou des institutions sociales ; observer les productions de la terre ou des mers dans toutes les températures, dans tous les climats. Ainsi, les ressources de toute espèce, que ces productions offrent aux hommes, encore si éloignés d'en avoir épuisé, d'en soupçonner même l'entière étendue, tout ce que la connaissance de ces objets peut ajouter aux sciences de vérités nouvelles, et détruire d'erreurs accréditées ; l'activité du commerce, qui a fait prendre un nouvel essor à l'industrie, à la navigation, et, par un enchaînement nécessaire, à toutes les sciences comme à tous les arts ; la force que cette activité a donnée aux nations libres pour résister aux tyrans, aux peuples asservis pour briser leurs fers, pour relâcher du moins ceux de la féodalité : telles ont été les conséquences heureuses de ces découvertes. Mais ces avantages n'auront expié ce qu'ils ont coûté à l'humanité, qu'au moment où l'Europe, renonçant au système oppresseur et mesquin d'un commerce de monopole, se souviendra que les hommes de tous les climats, égaux et frères par le vœu de la nature, n'ont point été formés par elle pour nourrir l'orgueil et l'avarice de quelques nations privilégiées; qu'au moment où, mieux éclairée sur ses véritables intérêts, elle appellera tous les peuples au partage de son indépendance, de sa liberté et de ses lumières. Malheureusement, il faut se demander encore si cette révolution sera le fruit honorable des progrès de la philosophie, ou seulement, comme nous l'avons vu déjà, la suite honteuse des jalousies nationales et des excès de la tyrannie. 
Jusqu'à cette époque, les attentats du sacerdoce avaient été impunis. Les réclamations de l'humanité opprimée, de la raison outragée, avaient été étouffées dans le sang et dans les flammes. L'esprit qui avait dicté ces réclamations n'était pas éteint ; mais ce silence de la terreur enhardissait à de nouveaux scandales. Enfin, le scandale d'affermer à des moines, de faire vendre, par eux, dans les cabarets, dans les places publiques, l'expiation des péchés, causa une explosion nouvelle. Luther, tenant d'une main les livres sacrés, montrait de l'autre le droit que s'arrogeait le pape d'absoudre du crime et d'en vendre le pardon ; l'insolent despotisme qu'il exerçait sur les évêques, longtemps ses égaux ; la cène fraternelle des premiers chrétiens, devenue, sous le nom de messe, une espèce d'opération magique et un objet (le commerce ; les prêtres condamnés à la corruption d'un célibat irrévocable ; cette loi barbare ou scandaleuse s'étendant à ces moines, à ces religieuses, dont l'ambition pontificale avait inondé et souillé l'Église ; tous les secrets des laïques, livrés par la confession aux intrigues et aux passions des prêtres ; Dieu lui-même, enfin, conservant à peine une faible portion dans ces adorations prodiguées à du pain, à des hommes, à des ossements ou à des statues.

Luther annonçait aux peuples étonnés, que ces institutions révoltantes n'étaient point le christianisme, mais en étaient la dépravation et la honte, et que, pour être fidèle à la religion de Jésus-Christ, il fallait commencer par abjurer celle de ses prêtres. Il employait également les armes de la dialectique ou de l'érudition, et les traits non moins puissants du ridicule. Il écrivait à la fois en allemand et en latin. Ce n'était plus comme au temps des Albigeois ou de Jean Hus, dont la doctrine, inconnue au delà des limites de leurs églises, était si aisément calomniée. Les livres allemands des nouveaux apôtres pénétraient en même temps dans toutes les bourgades de l'Empire, tandis que leurs livres latins arrachaient l'Europe entière au honteux sommeil où la superstition l'avait plongée. Ceux dont la raison avait prévenu les réformateurs, mais que la crainte retenait dans le silence ; ceux qu'agitait un doute secret, et qui tremblaient de l'avouer, même à leur conscience ; ceux qui, plus simples, avaient ignoré toute l'étendue des absurdités théologiques; ceux qui. n'ayant jamais réfléchi sur les questions contestées, étaient étonnés d'apprendre qu'ils avaient à choisir entre des opinions diverses ; tous se livrèrent avec avidité à ces discussions, 
dont ils voyaient dépendre à la fois, et leurs intérêts temporels, et leur félicité future.

Toute l'Europe chrétienne, de la Suède jusqu'à l'Italie, de la Hongrie jusqu'à l'Espagne, fut en un instant couverte de partisans des nouvelles doctrines ; et la réforme eût délivré du joug de Rome tous les peuples qui habitent l'Europe, si la fausse politique de quelques princes n'eût relevé ce même sceptre sacerdotal, qui s'était si souvent appesanti sur la tête des rois.

Leur politique, que malheureusement leurs successeurs n'ont pas encore abjurée, était alors de ruiner leurs États pour en acquérir de nouveaux, et de mesurer leur puissance par l'étendue de leur territoire, plutôt que par le nombre de leurs sujets.

Aussi, Charles-Quint et François 1er, occupés de se disputer l'Italie, sacrifièrent-ils à l'intérêt de ménager le pape, celui de profiter des avantages qu'offrait la réforme aux pays qui sauraient l'adopter.

L'Empereur, voyant que les princes de l'Empire favorisaient des opinions qui devaient augmenter leur pouvoir et leurs richesses, se rendit le protecteur des anciens abus, dans l'espoir qu'une guerre religieuse lui offrirait une occasion d'envahir leurs États et de détruire leur indépendance. François imagina qu'en faisant brûler les protestants, et en protégeant leurs chefs en Allemagne, il conserverait l'amitié du pape, sans perdre des alliés utiles.

Mais ce ne fut pas leur seul motif ; le despotisme a aussi son instinct ; et cet instinct avait révélé à ces rois, que les hommes, après avoir soumis les préjugés religieux à l'examen de la raison, l'étendraient bientôt jusqu'aux préjugés politiques ; qu'éclairés sur les usurpations des papes, ils finiraient par vouloir l'être sur les usurpations des rois ; et que la réforme des abus ecclésiastiques, si utile à la puissance royale, entraînerait celle des abus plus oppresseurs sur lesquels cette puissance était fondée. Aussi, aucun roi d'une grande nation ne favorisa volontairement le parti des réformateurs. Henri VIII, frappé de l'anathème pontifical, les persécutait encore ; Edouard, Elisabeth, ne pouvant s'attacher au papisme sans se déclarer usurpateurs, établirent en Angleterre la croyance et le culte qui s'en rapprochaient le 
plus. Les monarques protestants de la Grande-Bretagne ont favorisé constamment le catholicisme, toutes les fois qu'il a cessé de les menacer d'un prétendant à leur couronne.

En Suède, en Danemark, l'établissement du luthéranisme ne fut, aux yeux des rois, qu'une précaution nécessaire pour assurer l'expulsion du tyran catholique qu'ils remplaçaient; et nous voyons déjà, dans la monarchie prussienne, fondée par un prince philosophe, son successeur ne pouvoir cacher un penchant secret pour cette religion si chère aux rois.

L'intolérance religieuse était commune à toutes les sectes, qui l'inspiraient à tous les gouvernements. Les papistes persécutaient toutes les communions réformées; et celles-ci, s'anathématisant entre elles, se réunissaient contre les antitrinitaires, qui, plus conséquents, avaient soumis également tous les dogmes à l'examen, sinon de la raison, au moins d'une critique raisonnée, et n'avaient pas cru devoir se soustraire a quelques absurdités, pour en conserver d'aussi révoltantes.

Cette intolérance servit la cause du papisme. Depuis longtemps il existait en Europe, et surtout en Italie, une classe d'hommes qui, rejetant toutes les superstitions, indifférents à tous les cultes, soumis à la raison seule, regardaient les religions comme des inventions humaines, dont on pouvait se moquer en secret, mais que la prudence ou la politique ordonnaient de paraître respecter.

Ensuite, on porta plus loin la hardiesse ; et, tandis que dans les écoles on employait la philosophie mal entendue d'Aristote, à perfectionner l'art des subtilités théologiques, à rendre ingénieux ce qui naturellement n'aurait été qu'absurde, quelques savants cherchaient à établir, sur sa véritable doctrine, un système destructeur de toute idée religieuse ; un système dans lequel l'âme humaine n'était qu'une faculté qui s'évanouissait avec la vie ; dans lequel on n'admettait d'autre providence, d'autre ordonnateur du monde, que les lois nécessaires de la nature. Ils étaient combattus par des platoniciens, dont les opinions, se rapprochant de ce que depuis on a nommé déisme, n'en étaient que plus effrayantes pour l'orthodoxie sacerdotale. 
La terreur des supplices arrêta bientôt cette imprudente franchise. L'Italie, la France, furent souillées du sang de ces martyrs de la liberté de penser. Toutes les sectes, tous les gouvernements, tous les genres d'autorité, ne se montrèrent d'accord que contre la raison. Il fallut la couvrir d'un voile qui, la dérobant aux regards des tyrans, se laissât pénétrer par ceux de la philosophie.

On fut donc obligé de se renfermer dans la timide réserve de cette doctrine secrète, qui n'avait jamais cessé d'avoir un grand nombre de sectateurs. Elle s'était propagée surtout parmi les chefs des gouvernements, comme parmi ceux de l'Église ; et, vers le temps de la réforme, les principes du machiavélisme religieux étaient devenus la seule croyance des princes, des ministres et des pontifes. Ces opinions avaient même corrompu la philosophie. Quelle morale, en effet, attendre d'un système, dont un des principes est qu'il faut appuyer celle du peuple sur de fausses opinions; que les hommes éclairés sont en droit de le tromper, pourvu qu'ils lui donnent des erreurs utiles, et de le retenir dans les chaînes dont eux-mêmes ont su s'affranchir ?

Si l'égalité naturelle des hommes, première base de leurs droits, est le fondement de toute vraie morale, que pouvait-elle espérer d'une philosophie, dont un mépris ouvert de cette égalité et de ces droits était une des maximes ? Sans doute, cette même philosophie a pu servir aux progrès de la raison, dont elle préparait le règne en silence : mais, tant qu'elle subsista seule, elle n'a fait que substituer l'hypocrisie au fanatisme, et corrompre, même en les élevant au-dessus des préjugés, ceux qui présidaient à la destinée des États.

Les philosophes vraiment éclairés, étrangers à l'ambition, qui se bornant à ne détromper les hommes qu'avec une extrême timidité, sans se permettre de les entretenir dans leurs erreurs, ces philosophes auraient naturellement été portés à embrasser la réforme : mais, rebutés de trouver partout une égale intolérance, la plupart ne crurent pas devoir s'exposer aux embarras d'un changement, après lequel ils se trouveraient soumis à la même contrainte. Puisqu'ils auraient été toujours obligés de paraître croire des absurdités qu'ils rejetaient, ils ne trouvèrent pas un grand avantage à en diminuer un peu le nombre ; ils craignirent même de se donner, par leur abjuration, l'apparence d'une hypocrisie volontaire : et en restant attachés à la vieille religion, ils la 
fortifièrent de l'autorité de leur renommée. L'esprit qui animait les réformateurs ne conduisait pas à la véritable liberté de penser. Chaque religion, dans le pays où elle dominait, ne permettait que de certaines opinions. Cependant, comme ces diverses croyances étaient opposées entre elles, il y avait peu d'opinions qui ne fussent attaquées ou soutenues dans quelques parties de l'Europe. D'ailleurs, les communions nouvelles avaient été forcées de se relâcher un peu de la rigueur dogmatique. Elles ne pouvaient, sans une contradiction grossière, réduire le droit d'examiner dans des limites trop resserrées, puisqu'elles venaient d'établir sur ce même droit la légitimité de leur séparation. Si elles refusaient de rendre à la raison toute sa liberté, elles consentaient que sa prison fût moins étroite : la chaîne n'était pas brisée, mais elle était moins pesante et plus prolongée. Enfin, dans ces pays où il avait été impossible à une religion d'opprimer toutes les autres, il s'établit ce que l'insolence du culte dominateur osa nommer tolérance, c'est-àdire, une permission donnée par des hommes à d'autres hommes de croire ce que leur raison adopte, de faire ce que leur conscience leur ordonne, de rendre à leur Dieu commun l'hommage qu'ils imaginent lui plaire davantage. On put donc alors y soutenir toutes les doctrines tolérées, avec une franchise plus ou moins entière.

Ainsi l'on vit naître en Europe une sorte de liberté de penser, non pour les hommes, mais pour les chrétiens; et, si nous exceptons la France, c'est pour les seuls chrétiens que partout ailleurs elle existe encore aujourd'hui.

Mais cette intolérance força la raison humaine à rechercher des droits trop longtemps oubliés, ou qui plutôt n'avaient jamais été, ni bien connus, ni bien éclaircis.

Indignés de voir les peuples opprimés jusque dans le sanctuaire de leur conscience par des rois, esclaves superstitieux ou politiques du sacerdoce, quelques hommes généreux osèrent enfin examiner les fondements de leur puissance; et ils révélèrent aux peuples cette grande vérité, que leur liberté est un bien inaliénable ; qu'il n'y a point de prescription en faveur de la tyrannie, point de convention qui puisse irrévocablement lier une nation à une famille ; que les magistrats, quels que soient leurs titres, leurs fonctions, leur puissance, sont les officiers du peuple, et ne sont pas ses maîtres ; qu'il conserve le 
pouvoir de leur retirer une autorité émanée de lui seul, soit quand ils en ont abusé, soit même quand il cesse de croire utile à ses intérêts de la leur conserver : qu'enfin il a le droit de les punir, comme celui de les révoquer.

Telles sont les opinions qu'Althusius, Languet, et depuis Needham, Harrington, professèrent avec courage et développèrent avec énergie.

Payant le tribut à leur siècle, ils appuyèrent trop souvent sur des textes, sur des autorités, sur des exemples : on voit qu'ils durent ces opinions bien plus à l'élévation de leur esprit, à la force de leur caractère, qu'à une analyse exacte des vrais principes de l'ordre social.

Cependant, d'autres philosophes plus timides se contentèrent d'établir entre les peuples et les rois, une exacte réciprocité de droits et de devoirs, une égale obligation de maintenir les conventions. On pouvait bien déposer ou punir un magistrat héréditaire, mais seulement s'il avait violé ce contrat sacré, qui n'en subsistait pas moins avec sa famille. Cette doctrine, qui écartait le droit naturel, pour tout ramener au droit positif, fut appuyée par les jurisconsultes, par les théologiens : elle était plus favorable aux intérêts des hommes puissants, aux projets des ambitieux ; elle frappait bien plus sur l'homme revêtu du pouvoir que sur le pouvoir même. Aussi fut-elle presque généralement suivie par les publicistes, et adoptée pour base dans les révolutions, dans les dissensions politiques.

[L'histoire nous montrera, durant cette époque, peu de progrès réels vers la liberté, mais plus d'ordre et plus de force dans les gouvernements, et dans les nations un sentiment plus fort et surtout plus juste de leurs droits. Les lois sont mieux combinées ; elles paraissent moins souvent l'ouvrage informe des circonstances et du caprice : elles sont faites par des savants, si elles ne le sont pas encore par des philosophes.]

Les mouvements populaires, les révolutions qui avaient agité les républiques d'Italie, l'Angleterre et la France, devaient attirer les regards des philosophes vers cette partie de la politique, qui consiste à observer et à prévoir les effets que les constitutions, les lois, les institutions publiques, peuvent avoir sur la liberté des peuples, sur la pros- 
périté, sur la force des États, sur la conservation de leur indépendance, de la forme de leurs gouvernements. Les uns, imitant Platon, tels que Morus et Hobbes, déduisaient, de quelques principes généraux, le plan d'un système entier d'ordre social, et présentaient le modèle dont il fallait que la pratique tendît sans cesse à se rapprocher. Les autres, comme Machiavel, cherchaient, dans l'examen approfondi des faits de l'histoire, les règles d'après lesquelles on pourrait se flatter de maîtriser l'avenir.

[La science économique n'existait pas encore; les princes ne comptaient pas le nombre des hommes, mais celui des soldats ; la finance n'était que l'art de piller les peuples sans les pousser à la révolte ; et les gouvernements ne s'occupaient du commerce que pour le rançonner par des taxes, le gêner par des privilèges, ou s'en disputer le monopole.]

Les nations de l'Europe, occupées des intérêts communs qui les réunissaient, des intérêts opposés qu'elles croyaient avoir, sentirent le besoin de reconnaître certaines règles entre elles, qui, même indépendamment des traités, présidassent à leurs relations pacifiques ; tandis que d'autres règles, respectées même au milieu de la guerre, en adouciraient les fureurs, en diminueraient les ravages, et préviendraient du moins les maux inutiles.

Il exista donc une science du droit des gens : mais malheureusement on chercha ces lois des nations, non dans la raison et dans la nature, seules autorités que les peuples indépendants puissent reconnâ̂tre, mais dans les usages établis ou dans les opinions des anciens. On s'occupa moins des droits de l'humanité, de la justice envers les individus, que de l'ambition, de l'orgueil ou de l'avidité des gouvernements.

C'est ainsi qu'à cette même époque on ne voit point les moralistes interroger le cœur de l'homme, analyser ses facultés et ses sentiments, pour y découvrir sa nature, l'origine, la règle et la sanction de ses devoirs. Mais ils savent employer toute la subtilité de la scolastique à trouver, pour les actions dont la légitimité paraît incertaine, la limite précise où l'innocence finit et où le péché commence ; à déterminer quelle autorité a le poids nécessaire pour justifier, dans la pratique, 
une de ces actions douteuses ; à classer méthodiquement les péchés, tantôt par genres et par espèces, tantôt suivant leur gravité respective ; à bien distinguer surtout ceux dont un seul suffit pour mériter la damnation éternelle.

La science de la morale ne pouvait sans doute exister encore, puisque les prêtres jouissaient du privilège exclusif d'en être les interprètes et les juges. Mais ces mêmes subtilités, également ridicules et scandaleuses, conduisirent à chercher, aidèrent à faire connaître le degré de moralité des actions ou de leurs motifs ; l'ordre et les limites des devoirs ; les principes d'après lesquels on doit choisir quand ils paraissent se combattre : ainsi, en étudiant une machine grossière, que le hasard a fait tomber dans ses mains, souvent un mécanicien habile parvient à en construire une nouvelle moins imparfaite et vraiment utile.

[La réforme, en détruisant la confession, les indulgences, les moines, et le célibat des prêtres, épura les principes de la morale, et diminua même la corruption des mœurs dans les pays qui l'embrassèrent ; elle les délivra des expiations sacerdotales, ce dangereux encouragement du crime, et du célibat religieux, destructeur de toutes les vertus, puisqu'il est l'ennemi des vertus domestiques.]

Cette époque fut plus souillée qu'aucune autre par de grandes atrocités. Elle fut celle des massacres religieux, des guerres sacrées, de la dépopulation du nouveau monde.

[Elle y vit rétablir l'ancien esclavage, mais plus barbare, plus fécond en crimes contre la nature ; elle vit l'avidité mercantile commercer du sang des hommes, les vendre comme des marchandises, après les avoir achetés par la trahison, le brigandage ou le meurtre, et les enlever à un hémisphère pour les dévouer dans un autre, au milieu de l'humiliation et des outrages, au supplice prolongé d'une lente et cruelle destruction.]

En même temps l'hypocrisie couvre l'Europe de bûchers et d'assassins. Le monstre du fanatisme, irrité de ses blessures, semble redoubler de férocité et se hâter d'entasser ses victimes, parce que la raison va bientôt les arracher de ses mains. Cependant l'on voit enfin reparaî- 
tre quelques-unes de ces vertus douces et courageuses, qui honorent et consolent l'humanité. L'histoire offre des noms qu'elle peut prononcer sans rougir ; des âmes pures et fortes, de grands caractères réunis à des talents supérieurs, se montrent d'espace en espace à travers ces scènes de perfidie, de corruption et de carnage. L'espèce humaine révolte encore le philosophe qui en contemple le tableau ; mais elle ne l'humilie plus, et elle lui montre des espérances plus prochaines.

La marche des sciences devient rapide et brillante. La langue algébrique est généralisée, simplifiée, perfectionnée, ou plutôt, c'est alors seulement qu'elle a été véritablement formée. Les premières bases de la théorie générale des équations sont posées ; la nature des solutions qu'elles donnent est approfondie ; celles du troisième et du quatrième degré sont résolues.

L'ingénieuse invention des logarithmes, en abrégeant les opérations de l'arithmétique, facilite toutes les applications du calcul à des objets réels, et étend ainsi la sphère de toutes les sciences, dans lesquelles ces applications numériques, à la vérité particulière qu'on cherche à connaître, sont un des moyens de comparer, avec les faits, les résultats d'une hypothèse ou d'une théorie, et de parvenir, par cette comparaison, à la découverte des lois de la nature. En effet, dans les mathématiques, la longueur, la complication purement pratique des calculs, ont un terme au delà duquel le temps, les forces même ne peuvent atteindre ; terme qui, sans le secours de ces heureuses abréviations, marquerait les bornes de la science même, et la limite que les efforts du génie ne pourraient franchir.

La loi de la chute des corps fut découverte par Galilée, qui sut en déduire la théorie du mouvement uniformément accéléré, et calculer la courbe que décrit un corps lancé dans le vide avec une vitesse déterminée, et animé d'une force constante, qui agisse suivant des directions parallèles.

Copernic ressuscita le véritable système du monde, oublié depuis si longtemps ; détruisit, par la théorie des mouvements apparents, ce que ce système avait de révoltant pour les sens ; opposa l'extrême simplicité des mouvements réels qui résultent de ce système, à la complication presque ridicule de ceux qu'exigeait l'hypothèse de Ptolémée. Les 
mouvements des planètes furent mieux connus, et le génie de Kepler découvrit la forme de leurs orbites, et les lois éternelles suivant lesquelles ces orbites sont parcourues.

Galilée, appliquant à l'astronomie la découverte récente des lunettes qu'il perfectionna, ouvrit un nouveau ciel aux regards des hommes. Les taches qu'il observa sur le disque du soleil lui en firent connaître la rotation, dont il détermina la période et les lois. Il démontra les phases de Vénus; il découvrit ces quatre lunes qui entourent Jupiter et l'accompagnent dans son immense orbite.

Il apprit à mesurer le temps avec exactitude par les oscillations d'un pendule.

Ainsi l'homme dut à Galilée la première théorie mathématique d'un mouvement qui ne fût pas à la fois uniforme et rectiligne, et la première connaissance d'une des lois mécaniques de la nature ; il dut à Kepler celle d'une de ces lois empiriques, dont la découverte a le double avantage, et de conduire à la connaissance de la loi mécanique dont elles expriment le résultat, et de suppléer à cette connaissance tant qu'il n'est pas encore permis d'y atteindre.

La découverte de la pesanteur de l'air et celle de la circulation du sang marquent les progrès de la physique expérimentale, qui naquit dans l'école de Galilée, et de l'anatomie déjà trop étendue pour ne point se séparer de la médecine.

L'histoire naturelle, la chimie, malgré ses chimériques espérances et son langage énigmatique, la médecine, la chirurgie étonnent par la rapidité de leurs progrès ; mais elles affligent souvent par le spectacle des monstrueux préjugés qu'elles conservent encore.

[Sans parler des ouvrages où Gesner et Agricola renfermèrent tant de connaissances réelles, que le mélange des erreurs scientifiques ou populaires altérait si rarement, on vit Bernard de Palissi, tantôt nous montrer, et les carrières où nous puisons les matériaux de nos édifices, et les masses de pierre qui composent nos montagnes. formées par les débris des animaux marins, monuments authentiques des anciennes révolutions du globe ; tantôt expliquer comment les eaux enlevées à la 
mer par l'évaporation, rendues à la terre par les pluies, arrêtées par les couches de glaise, rassemblées en glaces sur les montagnes, entretiennent l'éternel écoulement des fontaines, des rivières et des fleuves ; tandis que Jean Rei découvrait le secret de ces combinaisons de l'air avec les substances métalliques, premier germe que ces théories brillantes, qui, depuis quelques années, ont reculé les bornes de la chimie.]

Dans l'Italie, l'art de la poésie épique, de la peinture, de la sculpture, atteignirent une perfection que les anciens n'avaient pas connue. Corneille annonçait que l'art dramatique en France était près d'en acquérir une plus grande encore ; car si l'enthousiasme pour l'antiquité croit peut-être avec justice reconnaître quelque supériorité dans le génie des hommes qui en ont créé les chefs-d'œuvre, il est bien difficile qu'en comparant leurs ouvrages avec les productions de l'Italie et de la France, la raison n'aperçoive pas les progrès réels que l'art même a faits entre les mains des modernes.

La langue italienne était entièrement formée ; celles des autres peuples voyaient chaque jour s'effacer quelques traces de leur ancienne barbarie.

On commençait à sentir l'utilité de la métaphysique, de la grammaire ; à connaître l'art d'analyser, d'expliquer philosophiquement, soit les règles, soit les procédés établis par l'usage dans la composition des mots et des phrases.

Partout, à cette époque, on voit la raison et l'autorité se disputer l'empire, combat qui préparait et qui présageait le triomphe de la raison.

C'est donc alors que devait naître cet esprit de critique qui seul peut rendre l'érudition vraiment utile. On avait encore besoin de connaître tout ce qu'avaient fait les anciens ; et l'on commençait à savoir que si on devait les admirer, on avait aussi le droit de les juger. La raison, qui s'appuyait quelquefois sur l'autorité, et contre qui on l'employait si souvent, voulait apprécier, soit la valeur du secours qu'elle espérait y trouver, soit le motif du sacrifice qu'on exigeait d'elle. Ceux qui prenaient l'autorité pour base de leurs opinions, pour 
guide de leur conduite, sentaient combien il leur importait de s'assurer de la force de leurs armes, et de ne pas s'exposer à les voir se briser contre les premières attaques de la raison.

L'usage exclusif d'écrire en latin sur les sciences, sur la philosophie, sur la jurisprudence, et presque sur l'histoire, céda peu à peu la place à celui d'employer la langue usuelle de chaque pays. Et c'est ici le moment d'examiner quelle fut, sur les progrès de l'esprit humain, l'influence de ce changement, qui rendit les sciences plus populaires, mais en diminuant pour les savants la facilité d'en suivre la marche générale; qui fit qu'un livre était lu dans un même pays par plus d'hommes faiblement instruits, et qu'il l'était moins en Europe par des hommes plus éclairés; qui dispense d'apprendre la langue latine un grand nombre d'hommes avides de s'instruire, et n'ayant ni le temps, ni les moyens d'atteindre à une instruction étendue et approfondie ; mais qui force les savants à consumer plus de temps dans l'étude de plus de langues différentes.

Nous montrerons que, s'il était impossible de faire du latin une langue vulgaire, commune à l'Europe entière, la conservation de l'usage d'écrire en latin sur les sciences n'eût eu, pour ceux qui les cultivent, qu'une utilité passagère ; que l'existence d'une sorte de langue scientifique, la même chez toutes les nations, tandis que le peuple de chacune d'elles en parlerait une différente, y eût séparé les hommes en deux classes, eût perpétué dans le peuple les préjugés et les erreurs, eût mis un éternel obstacle à la véritable égalité, à un usage égal de la même raison, à une égale connaissance des vérités nécessaires ; et en arrêtant ainsi les progrès de la masse de l'espèce humaine, eût fini, comme dans l'Orient, par mettre un terme à ceux des sciences ellesmêmes.

Il n'y avait eu longtemps d'instruction que dans les églises et dans les cloîtres.

Les universités furent encore dominées par les prêtres. Forcés d'abandonner au gouvernement une partie de leur influence, ils se la réservèrent tout entière sur l'instruction générale et première ; sur celle qui renferme les lumières nécessaires à toutes les professions communes, à toutes les classes d'hommes, et qui, s'emparant de l'enfance et 
de la jeunesse, en modèle à son gré l'intelligence flexible, l'âme incertaine et facile. Ils laissèrent seulement à la puissance séculière le droit de diriger l'étude de la jurisprudence, de la médecine, l'instruction approfondie des sciences, de la littérature, des langues savantes ; écoles moins nombreuses, où l'on n'envoyait que des hommes déjà façonnés au joug sacerdotal.

Les prêtres perdirent cette influence dans les pays réformés. A la vérité, l'instruction commune, quoique dépendante du gouvernement, ne cessa point d'y être dirigée par l'esprit théologique ; mais elle ne fut plus exclusivement confiée à des membres de la corporation presbytérale. Elle continua de corrompre les esprits par des préjugés religieux, mais elle ne les courba plus sous le joug de l'autorité sacerdotale ; elle fit encore des fanatiques, des illuminés, des sophistes, mais elle ne forma plus d'esclaves pour la superstition.

Cependant l'enseignement, partout asservi, corrompait partout la masse générale des esprits, en opprimant la raison de tous les enfants sous le poids des préjugés religieux de leur pays ; en étouffant, par des préjugés politiques, l'esprit de liberté des jeunes gens destinés à une instruction plus étendue.

Non seulement chaque homme abandonné à lui-1même trouvait entre lui et la vérité l'épaisse et terrible phalange des erreurs de son pays et de son siècle ; mais déjà on lui avait rendu personnelles, en quelque sorte, les plus dangereuses de ces erreurs. Chaque homme, avant de pouvoir dissiper celles d'autrui, devait commencer par reconnaître les siennes ; avant de combattre les difficultés que la nature oppose à la découverte de la vérité, il avait besoin de refaire en quelque sorte sa propre intelligence. L'instruction donnait déjà des lumières ; mais pour qu'elles fussent utiles, il fallait les épurer, les séparer du nuage dont la superstition, d'accord avec la tyrannie, avait su les envelopper.

Nous montrerons quels obstacles plus ou moins puissants ces vices de l'instruction publique, ces croyances religieuses opposées entre elles, cette influence des diverses formes de gouvernement, apportèrent aux progrès de l'esprit humain. On verra que ces progrès furent d'autant plus lents, que les objets soumis à la raison touchaient davantage 
aux intérêts politiques ou religieux; que la philosophie générale, la métaphysique, dont les vérités attaquaient directement toutes les superstitions, furent plus opiniâtrement retardées dans leur marche, que la politique dont le perfectionnement ne menaçait que l'autorité des rois ou des sénats aristocratiques ; que la même observation peut également s'appliquer aux sciences physiques.

Nous développerons les autres sources d'inégalité qui ont pu naître de la nature des objets que chaque science envisage, ou des méthodes qu'elle emploie.

Celle qu'on peut également observer pour une même science, dans les divers pays, est aussi l'effet composé de causes politiques et de causes naturelles. Nous chercherons ce qui, dans ces différences, appartient à la diversité des religions, à la forme du gouvernement, à la richesse, à la puissance de la nation, à son caractère, à sa position géographique, aux événements dont elle a été le théâtre ; enfin, au hasard qui a fait naître dans son sein quelques-uns de ces hommes extraordinaires dont l'influence, en s'étendant sur l'humanité tout entière, s'exerce cependant autour d'eux avec plus d'énergie.

Nous distinguerons les progrès de la science même, qui n'ont pour mesure que la somme des vérités qu'elle renferme, et ceux d'une nation dans chaque science, progrès qui se mesurent alors, sous un rapport, par le nombre des hommes qui en connaissent les vérités les plus usuelles, les plus importantes, et, sous un autre, par le nombre et la nature de ces vérités généralement connues.

En effet, nous sommes arrivés au point de civilisation, où le peuple profite des lumières, non seulement par les services qu'il reçoit des hommes éclairés, mais parce qu'il a su s'en faire une sorte de patrimoine, et les employer immédiatement à se défendre contre l'erreur, à prévenir ou satisfaire ses besoins, à se préserver des maux de la vie ou à les adoucir par des jouissances nouvelles.

L'histoire des persécutions auxquelles furent exposés, dans cette époque, les défenseurs de la vérité, ne sera point oubliée. Nous verrons ces persécutions s'étendre des vérités philosophiques ou politiques jusque sur celles de la médecine, de l'histoire naturelle, de la 
physique et de l'astronomie. Dans le huitième siècle, un pape ignorant avait persécuté un diacre pour avoir soutenu la rondeur de la terre, contre l'opinion du rhéteur Augustin. Dans le dix-septième, l'ignorance bien plus honteuse d'un autre pape livra aux inquisiteurs, Galilée, convaincu d'avoir prouvé le mouvement diurne et annuel de la terre. Le plus grand génie que l'Italie moderne ait donné aux sciences, accablé de vieillesse et d'infirmités, fut obligé, pour se soustraire au supplice ou à la prison, de demander pardon à Dieu d'avoir appris aux hommes à mieux connaître ses ouvrages, à l'admirer dans la simplicité des lois éternelles par lesquelles il gouverne l'univers.

Cependant l'absurdité des théologiens était si palpable, que, cédant au respect humain, ils permirent de soutenir le mouvement de la terre, pourvu que ce fût comme une hypothèse, et que la foi n'en reçût aucune atteinte. Mais les astronomes ont fait précisément le contraire ; ils ont cru au mouvement réel de la terre, et ont calculé suivant l'hypothèse de son immobilité.

Trois grands hommes ont marqué le passage de cette époque à celle qui va suivre, Bacon, Galilée, Descartes.

Bacon a révélé la véritable méthode d'étudier la nature, d'employer les trois instruments qu'elle nous a donnés pour pénétrer ses secrets, l'observation, l'expérience et le calcul. Il veut que le philosophe, jeté au milieu de l'univers, commence par renoncer à toutes les croyances qu'il a reçues, et même à toutes les notions qu'il s'est formées, pour se recréer, en quelque sorte, un entendement nouveau, dans lequel il ne doit plus admettre que des idées précises,. des notions justes, des vérités dont le degré de certitude ou de probabilité ait été rigoureusement pesé. Mais Bacon, qui possédait le génie de la philosophie au point le plus élevé, n'y joignit point celui des sciences ; et ces méthodes de découvrir la vérité, dont il ne donne point l'exemple, furent admirées des philosophes, mais ne changèrent point la marche des sciences.

Galilée les avait enrichies de découvertes utiles et brillantes; il avait enseigné, par son exemple, les moyens de s'élever à la connaissance des lois de la nature par une méthode sûre et féconde, qui n'oblige point de sacrifier l'espérance du succès à la crainte de s'égarer. Il fonda pour les sciences la première école où elles aient été 
cultivées sans aucun mélange de superstition, soit pour les préjugés, soit pour l'autorité ; où l'on ait rejeté, avec une sévérité philosophique, tout autre moyen que l'expérience et le calcul. Mais se bornant exclusivement aux sciences mathématiques et physiques, il ne put imprimer aux esprits ce mouvement qu'ils semblaient attendre.

Cet honneur était réservé à Descartes, philosophe ingénieux et hardi. Doué d'un grand génie pour les sciences, il joignit l'exemple au précepte, en donnant la méthode de trouver, de reconnaître la vérité. Il en montrait l'application dans la découverte des lois de la dioptrique, de celles du choc des corps ; enfin, d'une nouvelle branche de mathématiques qui devait en reculer toutes les bornes.

Il voulait étendre sa méthode à tous les objets de l'intelligence humaine ; Dieu, l'homme, l'univers étaient tour à tour le sujet de ses méditations. Si, dans les sciences physiques, sa marche est moins sûre que celle de Galilée ; si sa philosophie est moins sage que celle de Bacon ; si on peut lui reprocher de n'avoir pas assez appris par les leçons de l'un, par l'exemple de l'autre, à se défier de son imagination, à n'interroger la nature que par des expériences, à ne croire qu'au calcul, à observer l'univers, au lieu de le construire, à étudier l'homme, au lieu de le deviner, l'audace même de ses erreurs servit aux progrès de l'espèce humaine. Il agita les esprits, que la sagesse de ses rivaux n'avait pu réveiller. Il dit aux hommes de secouer le joug de l'autorité, de ne plus reconnaître que celle qui serait avouée par leur raison; et il fut obéi, parce qu'il subjuguait par sa hardiesse, qu'il entraînait par son enthousiasme.

L'esprit humain ne fut pas libre encore, mais il sut qu'il était formé pour l'être. Ceux qui osèrent s'opiniâtrer à lui conserver ses chaînes, ou essayer de lui en donner de nouvelles, furent forcés de lui prouver qu'il devait les garder ou les recevoir ; et dès lors on put prévoir qu'elles seraient bientôt brisées. 
CONDORCET,

Esquisse d'un tableau historique des progrès de l'esprit humain

(1793-1794).

\section{Neuvième époque}

\section{Depuis Descartes jusqu'à la formation de la République française.}

Nous avons vu la raison humaine se former lentement par les progrès naturels de la civilisation ; la superstition s'emparer d'elle pour la corrompre, et le despotisme dégrader et engourdir les esprits sous le poids de la crainte et du malheur.

Un seul peuple échappe à cette double influence. De cette terre heureuse où la liberté vient d'allumer le flambeau du génie, l'esprit humain, affranchi des liens de son enfance, s'avance vers la vérité d'un pas ferme. Mais la conquête ramène bientôt avec elle la tyrannie, que suit la superstition, sa compagne fidèle, et l'humanité tout entière est replongée dans des ténèbres qui semblent devoir être éternelles. Cependant, le jour renaît peu à peu ; les yeux, longtemps condamnés à l'obscurité, l'entrevoient, se referment, s'y accoutument lentement, fixent enfin la lumière, et le génie ose se remontrer sur ce globe, d'où le fanatisme et la barbarie l'avaient exilé. 
Déjà nous avons vu la raison soulever ses chaînes, en relâcher quelques-unes ; et acquérant sans cesse des forces nouvelles, préparer, accélérer l'instant de sa liberté.

Il nous reste à parcourir l'époque où elle acheva de les rompre, où, forcée d'en traîner encore les restes, elle s'en délivre peu à peu ; où, libre enfin dans sa marche, elle ne peut plus être arrêtée que par ces obstacles dont le renouvellement est inévitable à chaque nouveau progrès, parce qu'ils ont pour cause nécessaire la constitution même de notre intelligence, c'est-à-dire, un rapport établi par la nature entre nos moyens pour découvrir la vérité, et la résistance qu'elle oppose à nos efforts. L'intolérance religieuse avait forcé sept des provinces belgiques à secouer le joug de l'Espagne, et à former une république fédérative. Elle seule avait réveillé la liberté anglaise, qui, fatiguée par de longues et sanglantes agitations, a fini par se reposer dans une constitution longtemps admirée par la philosophie, et désormais réduite à n'avoir plus pour appui que la superstition nationale et l'hypocrisie politique.

Enfin, c'était encore aux persécutions sacerdotales que la nation suédoise avait dû le courage de ressaisir une partie de ses droits.

Cependant, au milieu de ces mouvements, causés par des querelles théologiques, la France, l'Espagne, la Hongrie, la Bohême, avaient vu s'anéantir leurs faibles libertés, ou ce qui, du moins, en avait l'apparence.

On chercherait en vain, dans les pays appelés libres, cette liberté qui ne blesse aucun des droits naturels de l'homme; qui non seulement lui en réserve la propriété, mais lui en conserve l'exercice. Celle qu'on y. trouve, fondée sur un droit positif inégalement réparti, accorde plus ou moins de prérogatives à un homme, suivant qu'il habite telle ou telle ville, qu'il est né dans telle ou telle classe, qu'il a telle ou telle fortune, qu'il exerce telle ou telle profession ; et le tableau rapproché de ces distinctions bizarres dans les diverses nations, sera la meilleure réponse que nous puissions opposer à ceux qui en soutiennent encore les avantages et la nécessité. 
Mais, dans ces mêmes pays, les lois garantissent la liberté individuelle et civile ; mais si l'homme n'y est pas tout ce qu'il doit être, la dignité de sa nature n'y est point avilie : quelques-uns de ces droits sont au moins reconnus; on ne peut plus dire qu'il soit esclave ; on doit dire seulement qu'il ne sait pas encore être 'vraiment libre.

Chez les nations où, pendant le même temps, la liberté a fait des pertes plus ou moins réelles, les droits politiques dont la masse du peuple jouissait étaient renfermés dans des limites si étroites, que la destruction de l'aristocratie presque arbitraire sous laquelle il avait gémi semble en avoir plus que compensé la perte. Il a perdu ce titre de citoyen, que l'inégalité rendait presque illusoire; mais la qualité d'homme a été plus respectée ; et le despotisme royal l'a sauvé de l'oppression féodale, l'a soustrait à cet état d'humiliation, d'autant plus pénible que le nombre et la présence de ses tyrans en renouvellent sans cesse le sentiment. Les lois ont dû se perfectionner et dans les constitutions demi-libres, parce que l'intérêt de ceux qui y exercent un véritable pouvoir, n'est pas habituellement contraire aux intérêts généraux du peuple ; et dans les États despotiques, soit parce que l'intérêt de la prospérité publique se confond souvent avec celui du despote, soit parce que, cherchant lui-même à détruire les restes du pouvoir des nobles ou du clergé, il en résultait dans les lois un esprit d'égalité, dont le motif était d'établir celle de l'esclavage, mais dont les effets pouvaient souvent être salutaires.

Nous exposerons en détail les causes qui ont produit en Europe ce genre de despotisme dont, ni les siècles antérieurs, ni les autres parties du monde, n'ont offert d'exemple ; où l'autorité presque arbitraire, contenue par l'opinion, réglée par les lumières, adoucie par son propre intérêt, a souvent contribué aux progrès de la richesse, de l'industrie, de l'instruction, et quelquefois même à ceux de la liberté civile.

Les mœurs se sont adoucies par l'affaiblissement des préjugés qui en avaient maintenu la férocité ; par l'influence de cet esprit de commerce et d'industrie, ennemi des violences et des troubles qui font fuir-la richesse ; par l'horreur qu'inspirait le tableau encore récent des barbaries de l'époque précédente ; par une propagation plus générale des idées philosophiques, d'égalité et d'humanité ; enfin, par l'effet lent, mais sûr, du progrès général des lumières. 
L'intolérance religieuse a subsisté, mais comme une invention de la prudence humaine, comme un hommage aux préjugés du peuple, ou une précaution contre son effervescence. Elle a perdu ses fureurs ; les bûchers, rarement allumés, ont été remplacés par une oppression souvent plus arbitraire, mais moins barbare ; et dans ces derniers temps, on n'a plus persécuté que de loin en loin, et, en quelque sorte, par habitude ou par complaisance. Partout, et sur tous les points, la pratique des gouvernements avait suivi, mais lentement et comme à regret, la marche de l'opinion, et même celle de la philosophie.

En effet, si, dans les sciences morales et politiques, il existe à chaque instant une grande distance entre le point où les philosophes ont porté les lumières, et le terme moyen où sont parvenus les hommes qui cultivent leur esprit, et dont la doctrine commune forme cette espèce de croyance généralement adoptée, qu'on nomme opinion ; ceux qui dirigent les affaires publiques, qui influent immédiatement sur le sort du peuple, quel que soit le genre de leur constitution, sont bien loin de s'élever au niveau de cette opinion ; ils la suivent, mais sans l'atteindre, bien loin de la devancer ; ils se trouvent constamment audessous d'elle, et de beaucoup d'années, et de beaucoup de vérités.

Ainsi, le tableau des progrès de la philosophie et de la propagation des lumières, dont nous avons exposé déjà les effets les plus généraux et les plus sensibles, va nous conduire à l'époque où l'influence de ces progrès sur l'opinion, de l'opinion sur les nations ou sur leurs chefs, cessant tout à coup d'être lente et insensible, a produit dans la masse entière de quelques peuples, une révolution, gage certain de celle qui doit embrasser la généralité de l'espèce, humaine.

Après de longues erreurs, après s'être égarés dans des théories incomplètes ou vagues, les publicistes sont parvenus à connaître enfin les véritables droits de l'homme, à les déduire de cette seule vérité, qu'il est un être sensible, capable de former des raisonnements et d'acquérir des idées morales.

Ils ont vu que le maintien de ces droits était l'objet unique de la réunion des hommes en sociétés politiques, et que l'art social devait être celui de leur garantir la conservation de ces droits avec la plus entière 
égalité, comme dans la plus grande étendue. On a senti que ces moyens d'assurer les droits de chacun, devant être soumis dans chaque société à des règles communes, le pouvoir de choisir ces moyens, de déterminer ces règles, ne pouvait appartenir qu'à la majorité des membres de la société même ; parce que chaque individu ne pouvant, dans ce choix, suivre sa propre raison sans y assujettir les autres, le vœu de la majorité est le seul caractère de vérité qui puisse être adopté par tous, sans blesser l'égalité.

Chaque homme peut réellement se lier d'avance à ce vœu de la majorité, qui devient alors celui de l'unanimité ; mais il ne peut y lier que lui seul : il ne peut être engagé, même envers cette majorité, qu'autant qu'elle ne blessera pas ses droits individuels, après les avoir reconnus.

Tels sont à la fois les droits de la majorité sur la société ou sur ses membres, et les limites de ces droits. Telle est l'origine de cette unanimité, qui rend obligatoires pour tous les engagements pris par la majorité seule : obligation qui cesse d'être légitime quand, par le changement des individus, cette sanction de l'unanimité a cessé elle-même d'exister. Sans doute, il est des objets sur lesquels la majorité prononcerait peut-être plus souvent en faveur de l'erreur et contre l'intérêt commun de tous ; mais c'est encore à elle à décider quels sont ces objets sur lesquels elle ne doit point s'en rapporter immédiatement à ses propres décisions ; c'est à elle à déterminer qui seront ceux dont elle croit devoir substituer la raison à la sienne ; à régler la méthode qu'ils doivent suivre pour arriver plus sûrement à la vérité ; et elle ne peut abdiquer l'autorité de prononcer si leurs décisions n'ont point blessé les droits communs à tous.

Ainsi, l'on vit disparaître, devant des principes si simples, ces idées d'un contrat entre un peuple et ses magistrats, qui ne pourrait être annulé que par un consentement mutuel, ou par l'infidélité d'une des parties ; et cette opinion moins servile, mais non moins absurde, qui enchaînait un peuple aux formes de constitution une fois établies, comme si le droit de les changer n'était pas la première garantie de tous les autres ; comme si les institutions humaines, nécessairement défectueuses et susceptibles d'une perfection nouvelle à mesure que les hommes s'éclairent, pouvaient être con. damnées à une éternelle durée de leur enfance. Ainsi, l'on se vit obligé de renoncer à cette poli- 
tique astucieuse et fausse, qui, oubliant que tous les hommes tiennent des droits égaux de leur nature même, voulait tantôt mesurer l'étendue de ceux qu'il fallait leur laisser, sur la grandeur du territoire, sur la température du climat, sur le caractère national, sur la richesse du peuple, sur le degré de perfection du commerce et de l'industrie; et tantôt partager, avec inégalité, ces mêmes droits entre diverses classes d'hommes, en accorder à la naissance, à la richesse, à la profession, et créer ainsi des intérêts contraires, des pouvoirs opposés, pour établir ensuite entre eux un équilibre que ces institutions seules ont rendu nécessaire, et qui n'en corrige même pas les influences dangereuses.

Ainsi, l'on n'osa plus partager les hommes en deux races différentes, dont l'une est destinée à gouverner, l'autre à obéir ; l'une à mentir, l'autre à être trompée ; on fut obligé de reconnaître que tous ont un droit égal de s'éclairer sur tous leurs intérêts, de connaître toutes les vérités ; et qu'aucun des pouvoirs établis par eux sur eux-mêmes, ne peut avoir le droit de leur en cacher aucune.

Ces principes que le généreux Sydney paya de son sang, auxquels Locke attacha l'autorité de son nom, furent développés depuis par Rousseau, avec plus de précision, d'étendue et de force, et il mérita la gloire de les placer au nombre de ces vérités qu'il n'est plus permis, ni d'oublier, ni de combattre.

L'homme a des besoins et des facultés pour y pourvoir ; de ces facultés et de leur produit, différemment modifiés, distribués, résulte une masse de richesses destinées à subvenir aux besoins communs. Mais quelles sont les lois suivant lesquelles ces richesses se forment ou se partagent, se conservent ou se consomment, s'accroissent ou se dissipent ? Quelles sont aussi les lois de cet équilibre, qui tend sans cesse à s'établir entre les besoins et les ressources, et d'où il résulte plus de facilité pour satisfaire les besoins, par conséquent, plus de bien-être quand la richesse augmente, jusqu'à ce qu'elle ait atteint le terme de son accroissement ; et, au contraire, quand la richesse diminue, plus de difficultés, et par conséquent de la souffrance, jusqu'à ce que la dépopulation et les privations aient ramené le niveau ? Comment, dans cette étonnante variété de travaux et de produits, de besoins et de ressources ; dans cette effrayante complication d'intérêts, qui lient au système général des sociétés, la subsistance, le bien-être 
d'un individu isolé ; qui le rend dépendant de tous les accidents de la nature, de tous les événements de la politique ; qui étend, en quelque sorte, au globe entier sa faculté d'éprouver, on des jouissances, ou des privations ; comment, dans ce chaos apparent, voit-on néanmoins, par une loi générale du monde moral, les efforts de chacun pour lui-même servir au bien-être de tous, et, malgré le choc extérieur des intérêts opposés, l'intérêt commun exiger que chacun sache entendre le sien propre, et puisse y obéir sans obstacle ?

Ainsi, l'homme doit pouvoir déployer ses facultés, disposer de ses richesses, pourvoir à ses besoins avec une liberté entière. L'intérêt général de chaque société, loin d'ordonner d'en restreindre l'exercice, défend au contraire d'y porter atteinte, et dans cette partie de l'ordre publie, le soin d'assurer à chacun les droits qu'il tient de la nature est encore à la fois la seule politique utile, le seul devoir de la puissance sociale, et le seul droit que la volonté générale puisse légitimement exercer sur les individus.

Mais ce principe une fois reconnu, il reste encore à la puissance publique des devoirs à remplir ; elle doit établir des mesures reconnues par la loi, qui servent à constater, dans les échanges de toute espèce, le poids, le volume, l'étendue, la longueur des choses échangées.

Elle doit créer une mesure commune des valeurs qui les représente toutes ; qui facilite le calcul de leurs variations et de leurs rapports ; qui, ayant ensuite elle-même sa propre valeur, puisse être échangée contre toutes les choses susceptibles d'en avoir une ; moyen sans lequel le commerce, borné à des échanges directs, ne peut acquérir que bien peu d'activité et d'étendue.

La reproduction de chaque année offre une portion disponible, puisqu'elle n'est destinée à payer, ni le travail dont cette reproduction est le fruit, ni celui qui doit assurer une nouvelle reproduction égale ou plus abondante. Le possesseur de cette portion disponible ne la doit point immédiatement à son travail ; il la possède indépendamment de l'usage qu'il peut faire de ses facultés, pour subvenir à ses besoins. C'est donc sur cette portion disponible de la richesse annuelle que, sans blesser aucun droit, la puissance sociale peut établir les fonds nécessaires aux dépenses qu'exigent la sûreté de l'État, sa tranquillité 
intérieure, la garantie des droits des individus, l'exercice des autorités instituées pour la formation ou pour l'exécution de la loi ; enfin, le maintien de la prospérité publique.

Il existe des travaux, des établissements, des institutions utiles à la société générale, qu'elle doit établir, diriger ou surveiller, et qui suppléent à ce que les volontés personnelles et le concours des intérêts individuels ne peuvent faire immédiatement, soit pour les progrès de l'agriculture, de l'industrie, du commerce, soit pour prévenir, pour atténuer les maux inévitables de la nature, ou ceux que des accidents imprévus viennent y ajouter.

Jusqu'à l'époque dont nous parlons, et même longtemps après, ces divers objets avaient été abandonnés au hasard, à l'avidité des gouvernements, à l'adresse des charlatans, aux préjugés ou à l'intérêt de toutes les classes puissantes ; mais un disciple de Descartes, l'illustre et malheureux Jean de Witt, sentit que l'économie politique devait, comme toutes les sciences, être soumise aux principes de la philosophie et à la précision du calcul.

Elle fit peu de progrès jusqu'au moment où la paix d'Utrecht promit à l'Europe une tranquillité durable. À cette époque, on vit les esprits prendre une direction presque générale vers cette étude jusqu'alors négligée ; et cette science nouvelle a été portée par Stewart, par Smith, et surtout par les économistes français, du moins, pour la précision et la pureté des principes, à un degré qu'on ne pouvait espérer d'atteindre si promptement, après une si longue indifférence.

Mais ces progrès dans la politique et dans l'économie politique avaient pour première cause ceux de la philosophie générale ou de la métaphysique, en prenant ce mot dans son sens le plus étendu.

Descartes l'avait réunie au domaine de la raison ; il avait bien senti qu'elle devait émaner tout entière des vérités évidentes et premières que l'observation des opérations de notre esprit devait nous révéler. Mais bientôt son imagination impatiente l'écarta de cette même route qu'il avait tracée, et la philosophie parut quelque temps n'avoir repris son indépendance que pour s'égarer dans des erreurs nouvelles. 
Enfin, Locke saisit le fil qui devait la guider ; il montra qu'une analyse exacte, précise, des idées, en les réduisant successivement à des idées plus immédiates dans leur origine, ou plus simples dans leur composition, était le seul moyen de ne pas se perdre dans ce chaos de notions incomplètes, incohérentes, indéterminées, que le hasard nous a offertes sans ordre, et que nous avons reçues sans réflexion.

Il prouva, par cette analyse même, que toutes sont le résultat des opérations de notre intelligence sur les sensations que nous avons reçues, ou, plus exactement encore, des combinaisons de ces sensations que la mémoire nous représente simultanément, mais de manière que l'attention s'arrête, que la perception se borne à une partie seulement de chacune de ces sensations composées.

Il fait voir qu'en attachant un mot à chaque idée, après l'avoir analysée et circonscrite, nous parvenons à nous la rappeler constamment la même, c'est-à-dire, toujours formée des mêmes idées plus simples, toujours renfermée dans les mêmes limites, et par conséquent, à pouvoir l'employer dans une suite de raisonnements, sans jamais risquer de nous égarer.

Au contraire, si les mots ne répondent point à une idée bien déterminée, ils peuvent successivement en réveiller de différentes dans un même esprit ; et telle est la source la plus féconde de nos erreurs.

Enfin, Locke osa, le premier, fixer les bornes de l'intelligence humaine, ou plutôt déterminer la nature des vérités qu'elle peut connaître, des objets qu'elle peut embrasser.

Cette méthode devint bientôt celle de tous les philosophes ; et c'est en l'appliquant à la morale, à la politique, à l'économie publique, qu'ils sont parvenus à suivre dans ces sciences une marche presque aussi sûre que celle des sciences naturelles ; à n'y plus admettre que des vérités prouvées ; à séparer ces vérités de tout ce qui peut rester encore de douteux et d'incertain ; à savoir ignorer, enfin, ce qu'il est encore, ce qu'il sera toujours impossible de connaître.

[Ainsi, l'analyse de nos sentiments nous fait découvrir, dans le développement de notre faculté d'éprouver du plaisir et de la douleur, 
l'origine de nos idées morales, le fondement des vérités générales qui, résultant de ces idées, déterminent les lois immuables, nécessaires, du juste et de l'injuste ; enfin, les motifs d'y conformer notre conduite, puisés dans la nature même de notre sensibilité, dans ce qu'on pourrait appeler, en quelque sorte, notre constitution morale.]

Cette même méthode devint, en quelque sorte, un instrument universel ; on apprit à l'employer pour perfectionner celle des sciences physiques, pour en éclaircir les principes, pour en apprécier les preuves ; on l'étendit à l'examen des faits, aux règles du goût.

Ainsi, cette métaphysique s'appliquant à tous les objets de l'intelligence humaine, analysait les procédés de l'esprit dans chaque genre de connaissances, faisait connaître la nature des vérités qui en forment le système, celle de l'espèce de certitude qu'on peut y atteindre ; et c'est ce dernier pas de la philosophie qui a mis, en quelque sorte, une barrière éternelle entre le genre humain et les vieilles erreurs de son enfance ; qui doit l'empêcher d'être jamais ramené à son ancienne ignorance par des préjugés nouveaux, comme il assure la chute de tous ceux que nous conservons, sans peut-être les connaître tous encore ; et de ceux même qui pourront les remplacer, mais pour ne plus avoir qu'une faible influence et une existence éphémère.

Cependant, en Allemagne, un homme d'un génie vaste et profond jetait les fondements d'une doctrine nouvelle. Son imagination ardente, audacieuse, ne put se reposer dans une philosophie modeste, qui laissait subsister des doutes sur ces grandes questions de la spiritualité ou de la persistance de l'âme humaine, de la liberté de l'homme ou de celle de Dieu, de l'existence de la douleur et du crime dans un univers gouverné par une intelligence toute-puissante, dont la sagesse, la justice et la bonté semblent devoir exclure le crime et la douleur. Il trancha le nœud qu'une sage analyse n'aurait pu dénouer. Il composa l'univers d'êtres simples, indestructibles, égaux par leur nature. Les rapports de chacun de ces êtres avec chacun de ceux qui entrent avec lui dans le système de l'univers, déterminent ses qualités par lesquelles il diffère de tous les autres ; l'âme humaine et le dernier atome qui termine un bloc de pierre sont également une de ces monades. Elles ne diffèrent que par la place différente qu'elles occupent dans l'ordre de l'univers. 
Parmi toutes les combinaisons possibles de ces êtres, une intelligence infinie en a préféré une, et n'en a pu préférer qu'une seule, la plus parfaite de toutes. Si celle qui existe nous afflige par le spectacle du malheur et du crime, c'est que toute autre combinaison eût encore présenté des résultats plus douloureux.

Nous exposerons ce système, qui, adopté, ou du moins soutenu par les compatriotes de Leibnitz, a retardé parmi eux les progrès de la philosophie. On vit une école entière de philosophes anglais embrasser avec enthousiasme et défendre avec éloquence la doctrine de l'optimisme ; mais moins adroits et moins profonds que Leibnitz, qui la fondait principalement sur ce qu'une intelligence toute-puissante, par la nécessité même de sa nature, n'avait pu choisir que le meilleur des univers possibles, ils cherchèrent, dans l'observation du nôtre, la preuve de sa supériorité ; et perdant tous les avantages que conserve ce système, tant qu'il reste dans une abstraite généralité, ils s'égarèrent trop souvent dans des détails ou révoltants, ou ridicules.

Cependant, en Écosse, d'autres philosophes, ne trouvant point que l'analyse du développement de nos facultés réelles conduisît à un principe qui donnât à la moralité de nos actions une base assez pure, assez solide, Imaginèrent d'attribuer à l'âme humaine une faculté nouvelle, distincte de celles de sentir ou de raisonner, mais se combinant avec elles, faculté dont ils ne prouvaient l'existence qu'en assurant qu'il leur était impossible de s'en passer. Nous ferons l'histoire de ces opinions, et nous montrerons comment, si elles ont nui à la marche de la philosophie, elles ont été utiles à la propagation plus rapide des idées philosophiques.

Jusqu'ici nous n'avons montré les progrès de la philosophie que dans les hommes qui l'ont cultivée approfondie, perfectionnée : il nous reste à faire voir quels ont été ses effets sur l'opinion générale, et comment, tandis que, s'élevant enfin -à la connaissance de la méthode certaine de découvrir, de reconnaître la vérité, la raison apprenait à se préserver des erreurs où le respect pour l'autorité et l'imagination l'avaient si souvent entraînée : elle détruisait en même temps, dans la masse générale des individus, les préjugés qui ont si longtemps affligé et corrompu l'espèce humaine. 
Il fut enfin permis de proclamer hautement ce droit si longtemps méconnu, de soumettre toutes les opinions à notre propre raison, c'està-dire, d'employer, pour saisir la vérité, le seul instrument qui nous ait été donné pour la reconnaître. Chaque homme apprit, avec une sorte d'orgueil, que la nature ne l'avait pas absolument destiné à croire sur la parole d'autrui ; et la superstition de l'antiquité, l'abaissement de la raison devant le délire d'une foi surnaturelle, disparurent de la société comme de la philosophie.

Il se forma bientôt en Europe une classe d'hommes moins occupés encore de découvrir ou d'approfondir la vérité, que de la répandre ; qui, se dévouant à poursuivre les préjugés dans les asiles où le clergé, les écoles, les gouvernements, les corporations anciennes les avaient recueillis et protégés, mirent leur gloire à détruire les erreurs populaires, plutôt qu'à reculer les limites des connaissances humaines ; manière indirecte de servir à leurs progrès, qui n'était ni la moins périlleuse, ni la moins utile.

En Angleterre, Collins et Bolingbroke ; en France, Bayle, Fontenelle, Voltaire, Montesquieu et les écoles formées par ces hommes célèbres, combattirent en faveur de la vérité, employant tour à tour toutes les armes que l'érudition, la philosophie, l'esprit, le talent d'écrire peuvent fournir à la raison ; prenant tous les tons, employant toutes les formes, depuis la plaisanterie jusqu'au pathétique, depuis la compilation la plus savante et la plus vaste, jusqu'au roman, ou au pamphlet du jour ; couvrant la vérité d'un voile qui ménageait les yeux trop faibles, et laissait le plaisir de la deviner ; caressant les préjugés avec adresse, pour leur porter des coups plus certains ; n'en menaçant presque jamais, ni plusieurs à la fois, ni même un seul tout entier ; consolant quelquefois les ennemis de la raison, en paraissant ne vouloir dans la religion qu'une demi-tolérance, dans la politique qu'une demi-liberté ; ménageant le despotisme quand ils combattaient les absurdités religieuses, et le culte quand ils s'élevaient contre la tyrannie ; attaquant ces deux fléaux dans leur principe, quand même ils paraissaient n'en vouloir qu'à des abus révoltants ou ridicules, et frappant ces arbres funestes dans leurs racines, quand ils semblaient se borner à élaguer quelques branches égarées ; tantôt apprenant aux amis de la liberté que la superstition, qui couvre le despotisme d'un bouclier im- 
pénétrable, est la première victime qu'ils doivent immoler, la première chaîne qu'ils doivent briser ; tantôt, au contraire, la dénonçant aux despotes comme la véritable ennemie de leur pouvoir, et les effrayant du tableau de ses hypocrites complots et de ses fureurs sanguinaires ; mais ne se lassant jamais de réclamer l'indépendance de la raison, la liberté d'écrire comme le droit, comme le salut du genre humain ; s'élevant, avec une infatigable énergie, contre tous les crimes du fanatisme et de la tyrannie ; poursuivant dans la religion, dans l'administration, dans les mœurs, dans les lois, tout ce qui portait le caractère dé l'oppression, de la dureté, de la barbarie ; ordonnant, au nom de la nature, aux rois, aux guerriers, aux magistrats, aux prêtres, de respecter le sang des hommes ; leur reprochant, avec une énergique sévérité, celui que leur politique ou leur indifférence prodiguait encore dans les combats ou dans les supplices ; prenant enfin, pour cri de guerre, raison, tolérance, humanité.

Telle fut cette philosophie nouvelle, objet de la haine commune de ces classes nombreuses qui n'existent que par les préjugés, ne vivent que d'erreurs, ne sont puissantes que par la crédulité ; presque partout accueillie, mais persécutée ; ayant des rois, des prêtres, des grands, des magistrats pour disciples et pour ennemis. Ses chefs eurent presque toujours l'art d'échapper à la vengeance, en s'exposant à la haine ; de se cacher à la persécution, en se montrant assez pour ne >rien perdre de leur gloire.

Souvent un gouvernement les récompensait d'une main, en payant de l'autre leurs calomniateurs ; les proscrivait, et s'honorait que le sort eût placé leur naissance sur son territoire ; les punissait de leurs opinions, et aurait été humilié d'être soupçonné de ne pas les partager.

Ces opinions devaient donc devenir bientôt celles de tous les hommes éclairés, avouées par les uns, dissimulées par les autres avec une hypocrisie plus ou moins transparente suivant que leur caractère était plus ou moins timide, et qu'ils cédaient aux intérêts opposés de leur profession ou de leur vanité. Mais déjà cet intérêt de leur vanité était assez puissant, pour qu'au lieu de cette dissimulation profonde des âges précédents on se contentât pour soi-même et souvent pour les autres d'une réserve prudente. 
Nous suivrons les progrès de cette philosophie dans les diverses parties de l'Europe, où l'inquisition des gouvernements et des prêtres ne, put empêcher la langue française, devenue presque universelle, de la porter avec rapidité. Nous montrerons avec quelle adresse la politique et la superstition employèrent contre elle tout ce que la connaissance de l'homme peut offrir de motifs pour se défier de sa raison, d'arguments pour en montrer les bornes et la faiblesse ; et comment on sut faire servir le pyrrhonisme même à la cause de la crédulité.

Ce système si simple, qui plaçait dans la jouissance d'une liberté indéfinie les plus sûrs encouragements du commerce et de l'industrie, qui délivrait les peuples du fléau destructeur et du joug humiliant de ces impôts répartis avec tant d'inégalité, levés avec tant de dépense, et souvent avec tant de barbarie, pour y substituer une contribution juste, égale et presque insensible ; cette théorie qui liait la véritable puissance et la richesse des États au bien-être des individus, et au respect pour leurs droits ; qui unissait, par le lien d'une félicité commune, les différentes classes entre lesquelles ces sociétés se divisent naturellement ; cette idée si consolante d'Une fraternité du genre humain, dont aucun intérêt national ne devait plus troubler la douce harmonie ; ces principes, séduisants par leur générosité comme par leur simplicité et leur étendue, furent propagés avec enthousiasme par les économistes français. Leur succès fut moins prompt, moins général que celui des philosophes ; ils avaient à combattre des préjugés moins grossiers, des erreurs plus subtiles. Ils avaient besoin d'éclairer avant de détromper, et d'instruire le bon sens avant de le prendre pour juge.

Mais s'ils n'ont pu faire à l'ensemble de leur doctrine qu'un petit nombre de partisans; si on a été effrayé de la généralité de leurs maximes, de l'inflexibilité de leurs principes ; s'ils ont nui eux-mêmes à la bonté de leur cause, en affectant un langage obscur et dogmatique ; en paraissant trop oublier, pour les intérêts de la liberté du commerce, ceux de la liberté politique ; en présentant, d'une manière trop absolue et trop magistrale, quelques portions de leur système qu'ils n'avaient point assez approfondies, du moins ils sont parvenus à rendre odieuse et méprisable cette politique lâche, astucieuse et corrompue, qui plaçait la prospérité d'une nation dans l'appauvrissement de ses voisins, dans les vues étroites d'un régime prohibitif, dans les petites combinaisons d'une fiscalité tyrannique. 
Mais les vérités nouvelles dont le génie avait enrichi la philosophie, la politique et l'économie publique, adoptées avec plus ou moins d'étendue par les hommes éclairés, portèrent plus loin leur salutaire influence.

L'art de l'imprimerie s'était répandu sur tant de points ; il avait tellement multiplié les livres ; on avait su les proportionner si bien à tous les degrés de connaissances, d'application, et même de fortune ; on les avait pliés avec tant d'habileté à tous les goûts, à tous les genres d'esprit ; ils présentaient une instruction si facile, souvent même si agréable ; ils avaient ouvert tant de portes à la vérité, qu'il était devenu presque impossible de les lui fermer toutes; qu'il n'y avait plus de classe, de profession à laquelle on pût l'empêcher de parvenir. Alors, quoiqu'il restât toujours un très grand nombre d'hommes condamnés à une ignorance volontaire ou forcée, la limite tracée entre la portion grossière et la portion éclairée du genre humain s'était presque entièrement effacée, et une dégradation insensible remplissait l'espace qui en sépare les deux extrêmes, le génie et la stupidité.

Ainsi, une connaissance générale des droits naturels de l'homme ; l'opinion même que ces droits sont inaliénables et imprescriptibles ; un vœu fortement prononcé pour la liberté de penser et d'écrire, pour celle du commerce et de l'industrie, pour le soulagement du peuple, pour la proscription de toute loi pénale contre les religions dissidentes, pour l'abolition de la torture et des supplices barbares; le désir d'une législation criminelle plus douce, d'une jurisprudence qui donnât à l'innocence une entière sécurité, d'un code civil plus simple, plus conforme à la raison et à la nature ; l'indifférence pour les religions, placées enfin au nombre des superstitions ou des inventions politiques ; la haine de l'hypocrisie et du fanatisme ; le mépris des préjugés; le zèle pour la propagation des lumières; ces principes passant peu à peu des ouvrages des philosophes dans toutes les classes de la société où l'instruction s'étendait plus loin que le catéchisme et l'écriture, devinrent la profession commune, le symbole de tous ceux qui n'étaient ni machiaviélistes ni imbéciles. Dans quelques pays, ces principes formaient une opinion publique assez générale, pour que la masse même du peuple parût prête à se laisser diriger par elle et à lui obéir. Le sentiment de l'humanité, c'est-à-dire, celui d'une compassion 
tendre, active, pour tous les maux qui affligent l'espèce humaine, d'une horreur pour tout ce qui, dans les institutions publiques, dans les actes du gouvernement, dans les actions privées, ajoutait des douleurs nouvelles aux douleurs inévitables de la nature ; ce sentiment d'humanité était une conséquence naturelle de ces principes ; il respirait dans tous les écrits, dans tous les discours, et déjà son heureuse influence s'était manifestée dans les lois, dans les institutions publiques même des peuples soumis au despotisme.

Les philosophes des diverses nations embrassant, dans leurs méditations, les intérêts de l'humanité entière sans distinction de pays, de race ou de secte, formaient, malgré la différence de leurs opinions spéculatives, une phalange fortement unie contre toutes les erreurs, contre tous les genres de tyrannie. Animés par le sentiment d'une philanthropie universelle, ils combattaient l'injustice, lorsque, étrangère à leur patrie, elle ne pouvait les atteindre ; ils la combattaient encore, lorsque c'était leur patrie même qui s'en rendait coupable envers d'autres peuples ; ils s'élevaient en Europe contre les crimes dont l'avidité souille les rivages de l'Amérique, de l'Afrique ou de l'Asie. Les philosophes de l'Angleterre et de la France s'honoraient de prendre le nom, de remplir les devoirs d'amis de ces mêmes noirs, que leurs stupides tyrans dédaignaient de compter au nombre des hommes. Les éloges des écrivains français étaient le prix de la tolérance accordée en Russie et en Suède, tandis que Beccaria réfutait en Italie les maximes barbares de la jurisprudence française.

On cherchait en France à guérir l'Angleterre de ses préjugés commerciaux, de son respect superstitieux pour les vices de sa constitution et de ses lois, tandis que le respectable Howard dénonçait aux Français la barbare insouciance qui, dans leurs cachots et leurs hôpitaux, immolait tant de victimes humaines.

Les violences ou la séduction des gouvernements, l'intolérance des prêtres, les préjugés nationaux eux-mêmes, avaient perdu le funeste pouvoir d'étouffer la voix de la vérité, et rien ne pouvait soustraire ni les ennemis de la raison, ni les oppresseurs de la liberté, à un jugement qui devenait bientôt celui de l'Europe entière. 
Enfin, on y vit se développer une doctrine nouvelle, qui devait porter le dernier coup à l'édifice déjà chancelant des préjugés : c'est celle de la perfectibilité indéfinie de l'espèce humaine, doctrine dont Turgot, Price et Priestley ont été les premiers et les plus illustres apôtres ; elle appartient à la dixième époque, où nous la développerons avec étendue. Mais nous devons ex-. poser ici l'origine et les progrès d'une fausse philosophie, contre laquelle l'appui de cette doctrine est devenu si nécessaire au triomphe de la raison.

Née, dans les uns, de l'orgueil, dans les autres, de l'intérêt, ayant pour but secret de perpétuer l'ignorance, et de prolonger le règne des erreurs, on en a vu les nombreux sectateurs, tantôt corrompre la raison par de brillants paradoxes, ou la séduire par la paresse commode d'un pyrrhonisme absolu ; tantôt mépriser assez l'espèce humaine pour annoncer que le progrès des lumières serait inutile ou dangereux à son bonheur comme à sa liberté ; tantôt, enfin, l'égarer par le faux enthousiasme d'une grandeur ou. d'une sagesse imaginaires, qui dispensent la vertu d'être éclairée, et le bon sens de s'appuyer sur des connaissances réelles ; ici, parler de la philosophie et des sciences profondes comme de théories trop supérieures à un être borné, entouré de besoins, et soumis à des devoirs journaliers et pénibles ; ailleurs, les dédaigner comme un ramas de spéculations incertaines, exagérées, qui doivent disparaître devant l'expérience des affaires et l'habileté d'un homme d'État. Sans cesse on les entendait se plaindre de la décadence des lumières au milieu de leurs progrès ; gémir sur la dégradation de l'espèce humaine, à mesure que les hommes se ressouvenaient de leurs droits, se servaient de leur raison ; annoncer même l'époque prochaine d'une de ces oscillations qui doivent la ramener à la barbarie, à l'ignorance, à l'esclavage, au moment où tout se réunissait pour prouver qu'elle n'avait plus à les redouter. Ils semblaient humiliés de son perfectionnement, parce qu'ils ne partageaient point la gloire d'y avoir contribué, ou effrayés de ses progrès, qui leur annonçaient la chute de leur importance ou de leur pouvoir. [Cependant, plus habiles que ceux qui, d'une main maladroite, s'efforçaient d'étayer l'édifice des superstitions antiques, dont la philosophie avait sapé les fondements, quelques charlatans tentèrent d'en employer les ruines à l'établissement d'un système religieux, où l'on exigerait de la raison, rétablie dans ses droits, qu'une demi-soumission ; où elle resterait presque libre dans sa croyance, pourvu qu'elle consentît à croire quelque chose d'incompré- 
hensible : tandis que d'autres essayaient de ressusciter, dans des associations secrètes, les mystères oubliés de l'ancienne théurgie ; et, laissant au peuple ses vieilles erreurs, enchaînant leurs disciples par des superstitions nouvelles, ils osaient espérer de rétablir, en faveur de quelques adeptes, l'ancienne tyrannie des rois-pontifes de l'Inde et de l'Égypte. Mais la philosophie, appuyée sur cette base inébranlable que les sciences lui avaient préparée, leur opposait une barrière contre laquelle leurs impuissants efforts devaient bientôt se briser.

En comparant la disposition des esprits, dont j'ai ci-dessus tracé l'esquisse, avec ce système politique des gouvernements, on pouvait aisément prévoir qu'une grande révolution était infaillible ; et il n'était pas difficile de juger qu'elle ne pouvait être amenée que de deux manières : il fallait ou que le peuple établît lui-même ces principes de la raison et de la nature, que la philosophie avait su lui rendre chers; ou que les gouvernements se hâtassent de le prévenir, et réglassent leur marche sur celle de ses opinions. L'une de ces révolutions devait être plus entière et plus prompte, mais plus orageuse ; l'autre plus lente, plus incomplète, mais plus tranquille : dans l'une, on devait acheter la liberté et le bonheur par des, maux passagers ; dans l'autre, on évitait ces maux, mais en retardant pour longtemps, peut-être, la jouissance d'une partie des biens que cependant elle devait infailliblement produire.

La corruption et l'ignorance des gouvernements ont préféré le premier moyen ; et le triomphe rapide de la raison et de la liberté a vengé le genre humain.

Le simple bon sens avait appris aux habitants des colonies britanniques, que des Anglais, nés au delà de l'Océan Atlantique, avaient reçu de la nature précisément les mêmes droits que d'autres Anglais nés sous le méridien de Greenwich, et qu'une différence de soixantedix degrés de longitude n'avait pu changer ces droits. Ils connaissaient, peut-être mieux que les Européens, quels étaient ces droits communs à tous les individus de l'espèce humaine ; et ils y comprenaient celui de ne payer aucune taxe sans y avoir consenti. Mais le gouvernement britannique faisait semblant de croire que Dieu avait créé l'Amérique comme l'Asie, pour le plaisir des habitants de Londres, et voulait, en effet, tenir entre ses mains, au delà des mers, une 
nation sujette, dont il se servirait, quand il en serait temps, pour opprimer l'Angleterre européenne. Il ordonna aux dociles représentants du peuple anglais de violer les droits de l'Amérique, et de la soumettre à des taxes involontaires. L'Amérique prononça que l'injustice avait brisé ses liens, et déclara son indépendance.

On vit alors, pour la première fois, un grand peuple délivré de toutes ses chaînes, se donner paisiblement à lui-même la constitution et les lois qu'il croyait les plus propres à faire son bonheur ; et comme sa position géographique, son ancien état politique, l'obligeaient à former une république fédérative, on vit se préparer à la fois, dans son sein, treize constitutions républicaines, ayant pour base une reconnaissance solennelle des droits naturels de l'homme, et, pour premier objet, la conservation de ces droits. Nous tracerons le tableau de ces constitutions ; nous montrerons ce qu'elles doivent aux progrès des sciences politiques, et ce que les préjugés de l'éducation ont pu y mêler des anciennes erreurs : pourquoi, par exemple, le système de l'équilibre des pouvoirs en altère encore la simplicité ; pourquoi elles ont eu pour principe l'identité des intérêts, plus encore que l'égalité des droits. Nous prouverons, non seulement combien ce principe de l'identité des intérêts, si on en fait la règle des droits politiques, en est une violation à l'égard de ceux auxquels on se permet de ne pas en laisser l'entier exercice, mais que cette identité cesse d'exister, précisément dans l'instant même où elle devient une véritable inégalité. Nous insisterons sur cet objet, parce que cette erreur est la seule qui soit encore dangereuse, parce qu'elle est la seule dont les hommes vraiment éclairés ne soient pas encore désabusés. Nous montrerons comment les républiques américaines ont réalisé cette idée, alors presque nouvelle en théorie, de la nécessité d'établir et de régler, par la loi, un mode régulier et paisible pour réformer les constitutions elles-mêmes, et de séparer ce pouvoir de celui de faire des lois.

Mais dans la guerre qui s'élevait entre deux peuples éclairés, dont l'un défendait les droits naturels de l'humanité, dont l'autre leur opposait la doctrine impie qui soumet ces droits à la prescription, aux intérêts politiques, aux conventions écrites ; cette grande cause fut plaidée au tribunal de l'opinion, en présence de l'Europe entière ; les droits des hommes furent hautement soutenus et développés sans restriction, sans réserve, dans des écrits qui circulaient avec liberté des bords de 
la Néva à ceux du Guadalquivir. Ces discussions pénétrèrent dans les contrées les plus asservies, dans les bourgades les plus reculées, et les hommes qui les habitaient furent étonnés d'entendre qu'ils avaient des droits ; ils apprirent à les connaître ; ils surent que d'autres hommes osaient les reconquérir ou les défendre.

La révolution américaine devait donc s'étendre bientôt en Europe ; et s'il y existait un peuple où l'intérêt pour la cause des Américains eût répandu plus qu'ailleurs leurs écrits et leurs principes, qui fût à la fois le pays le plus éclairé et un des moins libres ; celui où les philosophes avaient le plus de véritables lumières, et le gouvernement une ignorance plus insolente et plus profonde ; un peuple où les lois fussent assez au-dessous de l'esprit publie, pour qu'aucun orgueil national, aucun préjugé, ne l'attachât à ses institutions antiques; ce peuple n'était-il point destiné, par la nature même des choses, à donner le premier mouvement à cette révolution, que les amis de l'humanité attendaient avec tant d'espoir et d'impatience ? Elle devait donc commencer par la France.

La maladresse de son gouvernement a précipité cette révolution ; la philosophie en a dirigé les principes, la force populaire a détruit les obstacles qui pouvaient arrêter les mouvements.

Elle a été plus entière que celle de l'Amérique, et par conséquent moins paisible dans l'intérieur, parce que les Américains, contents des lois civiles et criminelles qu'ils avaient reçues de l'Angleterre ; n'ayant point à réformer un système vicieux d'impositions ; n'ayant à détruire ni tyrannies féodales, ni distinctions héréditaires, ni corporations privilégiées, riches ou puissantes, ni un système d'intolérance religieuse, se bornèrent à établir de nouveaux pouvoirs, à les substituer à ceux que la nation britannique avait jusqu'alors exercés sur eux. Rien, dans ces innovations, n'atteignait la masse du peuple ; rien ne changeait les relations qui s'étaient formées entre les individus. En France, par la raison contraire, la révolution devait embrasser l'économie tout entière de la société, changer toutes les relations sociales, et pénétrer jusqu'aux derniers anneaux de la chaîne politique ; jusqu'aux individus qui, vivant en paix de leurs biens ou de leur industrie, ne tiennent aux mouvements publics ni par leurs opinions, ni par leurs occupations, ni par des intérêts de fortune, d'ambition ou de gloire. 
Les Américains, qui paraissaient ne combattre que contre les préjugés tyranniques de la mère patrie, eurent pour alliés les puissances rivales de l'Angleterre; tandis que les autres, jalouses de ses richesses et de son orgueil, hâtaient, par des vœux secrets, le triomphe de la justice : ainsi, l'Europe entière parut réunie contre les oppresseurs. Les Français, au contraire, ont attaqué en. même temps et le despotisme des rois, et l'inégalité politique des constitutions à demi libres, et l'orgueil des nobles, et la domination, l'intolérance, les richesses des prêtres, et les abus de la féodalité, qui couvrent encore l'Europe presque entière ; et les puissances de l'Europe ont dû se liguer en faveur de la tyrannie. Ainsi, la France n'a pu voir s'élever en sa faveur que la voix de quelques sages, et le vœu timide des peuples opprimés, secours que la calomnie devait encore s'efforcer de lui ravir.

Nous montrerons pourquoi les principes sur lesquels la constitution et les lois de la France ont été combinées, sont plus purs, plus précis, plus profonds, que ceux qui ont dirigé les Américains ; pourquoi ils ont échappé bien plus complètement à l'influence de toutes les espèces de préjugés ; comment l'égalité des droits n'y a, nulle part, été remplacée par cette identité d'intérêt, qui n'en est que le faible et hypocrite supplément ; comment on y a substitué les limites des pouvoirs, à ce vain équilibre si longtemps admiré ; comment, dans une grande nation, nécessairement dispersée et partagée en un grand nombre d'assemblées isolées et partielles, on a osé, pour la première fois, conserver au peuple son droit de souveraineté, celui de n'obéir qu'à des lois dont le mode de formation, si elle est confiée à des représentants, ait été légitimé par son approbation immédiate ; dont, si elles blessent ses droits ou ses intérêts, il puisse toujours obtenir la réforme, par un acte régulier de sa volonté souveraine.

Depuis le moment où le génie de Descartes imprima aux esprits cette impulsion générale, premier principe d'une révolution dans les destinées de l'espèce humaine, jusqu'à l'époque heureuse de l'entière et pure liberté sociale, où l'homme n'a pu remplacer son indépendance naturelle, qu'après avoir passé par une longue suite de siècles d'esclavage et de malheur, le tableau du progrès des sciences mathématiques et physiques nous présente un horizon immense, dont il faut distribuer 
et ordonner les diverses parties, si l'on veut en bien saisir l'ensemble, en bien observer les rapports.

Non seulement l'application de l'algèbre à la géométrie devint une source féconde de découvertes dans ces deux sciences, mais en prouvant, par ce grand exemple, comment les méthodes du calcul des grandeurs en général pouvaient s'étendre à toutes les questions qui avaient pour objet la mesure de l'étendue, Descartes annonçait d'avance qu'elles seraient employées, avec un succès égal, à tous les objets dont les rapports sont susceptibles d'être évalués avec précision ; et cette grande découverte, en montrant pour la première fois ce dernier but des sciences, d'assujettir toutes les vérités à la rigueur du calcul, donnait l'espérance d'y atteindre, et en faisait entrevoir les moyens.

Bientôt à cette découverte succéda celle d'un calcul nouveau, qui enseigne à trouver les rapports des accroissements ou des décroissements successifs d'une quantité variable, ou à retrouver la quantité elle-même, d'après la connaissance de ce rapport ; soit que l'on suppose à ces accroissements une grandeur finie, soit qu'on n'en cherche le rapport que pour l'instant où ils s'évanouissent; méthode qui, s'étendant à toutes les combinaisons de grandeurs variables, à toutes les hypothèses de leurs variations, conduit également à déterminer, pour toutes les choses dont les changements sont susceptibles d'une mesure précise, soit les rapports de leurs éléments, soit les rapports des choses, d'après la connaissance de ceux qu'elles ont entre ellesmêmes, lorsque ceux de leurs éléments sont seulement connus.

On doit à Newton et à Leibnitz l'invention de ces calculs, dont les travaux des géomètres de la génération précédente avaient préparé la découverte. Leurs progrès, non interrompus depuis plus d'un siècle, ont été l'ouvrage et ont fait la gloire de plusieurs hommes de génie, et ils présentent, aux yeux du philosophe qui peut les observer, même sans les suivre, un monument imposant des forces de l'intelligence humaine.

En exposant la formation et les principes de la langue de l'algèbre, la seule vraiment exacte, vraiment analytique, qui existe encore ; la nature des procédés techniques de cette science; la comparaison de 
ces procédés avec les opérations naturelles de l'entendement humain ; nous montrerons que si cette méthode n'est par elle-même qu'un instrument particulier à la science des quantités, elle renferme les principes d'un instrument universel, applicables à toutes les combinaisons d'idées.

La mécanique rationnelle devient bientôt une science vaste et profonde. Les véritables lois du choc des corps, sur lesquelles Descartes s'était trompé, sont enfin connues.

Huyghens découvre celles du mouvement d'un corps dans le cercle ; il donne en même temps la méthode de déterminer à quel cercle chaque élément d'une courbe quelconque doit appartenir. En réunissant ces deux théories, Newton trouva la théorie du mouvement curviligne ; il l'applique à ces lois, suivant lesquelles Kepler a découvert que les planètes parcouraient leurs orbites elliptiques.

Une planète, qu'on suppose lancée dans l'espace en un instant donné, avec une vitesse et suivant une direction déterminée, parcourt, autour du soleil, une ellipse, en vertu d'une force dirigée vers cet astre, et proportionnelle à la raison inverse du carré des distances. La même force retient les satellites dans leurs orbites, autour de la planète principale. Elle s'étend à tout le système des corps célestes ; elle est réciproque entre tous les éléments qui les composent.

La régularité des ellipses planétaires en est troublée, et le calcul explique, avec précision, jusqu'aux nuances les plus légères de ces perturbations. Elle agit sur les comètes, dont la même théorie enseigné à déterminer les orbites, à prédire le retour. Les mouvements observés dans les axes de rotation de la terre et de la lune, attestent encore l'existence de cette force universelle. Elle est enfin la cause de la pesanteur des corps terrestres, dans lesquels elle paraît constante, parce que nous ne pouvons les observer à des distances assez différentes entre elles du centre d'action.

Ainsi, l'homme a connu enfin, pour la première fois, une des lois physiques de l'univers; et elle est unique encore jusqu'ici, comme la gloire de celui qui l'a révélée. 
Cent ans de travaux ont confirmé cette loi, à laquelle tous les phénomènes célestes ont paru soumis avec une exactitude pour ainsi dire miraculeuse ; toutes les fois qu'un d'eux a paru s'y soustraire, cette incertitude passagère est devenue bientôt le sujet d'un nouveau triomphe.

La philosophie est presque toujours forcée de chercher, dans les ouvrages d'un homme de génie, le fil secret qui l'a dirigé ; mais ici, l'intérêt, inspiré par l'admiration, a fait découvrir et conserver des anecdotes précieuses, qui permettent de suivre pas à pas la marche de Newton. Elles nous serviront à montrer comment les heureuses combinaisons du hasard concourent, avec les efforts du génie, à une grande découverte ; et comment des combinaisons moins favorables auraient pu les retarder, ou les réserver à d'autres mains.

Mais Newton fit plus, peut-être, pour les progrès de l'esprit humain, que de découvrir cette loi générale de la nature ; il apprit aux hommes à n'admettre, dans la physique, que des théories précises et calculées, qui rendissent raison non seulement de l'existence d'un phénomène, mais de sa quantité, de son étendue. Cependant, on l'accusa de renouveler les qualités occultes des anciens, parce qu'il s'était borné à renfermer la cause générale des phénomènes célestes dans un fait simple, dont l'observation prouvait l'incontestable réalité. Et cette accusation même prouve combien les méthodes des sciences avaient encore besoin d'être éclairées par la philosophie.

Une foule de problèmes de statique, de dynamique, avaient été successivement proposés et résolus, lorsque D'Alembert découvre un principe général, qui suffit seul pour déterminer le mouvement d'un nombre quelconque de points, animés de forces quelconques, et liés entre eux par des conditions. Bientôt il étend ce même principe aux corps finis d'une figure déterminée ; à ceux qui, élastiques ou flexibles, peuvent changer de figure, mais d'après certaines lois, et en conservant certaines relations entre leurs parties; enfin, aux fluides eux-mêmes, soit qu'ils conservent la même densité, soit qu'ils se trouvent dans l'état d'expansibilité. Un nouveau calcul était nécessaire pour résoudre ces dernières questions ; il ne peut échapper à son génie ; et la mécanique n'est plus qu'une science de pur calcul. 
Ces découvertes appartiennent aux sciences mathématiques ; mais la nature, soit de cette loi de la gravitation universelle, soit de ces principes de mécanique, les conséquences qu'on peut en tirer pour l'ordre éternel de l'univers, sont du ressort de la philosophie. On apprit que tous les corps sont assujettis à des lois nécessaires qui tendent par elles-mêmes à produire ou à maintenir l'équilibre, à faire naître ou à conserver la régularité dans les mouvements.

La connaissance de celles qui président aux phénomènes célestes, les découvertes de l'analyse mathématique, qui conduisent à des méthodes plus précises d'en calculer les apparences; cette perfection, dont on n'avait pas même conçu l'espérance, à laquelle sont portés et les instruments d'optique, et ceux où l'exactitude des divisions devient la mesure de celle des observations ; la précision des machines destinées à mesurer le temps ; le goût plus général pour les sciences, qui s'unit à l'intérêt des gouvernements pour multiplier les astronomes et les observatoires; toutes ces causes réunies assurent les progrès de l'astronomie. Le ciel s'enrichit pour l'homme de nouveaux astres, et il sait en déterminer et en prévoir, avec exactitude, et la position, et les mouvements.

La physique, se délivrant peu à peu des explications vagues introduites par Descartes, comme elle s'était débarrassée des absurdités scolastiques, n'est plus que l'art d'interroger la nature par des expériences, pour chercher à en déduire ensuite, par le calcul, des faits plus généraux.

La pesanteur de l'air est connue et mesurée ; on découvre que la transmission de la lumière n'est pas instantanée, on en détermine la vitesse ; on calcule les effets qui doivent en résulter pour la position apparente des corps célestes; le rayon solaire est décomposé en rayons plus simples, différemment réfrangibles et diversement colorés. L'arc-en-ciel est expliqué, et les moyens de produire ou de faire disparaître ses couleurs, sont soumis au calcul. L'électricité, qui n'était connue que par la propriété de certaines substances, d'attirer les corps légers, après avoir été frottées, devient un des phénomènes généraux de l'uni ;vers. La cause de la foudre n'est plus un secret ; et Franklin a dévoilé aux hommes l'art de la détourner et de la diriger à leur gré. Des instruments nouveaux sont employés à mesurer les variations du 
poids de l'atmosphère, celles de l'humidité de l'air et les degrés de température des corps. Une science nouvelle, sous le nom de météorologie, apprend à connaître, quelquefois à prévoir, les phénomènes de l'atmosphère, dont elle nous fera découvrir un jour les lois encore inconnues.

En présentant le tableau de ces découvertes, nous montrerons comment les méthodes qui ont conduit les physiciens dans leurs recherches, se sont épurées et perfectionnées ; comment l'art de faire les expériences, de construire les instruments, a successivement acquis plus de précision; de manière que la physique, non seulement s'est enrichie chaque jour de vérités nouvelles, mais que les vérités déjà prouvées ont acquis une exactitude plus grande ; que non seulement une foule de faits inconnus ont été observés, analysés, mais que tous ont été soumis, dans leurs détails, à des mesures plus rigoureuses.

La physique n'avait eu à combattre que les préjugés de la scolastique, et l'attrait, si séduisant pour la paresse, des hypothèses générales. D'autres obstacles retardaient les progrès de la chimie. On avait imaginé qu'elle devait donner le secret de faire de l'or, et celui de rendre immortel.

Les grands intérêts rendent l'homme superstitieux. On ne crut pas que de telles promesses, qui caressaient les deux plus fortes passions des âmes vulgaires, et allumaient encore celle de la gloire, pussent être remplies par des moyens ordinaires ; et tout ce que la crédulité en délire avait jamais inventé d'extravagances semblait s'être réuni dans la tête des chimistes.

Mais ces chimères cédèrent peu à peu à la philosophie mécanique de Descartes, qui, rejetée elle-même, fit place à une chimie vraiment expérimentale. L'observation des phénomènes qui accompagnaient les compositions et les décompositions réciproques des corps ; la recherche des lois de ces opérations ; l'analyse des substances en éléments de plus en plus simples, acquirent une précision,, une rigueur toujours croissante.

Mais il faut ajouter à ces progrès de la chimie quelques-uns de ces perfectionnements qui, embrassant le système entier d'une science, et 
consistant encore plus à en étendre les méthodes qu'à augmenter le nombre des vérités qui en forment l'ensemble, présagent et préparent une heureuse révolution. Telle a été la découverte des nouveaux moyens de retenir, de soumettre aux expériences, les fluides expansibles qui s'y étaient jusqu'alors dérobés ; [découverte qui, permettant d'agir sur une classe entière d'êtres nouveaux, et sur ceux déjà connus, réduits à un état où ils échappaient à nos recherches, et ajoutant un élément de plus à presque toutes les combinaisons, a changé, pour ainsi dire, le système entier de la chimie. Telle a été] la formation d'une langue où les noms qui désignent les substances expriment, soit les rapports ou les différences de celles qui ont un élément commun, soit la classe à laquelle elles appartiennent. Tels ont été encore et l'usage d'une écriture scientifique, où ces substances sont représentées par des caractères analytiquement combinés, et qui peut même exprimer les opérations les plus communes ; et les lois générales des affinités ; et l'emploi de tous les moyens, de tous les instruments, qui servent dans la physique à calculer, avec une rigoureuse précision, le résultat des expériences ; et l'application, enfin, du calcul aux phénomènes de la cristallisation, aux lois suivant lesquelles les éléments de certains corps affectent, en se réunissant, des formes régulières et constantes. Les hommes, qui n'avaient su longtemps qu'exprimer, par des rêves superstitieux ou philosophiques, la formation du globe, avant de chercher à le bien connaître, ont enfin senti la nécessité d'étudier avec une attention scrupuleuse, soit à la surface, soit dans cette partie de l'intérieur où leurs besoins les ont fait pénétrer, et les substances qui s'y trouvent, et leur distribution fortuite ou régulière, et la disposition des masses qu'elles y ont formées. Ils ont appris à y reconnaître les traces de l'action lente et longtemps prolongée de l'eau de la mer, des eaux terrestres, du feu; à distinguer la partie de la surface et de la croûte extérieure du globe, où les inégalités, la disposition des substances qu'on y trouve, et souvent ces substances mêmes, sont l'ouvrage du feu, des eaux terrestres, des eaux de mer, d'avec cette autre portion du globe, formée en grande partie des substances hétérogènes, et portant des marques de révolutions plus anciennes, dont les agents nous sont encore inconnus.

Les minéraux, les végétaux, les animaux, se divisent en plusieurs espèces, dont les individus ne diffèrent que par des variétés insensibles, peu constantes, ou produites par des causes purement locales: 
plusieurs de ces espèces se rapprochent par un nombre plus ou moins grand de qualités communes qui servent à établir des divisions successives et de plus en plus étendues. Les naturalistes ont appris à classer méthodiquement les individus, d'après des caractères déterminés, faciles à saisir, seul moyen de se reconnaître au milieu de cette innombrable multitude d'êtres divers. Ces méthodes sont une espèce de langue réelle, où chaque objet est désigné par quelques-unes de ses qualités les plus constantes, et au moyen de laquelle, en connaissant ces qualités, on peut retrouver le nom que porte un objet dans la langue de convention. Ces mêmes langues, lorsqu'elles sont bien faites, apprennent encore quelles sont, pour chaque classe d'êtres naturels, les qualités vraiment essentielles, dont la réunion emporte une ressemblance plus ou moins entière dans le reste de leurs propriétés.

Si l'on a vu quelquefois cet orgueil, qui grossit aux. yeux des hommes les objets d'une étude exclusive et de connaissances péniblement acquises, attacher à ces méthodes une importance exagérée, et prendre, pour la science même ce qui n'était, en quelque sorte, que le dictionnaire et la grammaire de sa langue réelle ; souvent aussi, par un excès contraire, une fausse philosophie a trop rabaissé ces mêmes méthodes, en les confondant avec des nomenclatures arbitraires, comme de futiles et laborieuses compilations.

L'analyse chimique des substances qu'offrent les trois grands règnes de la nature ; la description de leur forme extérieure ; l'exposition de leurs qualités physiques, de leurs propriétés usuelles ; l'histoire du développement des corps organisés, animaux ou plantes, de leur nutrition et de leur reproduction ; les détails de leur organisation ; l'anatomie de leurs diverses parties, les fonctions de chacune d'elles ; l'histoire des mœurs des animaux, de leur industrie pour se procurer de la nourriture, des abris, un logement ; pour saisir leur proie ou se dérober à leurs ennemis ; les sociétés de famille ou d'espèce qui se forment entre eux ; cette foule de vérités où l'on est conduit, en parcourant la chaîne immense des êtres; les rapports dont les anneaux successifs conduisent de la matière brute au plus faible degré d'organisation, de la matière organisée à celle qui donne les premiers indices de sensibilité et de mouvement spontané ; enfin, de celle-ci jusqu'à l'homme ; les rapports de tous ces êtres avec l'homme, soit relativement à ses besoins, soit dans les analogies qui le rapprochent d'eux, ou dans les 
différences qui l'en séparent : tel est le tableau que nous présente aujourd'hui l'histoire naturelle.

L'homme physique est lui-même l'objet d'une science à part ; l'anatomie, qui, dans son acception générale, renferme la physiologie, cette science qu'un respect superstitieux pour les morts avait retardée, a profité de l'affaiblissement général des préjugés, et y a heureusement opposé cet intérêt de leur propre conservation, qui lui a concilié le secours des hommes puissants. Ses progrès ont été tels, qu'elle semble en quelque sorte s'être épuisée, attendre des instruments plus parfaits, et des méthodes nouvelles ; être presque réduite à chercher, dans la comparaison entre les parties des animaux et celles de l'homme, entre les organes communs à différentes espèces, entre la manière dont s'exercent des fonctions semblables, les vérités que l'observation directe de l'homme paraît aujourd'hui refuser. Presque tout ce que l'œil de l'observateur, aidé du microscope, a pu découvrir, est déjà dévoilé. L'anatomie paraît avoir besoin du secours des expériences, si utile au progrès des autres sciences, et la nature de son objet éloigne d'elle ce moyen maintenant nécessaire à son perfectionnement.

La circulation du sang était depuis longtemps connue ; mais la disposition des vaisseaux qui portent le chyle destiné à se mêler avec lui pour en réparer les pertes; mais l'existence d'un sue gastrique, qui dispose les aliments à cette décomposition nécessaire, pour en séparer la portion propre à s'assimiler avec les fluides vivants, avec la matière organisée ; mais les changements qu'éprouvent les diverses parties, les divers organes, et dans l'espace qui sépare la conception de la naissance, et depuis cette époque, dans les différents âges de la vie ; mais la distinction des parties douées de sensibilité, ou de cette irritabilité, propriété découverte par Haller, et commune à presque tous les êtres organiques ; voilà ce que la physiologie a su, dans cette époque brillante, découvrir, et appuyer sur des observations certaines; et tant de vérités importantes doivent obtenir grâce pour ces explications mécaniques, chimiques, organiques, qui, se succédant tour à tour, l'ont surchargée d'hypothèses funestes aux progrès de la science, dangereuses quand leur application s'est étendue jusqu'à la médecine. 
Au tableau des sciences doit S'unir celui des arts qui, s'appuyant sur elles, ont pris une marche plus sûre, et ont brisé les chaînes où la routine les avait jusqu'alors retenus.

Nous montrerons l'influence que les progrès de la mécanique, ceux de l'astronomie, de l'optique et de l'art de mesurer le temps, ont exercée sur l'art de construire, de mouvoir, de diriger les vaisseaux. Nous exposerons comment l'accroissement du nombre des observateurs, l'habileté plus grande du navigateur, une exactitude plus rigoureuse dans les déterminations astronomiques des positions, et dans les méthodes topographiques, ont fait connaître enfin ce globe encore presque ignoré vers la fin du siècle dernier ; combien les arts mécaniques proprement dits ont dû de perfectionnements à ceux de l'art de construire les instruments, les machines, les métiers ; et ceux-ci aux progrès de la mécanique rationnelle et de la physique ; ce que doivent ces mêmes arts à la science d'employer les moteurs déjà connus, avec moins de dépense et de perte, ou à l'invention de nouveaux moteurs.

On verra l'architecture puiser dans la science de l'équilibre et dans la théorie des fluidess les moyens de donner aux voûtes des formes plus commodes et moins dispendieuses sans craindre d'altérer la solidité des constructions; d'opposer à l'effort des eaux une résistance plus sûrement calculée ; d'en diriger le cours ; de les employer en canaux avec plus d'habileté et de succès.

On verra les arts chimiques s'enrichir de procédés nouveaux ; épurer, simplifier les anciennes méthodes; se débarrasser de tout ce que la routine y avait introduit de substances Inutiles ou nuisibles, de pratiques vaines ou imparfaites ; tandis qu'on trouvait, en même temps, les moyens de prévenir une partie des dangers, souvent terribles, auxquels les ouvriers y étaient exposés ; et qu'ainsi, en procurant plus de jouissance, plus de richesses, ils ne les faisaient plus acheter par tant de sacrifices douloureux, et par tant de remords.

Cependant, la chimie, la botanique, l'histoire naturelle, répandaient une lumière féconde sur les arts économiques, sur la culture des végétaux destinés à nos divers besoins ; sur l'art de nourrir, de multiplier, de conserver les animaux domestiques, d'en perfectionner les races, d'en améliorer les produits ; sur celui de préparer, de conserver les 
productions de la terre, ou les denrées que nous fournissent les animaux.

La chirurgie et la pharmacie deviennent des arts presque nouveaux, dès l'instant où l'anatomie et la chimie viennent leur offrir des guides plus éclairés et plus sûrs.

La médecine, qui, dans la pratique, doit être considérée comme un art, se délivre du moins de ses fausses théories, de son jargon pédantesque, de sa routine meurtrière, de sa soumission servile à l'autorité des hommes, aux doctrines des facultés ; elle apprend à ne plus croire qu'à l'expérience. Elle a multiplié ses moyens; elle sait mieux les combiner et les employer ; et si, dans quelques parties, ses progrès sont en quelque sorte négatifs, s'ils se bornent à la destruction de pratiques dangereuses, des préjugés nuisibles, les méthodes nouvelles d'étudier la médecine chimique et de combiner les observations, annoncent des progrès plus réels et plus étendus.

Nous chercherons surtout à suivre cette marche du génie des sciences, qui tantôt descendant d'une théorie abstraite et profonde à des applications savantes et délicates ; simplifiant ensuite ses moyens, les proportionnant aux besoins, finit par répandre ses bienfaits sur les pratiques les plus vulgaires; et tantôt réveillé par les besoins de cette même pratique, va chercher dans les spéculations les plus élevées, les ressources que des connaissances communes auraient refusées.

Nous ferons voir que les déclamations contre l'inutilité des théories, même pour les arts les plus simples, n'ont jamais prouvé que l'ignorance des déclamateurs. Nous montrerons que ce n'est point à la profondeur de ces théories, mais au contraire à leur imperfection, qu'il faut attribuer l'inutilité ou les effets funestes de tant d'applications malheureuses.

Ces observations conduiront à cette vérité générale, que, dans tous les arts, les vérités de la théorie sont nécessairement modifiées dans la pratique ; qu'il existe des inexactitudes réellement inévitables, dont il faut chercher à rendre l'effet insensible, sans se livrer au chimérique espoir de les prévenir ; qu'un grand nombre de données relatives aux besoins, aux moyens, au temps, à la dépense, nécessairement négli- 
gées dans la théorie, doivent entrer dans le problème relatif à une pratique immédiate et réelle ; et qu'enfin, en y introduisant ces données avec une habileté qui est vraiment le génie de la pratique, on peut à la fois et franchir les limites étroites OÙ les préjugés contre la théorie menacent de retenir les arts, et prévenir les erreurs dans lesquelles un usage maladroit de la théorie pourrait entraîner.

Les sciences, qui s'étaient divisées, n'ont pu s'étendre sans se rapprocher, sans qu'il se formât entre elles des points de contact.

L'exposition des progrès de chaque science suffirait pour montrer quelle a été dans plusieurs l'utilité de l'application immédiate du calcul ; combien, dans presque toutes, il a pu être employé à donner aux expériences et aux observations une précision plus grande ; ce qu'elles ont dû à la mécanique qui leur a donné des instruments plus parfaits et plus exacts ; combien la découverte des microscopes et celles des instruments météorologiques ont contribué au perfectionnement de l'histoire naturelle ; ce que cette science doit à la chimie, qui seule a pu la conduire à une connaissance plus approfondie des objets qu'elle considère ; lui en dévoiler la nature la plus intime, les différences les plus essentielles, en lui en montrant la composition et les éléments ; tandis que l'histoire naturelle offrait à la chimie tant de produits à séparer et à recueillir, tant d'opérations à exécuter, tant de combinaisons formées par la nature, dont il fallait séparer les véritables éléments, et quelquefois découvrir ou même imiter le secret ; enfin quels secours mutuels la physique et la chimie se sont prêtés, et combien l'anatomie en a déjà reçu, on de l'histoire naturelle, ou de ces sciences. Mais on n'aurait encore exposé que la plus petite portion des avantages qu'on a reçus, qu'on peut attendre de cette application. Plusieurs géomètres ont donné des méthodes générales de trouver, d'après les observations les lois empiriques des phénomènes, méthodes qui s'étendent à toutes les sciences, puisqu'elles peuvent également conduire à connaître, soit la loi des valeurs successives d'une même quantité pour une suite d'instants ou de positions, soit celle suivant laquelle se distribuent, ou diverses propriétés, ou diverses valeurs d'une qualité semblable, entre un nombre donné d'objets.

Déjà quelques applications ont prouvé qu'on peut employer avec succès la science des combinaisons. pour disposer les observations de 
manière à en pouvoir saisir avec plus de facilité les rapports, les résultats et l'ensemble.

Les applications du calcul des probabilités font présager combien elles peuvent concourir aux progrès des autres sciences ; ici, en déterminant la vraisemblance des faits extraordinaires, et en apprenant à juger s'ils doivent être rejetés, ou si, au contraire, ils méritent d'être vérifiés ; là, en calculant celle du retour constant de ces faits qui se présentent souvent dans la pratique des arts, et qui ne sont point liés par eux-mêmes à un ordre déjà regardé comme une loi générale : tel est, par exemple, en médecine, l'effet salutaire de certains remèdes, le succès de certains préservatifs. Ces applications nous montrent encore quelle est la probabilité qu'un ensemble de phénomènes résulte de l'intention d'un être intelligent, qu'il dépend d'autres phénomènes qui lui coexistent, ou l'ont précédé ; et celle qu'il doive être attribué à cette cause nécessaire et inconnue que l'on nomme hasard ; mot dont l'étude de ce calcul peut seule bien faire connaître le véritable sens.

Ces applications ont appris également à reconnaître les divers degrés de certitude où nous pouvons espérer d'atteindre ; la vraisemblance d'après laquelle nous pouvons adopter une opinion, en faire la base de nos raisonnements, sans blesser les droits de la raison et la règle de notre conduite ; sans manquer à la prudence, ou sans offenser la justice. Elles montrent quels sont les avantages ou les inconvénients des diverses formes d'élection, des divers modes de décisions prises à la pluralité des voix ; les différents degrés de probabilité qui en peuvent résulter ; celui que l'intérêt publie doit exiger suivant la nature de chaque question ; les moyens, soit de l'obtenir presque sûrement lorsque la décision n'est pas nécessaire, ou que les inconvénients de deux partis étant inégaux, l'un d'eux ne peut être légitime tant qu'il reste audessous de cette probabilité ; soit d'être assuré d'avance d'obtenir souvent cette même probabilité, lorsqu'au contraire la décision est nécessaire, et que la plus faible vraisemblance suffit pour s'y conformer.

On peut mettre encore au nombre de ces applications l'examen de la probabilité des faits, pour celui qui ne peut appuyer son adhésion sur ses propres observations ; probabilité qui résulte, ou de l'autorité des témoignages, ou de la liaison de ces faits avec d'autres immédiatement observés. 
Combien les recherches sur la durée de la vie des hommes, sur l'influence qu'exerce sur cette durée, la différence des sexes, des températures, du climat, des professions, des gouvernements, des habitudes de la vie; sur la mortalité qui résulte des diverses maladies; sur les changements que la population éprouve ; sur l'étendue de l'action des diverses causes qui produisent ces changements ; sur la manière dont elle est distribuée dans chaque pays, suivant les âges, les sexes, les occupations ; combien toutes ces recherches ne peuvent-elles pas être utiles à la connaissance physique de l'homme, à la médecine, à l'économie publique!

Combien l'économie publique n'a-t-elle pas fait usage de ces mêmes calculs, pour les établissements des rentes viagères, des tontines, des caisses d'accumulation et de secours, des chambres d'assurance de toute espèce !

L'application du calcul n'est-elle pas encore nécessaire à cette partie de l'économie publique qui embrasse la théorie des mesures, celles des monnaies, des banques, des opérations de finances, enfin celle des impositions, de leur répartition établie par la loi, de leur distribution réelle qui s'en écarte si souvent, de leurs effets sur toutes les parties du système social ?

Combien de questions importantes, dans cette même science, n'ont pu être bien résolues qu'à l'aide des connaissances acquises sur l'histoire naturelle, sur l'agriculture, sur la physique végétale, sur les arts mécaniques ou chimiques !

En un mot, tel a été le progrès général des sciences qu'il n'en est pour ainsi dire aucune qui puisse être embrassée tout entière dans ses principes, dans ses détails, sans être obligée d'emprunter le secours de toutes les autres.

En présentant ce tableau, et des vérités nouvelles dont chaque science s'est enrichie, et de ce que chacune doit à l'application des théories ou des méthodes qui semblent appartenir plus particulièrement à des connaissances d'un autre ordre, nous chercherons quelle est la nature et la limite des vérités auxquelles l'observation, l'expérience, 
la méditation peuvent nous conduire dans chaque science ; nous chercherons également en quoi, pour chacune d'elles, consiste précisément Je talent de l'invention, cette première faculté de l'intelligence humaine, à laquelle on a donné le nom de génie ; par quelles opérations l'esprit peut atteindre les découvertes qu'il poursuit, ou quelquefois être conduit à celles qu'il ne cherchait pas, qu'il n'avait pu même prévoir. Nous montrerons comment les méthodes qui nous mènent à des découvertes peuvent s'épuiser de manière que la science soit en quelque sorte forcée de s'arrêter, si des méthodes nouvelles ne viennent fournir un nouvel instrument au génie, ou lui faciliter l'usage de celles qu'il ne peut plus employer sans y consommer trop de temps et de fatigues.

Si nous nous bornions à montrer les avantages qu'on a retirés des sciences dans leurs usages immédiats, ou dans leurs applications aux arts, soit pour le bien-être des individus, soit pour la prospérité des nations, nous n'aurions fait connaître encore qu'une faible partie de leurs bienfaits.

Le plus important peut-être est d'avoir détruit les préjugés, et redressé en quelque sorte l'intelligence humaine, forcée de se plier aux fausses directions que lui imprimaient les croyances absurdes transmises à l'enfance de chaque génération, avec les terreurs de la superstition et la crainte de la tyrannie.

Toutes les erreurs en politique, en morale, ont pour base des erreurs philosophiques, qui elles-mêmes sont liées à des erreurs physiques. Il n'existe, ni un système religieux, ni une extravagance surnaturelle, qui ne soit fondée sur l'ignorance des lois de la nature. Les inventeurs, les défenseurs de ces absurdités, ne pouvaient prévoir le perfectionnement successif de l'esprit humain. Persuadés que les hommes savaient, de leur temps, tout ce qu'ils pouvaient jamais savoir, et croiraient toujours ce qu'ils croyaient alors, ils appuyaient avec confiance leurs rêveries sur les opinions générales de leur pays et de leur siècle.

Les progrès des connaissances physiques sont même d'autant plus funestes à ces erreurs, que souvent ils les détruisent sans paraître les attaquer, [et en répandant sur ceux qui s'obstinent àles défendre le ridicule avilissant de l'ignorance]. 
En même temps l'habitude de raisonner juste sur les objets de ces sciences, les idées précises que donnent leurs méthodes, les moyens de reconnaître ou de prouver une vérité, doivent conduire naturellement à comparer le sentiment qui nous force d'adhérer à des opinions fondées sur ces motifs réels de crédibilité, et celui qui nous attache à nos préjugés d'habitude, ou qui nous force de céder à l'autorité : et cette comparaison suffit pour apprendre à se délier de ces dernières opinions, pour faire sentir qu'on ne les croit réellement pas, lors même qu'on se vante de les croire, qu'on les professe avec la plus pure sincérité. Or ce secret, une fois découvert, rend leur destruction prompte et certaine.

Enfin, cette marche des sciences physiques que les passions et l'intérêt ne viennent pas troubler, où l'on ne croit pas que la naissance, la profession, les places donnent le droit de juger ce qu'on n'est pas en état d'entendre ; cette marche plus sûre ne pouvait être observée sans que les hommes éclairés cherchassent dans les autres sciences à s'en rapprocher sans cesse ; elle leur offrait à chaque pas le modèle qu'ils devaient suivre, d'après lequel ils pouvaient juger de leurs propres efforts, reconnaître les fausses routes où ils auraient pu s'engager, se préserver du pyrrhonisme comme de la crédulité et d'une aveugle défiance, d'une soumission trop entière même à l'autorité des lumières et de la renommée.

Sans doute, l'analyse métaphysique conduisait aux mêmes résultats ; mais elle n'eût donné que des préceptes abstraits ; et ici les mêmes principes abstraits, mis en action, étaient éclairés par l'exemple, fortifiés par le succès.

Jusqu'à cette époque les sciences n'avaient été que le patrimoine de quelques hommes; déjà elles sont devenues communes, et le moment approche où leurs éléments, leurs principes, leurs méthodes les plus simples deviendront vraiment populaires. C'est alors que leur application aux arts, que leur influence sur la justesse générale des esprits sera d'une utilité vraiment universelle.

Nous suivrons les progrès des nations européennes dans l'instruction, soit des enfants, soit des hommes ; progrès faibles jusqu'ici, si 
l'on regarde seulement le système philosophique de cette instruction, qui, presque partout, est encore livrée aux préjugés scolastiques ; mais très rapides, si l'on considère l'étendue et la nature des objets de l'enseignement, qui, n'embrassant presque plus que des connaissances réelles, renferme les éléments de presque toutes les sciences, tandis que les hommes de tous les âges trouvent, dans les dictionnaires, dans les abrégés, dans les journaux, les lumières dont ils ont besoin, quoiqu'elles n'y soient pas toujours assez pures. Nous examinerons quelle a été l'utilité de joindre l'instruction orale des sciences, à celle qu'on reçoit immédiatement par les livres et par l'étude ; s'il est résulté quelque avantage de ce que le travail des compilations est devenu un véritable métier, un moyen de subsistance, ce qui a multiplié le nombre des ouvrages médiocres, mais en multipliant aussi, pour les hommes peu instruits, les moyens d'acquérir des connaissances communes. Nous exposerons l'influence qu'ont exercée, sur les progrès de l'esprit humain, ces sociétés savantes, barrière qu'il sera encore longtemps utile d'opposer à la charlatanerie et au faux savoir ; nous ferons, enfin, l'histoire des encouragements donnés par les gouvernements aux progrès de l'esprit humain, et des obstacles qu'ils y ont opposés souvent dans le même pays et à la même époque ; nous ferons voir quels préjugés ou quels principes de machiavélisme, les ont dirigés dans cette opposition à la marche des esprits vers la vérité ; quelles vues de politique intéressée ou même de bien publie les ont guidés, quand ils ont paru au contraire vouloir l'accélérer et la protéger.

Le tableau des beaux-arts n'offre pas des résultats moins brillants, La musique est devenue, en quelque sorte, un art nouveau, en même temps que la science des combinaisons et l'application du calcul aux vibrations du corps sonore, et des oscillations de l'air, en ont éclairé la théorie. Les arts du dessin, qui déjà avaient passé d'Italie en Flandre, en Espagne, en France, s'élevèrent, dans ce dernier pays, à ce même degré où l'Italie les avait portés dans l'époque précédente, et ils s'y sont soutenus avec plus d'éclat qu'en Italie même. L'art de nos peintres est celui des Raphaël et des Carraches. Tous ces moyens, conservés dans les écoles, loin de se perdre, ont été plus répandus. Cependant, il s'est écoulé trop de temps sans produire de génie qui puisse lui être comparé, pour n'attribuer qu'au hasard cette longue stérilité. Ce n'est pas que les moyens de l'art aient été épuisés, quoique les grands succès y soient réellement devenus plus difficiles. Ce n'est pas que la na- 
ture nous ait refusé des organes aussi parfaits que ceux des Italiens du XVIe siècle; c'est uniquement aux changements dans la politique, dans les mœurs, qu'il faut attribuer, non la décadence de l'art, mais la faiblesse de ses productions.

Les lettres cultivées en Italie avec moins de succès, mais sans y avoir dégénéré, on fait, dans la langue française, des progrès qui lui ont mérité l'honneur de devenir, en quelque sorte, la langue universelle de l'Europe.

L'art tragique, entre les mains de Corneille, de Racine, de Voltaire, s'est élevé, par des progrès successifs, à une perfection jusqu'alors inconnue. L'art comique doit à Molière d'être parvenu plus, promptement à une hauteur qu'aucune nation n'a pu encore atteindre.

En Angleterre, dès le commencement de cette époque, et dans un temps plus voisin de nous, en Allemagne, la langue s'est perfectionnée. L'art de la poésie, celui d'écrire en prose, ont été soumis, mais avec moins de docilité qu'en France, à ces règles universelles de la raison et de la nature qui doivent les diriger. Elles sont également vraies pour toutes les langues, pour tous les peuples, bien que jusqu'ici un petit nombre seulement ait pu les connaître, et s'élever à ce goût juste et sûr, qui n'est que le sentiment de ces mêmes règles, qui présidait aux compositions de Sophocle et de Virgile, comme à celles de Pope et de Voltaire, qui enseignait aux Grecs, aux Romains, comme aux Français, à être frappés des mêmes beautés et révoltés des mêmes défauts.

Nous ferons voir ce qui, dans chaque nation, a favorisé ou retardé les progrès de ces arts; par quelles causes les divers genres de poésie ou d'ouvrages en prose ont atteint, dans les différents pays, une perfection si inégale, et comment ces règles universelles .peuvent, sans blesser même les principes qui en sont la base, être modifiées par les mœurs, par les opinions des peuples qui doivent jouir des productions de ces arts, et par la nature même des usages auxquels leurs différents genres sont destinés. Ainsi, par exemple, la tragédie, récitée tous les jours devant un petit nombre de spectateurs dans une salle peu étendue, ne peut avoir les mêmes règles pratiques que la tragédie chantée sur un théâtre immense, dans des fêtes solennelles où tout un peuple 
était invité. Nous essayerons de prouver que les règles du goût ont la même généralité, la même constance, mais sont susceptibles du même genre de modification que les autres lois de l'univers moral et physique, quand il faut les appliquer à la pratique immédiate d'un art usuel.

Nous montrerons comment l'impression multipliant, répandant les ouvrages même destinés à être publiquement lus ou récités, les transmet à un nombre de lecteurs incomparablement plus grand que celui des auditeurs ; comment presque toutes les décisions importantes, prises dans des assemblées nombreuses, étant déterminées d'après l'instruction que leurs membres reçoivent par la lecture, il a dû en résulter, entre les règles de l'art de persuader chez les anciens et chez les modernes, des différences analogues à celle de l'effet qu'il doit produire, et du moyen qu'il emploie ; comment, enfin, dans les genres où, même chez les anciens, on se bornait à la lecture des ouvrages, comme l'histoire ou la philosophie, la facilité que donne l'invention de l'imprimerie de se livrer à plus de développements et de détails, a dû encore influer sur ces mêmes règles.

Les progrès de la philosophie et des sciences ont étendu, ont favorisé ceux des lettres, et celles-ci ont servi à rendre l'étude des sciences plus facile, et la philosophie plus populaire. Elles se sont prêté un mutuel appui, malgré les efforts de l'ignorance et de la sottise pour les désunir, pour les rendre ennemies. L'érudition, que la soumission à l'autorité humaine, le respect pour les choses anciennes, semblait destiner à soutenir la cause des préjugés nuisibles ; l'érudition a cependant aidé à les détruire, parce que les sciences et la philosophie lui ont prêté le flambeau d'une critique plus saine. Elle savait déjà peser les autorités, les comparer entre elles ; elle a fini par les soumettre ellesmêmes au tribunal de la raison. Elle avait rejeté les prodiges, les contes absurdes, les faits contraires à la vraisemblance ; mais en attaquant les témoignages sur lesquels ils s'appuyaient, elle a su depuis les rejeter, malgré la force de ces témoignages, pour ne céder qu'à celle qui pourrait l'emporter sur l'invraisemblance physique ou morale des faits extraordinaires.

Ainsi, toutes les occupations intellectuelles des hommes, quelque différentes qu'elles soient par leur objet, leur méthode, ou par les qualités d'esprit qu'elles exigent, ont concouru aux progrès de la raison 
humaine. Il en est, en effet, du système entier des travaux des hommes, comme d'un ouvrage bien fait, dont les parties, distinguées avec méthode, doivent être cependant étroitement liées, ne former qu'un seul tout, et tendre à un but unique.

En portant maintenant un regard général sur l'espèce humaine, nous montrerons que la découverte des vraies méthodes dans toutes les sciences, l'étendue des théories qu'elles renferment, leur application à tous les objets de la nature, à tous les besoins des hommes, les lignes de communication qui se sont établies entre elles, le grand nombre de ceux qui les cultivent ; enfin, la multiplication des imprimeries, suffisent pour nous répondre qu'aucune d'elles ne peut descendre désormais au-dessous du point où elle a été portée. Nous ferons observer que les principes de la philosophie, les maximes de la liberté, la connaissance des véritables droits de l'homme et de ses intérêts réels, sont répandus dans un trop grand nombre de nations, et dirigent dans chacune d'elles les opinions d'un trop grand nombre d'hommes éclairés, pour qu'on puisse redouter de les voir jamais retomber dans l'oubli.

Et quelle crainte pourrait-on conserver encore, en voyant que les deux langues qui sont les plus répandues, sont aussi les langues des deux peuples qui jouissent de la liberté la plus entière ; qui en ont le mieux connu les principes ; en sorte que, ni aucune ligue de tyrans, ni aucune des combinaisons politiques possibles, ne peut empêcher de défendre hautement, dans ces deux langues, les droits de la raison, comme ceux de la liberté ?

Mais, si tout nous répond que le genre humain ne doit plus retomber dans son ancienne barbarie ; si tout doit nous rassurer contre ce système pusillanime et corrompu, qui le condamne à d'éternelles oscillations entre la vérité et l'erreur, la liberté et la servitude, nous voyons en même temps les lumières n'occuper encore qu'une faible partie du globe, et le nombre de ceux qui en ont de réelles disparaître devant la masse des hommes livrés aux préjugés et à l'ignorance. Nous voyons de vastes contrées gémissant dans l'esclavage, et n'offrant que des nations, ici dégradées par les vices d'une civilisation dont la corruption ralentit la marché ; là, végétant encore dans l'enfance de ses premières époques. Nous voyons que les travaux de ces derniers âges ont beau- 
coup fait pour le progrès de l'esprit humain, mais peu pour le perfectionnement de l'espèce humaine; beaucoup pour la gloire de l'homme ; quelque chose pour sa liberté, presque rien encore pour son bonheur. Dans quelques points, nos yeux sont frappés d'une lumière éclatante ; mais d'épaisses ténèbres couvrent encore un immense horizon. L'âme du philosophe se repose avec consolation sur un petit nombre d'objets ; mais le spectacle de la stupidité, de l'esclavage, de l'extravagance, de la barbarie, l'afflige plus souvent encore ; et l'ami de l'humanité ne peut goûter de plaisir sans mélange qu'en s'abandonnant aux douces espérances de l'avenir.

Tels sont les objets qui doivent entrer dans un tableau historique des progrès de l'esprit humain. Nous chercherons, en les présentant, à montrer surtout l'influence de ces progrès sur les opinions, sur le bienêtre de la masse générale des diverses nations, aux différentes époques de leur existence politique; à montrer quelles vérités elles ont connues ; de queues erreurs elles ont été détrompées ; quelles habitudes vertueuses elles ont contractées; quel développement nouveau de leurs facultés a établi une proportion plus heureuse entre ces facultés et leurs besoins ; et, sous un point de vue opposé, de quels préjugés elles ont été les esclaves ; quelles superstitions religieuses ou politiques s'y sont introduites ; par quels vices l'ignorance ou le despotisme les ont corrompues ; à quelles misères la violence ou leur propre dégradation les ont soumises.

Jusqu'ici, l'histoire politique, comme celle de la philosophie et des sciences, n'a été que l'histoire de quelques hommes ; ce qui forme véritablement l'espèce humaine, la masse des familles qui subsistent presque en entier de leur travail a été oubliée ; et même dans la classe de ceux qui, livrés à des professions publiques, agissent, non pour eux-mêmes, mais pour la société ; dont l'occupation est d'instruire, de gouverner, de défendre, de soulager les autres hommes, les chefs seuls ont fixé les regards des historiens.

Pour l'histoire des individus, il suffit de recueillir les faits; mais celle d'une masse d'hommes ne peut s'appuyer que sur des observations ; et, pour les choisir, pour en saisir les traits essentiels, il faut déjà des lumières, et presque autant de philosophie que pour les bien employer. 
D'ailleurs, ces observations ont ici pour objet des choses communes, qui frappent tous les yeux, que chacun peut, quand il veut, connaître par lui-même. Aussi, presque toutes celles qui ont été recueillies sont dues à des voyageurs, ont été faites par des étrangers, parce que ces choses, si triviales dans le lieu où elles existent, deviennent pour eux un objet de curiosité. Or, malheureusement, ces voyageurs sont presque toujours des observateurs inexacts; ils voient les objets avec trop de rapidité, au travers des préjugés de leur pays, et souvent par les yeux des hommes de la contrée qu'ils parcourent. Ils consultent ceux avec qui le hasard les a liés ; et c'est l'intérêt, l'esprit de parti, l'orgueil national ou l'humeur, qui dictent presque toujours la réponse.

Ce n'est donc point seulement à la bassesse des historiens, comme on l'a reproché avec justice à ceux des monarchies, qu'il faut attribuer la disette des monuments d'après lesquels on peut tracer cette partie la plus importante de l'histoire des hommes.

On ne peut y suppléer qu'imparfaitement par la connaissance des lois, des principes pratiques de gouvernement et d'économie publique, ou par celle des religions, des préjugés généraux.

En effet, la loi écrite et la loi exécutée ; les principes de ceux qui gouvernent, et la manière dont leur action est modifiée par l'esprit de ceux qui sont gouvernés ; l'institution telle qu'elle émane des hommes qui la forment, et l'institution réalisée ; la religion des livres et celle du peuple ; l'universalité apparente d'un préjugé, et l'adhésion réelle qu'il obtient, peuvent différer tellement, que les effets cessent absolument de répondre à ces causes publiques et connues.

C'est à cette partie de l'histoire de l'espèce humaine, lui plus obscure, la plus négligée, et pour laquelle les monuments nous offrent si peu de matériaux, qu'on doit surtout s'attacher dans ce tableau ; et, soit qu'on y rende compte d'une découverte, d'une théorie importante, d'un nouveau système de lois, d'une révolution politique, on s'occupera de déterminer quels effets ont dû en résulter pour la portion la plus nombreuse de chaque société ; car c'est là le véritable objet de la philosophie, puisque tous les effets intermédiaires de ces mêmes causes ne 
peuvent être regardés que comme des moyens d'agir enfin sur cette portion qui constitue vraiment la masse du genre humain.

C'est en parvenant à ce dernier degré de la chaîne, que l'observation des événements passés, comme les connaissances acquises par la méditation, deviennent véritablement utiles. C'est en arrivant à ce terme, que les hommes peuvent apprécier leurs titres réels à la gloire, ou jouir, avec un plaisir certain, des progrès de leur raison ; c'est là seulement qu'on peut juger du véritable perfectionnement de l'espèce humaine.

Cette idée, de tout rapporter à ce dernier point, est dictée par la justice et par la raison ; mais on serait tenté de la regarder comme chimérique ; cependant, elle ne l'est pas : il doit nous suffire ici de le prouver par deux exemples frappants.

La possession des objets de consommation les plus communs, qui satisfont avec quelque abondance aux besoins de l'homme dont les mains fertilisent notre sol, est due aux longs efforts d'une industrie secondée par la lumière des sciences ; et dès lors cette possession s'attache, par l'histoire, au gain de la bataille de Salamine, sans lequel les ténèbres du despotisme oriental menaçaient d'envelopper la terre entière. Le matelot, qu'une exacte observation de la longitude préserve du naufrage, doit la vie à une théorie qui, par une chaîne de vérités, remonte à des découvertes faites dans l'école de Platon, et ensevelies pendant vingt siècles dans une entière inutilité. 


\section{Dixième époque}

\section{Des progrès futurs de l'esprit humain.}

Si l'homme peut prédire, avec une assurance presque entière les phénomènes dont il connaît les lois ; si, lors même qu'elles lui sont inconnues, il peut, d'après l'expérience du passé, prévoir, avec une grande probabilité, les événements de l'avenir ; pourquoi regarderaiton comme une entreprise chimérique, celle de tracer, avec quelque vraisemblance, le tableau des destinées futures de l'espèce humaine, d'après les résultats de son histoire ? Le seul fondement de croyance dans les sciences naturelles, est cette idée, que les lois générales, connues ou ignorées, qui règlent les phénomènes de l'univers, sont nécessaires et constantes; et par quelle raison ce principe serait-il moins vrai pour le développement des facultés intellectuelles et morales de l'homme, que pour les autres opérations de la nature ? Enfin, puisque des opinions formées d'après l'expérience du passé, sur des objets du même ordre, sont la seule règle de la conduite des hommes les plus sages, pourquoi interdirait-on au philosophe d'appuyer ses conjectures sur cette même base, pourvu qu'il ne leur attribue pas une 
certitude supérieure à celle qui peut naître du nombre, de la constance, de l'exactitude des observations?

Nos espérances sur l'état à venir de l'espèce humaine peuvent se réduire à ces trois points importants : la destruction de l'inégalité entre les nations; les progrès de l'égalité dans un même peuple; enfin, le perfectionnement réel de l'homme. Toutes les nations doivent-elles se rapprocher un jour de l'état de civilisation où sont parvenus les peuples les plus éclairés, les plus libres, les plus affranchis de préjugés, tels que les Français et les Anglo-Américains ? Cette distance immense qui sépare ces peuples de la servitude des nations soumises à des rois, de la barbarie des peuplades africaines, de l'ignorance des sauvages, doit-elle peu à peu s'évanouir?

Y a-t-il sur le globe des contrées dont la nature ait condamné les habitants à ne jamais jouir de la liberté, à ne jamais exercer leur raison?

Cette différence de lumières, de moyens ou de richesses, observée jusqu'à présent chez tous les peuples civilisés entre les différentes classes qui composent chacun d'eux ; cette inégalité, que les premiers progrès de la société ont augmentée, et pour ainsi dire produite, tientelle à la civilisation même, ou aux imperfections actuelles de l'art social ? doit-elle continuellement s'affaiblir pour faire place à cette égalité de fait, dernier but de l'art social, qui, diminuant même les effets de la différence naturelle des facultés, ne laisse plus subsister qu'une inégalité utile à l'intérêt de tous, parce qu'elle favorisera les progrès de la civilisation, de l'instruction et de l'industrie, sans entraîner, ni dépendance, ni humiliation, ni appauvrissement ; en un mot, les hommes approcheront-ils de cet état où tous auront les lumières nécessaires pour se conduire d'après leur propre raison dans les affaires communes de la vie, et la maintenir exempte de préjugés, pour bien connaître leurs droits et les exercer d'après leur opinion et leur conscience ; où tous pourront, par le développement de leurs facultés, obtenir des moyens sûrs de pourvoir à leurs besoins ; où enfin, la stupidité et la misère ne seront plus que des accidents, et non l'état habituel d'une portion de la société ? 
Enfin, l'espèce humaine doit-elle s'améliorer, soit par de nouvelles découvertes dans les sciences et dans les arts, et, par une conséquence nécessaire, dans les moyens de bien-être particulier et de prospérité commune ; soit par des progrès dans les principes de conduite et dans la morale pratique ; soit enfin par le perfectionnement réel des facultés intellectuelles, morales et physiques, qui peut être également la suite, ou de celui des instruments qui augmentent l'intensité et dirigent l'emploi de ces facultés, ou même de celui de l'organisation naturelle de l'homme?

En répondant à ces trois questions, nous trouverons, dans l'expérience du passé, dans l'observation des progrès que les sciences, que la civilisation ont faits jusqu'ici, dans l'analyse de la marche de l'esprit humain et du développement de ses facultés, les motifs les plus forts de croire que la nature n'a mis aucun terme à nos espérances.

Si nous jetons un. coup d'œil sur l'état actuel du globe, nous verrons d'abord que, dans l'Europe, les principes de la constitution française sont déjà ceux de tous les hommes éclairés. Nous les y verrons trop répandus, et trop hautement professés, pour que les efforts des tyrans et des prêtres puissent les empêcher de pénétrer peu à peu jusqu'aux cabanes de leurs esclaves ; et ces principes y réveilleront bientôt un reste de bon sens, et cette sourde indignation que l'habitude de l'humiliation et de la terreur ne peut étouffer dans l'âme des opprimés.

En parcourant ensuite ces diverses nations, nous verrons dans chacune quels obstacles particuliers s'opposent à cette révolution, ou quelles dispositions la favorisent; nous distinguerons celles où elle doit être doucement amenée par la sagesse peut-être déjà tardive de leurs gouvernements, et celles où, rendue plus violente par leur résistance, elle doit les entraîner eux-mêmes dans ses mouvements terribles et rapides.

Peut-on douter que la sagesse ou les divisions insensées des nations européennes, secondant les effets lents, mais infaillibles, des progrès de leurs colonies, ne produisent bientôt l'indépendance du nouveau monde ? et dès lors, la population européenne, prenant des accroissements rapides sur cet immense territoire, ne doit-elle pas ci- 
viliser ou faire disparaître, même sans conquête, les nations sauvages qui y occupent encore de vastes contrées ?

Parcourez l'histoire de nos entreprises, de nos établissements en Afrique ou en Asie; vous verrez nos monopoles de commerce, nos trahisons, notre mépris sanguinaire pour les hommes d'une autre couleur ou d'une autre croyance ; l'insolence de nos usurpations ; l'extravagant prosélytisme ou les intrigues de nos prêtres, détruire ce sentiment de respect et de bienveillance que la supériorité de nos lumières et les avantages de notre commerce avaient d'abord obtenu.

Mais l'instant approche sans doute où, cessant de ne leur montrer que des corrupteurs et des tyrans, nous deviendrons pour eux des instruments utiles, ou de généreux libérateurs.

La culture du sucre, s'établissant dans l'immense continent de l'Afrique, détruira le honteux brigandage qui la corrompt et la dépeuple depuis deux siècles.

Déjà, dans la Grande-Bretagne, quelques amis de l'humanité en ont donné l'exemple ; et si son gouvernement machiavéliste, forcé de respecter la raison publique, n'a osé s'y opposer, que ne doit-on pas espérer du même esprit, lorsqu'après la réforme d'une constitution servile et vénale, il deviendra digne d'une nation humaine et généreuse ? La France ne s'empressera-t-elle pas d'imiter ces entreprises, que la philanthropie et l'intérêt bien entendu de l'Europe ont également dictées ? Les épiceries ont été portées dans les îles françaises, dans la Guyane, dans quelques possessions anglaises, et bientôt on verra la chute de ce monopole que les Hollandais ont soutenu par tant de trahisons, de vexations et de crimes. Ces nations de l'Europe apprendront enfin que les compagnies exclusives ne sont qu'un impôt mis sur elles, pour donner à leurs gouvernements un nouvel instrument de tyrannie.

Alors les Européens, se bornant à un commerce libre, trop éclairés sur leurs propres droits pour se jouer de ceux des autres peuples, respecteront cette indépendance, qu'ils ont jusqu'ici violée avec tant d'audace. Leurs établissements, au lieu de se remplir de protégés des gouvernements qui, à la faveur d'une place ou d'un privilège, courent amasser des trésors par le brigandage et la perfidie, pour revenir ache- 
ter en Europe des honneurs et des titres, se peupleront d'hommes industrieux, qui iront chercher dans ces climats heureux l'aisance qui les fuyait dans leur patrie. La liberté les y retiendra ; l'ambition cessera de les rappeler ; et ces comptoirs de brigands deviendront des colonies de citoyens qui répandront, dans l'Afrique et dans l'Asie, les principes et l'exemple de la liberté, les lumières et la raison de l'Europe. À ces moines, qui ne portaient chez ces peuples que de honteuses superstitions, et qui les révoltaient en les menaçant d'une domination nouvelle, on verra succéder des hommes occupés de répandre, parmi ces nations, les vérités utiles à leur bonheur, de les éclairer sur leurs intérêts comme sur leurs droits. Le zèle pour la vérité est aussi une passion, et il portera ses efforts vers les contrées éloignées, lorsqu'il ne verra plus autour de lui de préjugés grossiers à combattre, d'erreurs honteuses à dissiper.

Ces vastes pays lui offriront, ici, des peuples nombreux, qui semblent n'attendre, pour se civiliser, que d'en recevoir de nous les moyens, et de trouver des frères dans les Européens, pour devenir leurs amis et leurs disciples ; là, des nations asservies sous des despotes sacrés ou des conquérants stupides, et qui, depuis tant de siècles, appellent des libérateurs ; ailleurs, des peuplades presque sauvages, que la dureté de leur climat éloigne des douceurs d'une civilisation perfectionnée, tandis que cette même dureté repousse également ceux qui voudraient leur en faire connaître les avantages; ou des hordes conquérantes, qui ne connaissent de loi que la force, de métier que le brigandage. Les progrès de ces deux dernières classes de peuples seront plus lents, accompagnés de plus d'orages ; peut-être même que, réduits à un moindre nombre, à mesure qu'ils se verront repoussés par les nations civilisées, ils finiront par disparaître insensiblement, ou se perdre dans leur sein.

Nous montrerons comment ces événements seront une suite infaillible non seulement des progrès de l'Europe, mais même de la liberté que la république française, et celle de l'Amérique septentrionale, ont à la fois, et l'intérêt le plus réel et le pouvoir de rendre au commerce de l'Afrique et de l'Asie ; comment ils doivent naître aussi nécessairement, ou de la nouvelle sagesse des nations européennes, ou de leur attachement opiniâtre à leurs préjugés mercantiles. 
Nous ferons voir qu'une seule combinaison, une nouvelle invasion de l'Asie par les Tartares, pourrait empêcher cette révolution, et que cette combinaison est désormais impossible. Cependant tout prépare la prompte décadence de ces grandes religions de l'Orient, qui, presque partout abandonnées au peuple, partageant l'avilissement de leurs ministres, et déjà dans plusieurs contrées réduites à n'être plus, aux yeux des hommes puissants, que des inventions politiques, ne menacent plus de retenir la raison humaine dans un esclavage sans espérance, et dans une enfance éternelle.

La marche de ces peuples serait plus prompte et plus sûre que la nôtre, parce qu'ils recevraient de nous ce que nous avons été obligés de découvrir, et que, pour connaître ces vérités simples, ces méthodes certaines auxquelles nous ne sommes parvenus qu'après de longues erreurs, il leur suffirait d'en avoir pu saisir les développements et les preuves dans nos discours et dans nos livres. Si les progrès des Grecs ont été perdus pour les autres nations, c'est le défaut de communication entre les peuples, c'est la domination tyrannique des Romains qu'il en faut accuser. Mais quand des besoins mutuels ayant rapproché tous les hommes, les nations les plus puissantes auront placé l'égalité entre les sociétés comme entre les individus, et le respect pour l'indépendance des États faibles, comme l'humanité pour l'ignorance et la misère, au rang de leurs principes politiques ; quand, à des maximes qui tendent à comprimer le ressort des facultés humaines, auront succédé celles qui en favorisent l'action et l'énergie, serait-il alors permis de redouter encore qu'il reste sur le globe des espaces inaccessibles à la lumière, ou que l'orgueil du despotisme puisse opposer à la vérité des barrières longtemps insurmontables?

Il arrivera donc, ce moment où le soleil n'éclairera plus sur la terre que des hommes libres, ne reconnaissant d'autre maître que leur raison ; où les tyrans et les esclaves, les prêtres et leurs stupides ou hypocrites instruments n'existeront plus que dans l'histoire et sur les théâtres ; où l'on ne s'en occupera plus que pour plaindre leurs victimes et leurs dupes ; pour s'entretenir, par l'horreur de leurs excès, dans une utile vigilance ; pour savoir reconnaître et étouffer, sous le poids de la raison, les premiers germes de la superstition. et de la tyrannie, si jamais ils osaient reparaître ! 
En parcourant l'histoire des sociétés, nous aurons eu l'occasion de faire voir que souvent il existe un grand intervalle entre les droits que la loi reconnaît dans les citoyens et les droits dont ils ont une jouissance réelle ; entre l'égalité qui est établie par les institutions politiques et celle qui existe entre les individus : nous aurons fait remarquer que cette différence a été une des principales causes de la destruction de la liberté dans les républiques anciennes, des orages qui les ont troublées, de la faiblesse qui les a livrées à des tyrans étrangers.

Ces différences ont trois causes principales : l'inégalité de richesse, l'inégalité d'état entre celui dont les moyens de subsistance assurée pour lui-même se transmettent à sa famille, et celui pour qui ces moyens sont dépendants de la durée de sa vie, ou plutôt de la partie de sa vie où il est capable de travail ; enfin, l'inégalité d'instruction.

Il faudra donc montrer que ces trois espèces d'inégalité réelle doivent diminuer continuellement, sans pourtant s'anéantir ; car elles ont des causes naturelles et nécessaires, qu'il serait absurde et dangereux de vouloir détruire ; et l'on ne pourrait même tenter d'en faire disparaître entièrement les effets, sans ouvrir des sources d'inégalité plus fécondes, sans porter aux droits des hommes des atteintes plus directes et plus funestes.

Il est aisé de prouver que les fortunes tendent naturellement à l'égalité, et que leur excessive disproportion ou ne peut exister, ou doit promptement cesser, si les lois civiles n'établissent pas des moyens factices de les perpétuer et de les réunir ; si la liberté du commerce et de l'industrie fait disparaître l'avantage que toute loi prohibitive, tout droit fiscal, donnent à la richesse acquise; si des impôts sur les conventions, les restrictions mises à leur liberté, leur assujettissement à des formalités gênantes ; enfin, l'incertitude et les dépenses nécessaires pour en obtenir l'exécution, n'arrêtent pas l'activité du pauvre et n'engloutissent pas ses faibles capitaux ; si l'administration publique n'ouvre point à quelques hommes des sources abondantes d'opulence, fermées au reste des citoyens ; si les préjugés et l'esprit d'avarice, propre à l'âge avancé, ne président point aux mariages ; si enfin, par la simplicité des mœurs et la sagesse des institutions, les richesses ne sont plus des moyens de satisfaire la vanité ou l'ambition, sans que cependant une austérité mal entendue, ne permettant plus d'en faire un 
moyen de jouissances recherchées, force de conserver telles qui ont été une fois accumulées.

Comparons, dans les nations éclairées de l'Europe, leur population actuelle et l'étendue de leur territoire. Observons, dans le spectacle que présentent leur culture et leur industrie, la distribution des travaux et des moyens de subsistance ; et nous verrons qu'il serait impossible de conserver ces moyens dans le même degré, et, par une conséquence nécessaire, d'entretenir la même masse de population, si un grand nombre d'individus cessaient de n'avoir, pour subvenir presque entièrement à leurs besoins ou à ceux de leur famille, que leur industrie et ce qu'ils tirent des capitaux employés à l'acquérir ou à en augmenter le produit. Or, la conservation de l'une et de l'autre de ces ressources dépend de la vie, de la santé même du chef de chaque famille. C'est, en quelque sorte, une fortune viagère, ou même plus dépendante du hasard; et il en résulte une différence très réelle entre cette classe d'hommes et celle dont les ressources ne sont point assujetties aux mêmes risques, soit que le revenu d'une terre, ou l'intérêt d'un capital presque indépendant de leur industrie, fournisse à leurs besoins.

Il existe donc une cause nécessaire d'inégalité, de dépendance et même de misère, qui menace sans cesse la classe la plus nombreuse et la plus active de nos sociétés.

Nous montrerons qu'on peut la détruire en grande partie, en opposant le hasard à lui-même ; en assurant à celui qui atteint la vieillesse un secours produit par ses épargnes, mais augmenté de celles des individus qui, en faisant le même sacrifice, meurent avant le moment d'avoir besoin d'en recueillir le fruit; en procurant, par l'effet d'une compensation semblable, aux femmes, aux enfants, pour le moment où ils perdent leur époux ou leur père, une ressource égale et acquise au même prix, soit pour les familles qu'afflige une mort prématurée, soit pour celles qui conservent leur chef plus longtemps; enfin, en préparant aux enfants qui atteignent l'âge de travailler pour euxmêmes, et de fonder une famille nouvelle, l'avantage d'un capital nécessaire au développement de leur industrie, et s'accroissant aux dépens de ceux qu'une mort trop prompte empêche d'arriver à ce terme. C'est à l'application du calcul aux probabilités de la vie, aux placements d'argent, que l'on doit l'idée de ces moyens, déjà employés avec 
succès, sans jamais l'avoir été cependant avec cette étendue, avec cette variété de formes qui les rendraient vraiment utiles, non pas seulement à quelques individus, niais à la masse entière de la société qu'ils délivreraient de cette ruine périodique d'un grand nombre de familles, source toujours renaissante de corruption et de misère.

Nous ferons voir que ces établissements, qui peuvent être formés au nom de la puissance sociale, et devenir un de ses plus grands bienfaits, peuvent être aussi le résultat d'associations particulières, qui se formeront sans aucun danger, lorsque les principes d'après lesquels les établissements doivent s'organiser seront devenus plus populaires, et que les erreurs qui ont détruit un grand nombre de ces associations cesseront d'être à craindre pour elles.

[Nous exposerons d'autres moyens d'assurer cette égalité, soit en empêchant que le crédit continue d'être un privilège si exclusivement attaché à la grande fortune, en lui donnant cependant une base non moins solide ; soit en rendant les progrès de l'industrie et l'activité du commerce plus indépendants de l'existence des grands capitalistes ; et c'est encore à l'application du calcul que l'on devra ces moyens.]

L'égalité d'instruction que l'on peut espérer d'atteindre, mais qui doit suffire, est celle qui exclut toute dépendance, ou forcée, ou volontaire. Nous montrerons, dans l'état actuel des connaissances humaines, les moyens faciles de parvenir à ce but, même pour ceux qui ne peuvent donner à l'étude qu'un petit nombre de leurs premières années, et, dans le reste de leur vie, quelques heures de loisir. Nous ferons voir que par un choix heureux, et des connaissances elles-mêmes, et des méthodes de les enseigner, on peut instruire la masse entière d'un peuple de tout ce que chaque homme a besoin de savoir pour l'économie domestique, pour l'administration de ses affaires, pour le libre développement de son industrie et de ses facultés; pour connaître ses droits, les défendre et les exercer ; pour être instruit de ses devoirs, pour pouvoir les bien remplir ; pour juger ses actions et celles des autres, d'après ses propres lumières, et n'être étranger à aucun des sentiments élevés ou délicats qui honorent la nature humaine; pour ne point dépendre aveuglément de ceux à qui il est obligé de confier le soin de ses affaires ou l'exercice de ses droits, pour être en état de les choisir et de les surveiller, pour n'être plus la dupe de ces erreurs po- 
pulaires qui tourmentent la vie de craintes superstitieuses et d'espérances chimériques ; pour se défendre contre les préjugés avec les seules forces de sa raison ; enfin, pour échapper aux prestiges du charlatanisme, qui tendrait des pièges à sa fortune, à sa santé, à la liberté de ses opinions et de sa conscience, sous prétexte de l'enrichir, de le guérir et de le sauver.

Dès lors, les habitants d'un même pays n'étant plus distingués entre eux par l'usage d'une langue plus grossière ou plus raffinée ; pouvant également se gouverner par leurs propres lumières ; n'étant plus bornés à la connaissance machinale des procédés d'un art et de la routine d'une profession ; ne dépendant plus, ni pour les moindres affaires, ni pour se procurer la moindre instruction, d'hommes habiles qui les gouvernent par un ascendant nécessaire, il doit en résulter une égalité réelle, puisque la différence des lumières ou des talents ne peut plus élever une barrière entre des hommes à qui leurs sentiments, leurs idées, leur langage, permettent de s'entendre ; dont les uns peuvent avoir le désir d'être instruits par les autres, mais n'ont pas besoin d'être conduits par eux ; peuvent vouloir confier aux plus éclairés le soin de les gouverner, mais non être forcés de le leur abandonner avec une aveugle confiance.

C'est alors que cette supériorité devient un avantage pour ceux même qui ne le partagent pas, qu'elle existe pour eux, et non contre eux. La différence naturelle des facultés entre les hommes dont l'entendement n'a point été cultivé produit, même chez les sauvages, des charlatans et des dupes; des gens habiles et des hommes faciles à tromper; là même différence existe sans doute dans un peuple où l'instruction est vraiment générale ; ni ais elle n'est plus qu'entre les hommes éclairés et les hommes d'un esprit droit, qui sentent le prix des lumières sans en être éblouis ; entre le talent ou le génie, et le bon sens qui sait les apprécier et en jouir ; et quand même cette différence serait plus grande, si on compare seulement la force, l'étendue des facultés, elle ne deviendrait pas moins insensible, si on n'en compare que les effets dans les relations des hommes entre eux, dans ce qui intéresse leur indépendance et leur bonheur.

Ces diverses causes d'égalité n'agissent point d'une manière isolée ; elles s'unissent, se pénètrent, se sou" tiennent mutuellement, et de 
leurs effets combinés résulte une action plus forte, plus sûre, plus constante. Si l'instruction est plus égale, Il en naît une plus grande égalité dans l'industrie, et dès Ion dans les fortunes; et l'égalité des fortunes contribue nécessairement à celle de l'instruction; tandis que l'égalité entre les peuples, et celle qui s'établit pour chacun, ont encore l'une sur l'autre une influence mutuelle.

Enfin, l'instruction bien dirigée corrige l'inégalité naturelle des facultés, au lieu de la fortifier, comme les bonnes lois remédient à l'inégalité naturelle des moyens de subsistance ; comme dans les sociétés où les institutions auront amené cette égalité, la liberté, quoique soumise à une constitution régulière, sera plus étendue, plus entière que dans l'indépendance de la vie sauvage. Alors, l'art social a rempli son but, celui d'assurer et d'étendre pont tous la jouissance des droits communs, auxquels ils sont appelés par la nature.

Les avantages réels qui doivent résulter des progrès, dont on vient de montrer une espérance presque certaine, ne peuvent avoir de terme que celui du perfectionnement même de l'espèce humaine, puisque, à mesure que divers genres d'égalité l'établiront pour des moyens plus vastes de pourvoir à nos besoins, pour une instruction plus étendue, pour une liberté plus complète, plus cette égalité sera réelle, plus elle sera près d'embrasser tout ce qui intéresse véritablement le bonheur des hommes.

C'est donc en examinant la marche et les lois de ce perfectionnement que nous pourrons seulement connaître l'étendue ou le terme de nos espérances.

Personne n'a jamais pensé que l'esprit pût épuiser et tous les faits de la nature, et les derniers moyens de précision dans la mesure, dans l'analyse de ces faits et les rapports des objets entre eux, et toutes les combinaisons possibles d'idées. Les seuls rapports des grandeurs, les combinaisons de cette seule idée, la quantité ou l'étendue, forment un système déjà trop immense pour que jamais l'esprit humain puisse le saisir tout entier, pour qu'une portion de ce système, toujours plus vaste que celle qu'il aura pénétrée, ne lui reste toujours inconnue. Mais on a pu croire que l'homme ni-t pouvant jamais connaître qu'une partie des objets auxquels la nature de son intelligence lui permet d'at- 
teindre, il doit cependant rencontrer, enfin, un terme où le nombre et la complication de ceux qu'il connaît déjà, ayant absorbé toutes ses forces, tout progrès nouveau lui deviendrait réellement impossible.

Mais, comme à mesure que les faits se multiplient, l'homme apprend à les classer, à les réduire à des faits plus généraux ; comme les instruments et les méthodes qui servent à les observer, à les mesurer avec exactitude, acquièrent en même temps une précision nouvelle ; comme, à mesure que l'on connaît, entre un plus grand nombre d'objets, des rapports plus multipliés, on parvient à les réduire à des rapports plus étendus, et les renfermer sous des expressions plus simples, à les présenter sous des formes qui permettent d'en saisir un plus grand nombre, même en ne possédant qu'une même force de tête et n'employant qu'une égale intensité d'attention ; comme, à mesure que l'esprit s'élève à des combinaisons plus compliquées, des formules plus simples les lui rendent bientôt faciles, les vérités dont la découverte a coûté le plus d'effort, qui d'abord n'ont pu être entendues que par des hommes capables de méditations profondes, sont bientôt après développées et prouvées par des méthodes qui ne sont plus au-dessus d'une intelligence commune. Si les méthodes qui conduisaient à des combinaisons nouvelles sont épuisées ; si leurs applications aux questions non encore résolues exigent des travaux qui excèdent, ou le temps, ou les forces des savants, bientôt des méthodes plus générales, des moyens plus simples viennent ouvrir un nouveau champ au génie. La vigueur, l'étendue réelle des têtes humaines sera restée la même ; mais les instruments qu'elles peuvent employer se seront multipliés et perfectionnés ; mais la langue qui fixe et détermine les idées aura pu acquérir plus de précision, plus de généralité ; mais au lieu que, dans la mécanique, on ne peut augmenter la force qu'en diminuant la vitesse, ces méthodes, qui dirigeront le génie dans la découverte des vérités nouvelles, ont également ajouté, et à sa force, et à la rapidité de ses opérations.

Enfin, ces changements eux-mêmes étant la suite nécessaire du progrès dans la connaissance des vérités de détail, et la cause qui amène le besoin de ressources nouvelles produisant en même temps les moyens de les obtenir, il résulte que la masse réelle des vérités que forme le système des sciences d'observation, d'expérience ou de calcul, peut augmenter sans cesse ; et cependant, toutes les parties de ce 
même système ne sauraient se perfectionner sans cesse, en supposant aux facultés de l'homme la même force, la même activité, la même étendue.

En appliquant ces réflexions générales aux différentes sciences, nous donnerons, pour chacune d'elles, des exemples de ces perfectionnements successifs, qui ne laisseront aucun doute sur la certitude de ceux que nous devons attendre. Nous indiquerons particulièrement, pour celles que le préjugé regarde comme plus près d'être épuisées, les progrès dont l'espérance est la plus probable et la plus prochaine. Nous développerons tout ce qu'une application plus générale, plus philosophique des sciences de calcul à toutes les connaissances humaines doit ajouter d'étendue, de précision, d'unité au système entier de ces connaissances. Nous ferons remarquer comment une instruction plus universelle dans chaque pays, en donnant à un plus grand nombre d'hommes les connaissances élémentaires qui peuvent leur inspirer, et le goût d'un genre d'étude, et la facilité d'y faire des progrès, doit ajouter à ces espérances ; combien elles augmentent encore, si une aisance plus générale permet à plus d'individus de se livrer à ces occupations, puisqu'en effet à peine, dans les pays les plus éclairés, la cinquantième partie de ceux à qui la nature a donné des talents reçoivent l'instruction nécessaire pour les développer ; et qu'ainsi le nombre des hommes destinés à reculer les bornes des sciences par leurs découvertes devrait alors s'accroître dans cette même proportion.

Nous montrerons combien cette égalité d'instruction, et celle qui doit s'établir entre les diverses nations, accéléreraient la marche de ces sciences, dont les progrès dépendent d'observations répétées en plus grand nombre, étendues sur un plus vaste territoire ; tout ce que la minéralogie, la botanique, la zoologie, la météorologie, doivent en attendre ; enfin, quelle énorme disproportion existe pour ces sciences, entre la faiblesse des moyens qui cependant nous ont conduits à tant de vérités utiles, importantes, et la grandeur de ceux que l'homme pourrait alors employer.

Nous exposerons combien, dans les sciences même où les découvertes sont le prix de la seule méditation, l'avantage d'être cultivées par un plus grand nombre d'hommes peut encore contribuer à leurs progrès, par ces perfectionnements de détail qui n'exigent point cette 
force de tête nécessaire aux inventeurs, et qui se présentent d'euxmêmes à la simple réflexion.

Si nous passons aux arts dont la théorie dépend de ces mêmes sciences, nous verrons que les progrès qui doivent Suivre ceux de cette théorie ne doivent pas avoir d'autres limites; que les procédés des arts sont susceptibles du même perfectionnement, des mêmes simplifications que les méthodes scientifiques; que les instruments, que les machines, les métiers ajouteront de plus en plus à la force, à l'adresse des hommes, augmenteront à la fois la perfection et la précision des produits, en diminuant et le temps et le travail nécessaires pour les obtenir ; alors disparaîtront les obstacles qu'opposent encore à ces mêmes progrès, et les accidents qu'on apprendrait à prévoir, à prévenir, et l'insalubrité soit des travaux, soit des habitudes, soit des climats.

Alors un espace de terrain de plus en plus resserré pourra produire une masse de denrées d'une plus grande utilité ou d'une valeur plus haute ; des jouissances plus étendues pourront être obtenues avec une moindre consommation ; le même produit de l'industrie répondra à une moindre destruction de productions premières, ou deviendra d'un usage plus durable. L'on saura choisir, pour chaque sol, les productions qui sont relatives à plus de besoins ; entre les productions qui peuvent satisfaire aux besoins d'un même genre, celles qui satisfont une plus grande masse, en exigeant moins de travail et moins de consommation réelle. Ainsi, sans aucun sacrifice, les moyens de conservation, d'économie dans la consommation, suivront les progrès de l'art de reproduire les diverses substances, de les préparer, d'en fabriquer les produits.

Ainsi, non seulement le même espace de terrain pourra nourrir plus d'individus ; mais chacun d'eux, moins péniblement occupé, le sera d'une manière plus productive, et pourra mieux satisfaire à ses besoins.

Mais, dans ces progrès de l'industrie et du bien-être, dont il résulte une proportion plus avantageuse entre les facultés de l'homme et ses besoins, chaque génération, soit par ces progrès, soit par la conservation des produits d'une industrie antérieure, est appelée a des jouissan- 
ces plus étendues, et dès lors, par une suite de la constitution physique de l'espèce humaine, à un accroissement dans le nombre des individus ; alors, ne doit-il pas arriver un terme où ces lois, également nécessaires, viendraient à se contrarier; où l'augmentation du nombre des hommes surpassant celle de leurs moyens, il en résulterait nécessairement, sinon une diminution continue de bien-être et de population, une marche vraiment rétrograde, du moins une sorte d'oscillation entre le bien et le mal ? Cette oscillation dans les sociétés arrivées à ce terme, ne serait-elle pas une cause toujours subsistante de misères en quelque sorte périodiques ? Ne marquerait-elle pas la limite où toute amélioration deviendrait impossible, et à la perfectibilité de l'espèce humaine, le terme qu'elle atteindrait dans l'immensité des siècles, sans pouvoir jamais le passer?

Il n'est personne qui ne voie, sans doute, combien ce temps est éloigné de nous ; mais devons-nous y parvenir un jour ? Il est également impossible de prononcer pour ou contre la réalité future d'un événement, qui ne se réaliserait qu'à une époque où l'espèce humaine aurait nécessairement acquis des lumières dont nous pouvons à peine nous faire une idée. Et qui, en effet, oserait deviner ce que l'art de convertir les éléments en substances propres à notre usage doit devenir un jour?

Mais, en supposant que ce terme dût arriver, il n'en résulterait rien d'effrayant, ni pour le bonheur de l'espèce humaine, ni pour sa perfectibilité indéfinie; si on suppose qu'avant ce temps les progrès de la raison aient marché de pair avec ceux des sciences et des arts, que les ridicules préjugés de la superstition aient cessé de répandre sur la morale une austérité qui la corrompt et la dégrade au lieu de l'épurer et de l'élever, les hommes sauront alors que, s'ils ont des obligations à l'égard des êtres qui ne sont pas encore, elles ne consistent pas à leur donner l'existence, mais le bonheur ; elles ont pour objet le bien-être général de l'espèce humaine ou de la société dans laquelle ils vivent ; de la famille à laquelle ils sont attachés, et non la puérile idée de charger la terre d'êtres inutiles et malheureux. Il pourrait donc y avoir une limite à la masse possible des subsistances, et, par conséquent, à la plus grande population possible, sans qu'il en résultât cette destruction prématurée, si contraire à la nature et à la prospérité sociale d'une partie des êtres qui ont reçu la vie. 
Comme la découverte, ou plutôt l'analyse exacte des premiers principes de la métaphysique, de la morale, de la politique, est encore récente, et qu'elle avait été précédée de la connaissance d'un grand nombre de vérités de détail, le préjugé qu'elles ont atteint par là leur dernière limite s'est facilement établi ; on a supposé qu'il n'y avait rien à faire, parce qu'il ne restait plus à détruire d'erreurs grossières, et de vérités fondamentales à établir.

Mais il est aisé de voir combien l'analyse des facultés intellectuelles et morales de l'homme est encore imparfaite ; combien la connaissance de ses devoirs, qui suppose celle de l'influence de ses actions sur le bien-être de ses semblables, sur la société dont il est membre, peut s'étendre encore par une observation plus fixe, plus approfondie, plus précise de cette influence ; combien il reste de questions à résoudre, de rapports sociaux à examiner, pour connaître avec exactitude l'étendue des droits individuels de l'homme, et de ceux que l'état social donne à tous à l'égard de chacun! A-t-on même jusqu'ici, avec quelque précision, posé les limites de ces droits, soit entre les diverses sociétés, dans les temps de guerre, soit de ces sociétés sur leurs membres, dans les temps de troubles et de divisions, soit enfin ceux des individus, des réunions spontanées, dans le cas d'une formation libre et primitive, ou d'une séparation devenue nécessaire ?

Si on passe maintenant à la théorie qui doit diriger l'application de ces principes, et servir de base à l'art social, ne voit-on pas la nécessité d'atteindre à une précision dont ces vérités premières ne peuvent être susceptibles dans leur généralité absolue ? Sommes-nous parvenus au point de donner pour base à toutes les dispositions des lois, ou la justice, ou une utilité prouvée et reconnue, et non les vues vagues, incertaines, arbitraires, de prétendus avantages politiques? Avons-nous fixé des règles précises pour choisir, avec assurance, entre le nombre presque infini des combinaisons possibles, où les principes généraux de l'égalité et des droits naturels seraient respectés, celles qui assurent davantage la conservation de ces droits, laissent à leur exercice, à leur jouissance, une plus grande étendue, assurent davantage le repos, le bien-être des individus, la force, la paix, la prospérité des nations ? 
L'application du calcul des combinaisons et des probabilités à ces mêmes sciences, promet des progrès d'autant plus importants, qu'elle est à la fois le seul moyen de donner à leurs résultats une précision presque mathématique, et d'en apprécier le degré de certitude ou de vraisemblance. Les faits sur lesquels ces résultats sont appuyés peuvent bien, sans calcul et d'après la seule observation, conduire quelquefois à des vérités générales ; apprendre si l'effet produit par une telle cause a été favorable ou contraire ; mais, si ces faits n'ont pu être ni comptés, ni pesés ; si ces effets n'ont pu être soumis à une mesure exacte, alors on ne pourra connaître celle du bien ou du mal qui résulte de -cette cause ; et si l'un et l'autre se compensent avec quelque égalité ; si la différence n'est pas très grande, on ne pourra même prononcer, avec quelque certitude, de quel côté penche la balance. Sans l'application du calcul, souvent il serait impossible de choisir, avec quelque sûreté, entre deux combinaisons formées pour obtenir le même but, lorsque les avantages qu'elles présentent ne frappent point par une disproportion évidente. Enfin, sans ce même secours, ces sciences resteraient toujours grossières et bornées, faute d'instruments assez finis pour y saisir la vérité fugitive, de machines assez sûres pour atteindre la profondeur de la mine où se cache une partie de leurs richesses.

Cependant, cette application, malgré les efforts heureux de quelques géomètres, n'en est encore, pour ainsi dire, qu'à ses premiers éléments, et elle doit ouvrir, aux générations suivantes, une source de lumières aussi inépuisables que la science même du calcul, que le nombre des combinaisons, des rapports et des faits qu'on peut y soumettre.

Il est un autre progrès de ces sciences non moins important ; c'est le perfectionnement de leur langue, si vague encore et si obscure. Or, c'est à ce perfectionnement qu'elles peuvent devoir l'avantage de devenir véritablement populaires, même dans leurs premiers éléments. Le génie triomphe de ces inexactitudes des langues scientifiques comme des autres obstacles ; il reconnaît la vérité malgré ce masque étranger qui la cache ou qui la déguise ; mais celui qui ne peut donner à son instruction qu'un petit nombre d'instants, pourra-t-il acquérir, conserver ces notions les plus simples, si elles sont défigurées par un langage inexact ? Moins il peut rassembler et combiner d'idées, plus il 
a besoin qu'elles soient justes, qu'elles soient précises ; il ne peut trouver dans sa propre intelligence un système de vérités qui le défendent contre l'erreur, et son esprit, qu'il n'a ni fortifié, ni raffiné par un long exercice, ne peut saisir les faibles lueurs qui s'échappent, à travers les obscurités, les équivoques d'une langue imparfaite et vicieuse.

Les hommes ne pourront s'éclairer sur la nature et le développement de leurs sentiments moraux, sur les principes de la morale, sur les motifs naturels d'y conformer leurs actions, sur leurs intérêts, soit comme individus, soit comme membres d'une société, sans faire aussi dans la morale pratique des progrès non moins réels que ceux de la science même. L'intérêt mal entendu n'est-il pas la cause la plus fréquente des actions contraires au bien général ? La violence des passions n'est-elle pas souvent l'effet d'habitudes auxquelles on ne s'abandonne que par un faux calcul, ou de l'ignorance des moyens de résister à leurs premiers mouvements, de les adoucir, d'en détourner, d'en diriger l'action?

L'habitude de réfléchir sur sa propre conduite, d'interroger et d'écouter sur elle sa raison et sa conscience, et l'habitude des sentiments doux qui confondent notre bonheur avec celui des autres, ne sont-elles pas une suite nécessaire de l'étude de la morale bien dirigée, d'une plus grande égalité dans les conditions dg pacte social ? Cette conscience de sa dignité qui appartient à l'homme libre, une éducation fondée sur une connaissance approfondie de notre constitution morale, ne doivent-elles pas rendre communs à presque tous les hommes, ces principes d'une justice rigoureuse et pure, ces mouvements habituels d'une bienveillance active, éclairée, d'une sensibilité délicate et généreuse, dont la nature a placé le germe dans tous les cœurs, et qui n'attendent, pour s'y développer, que la douce influence des lumières et de la liberté ? De même que les sciences mathématiques et physiques servent à perfectionner les arts employés pour nos besoins les plus simples, n'est-il pas également dans l'ordre nécessaire de la nature, que les progrès des sciences morales et politiques exercent la même action sur les motifs qui dirigent nos sentiments et nos actions?

Le perfectionnement des lois, des institutions publiques, suite des progrès de ces sciences, n'a-t-il point pour effet de rapprocher, d'identifier l'intérêt commun de chaque homme avec l'intérêt commun de 
tous ? Le but de l'art social n'est-il pas de détruire cette opposition apparente ? et le pays dont la constitution et les lois se conformeront le plus exactement au vœu de la raison et do la nature, n'est-il pas celui où la vertu sera plus facile, où les tentations de s'en écarter seront les plus rares et les plus faibles ?

Quelle est l'habitude vicieuse, l'usage contraire à la bonne foi, quel est même le crime dont on ne puisse montrer l'origine, la cause première, dans la législation, dans les institutions, dans les préjugés du pays où l'on observe cet usage, cette habitude, où ce crime s'est commis ?

Enfin, le bien-être qui suit les progrès que font les arts utiles, en s'appuyant sur une saine théorie, ou ceux d'une législation juste, qui se fonde sur les vérités des sciences politiques, ne dispose-t-il pas les hommes à l'humanité, à la bienfaisance, à la justice ?

Toutes ces observations, enfin, que nous nous proposons de développer dans l'ouvrage même, ne prouvent-elles pas que la bonté morale de l'homme, résultat nécessaire de son organisation, est, comme toutes les autres facultés, susceptible d'un perfectionnement indéfini, et que la nature lie, par une chaîne indissoluble, la vérité, le bonheur et la vertu?

Parmi les progrès de l'esprit humain les plus importants pour le bonheur général, nous devons compter l'entière destruction des préjugés, qui ont établi entre les deux sexes une inégalité de droits funeste à celui même qu'elle favorise. On chercherait en vain des motifs de la justifier par les différences de leur organisation physique, par celle qu'on voudrait trou-ver dans la force de leur intelligence, dans leur sensibilité morale. Cette inégalité n'a eu d'autre origine que l'abus de la force, et c'est vainement qu'on a essayé depuis de l'excuser par des sophismes.

Nous montrerons combien la destruction des usages autorisés par ce préjugé, des lois qu'il a dictées, peut contribuer à augmenter le bonheur des familles, à rendre communes les vertus domestiques, premier fondement de toutes les autres; à favoriser les progrès de l'instruction, et surtout à la rendre vraiment générale, soit parce qu'on 
l'étendrait aux deux sexes avec plus d'égalité, soit parce qu'elle ne peut devenir générale, même pour les hommes, sans le concours des mères de famille. Cet hommage trop tardif, rendu enfin à l'équité et au bon sens, ne tarirait-il pas une source trop féconde d'injustices, de cruautés et de crimes, en faisant disparaître une opposition si dangereuse entre le penchant naturel le plus vif, le plus difficile à réprimer, et les devoirs de l'homme, ou les intérêts de la société ? Ne produirait-il pas, enfin, ce qui n'a jamais été jusqu'ici qu'une chimère, des mœurs nationales, douces et pures, formées, non de privations orgueilleuses, d'apparences hypocrites, de réserves imposées par la crainte de la honte ou les terreurs religieuses, mais d'habitudes librement contractées, inspirées par la nature, avouées par la raison?

Les peuples plus éclairés, se ressaisissant du droit de disposer euxmêmes de leur sang et de leurs richesses, apprendront peu à peu à regarder la guerre comme le fléau le plus funeste, comme le plus grand des crimes. On verra d'abord disparaître celles où les usurpateurs de la souveraineté des nations les entraînaient, pour de prétendus droits héréditaires.

Les peuples sauront qu'ils ne peuvent devenir conquérants sans perdre leur liberté ; que des confédérations perpétuelles sont le seul moyen de maintenir leur indépendance ; qu'ils doivent chercher la sûreté et non la puissance. Peu à peu les préjugés commerciaux se dissiperont ; un faux intérêt mercantile perdra l'affreux pouvoir d'ensanglanter la terre, et de ruiner les nations sous prétexte de les enrichir. Comme les peuples se rapprocheront enfin dans les principes de la politique et de la morale, comme chacun d'eux, pour son propre avantage, appellera les étrangers à un partage plus égal des biens qu'il doit à la nature ou à son industrie, toutes ces causes qui produisent, enveniment, perpétuent les haines nationales, s'évanouiront peu à peu ; elles ne fourniront plus à la fureur belliqueuse, ni aliment, ni prétexte.

Des institutions, mieux combinées que ces projets de paix perpétuelle, qui ont occupé lé loisir et consolé Pâme de quelques philosophes, accéléreront les progrès de cette fraternité des nations, et les guerres entre les peuples, comme les assassinats, seront au nombre de ces atrocités extraordinaires qui humilient et révoltent la nature, qui 
impriment un long opprobre sur le pays, sur le siècle dont les annales en ont été souillées.

En parlant des beaux-arts dans la Grèce, en Italie, en France, nous avons observé déjà qu'il fallait distinguer, dans leurs productions, ce qui appartenait réellement aux progrès de Part, et ce qui n'était dû qu'au talent de l'artiste. Nous indiquerons ici les progrès que les arts doivent attendre encore, soit de ceux de la philosophie et des sciences, soit des observations plus nombreuses, plus approfondies, sur l'objet, sur les effets, sur les moyens de ces mêmes arts, soit enfin de la destruction des préjugés qui en ont resserré la sphère, et qui les retiennent encore sous ce joug de l'autorité, que les sciences et la philosophie ont brisé. Nous examinerons si, comme on l'a cru, ces moyens doivent s'épuiser, parce que les beautés les plus sublimes ou les plus touchantes ayant été saisies, les sujets les plus heureux ayant été traités, les combinaisons les plus simples et les plus frappantes ayant été employées, les caractères les plus fortement prononcés, les plus généraux, ayant été tracés, les plus énergiques passions, leurs expressions les plus naturelles ou les plus vraies, les vérités les plus imposantes, les images les plus brillantes ayant été mises en œuvre, les arts sont condamnés, quelque fécondité qu'on suppose dans leurs moyens, à l'éternelle monotonie de l'imitation des premiers modèles.

Nous ferons voir que cette opinion n'est qu'un préjugé, né de l'habitude qu'ont les littérateurs et les artistes de juger les hommes au lieu de jouir des ouvrages ; que si l'on doit perdre de ce plaisir réfléchi, produit par la comparaison des productions des différents siècles ou des divers pays, par l'admiration qu'excitent les efforts ou les succès du génie, cependant les jouissances que donnent ces productions considérées en elles-mêmes doivent être aussi vives, quand même celui à qui on les doit aurait eu moins de mérite à s'élever jusqu'à cette perfection. A mesure que ces productions, vraiment dignes d'être conservées, se multiplieront, deviendront plus parfaites, chaque génération exercera sa curiosité, son admiration, sur celles qui méritent la préférence ; tandis qu'insensiblement les autres tomberont dans l'oubli ; et ces jouissances, dues à ces beautés plus simples, plus frappantes, qui ont été saisies les premières, n'en existeront pas moins pour les générations nouvelles, quand elles ne devraient les trouver que dans des productions plus modernes. 
Les progrès des sciences assurent les progrès de l'art d'instruire, qui eux-mêmes accélèrent ensuite ceux des sciences; et cette influence réciproque, dont l'action se renouvelle sans cesse, doit être placée au nombre des causes les plus actives, les plus puissantes du perfectionnement de l'espèce humaine. Aujourd'hui, un jeune homme, au sortir de nos écoles, sait, en mathématiques, au delà de ce que Newton avait appris par de profondes études, ou découvert par son génie; il sait mailler l'instrument du calcul avec une facilité alors inconnue. La même observation peut s'appliquer à toutes les sciences, cependant avec quelque inégalité. A mesure que chacune d'elles s'agrandit, les moyens de resserrer dans un plus petit espace les preuves d'un plus grand nombre de vérités, et d'en faciliter l'intelligence, se perfectionneront également. Ainsi, non seulement, malgré les nouveaux progrès des sciences, les hommes d'un génie égal se retrouvent à la même époque de leur vie, au niveau de l'état actuel de la science, mais pour chaque génération, ce qu'avec une même force de tête, une même attention, on peut apprendre dans le même espace de temps, s'accroîtra nécessairement, et la portion élémentaire de chaque science, celle à laquelle tous les hommes peuvent atteindre, devenant de plus en plus étendue, renfermera d'une manière plus complète ce qu'il peut être nécessaire à chacun de savoir, pour se diriger dans la vie commune, pour exercer sa raison avec une entière indépendance.

Dans les sciences politiques, il est un ordre de vérités qui, surtout chez les peuples libres (c'est-à-dire, dans quelques générations chez tous les peuples), ne peuvent être utiles que lorsqu'elles sont généralement connues et avouées. Ainsi l'influence du progrès de ces sciences sur la liberté, sur la prospérité des nations, doit en quelque sorte se mesurer sur le nombre de ces vérités, qui, par l'effet d'une instruction élémentaire, deviennent communes à tous les esprits ; ainsi, les progrès toujours croissants de cette instruction élémentaire, liés euxmêmes aux progrès nécessaires de ces sciences, nous répondent d'une amélioration dans les destinées de l'espèce humaine, qui peut être regardée comme indéfinie, puisqu'elle n'a d'autres limites que celles de ces progrès mêmes.

Il nous reste maintenant à parler de deux moyens généraux, qui doivent influer à la fois, et sur le perfectionnement de l'art d'instruire, 
et sur celui des sciences : l'un est l'emploi plus étendu et moins imparfait de ce qu'on peut appeler les méthodes techniques ; l'autre l'institution d'une langue universelle.

J'entends par méthodes techniques, l'art de réunir un grand nombre d'objets sous une disposition systématique, qui permette d'en voir d'un coup d'œil les rapports, d'en saisir rapidement les combinaisons, d'en former plus facilement de nouvelles.

Nous développerons les principes, nous ferons sentir l'utilité de cet art, qui est encore dans son enfance, et qui peut, en se perfectionnant, offrir, soit l'avantage de rassembler dans le petit espace d'un tableau, ce qu'il serait souvent difficile de faire entendre aussi promptement, aussi bien, dans un livre très étendu ; soit le moyen, plus précieux encore, de présenter les faits isolés dans la disposition la plus propre à en déduire des résultats généraux. Nous exposerons comment, à l'aide d'un petit nombre de ces tableaux, dont il serait facile d'apprendre l'usage, les nommes qui n'ont pu s'élever assez au-dessus de l'instruction la plus élémentaire, pour se rendre propres les connaissances de détail utiles dans la vie commune, pourront les retrouver à volonté lorsqu'ils en éprouveront le. besoin ; comment enfin l'usage de ces mêmes méthodes peut faciliter l'instruction élémentaire dans tous les genres où cette instruction se fonde, soit sur un ordre systématique de vérités, soit sur une suite d'observations ou de faits.

Une langue universelle est celle qui exprime par des signes, soit des objets réels, soit ces collections bien déterminées qui, composées d'idées simples et générales, se trouvent les mêmes, ou peuvent se former également dans l'entendement de tous les hommes; soit enfin les rapports généraux entre ces idées, les opérations de l'esprit humain, celles qui sont propres à chaque science, ou les procédés des arts. Ainsi, les hommes qui connaîtraient ces signes, la méthode de les combiner, et les lois de leur formation, entendraient ce qui est écrit dans cette langue, et l'exprimeraient avec une égale facilité dans la langue commune du pays.

On voit que cette langue pourrait être employée pour exposer, ou la théorie d'une science, ou les règles d'un art ; pour rendre compte d'une expérience ou d'une observation nouvelle, de l'invention d'un procédé, 
de la découverte, soit d'une vérité, soit d'une méthode ; que comme l'algèbre, lorsqu'elle serait obligée de se servir de signes nouveaux, ceux qui seraient déjà connus donneraient les moyens d'en expliquer la valeur.

Une telle langue n'a pas l'inconvénient d'un idiome scientifique différent du langage commun. Nous avons observé déjà que l'usage de cet idiome partagerait nécessairement les sociétés en deux classes inégales entre elles: l'une composée des hommes qui, connaissant ce langage, auraient la clef de toutes les sciences; l'autre de ceux qui, n'ayant pu l'apprendre, se trouveraient dans l'impossibilité presque absolue d'acquérir des lumières. Ici, au contraire, la langue universelle s'y apprendrait avec la science même, comme celle de l'algèbre ; on connaîtrait le signe en même temps que l'objet, l'idée, l'opération qu'il désigne. Celui qui, ayant appris les éléments d'une science, voudrait y pénétrer plus avant, trouverait dans les livres, non seulement les vérités qu'il peut entendre à l'aide des signes dont il connaît déjà la valeur, mais l'explication des nouveaux signes dont on a besoin pour s'élever à d'autres vérités.

Nous montrerons que la formation d'une telle langue, si elle se borne à exprimer des propositions simples, précises, comme celles qui forment le système d'une science, ou de la pratique d'un art, ne serait rien moins qu'une idée chimérique; que l'exécution même en serait déjà facile pour un grand nombre d'objets ; que l'obstacle le plus réel qui l'empêcherait de l'étendre à d'autres, serait la nécessité un peu humiliante de reconnaître combien peu nous avons d'idées précises de notions bien déterminées, bien convenues entre les esprits.

Nous indiquerons comment, se perfectionnant sans cesse, acquérant chaque jour plus d'étendue, elle servirait à porter sur tous les objets qu'embrasse l'intelligence humaine, une rigueur, une précision qui rendrait la connaissance de la vérité facile, et l'erreur presque impossible. Alors la marche de chaque science aurait la sûreté de celle des mathématiques, et les propositions qui en forment le système, toute la certitude géométrique, c'est-à-dire, toute celle que permet la nature de leur objet et de leur méthode. 
Toutes ces causes du perfectionnement de l'espèce humaine, tous ces moyens qui l'assurent, doivent, par leur nature, exercer une action toujours active, et acquérir une étendue toujours croissante.

Nous en avons exposé les preuves qui, dans l'ouvrage même, recevront par leur développement, une force plus grande ; nous pourrions donc conclure déjà, que la perfectibilité de l'homme est indéfinie ; et cependant, jusqu'ici, nous ne lui avons supposé que les mêmes facultés naturelles, la même organisation. Quelles seraient donc la certitude, l'étendue de ses espérances, si l'on pouvait croire que ces facultés naturelles elles-mêmes, cette organisation, sont aussi susceptibles de s'améliorer ? et c'est la dernière question qu'il nous reste à examiner.

La perfectibilité ou la dégénération organiques des races dans les végétaux, dans les animaux, peut être regardée comme une des lois générales de la nature.

Cette loi s'étend à l'espèce humaine, et personne ne doutera sans doute, que les progrès dans la médecine conservatrice, l'usage d'aliments et de logements plus sains, une manière de vivre qui développerait les forces par l'exercice, sans les détruire par des excès ; qu'enfin, la destruction des deux causes les plus actives de dégradation, la misère et la trop grande richesse, ne doivent prolonger, pour les hommes, la durée de la vie commune, leur assurer une santé plus constante, une constitution plus robuste. On sent que les progrès de la médecine préservatrice, devenus plus efficaces par ceux de la raison et de l'ordre social, doivent faire disparaître à la longue les maladies transmissibles ou contagieuses, et ces maladies générales qui doivent leur origine aux climats, aux aliments, à la nature des travaux. Il ne serait pas difficile de prouver que cette espérance doit s'étendre à presque toutes les autres maladies, dont il est vraisemblable que l'on saura un jour reconnaître les causes éloignées. Serait-il absurde, maintenant, de supposer que ce perfectionnement de l'espèce humaine doit être regardé comme susceptible d'un progrès indéfini, qu'il doit arriver un temps où la mort ne serait plus que l'effet, ou d'accidents extraordinaires, ou de la destruction de plus en plus lente des forces vitales, et qu'enfin la durée de l'intervalle moyen entre la naissance et cette destruction n'a elle-même aucun terme assignable ? Sans doute l'homme ne deviendra 
pas immortel ; mais la distance entre le moment où il commence à vivre et l'époque commune où naturellement, sans maladie, sans accident, il éprouve la difficulté d'être, ne peut-elle s'accroître sans cesse ? Comme nous parlons ici d'un progrès susceptible d'être représenté avec précision par des quantités numériques ou par des lignes, c'est le moment où il convient de développer les deux sens dont le mot indéfini est susceptible.

En effet, cette durée moyenne de la vie qui doit augmenter sans cesse, à mesure que nous enfonçons dans l'avenir, peut recevoir des accroissements, suivant une loi telle, qu'elle approche continuellement d'une étendue illimitée, sans pouvoir l'atteindre jamais ; ou bien suivant une loi telle, que cette même durée puisse acquérir, dans l'immensité des siècles, une étendue plus grande qu'une quantité déterminée quelconque qui lui aurait été assignée pour limite. Dans ce dernier cas, les accroissements sont réellement indéfinis dans le sens le plus absolu, puisqu'il n'existe pas de borne, en deçà de laquelle ils doivent s'arrêter.

Dans le premier, ils le sont encore par rapport à nous, si nous ne pouvons fixer ce terme, qu'ils ne peuvent jamais atteindre, et dont ils doivent toujours s'approcher ; surtout si, connaissant seulement qu'ils ne doivent point s'arrêter, nous ignorons même dans lequel de ces deux sens le terme d'indéfini leur doit être appliqué ; et tel est précisément le terme de nos connaissances actuelles sur la perfectibilité de l'espèce humaine ; tel est le sens dans lequel nous pouvons l'appeler indéfinie.

Ainsi, dans l'exemple que l'on considère ici, nous devons croire que cette durée moyenne de la vie humaine doit croître sans cesse, si des révolutions physiques ne s'y opposent pas ; mais nous ignorons quel est le terme qu'elle ne doit jamais passer, nous ignorons même si les lois générales de la nature en ont déterminé un au delà duquel elle ne puisse s'étendre.

Mais les facultés physiques, la force, l'adresse, la finesse des sens, ne sont-elles pas au nombre de ces qualités dont le perfectionnement individuel peut se transmettre? L'observation des diverses races 
d'animaux domestiques doit nous porter à le croire, et nous pourrons les confirmer par des observations directes faites sur l'espèce humaine.

Enfin, peut-on étendre ces mêmes espérances jusque sur les facultés intellectuelles et morales ? Et nos parents, qui nous transmettent les avantages ou les vices de leur conformation, de qui nous tenons, et les traits distinctifs de la figure, et les dispositions à certaines affections physiques, ne peuvent-ils pas nous transmettre aussi cette partie de l'organisation physique, d'où dépendent l'intelligence, la force de tête, l'énergie de l'âme ou la sensibilité morale ? N'est-il pas vraisemblable que l'éducation, en perfectionnant ces qualités, influe sur cette même organisation, la modifie et la perfectionne ? L'analogie, l'analyse du développement des facultés humaines, et même quelques faits, semblent prouver la réalité de ces conjectures, qui reculeraient encore les limites de nos espérances.

Telles sont les questions dont l'examen doit terminer cette dernière époque. Et combien ce tableau de l'espèce humaine, affranchie de toutes ces chaînes, soustraite à l'empire du hasard, comme à celui des ennemis de ses progrès, et marchant d'un pas ferme et sûr dans la route de la vérité, de la vertu et du bonheur, présente au philosophe un spectacle qui le console des erreurs, des crimes, des injustices dont la terre est encore souillée, et dont il est souvent la victime ! C'est dans la contemplation de ce tableau qu'il reçoit le prix de ses efforts pour les progrès de la raison, pour la défense de la liberté. Il ose alors les lier à la chaîne éternelle des destinées humaines : c'est là qu'il trouve la vraie récompense de la vertu, le plaisir d'avoir fait un bien durable, que la fatalité ne détruira plus par une compensation funeste, en ramenant les préjugés et l'esclavage. Cette contemplation est pour lui un asile, où le souvenir de ses persécuteurs ne peut le poursuivre; où, vivant par la pensée avec l'homme rétabli dans les droits comme dans la dignité de sa nature, il oublie celui que l'avidité, la crainte ou l'envie tourmentent et corrompent ; c'est là qu'il existe véritablement avec ses semblables, dans un élysée que sa raison a su se créer, et que son amour pour l'humanité embellit des plus pures jouissances. 


\section{Bibliographie}

$\underline{\text { Retour à la table des matières }}$

\section{I. - Ouvres de Condorcet}

Oeuvres complètes, publiées par M. L. S. de Condorcet, avec le concours de A. Barbier, Cabanis et Garat. Paris, Heinrichs, 1804, 21 volumes.

Ouvres, publiées par A. Condorcet, O'Connor et M. F. Arago. Paris, 1847-1849, 12 volumes.

\section{II. - Sur Condorcet}

Fr. ALENGRY : Condorcet, guide de la Révolution française, théoricien du droit constitutionnel et précurseur de la science sociale. Paris, Giard et Brière, 1904.

Fr. ALENGRY : La philosophie politique de la Révolution française dans son expression la plus élevée : C. Paris, Recueil Sirey, 1938.

J. M. ALLISON : C., a forgotten historian. In : Essays in honor of Albert Feuillerat. New-Haven, Yale University Press, 1943, pp. 183194.

H. ARCHAMBAULT DE MONTFORT : Les idées de C. sur le suffrage. Paris, Soc. fr. d'imprimerie et de librairie, 1915.

J.-R. BARNI : Fragments inédits sur C., p.p. Otto KARMIN, Genève, Impr. centrale, 1912. 
Ch.-E. BEAUDRY : Mme de Staël, disciple de C. Revue de l'Université Laval, vol. III, no 9, mai 1944, pp. 808-811.

H. BIGOT: Les idées de C. sur l'instruction publique. Poitiers, 1912.

Janine BOUISSOUNOUSE : C., le philosophe dans la Révolution, Préface de Louis de Villefosse. Paris, Hachette, 1962.

Germaine BOURDIN : C., textes et commentaires. Paris, Cercle parisien de la Ligue française de l'Enseignement, 1965.

Léon BRUNSCHVICG : Le progrès de la conscience dans la philosophie occidentale. Paris, Alcan, 1927 (vol. II, pp. 501-511).

F. BUISSON : Condorcet. Paris, Alcan, 1929.

J. B. BURY : The Idea of Progress. Londres, Macmillan, 1920.

G. BUSTICO : Il concetto di progresso nell storia in Mario Fagano $e$ in C. Genova, Tip. Carlini, 1905 (Extrait de la Rivista Ligure, sept.-oct. 1905).

E. CAILLAUD : Les idées économiques de C. Poitiers, 1908.

L. CAHEN C. et la Révolution française. Paris, Alcan, 1904.

L. CAHEN La société des Amis des Noirs et C. Dans la Révolution française, 1. L, 1906, pp. 481-511.

Alberto CENTO : Dei manoscritti del « Tableau » di C. Milano, U. Haepli, 1955.

Alberto CENTO : C. e l'idea di progresso. Firenze, Parenti, 1956.

A. CHARMA : C., sa vie et ses oeuvres. Caen, 1863. 
E. CODIGNOLA : Le idee pedagogiche di C. Dans la Rivista d'Italia, 1921, vol. I, pp. 44-73.

A. COMTE : Système de philosophie positive. Paris, Dunod, 18791883, 4 vol. (vol. IV, appendice général, pp. 109-120).

Conquérants (Les) de la science (D'Archimède à Cuvier), avec la collaboration de Jean Bleud et Marcel Clément et de MM. P. Bastier, R. Boudon, M. Brassart, L. Champagne, etc. Paris, O. Lesourd, 1945.

H. DELSAUX : C. journaliste. Paris, Champion, 1931.

A. DIANNYERE : Notice sur la vie et les ouvrages de C. Paris, an IV.

R. Doumic : Études de littérature française, 5e série. Paris, Perrin, 1906.

J. G. FRAZER: C. et le progrès de l'esprit humain. La Grande Revue, vol. CXLV, juil.-oct. 1934, pp. 534-555.

M. GHIO : Condorcet. Dans Filosofia, a. VI, no 2, avril 1955, pp. 227-263.

L. M. GIDNEY : L'influence des États-Unis d'Amérique sur Brissot, C. et Mme Roland, Paris, Rieder, 1930.

M. GILLET : L'utopie de C. Paris, Guillaumin, 1883.

Gilles-Gaston GRANGER : La mathématique sociale du Marquis de C. Paris, P.U.F., 1956.

René GROUSSET et Armand de GRAMMONT (Institut de France)

Inauguration de la statue élevée à la gloire de C. à Ribemont, le 27 avril 1947, Paris, Firmin-Didot, 1947. 
A. GUILLOIS : La marquise de Condorcet, sa famille, son salon, ses amis. Paris, Ollendorff, 1897.

Alexandre KOYRÉ : C. dans Études d'histoire de la pensée philosophique, pp. 95-115. Paris, A. Colin, 1961.

M.-J. LABOULLE : La mathématique sociale : C. et ses prédécesseurs. Revue d'hist. litt. de la France, 46e année, no 1, janv.-juin 1939, pp. 33-55.

E. LACROIX : Notice hist. sur la vie et les ouvrages de C. Paris, Impr. Sajou, 1813.

J. LALANDE : Notice sur la vie et les ouvrages de C. Mercure de France, t. XX, no 21, 30 nivôse an IV (20 janv. 1796), pp. 141-162.

K. LOEWITH : Meaning in History - The theological Implications of the Philosophy of History. Chicago, The University of Chicago Press, 1949 (pp. 91-103).

J. LOUGH : C. et Richard Price Revue de litt. comparée, 24' année, no 1, janv.-mars 1950, pp. 87-93.

Ci. PERROUD : A propos de la mort de C. Dans la Révolution française, t. LXIX, juil.-déc. 1916, pp. 506-516.

DI ROBINET : C., sa vie, son œuvre. Paris, Quantin, s. a. [1893].

SAINTE-13EUVE: Condorcet (à propos de l'éd. Arago - O. Connor). Caus. du Lundi, Ill, 336-359.

J. SALWYN SHAPIRO : C. and the rise of liberalism. New York, Harcour, Brace and C., 1934.

J.-B. SARRET : Notice sur la vie de C. pendant la proscription. Paris, Didot, an VII.

J.-B. SEVERAC: C., Choix de textes et introd. Paris, Michaud, s. a. [1930]. 
TORAU-BAYLE : C., marquis et philos., organisateur du monde moderne Paris, Impr. Dauer, S. a. [1938].

H. VALENTINO : Madame de Condorcet, ses amis et ses amours. Paris, Perrin, 1950.

Francisque VIAL : C. et l'éducation démocratique, Paris, Delaplane, 1902.

Fin du texte 